\title{
INTERNATIONAL TRADE AGREEMENTS AND BARGAINING
}

by

\section{Chuyi Fang}

Master of Finance, Queen's University, Canada, 2013

Bachelor of Finance, Shanghai University, China, 2012

Bachelor of Management, University of Technology Sydney, Australia, 2012

\author{
A dissertation \\ presented to Ryerson University
}

in partial fulfillment of the

requirements for the degree of

Doctor of Philosophy

in the program of

Economics

Toronto, Ontario, Canada, 2018

(C) Chuyi Fang, 2018 


\section{AUTHOR'S DECLARATION}

I hereby declare that I am the sole author of this dissertation. This is a true copy of the dissertation, including any required final revisions, as accepted by my examiners.

I authorize Ryerson University to lend this dissertation to other institutions or individuals for the purpose of scholarly research.

I further authorize Ryerson University to reproduce this dissertation by photocopying or by other means, in total or in part, at the request of other institutions or individuals for the purpose of scholarly research.

I understand that my dissertation may be made electronically available to the public. 


\title{
International Trade Agreements and Bargaining
}

Chuyi Fang

Doctor of Philosophy, 2018

Department of Economics

Ryerson University

\begin{abstract}
In this dissertation, I provide a compelling explanation about why the World Trade Organization (WTO) permits retaliation only after a lengthy delay. I then explain why it usually rejects requests for retaliation (or a reciprocal withdrawal of concessions) in other related international agreements. Next, I consider a more general problem about agents negotiating over an allocation of some surplus. This multilateral bargaining model could be applied to international trade or many real-world negotiations.

I begin by taking a dynamic mechanism design approach and analyze the welfare effects among same-sector retaliation with and without delay as well as cross-sector retaliation with and without delay. I show that a retaliation with delay mechanism generates higher welfare and supports a higher self-enforcing level of cooperation than does a retaliation without delay mechanism. I demonstrate that under certain conditions, a same-sector retaliation mechanism generates higher welfare and supports a higher self-enforcing level of cooperation than does a cross-sector retaliation mechanism. All the above results are showing to hold for several different stochastic process of how a state of the world evolves.

I then consider a more general case of bargaining where the size of the surplus is endogenized. In my model of the first two chapters after the introduction, although the size of the surplus varies across time, it still evolves in a stochastic manner. In many real-world negotiations, however, a surplus is usually created by players and each player may have certain power to influence a recognition process. Hence, my main innovation in the last chapter is to allow a surplus as well as recognition probabilities to be endogenously determined by players' actions. I assume that players' actions can have either persistent or transitory effects on a bargaining process. I compare the equilibrium outcomes under different voting rules and show that when a competition becomes less intensive (i.e., a proposal needs the consents of more players), it raises social welfare while it makes a free-ride problem more severe.
\end{abstract}




\section{Acknowledgements}

I would like to extend my sincerest thanks and regards to all those who supported and encouraged me during my $\mathrm{PhD}$ studies.

First, I would like to express my sincere gratitude to my supervisor Prof. Richard Chisik for his valuable advice, guidance, suggestions and professional support throughout my studies and the entire research work. His guidance helped me during the research and writing of this thesis. It was my great pleasure working under his supervision. Without his guidance, encouragement, advice and persistent help, this dissertation would not have been possible.

My sincere thank also goes to Prof. Haomiao Yu who gave his precious and valuable suggestions for my research and continually supported me throughout my $\mathrm{PhD}$ studies.

I would like to thank the rest of my thesis committee: Prof. Tsogbadral Galaabaatar, Prof. Sui Sui and Prof. Xianwen Shi, for dedicating their valuable times to review my dissertation and giving their constructive comments.

I am also grateful to the Department of Economics of Ryerson University for providing me with a congenial and wonderful environment for research and study.

Finally, I would like to thank my family: my parents and my husband Zichao Zheng who supported and encouraged me throughout my years of study and my life in general. My son Jiasheng Zheng who gave me lots of fun during my years of study. 


\section{Contents}

Abstract $\quad$ iii

List of Tables $\quad$ vii

List of Appendices viii

1 Introduction $\quad 1$

2 Chapter 2: Delayed Reciprocity in International Dispute Settlement 3

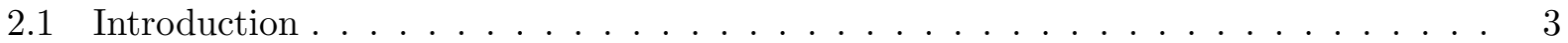

2.2 Basic $\operatorname{Setup} \ldots \ldots \ldots \ldots \ldots \ldots \ldots \ldots \ldots$

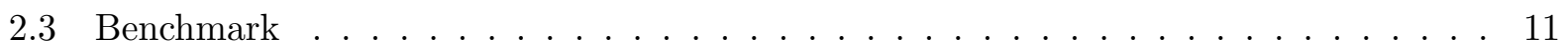

2.4 Retaliation without Delay Mechanism . . . . . . . . . . . . . . 13

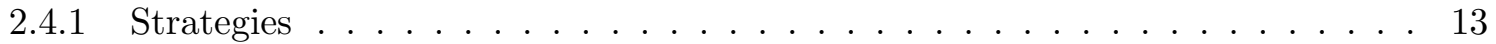

2.4.2 Negotiators' Maximization Problem . . . . . . . . . . . . . . . . . . 14

2.5 Retaliation with Delay Mechanism . . . . . . . . . . . . . . 17

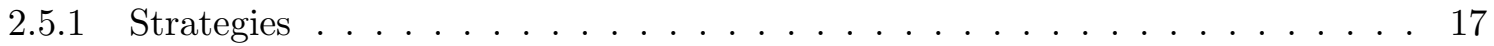

2.5.2 Negotiators' Maximization Problem . . . . . . . . . . . . . . . . 18

2.6 Dynamic Setup . . . . . . . . . . . . . . . . . . . . . . . 21

2.6.1 Nash Punishment . . . . . . . . . . . . . . . . . 22

2.6.2 Bellman Equations . . . . . . . . . . . . . . . . . . . 23

2.6.3 "Off-schedule" Violation and Voluntary Participation Constraints . . . . . . . 25

3 Chapter 3: Limited Cross-retaliation and Lengthy Delays in International $\begin{array}{ll}\text { Dispute Settlement } & 29\end{array}$

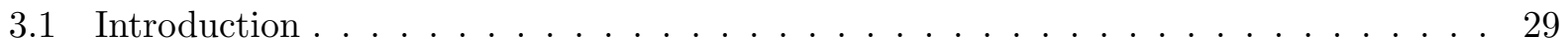

3.2 Basic Setup . . . . . . . . . . . . . . . . . . . 33

3.3 Benchmark: Perfect Information _ . . . . . . . . . . . . . . . . . 38

3.4 Incomplete Information with Same-sector Retaliation . . . . . . . . . . . . . . . . 40

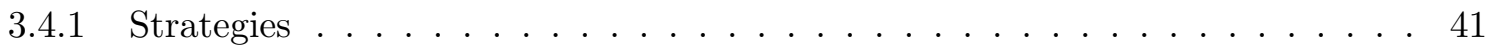


3.4.2 Negotiators's Maximization Problem . . . . . . . . . . . . . . . . . 42

3.5 Incomplete Information with Cross-sector Retaliation . . . . . . . . . . . . . . . 45

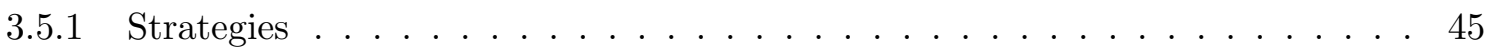

3.5.2 Negotiators' Maximization Problem . . . . . . . . . . . . . . . 45

3.6 Dynamic Setup: "Off-schedule" Violation . . . . . . . . . . . . . . . . . . . 48

$3.6 .1 \quad$ Nash Punishment . . . . . . . . . . . . . . . . . . . . . . . 49

3.6 .2 Bellman Equations . . . . . . . . . . . . . . . . . . 50

3.6.3 "Off-schedule" Violation . . . . . . . . . . . . . . . . . . . . . 53

4 Chapter 4: Multilateral Bargaining with Productive and Unproductive Efforts 57

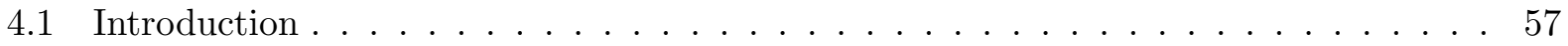

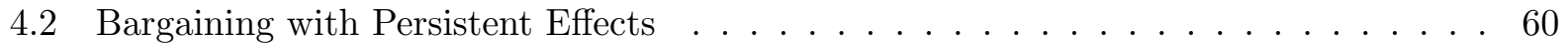

4.2 .1 The Model . . . . . . . . . . . . . . . . . . . . 60

4.2 .2 Unanimity Rule . . . . . . . . . . . . . . . . . . 62

$4.2 .3 \quad k$-Majority Rule . . . . . . . . . . . . . . . . . 68

4.3 Bargaining with Transitory Effects . . . . . . . . . . . . . . . 75

4.3.1 The Model . . . . . . . . . . . . . . . . . . . . 75

4.3 .2 Unanimity Rule . . . . . . . . . . . . . . . . 76

$4.3 .3 \quad k$-Majority Rule . . . . . . . . . . . . . . . . . 82

$\begin{array}{lr}\text { Bibliography } & 179\end{array}$ 


\section{List of Tables}

1 Cases Related to WTO Safeguard Clause . . . . . . . . . . . . . . . 3

2 Cases that Complainant Requests for Cross-sector Retaliation . . . . . . . . . . . . 30 


\section{List of Appendices}

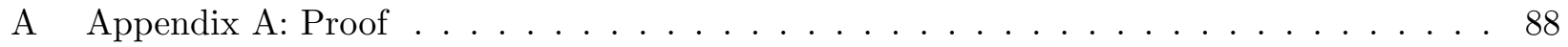

B Appendix B: I.I.D. Case . . . . . . . . . . . . . . . . . . . 156

C Appendix C: Delayed Retaliation . . . . . . . . . . . . . . 166 


\section{Introduction}

In domestic tort or criminal law, if a court finds the defendant guilty, it would administer a punishment without hesitation. Nevertheless, when there is a violation of an international trade agreement, the Dispute Settlement Process (DSP) in the World Trade Organization (WTO) tends to wait for a certain time before applying the countermeasures against the violating country. For instance, according to the WTO agreement on Safeguards, it clearly specifies that the reciprocal concession cannot be exercised during the first three years of a safeguard measure ${ }^{1}$.

Furthermore, in criminal law, a punishment rarely has the same form of the crime and, in contract law, there is no real limitation of a punishment as long as the parties come to an agreement ${ }^{2}$. On the contrary, when there is a violation of an international trade agreement, the WTO limits the composition in retaliation and prefers same-sector to cross-sector retaliation. For example, although the WTO Article 22.3 says that ".. if that party considers that it is not practical or effective to suspend concessions or other obligations with respect to the same sector(s), it may seek to suspend concessions or other obligations in other sectors under the same agreement...", there have only been three out of fourteen cases where cross-retaliation has been authorized (see Table 1).

The readers may have wondered what is the reason that international trade agreements vary from domestic tort and criminal laws and, moreover, what are the rationales behind the facts that the WTO prefer retaliation with delay to retaliation without delay and prefer same-sector retaliation to cross-sector retaliation?

To answer these questions, we take a dynamic mechanism design approach and analyze the welfare effects among same-sector retaliation with and without delay as well as cross-sector retaliation with and without delay.

In the first chapter after the introduction, we compare the welfare effects of retaliation with and without delay mechanisms. We show that a retaliation with delay mechanism generates higher welfare and supports a higher self-enforcing level of cooperation than does a retaliation without

\footnotetext{
${ }^{1}$ Note that the WTO's preference for retaliation with delay is also inconsistent with the traditional game theory literature in that from the perspective of a theoretical game theory view, a quick and swift punishment is usually prescribed because it is more efficient and provides more enforcement power.

${ }^{2}$ In many contract law cases, a dispute between the parties could be settled by a side payment of cash rather than by allowing the offended party to escape from the same rights or duties.
} 
delay mechanism. This result holds irrespective of whether retaliation happens in the sector where an initial violation takes place or not.

In the second chapter after the introduction, we compare the welfare effects of same and cross-sector retaliation mechanisms. We demonstrate that under certain conditions, a same-sector retaliation mechanism generates higher welfare and supports a higher self-enforcing level of cooperation than does a cross-sector retaliation mechanism. This result follows no matter whether there is a time lag between an initial violation and actual retaliation. The above results are showing to hold for several different stochastic process of how the state of the world evolves.

In the last chapter, we consider a more general case of bargaining in which agents negotiate over an allocation of some surplus and the size of the surplus is endogenized. In the first two chapters after the introduction, although the size of the surplus varies across time, it evolves according to a stochastic manner. In most of the multilateral bargaining literature, a surplus and probabilities of being recognized as a proposer are assumed to be exogenously given. In many real-world negotiations, however, a surplus is usually created by players and might vary among different types of agreements. Besides, each player may have certain power to influence a recognition process. Hence, our main innovation in the last chapter is to allow a surplus as well as recognition probabilities to be endogenously determined by players' actions. In particular, we assume that players' actions can have either persistent or transitory effects on the size of the surplus and the recognition probabilities. In both settings, we analyze how the equilibrium outcomes would change when players vary in their patient levels and their given resources. Furthermore, we compare the equilibrium outcomes under different voting rules and show that when a competition becomes less intensive (i.e., a proposal needs the consents of more players), it raises social welfare while it worsens a free-ride problem. Although the last chapter is still a purely theoretical bargaining model, it could be applied to international trade and many real-world negotiations. 


\section{Chapter 2: Delayed Reciprocity in International Dispute Settlement}

\subsection{Introduction}

When the court finds the defendant guilty, it would sentence him to jail without any hesitation. Similarly, in traditional game theory literature, when a deviation occurs, contrary to a delayed punishment, a quick and swift punishment is usually prescribed because it is more efficient and provides more enforcement power. On the other hand, when there is a violation of an international trade agreement, the Dispute Settlement Process (DSP) in the World Trade Organization (WTO) permits retaliation only after a lengthy delay.

Examples abound. Table 1 illustrates 10 dispute settlement cases whereby a WTO member re-

\begin{tabular}{|c|c|c|c|c|c|c|}
\hline Case name & Complaint & Respondent & $\begin{array}{l}\text { Consultation } \\
\text { requested date }\end{array}$ & $\begin{array}{l}\text { Panel } \\
\text { report date }\end{array}$ & $\begin{array}{c}\text { Time length } \\
\text { (days) }\end{array}$ & Panel's decision \\
\hline $\begin{array}{l}\text { Indonesia } \\
\text { - Iron or Steel Products }\end{array}$ & Viet Nam & Indonesia & $01 / 06 / 2015$ & $28 / 09 / 2015$ & 117 & Panel composed \\
\hline $\begin{array}{l}\text { Ukraine } \\
\text { - Passenger Cars }\end{array}$ & Japan & Ukraine & 03/10/2013 & $26 / 06 / 2015$ & 623 & $\begin{array}{l}\text { Report(s) adopted, with recommendation } \\
\text { to bring measure(s) into conformity }\end{array}$ \\
\hline $\begin{array}{l}\text { Argentina } \\
\text { - Import Measures }\end{array}$ & Japan & Argentina & $21 / 08 / 2012$ & $26 / 01 / 2015$ & 875 & $\begin{array}{l}\text { Report(s) adopted, with recommendation } \\
\text { to bring measure(s) into conformity }\end{array}$ \\
\hline $\begin{array}{l}\text { Dominican Republic } \\
\text { - Safeguard Measures }\end{array}$ & E1 Salvador & Dominican & $19 / 10 / 2010$ & $22 / 02 / 2012$ & 483 & $\begin{array}{l}\text { Report(s) adopted, with recommendation } \\
\text { to bring measure(s) into conformity }\end{array}$ \\
\hline $\begin{array}{l}\text { Chile } \\
\text { - Milk Safeguards } \\
\end{array}$ & Argentina & Chile & $25 / 10 / 2006$ & $01 / 08 / 2008$ & 636 & $\begin{array}{l}\text { Authority } \\
\text { for panel lapsed }\end{array}$ \\
\hline $\begin{array}{l}\text { US } \\
\text { - Steel Safeguards }\end{array}$ & Brazil & US & $21 / 05 / 2002$ & $10 / 11 / 2003$ & 529 & $\begin{array}{l}\text { Report(s) adopted, } \\
\text { no further action required }\end{array}$ \\
\hline $\begin{array}{l}\text { US } \\
\text { - Wire Rod and Line Pipe }\end{array}$ & EC & US & $01 / 12 / 2000$ & $10 / 09 / 2003$ & 999 & $\begin{array}{l}\text { Panel established, } \\
\text { but not yet composed }\end{array}$ \\
\hline $\begin{array}{l}\text { US } \\
\text { - Wheat Gluten }\end{array}$ & $\mathrm{EC}$ & US & $17 / 03 / 1999$ & $22 / 12 / 2000$ & 635 & $\begin{array}{l}\text { Report(s) adopted, with recommendation } \\
\text { to bring measure(s) into conformity }\end{array}$ \\
\hline $\begin{array}{l}\text { Argentina } \\
\text { - Footwear }(\mathrm{EC})\end{array}$ & EC & Argentina & $06 / 04 / 1998$ & $14 / 12 / 1999$ & 608 & Implementation notified by respondent \\
\hline $\begin{array}{l}\text { Korea } \\
\text { - Dairy }\end{array}$ & EC & Korea & $12 / 08 / 1997$ & $26 / 09 / 2000$ & 1124 & Authority for panel lapsed \\
\hline
\end{tabular}

Table 1: Cases Related to WTO Safeguard Clause

quested retaliation. Observe that it usually took the panel in the DSP of the WTO around 2-3 years on average to consider countermeasures upon a violation of a trade agreement, and during which the country that deviating from the trade agreement was still allowed to keep violating the 
agreements. Moreover, for the complainant governments, even if they get the approval of retaliations by the panel, they may still wait for a while or sometimes just threaten the violators without imposing any actual retaliation ${ }^{3}$.

In addition, from the WTO's amendment of the GATT escape clause, the documents actually change to recognize and support retaliations with delay. Specifically, according to the GATT escape clause (Article XIX), countries are allowed to take a "safeguard" action and temporarily violate the GATT obligations to the degree and time necessary to protect a domestic industry when this industry suffers from serious injury. The violating countries, however, must consult with affected contracting countries to determine the appropriate compensation. Otherwise, the affected contracting parties are authorized to take substantially equivalent trade actions. Nevertheless, the WTO agreement on Safeguards ("SG Agreement") clearly specifies that retaliations against the "safeguard" by affected contracting countries cannot be exercised during the first three years of application of a safeguard measure.

Hence, what is the intuition behind the preference of retaliations with delay in an international trade agreement?

To provide an explanation of the question above, we take a dynamic mechanism design approach and compare the welfare effects of retaliations with and without delay mechanisms.

As in a traditional tariff-setting political economy framework, our model includes two countries with two goods and a numeraire to ensure trade balance. We assume that the trade agreement is an incomplete contract. Specifically, there is information asymmetry about the political environment, or the level of the political pressure, faced by governments. Before Bagwell [5], economic literatures hardly consider information asymmetry. Nevertheless, information asymmetry is present in international trade negotiations. For example, unexpected changes from individual preferences, bad weather or political instability may cause the political environment to vary tremendously in a short time period. Affected trading countries do not usually have full and accurate information about

\footnotetext{
${ }^{3}$ According to the US-Steel Safeguards case, in 2002, President Geroge W. Bush imposed an average 30 percent tariffs on the imported steel products. This temporary violation of the GATT/WTO obligations caused great losses in its contracting parties, i.e., European Union (EU), Japan, China and Korea. However, instead of punishing the US immediately, EU, Japan, China and Korean led the case to the DSP and waited for the DSP to decide whether the US increase of tariffs was fair. Aplthough, in 2003, the WTO supported the complaints, saying that the US should quickly remove the tariffs and otherwise there would be a 2 billion ruling in sanctions, the largest penalty ever imposed by the WTO, it was until the end of 2003 that the U.S. actually withdrew the tariffs and there was no actual penalty for its violation.
} 
these changes and, consequently, one country's political environment becomes its government's private information.

Furthermore, the political pressure is assumed to evolve according to a first-oder markov process over time. The Markov process is commonly assumed in both micro and macro economic literatures. For example, to analyze the stochastic behaviour of equilibrium asset prices in a pure exchange economy, Lucas [16] assumes that the current income is a random shock that evolves according to a Markov process with certain transition probability. Nevertheless, the analysis under the markov process in our model is quite complicated. To show that our results do not depend on the markov assumption, we provide a simpler version in Appendix $\mathrm{B}^{4}$.

We consider two types of violations: the "on-schedule" and the "off-schedule". An "on-schedule" violation refers to the case where a country misreports its type and chooses a low tariff when it is a high type or vice versa. We follow the GATT/WTO provisions and assume equivalent retaliation under both delayed and no-delayed retaliation mechanisms. For example, according to GATT Article XIX paragraph (c), “...if, as a result of some unforseen developments, a contracting party takes measure inconsistent with the GATT obligations, ..., then the affected contracting party is free to suspend an equivalent concession ...". Also, GATT Article XXII paragraph (4) says that "...The level of the suspension of concessions or other obligations authorized by the DSB shall be equivalent to the level of the nullification or impairment...". In both cases, they are equivalent retaliations.

In a traditional tariff-setting model, as long as the "incentive-compatibility" or "truth-telling" conditions are satisfied, then a one-period equivalent retaliation mechanism is enough to prevent the "on-schedule" violation. Since our goal, however, is to compare delayed retaliation with no-delayed one, different from the traditional model, our model has to be at least two periods. Therefore, in our model, if we only confine our analysis to the "on-schedule" violation, then we need a two-period retaliation mechanism.

On the other hand, an "off-schedule" violation is a more egregious breaking of a trade agreement.

\footnotetext{
${ }^{4}$ In Appendix B, we assume that the political pressure is identically independently distributed (i.i.d) across every two periods while it remains the same within the two periods. Note that this i.i.d. case is more related to a traditional tariff setting model, yet the results as well as the intuitions behind the i.i.d and markov cases are identical. Nevertheless, it is less realistic to assume that there is a complete random fluctuations on the states across every period in the i.i.d case. Therefore, the political pressure is assumed to be i.i.d across every two periods while it still needs to be consistent within the two periods.
} 
It refers to the case where a country deviates from the trade agreements and chooses any arbitrary tariffs. Assume that an "off-schedule" deviation indicates leaving the GATT/WTO. Therefore, we use the Nash reversion strategies as a threat to this violation and focus on a dynamic version of the game. We call the conditions to prevent this "off-schedule" violations as the voluntary participation constraints.

We show that if the governments are sufficiently patient, then a retaliation with delay mechanism generates higher political welfare and supports a higher self-enforcing level of cooperation than does a retaliation without delay mechanism. The intuition behind this result is as follows. First, since the trade agreement is an incomplete contract, the equivalent retaliation strategy is necessary to ensure truth revelation. Nevertheless, the retaliating country may have different level of political pressure from the deviating country. Therefore, the equivalent retaliation strategy may not be an efficient action and the retaliating countries do not necessarily want to have an equivalent retaliation. However, when there is a time lag between actual retaliations and initial violations, it reduces the negative effect from the equivalent retaliation strategies while truthful revelation can still be guaranteed if the governments are patient enough.

We assume that the goods are strategic substitutes or strategic neutral. However, this assumption is not necessary for our main result to hold. Indeed, our result is still satisfied if there is a little amount of complementarity and, our result is strengthened if there is strategic substitutability between the two goods. This is because as mentioned previously, the equivalent retaliation without delay mechanism might result in some welfare losses from the retaliating country in that the level of the political pressure might be different between the retaliating and deviating countries. When the goods are strategic substitutes, it amplifies the negative impact under the retaliation without delay mechanism and, consequently, makes retaliation with delay mechanism be more desirable. Furthermore, our result provides a compelling explanation of the phenomenon in reality that both the DSP and the countries prefer delayed to no-delayed retaliation. It is also consistent with Beshkar [7] who suggests that it would be optimal for the punisher or the WTO to impose equivalent retaliation with certain probability. 


\subsection{Basic Setup}

We analyze a two-country, two-good tariff-setting political economy with incomplete information. It is an extension of the political economy model in Bagwell-Staiger [4], Bagwell [5] and Beshkar [8]. Specifically, we extend their models to consider a more general function form, to consider alternative transition probability between the states and to consider the viability of allowing for delayed retaliation.

Our model includes two countries, home and foreign, two traded goods, represented by $j \in\{x, y\}$, and a numeraire good, denoted by $z$. Time is infinite and discrete (i.e., $t=0,1, \ldots)$. Home preferences are represented by:

$$
U(\cdot)=\sum_{t=0}^{\infty} \delta^{t}\left[u_{t}(\cdot)+z_{t}\right]
$$

where $u_{t}(\cdot)$ and $z_{t}$ are the home utilities from the traded goods and the numeraire good in period $t$, respectively. Foreign preferences, denoted by $U^{*}(\cdot)$, are given by a similar expression.

Assume that the numeraire good is produced by both countries under constant return to scale and is abundant in each country. Denote $w_{t}$ and $l_{t}$ as the price of the numeraire good and the home aggregate labour supply in period $t$, respectively. Without loss of generality, we can normalize the price of the numeraire. Then the total wage income, represented by $I_{t}$, is just equal to the total labour supply, i.e., $I_{t}=w_{t} \cdot l_{t}=l_{t}$.

The consumer preferences and the cost functions in home $\left(\right.$ no $\left.{ }^{*}\right)$ and foreign $\left({ }^{*}\right)$ have the following properties:

\section{Assumption 1.}

(a) Let $u_{t}(\cdot, \cdot):\left[0, \mathbb{R}^{+}\right] \times\left[0, \mathbb{R}^{+}\right] \longrightarrow \mathbb{R}^{+}$represents the consumer utility function of home in period $t$ such that

$$
\frac{\partial u_{t}}{\partial q_{x t}^{d}} \geq 0 ; \quad \frac{\partial u_{t}}{\partial q_{y t}^{d}} \geq 0 ; \quad \frac{\partial^{2} u_{t}}{\partial q_{x t}^{2 d}} \leq 0 ; \quad \frac{\partial^{2} u_{t}}{\partial q_{y t}^{2 d}} \leq 0 ; \quad \frac{\partial u_{t}^{2}}{\partial q_{x t}^{d} \partial q_{y t}^{d}} \leq 0
$$

where $q_{j t}^{d}$ is the home demand function of good $j$ in period $t$.

(b) Let $C_{j}(\cdot):\left[0, \mathbb{R}^{+}\right] \longrightarrow \mathbb{R}^{+}$be the home production cost function of good $j$ in each period such 
that

$$
\frac{d C_{j}}{d q_{j}^{s}} \geq 0 ; \quad \frac{d^{2} C_{j}}{d q_{j}^{2 s}} \geq 0
$$

where $q_{j}^{s}$ represents the home supply function of good $j$.

(c) $C(0)=C^{*}(0)=0, \frac{\partial C_{x}\left(q_{x}^{s}\right)}{\partial q_{x}^{s}}<\frac{\partial C_{x}^{*}\left(q_{x}^{s^{*}}\right)}{\partial q_{x}^{*}}$ and $\frac{\partial C_{y}\left(q_{y}^{s}\right)}{\partial q_{y}^{s}}>\frac{\partial C_{y}^{*}\left(q_{y}^{s^{*}}\right)}{\partial q_{y}^{s *}}$, where $C_{j}^{*}(\cdot)$ and $q_{j}^{s^{*}}$ denote the foreign production cost function and supply function of good $j$ in each period, respectively.

Assumption 1(a) implies that the utility function at home is concave and twice differentiable and goods $x$ and $y$ are not complement. Assumption $1(b)$ says that home produces good $j$ according to a weakly convex and twice differentiable cost function. Assumption 1(c) shows that home has a comparative advantage in good $x$ while foreign has a comparative advantage in good $y$ and, therefore, home is an exporter of good $x$ while an import of good $y$.

Furthermore, assume that the foreign consumer utility function, denoted by $u_{i t}^{*}$, and the foreign demand function of good $j$, represented by $q_{j t}^{* d}$, are identical to the ones at home while the cost functions in foreign are the mirror images of those at home, i.e., $C_{x}=C_{y}^{*}$ and $C_{y}=C_{x}^{*}$.

Governments in home and foreign choose a sequence of import tariffs, $\left\{\tau_{t}\right\}_{t=0}^{\infty}$ and $\left\{\tau_{t}^{*}\right\}_{t=0}^{\infty}$, to maximize their total welfare, respectively. In every period $t$, the tariffs create a wedge between the domestic and foreign prices. Namely,

$$
p_{x t}^{*}=p_{x t}+\tau_{t}^{*} ; \quad p_{y t}=p_{y t}^{*}+\tau_{t},
$$

where $p_{j t}$ and $p_{j t}^{*}$ represent the prices of good $j$ in home and foreign, respectively.

We assume that in each period $t$, the political welfare is a weighted sum of the country's producer surplus, consumer surplus and tariff revenues in that period and the total political welfare is an 
infinite version of the per period one. In particular, the home welfare is defined as:

$$
\begin{aligned}
V\left(p_{x}\left(\tau_{t}^{*}\right), p_{y}\left(\tau_{t}\right), \theta_{t}\right) & =\sum_{t=0}^{\infty} \delta^{t} \vartheta_{t}\left(\tau_{t}, \tau_{t}^{*}, \theta_{t}\right)+l_{t} \\
& =\sum_{t=0}^{\infty} \delta^{t} \vartheta_{t}\left(p_{x}\left(\tau_{t}^{*}\right), p_{y}\left(\tau_{t}\right), \theta_{t}\right)+l_{t} \\
& =\sum_{t=0}^{\infty} \delta^{t}\left\{u_{t}\left[q_{x t}^{d}\left(p_{x}\left(\tau_{t}^{*}\right), p_{y}\left(\tau_{t}\right)\right), q_{y t}^{d}\left(p_{y}\left(\tau_{t}\right), p_{x}\left(\tau_{t}^{*}\right)\right)\right]\right. \\
& \left.-p_{x}\left(\tau_{t}^{*}\right) q_{x t}^{d}\left(p_{x}\left(\tau_{t}^{*}\right), p_{y}\left(\tau_{t}\right)\right)-p_{y}\left(\tau_{t}\right) q_{y t}^{d}\left(p_{y}\left(\tau_{t}\right), p_{x}\left(\tau_{t}^{*}\right)\right)\right\} \\
& +\sum_{t=0}^{\infty} \delta^{t}\left\{p_{x}\left(\tau_{t}^{*}\right) q_{x t}^{s}\left(p_{x}\left(\tau_{t}^{*}\right)\right)-c_{x t}\left(q_{x t}^{s}\left(p_{x}\left(\tau_{t}^{*}\right)\right)\right)\right\} \\
& +\sum_{t=0}^{\infty} \delta^{t}\left\{\theta_{t}\left[p_{y}\left(\tau_{t}\right) q_{y_{a} t}^{s}\left(p_{y_{a} t}\right)-c_{y_{a}}\left(q_{y_{a}}^{s}\left(p_{y_{a}}\right)\right)\right]\right\} \\
& +\sum_{t=0}^{\infty} \delta^{t}\left\{\tau_{t}\left[q_{y t}^{d}\left(p_{y}\left(\tau_{t}\right), p_{x}\left(\tau_{t}^{*}\right)\right)-q_{y t}^{s}\left(p_{y}\left(\tau_{t}\right)\right)\right]\right\}
\end{aligned}
$$

where $\theta_{t}$ is the political weight (pressure) of home producer surplus from industry $y$ in period $t$. Magee-Brock-Young [17] provides the earliest micro foundation for the above measure of the social welfare. They characterize a general equilibrium in a political economy where two parties compete for an election and a third party, which is called the "lobby groups", makes campaign contribution to them. In order to gain support and win the election, the two competing parties will commit to certain trade policies which might only bring benefits to the "lobby group". Grossman-Helpman [14] further analyze the interaction between the lobby groups and policy makers. In their framework, the lobbies have more power in that they can influence the trade policies by themselves. Recognizing the fact that trade policy is chosen by lobbying-influenced policy makers, Hillman [15] first applies this rationale to a trade policy formation and assumes that the social welfare function is strictly concave in the profit of each industry. The setup of the welfare function in our model is most related to Baldwin [2] who uses a reduced form of the social welfare function in Hillman [15]. In Baldwin [2], the interactions between the lobbiers and the policy makers are simply captured by the different weights of the producer surplus in the social welfare function.

We make the following assumptions about the political pressure at home, $\theta_{t}$. First, to capture the idea that the governments may face varying levels of political pressure, we assume that $\theta_{t}$ can 
take two values, which is either high, denoted by $\theta_{H}$, or low, denoted by $\theta_{L}$, i.e., $\theta_{t}=\left\{\theta_{L}, \theta_{H}\right\}$. Without loss of generality, assume that $\theta_{L}=1$ and $\theta_{H}>1$. Second, we assume that $\theta_{t}$ follows the probability distribution below within the period:

$$
\theta_{t}= \begin{cases}\theta_{L} & \text { with probability } \lambda \\ \theta_{H} & \text { with probability } 1-\lambda,\end{cases}
$$

and the markov process across time:

$$
\begin{gathered}
\operatorname{prob}\left(\theta_{t+1}=\theta_{L} \mid \theta_{t}=\theta_{L}\right)=\operatorname{prob}\left(\theta_{t+1}=\theta_{H} \mid \theta_{t}=\theta_{H}\right)=\beta ; \\
\operatorname{prob}\left(\theta_{t+1}=\theta_{H} \mid \theta_{t}=\theta_{L}\right)=\operatorname{prob}\left(\theta_{t+1}=\theta_{L} \mid \theta_{t}=\theta_{H}\right)=1-\beta,
\end{gathered}
$$

where $\beta \in[0,1]$ is the transition probability.

As alluded to in the introduction, we provide a simpler version of the transition probability in Appendix B. Specifically, we assume that $\theta_{t}$ is $i . i . d$ across every two periods and remains the same within each two periods. Formally,

$$
\rho\left(\theta_{t}, \theta_{t+1}\right)=1 \text { and } \rho\left(\theta_{t}, \theta_{t+2}\right)=0,
$$

where $t$ is odd and $\rho\left(\theta, \theta^{\prime}\right)$ represents the correlation coefficient between $\theta$ and $\theta^{\prime}$.

The political welfare from the traded goods in foreign and home are identical except that the weight of the producer surplus in the import-competing industries is equal to $1^{5}$. Let $\vartheta_{t}\left(\tau_{t}, \tau_{t}^{*}\right)$ denotes the foreign welfare from the traded goods in period $t$.

Since $\theta_{t}$ has two possible values at home, we can add information asymmetry to the model. In particular, we assume that $\theta_{t}$ is the private information of home and foreign only knows the distribution and the transition probability of it.

As mentioned previously, we analyze two types of violation: the "on-schedule" and the "offschedule". If we only consider the "on-schedule" violation, then different from the traditional

\footnotetext{
${ }^{5}$ Although it would be straightforward to allow foreign pressure to vary as well, the maths becomes slightly more complicated and there is no change in our results. Therefore, there is no need to have the foreign political pressure change across time.
} 
tariff setting model, we need a two-period retaliation mechanism. On the other hand, in terms of the "off-schedule" violation, we extend the two-period game to a game with infinite time horizon and use the Nash reversion strategy as a threat to this violation.

In each period, the timing of the game is as follows. It consists of three stages. In the first stage, nature moves. It chooses a type for home, which is either high, or, low. In the second stage, home moves. It sets its import tariff based on the realization of its type. In the third stage, foreign moves. Given the tariff that home has set in the previous stage, foreign imposes its import tariff ${ }^{6}$.

\subsection{Benchmark}

To show that retaliation with delay is more efficient than retaliation without delay, we first focus on the "on-schedule" violation and consider a two-period retaliation mechanism. We will show that under the two-period game, the best incentive-compatible negotiated tariff under the delayed retaliation mechanism leads to a smaller dead weight loss of the joint political welfare than under the no-delayed retaliation mechanism. Then we extend it to a dynamic version and verify that the retaliation with delay mechanism enhances more cooperation between the negotiators. However, before proceeding, to compare the optimal trade agreements between these two mechanisms, we first characterize a complete information game as a benchmark. Under the benchmark, we consider a trade agreement under full-commitments and assume that foreign has perfect information about the level of political pressure faced by home.

Under this perfect information game, both governments set their import tariffs based on home's

\footnotetext{
${ }^{6}$ Indeed, as long as home sticks to the trade agreement, the game is as if home announces its type and then the tariffs are chosen simultaneously. However, $\mathrm{p}$ it would be more realistic that rather than announcing the type, home would choose a tariff ro reveal its type. The readers may have wondered that if home chooses its tariff first, then it may have a first mover advantage. Nevertheless, it would not happen if the mechanism satisfies both incentive compatibility and voluntary participation conditions. Or, home does not have a first mover advantage if it has no incentive to violate the "on-schedule" and "off-schedule" violations. The reasons are as follows. First, if we only focus on the "on-schedule" violation, then home only has a couple of choice of tariffs and it cannot have a first mover advantage because if it takes the first mover advantage, then it would be an "off-schedule" violation. Second, although under a dynamic game, home can choose an "off-schedule" violation and use its first mover advantage, it will never do that in equilibrium if the threat of the "off-schedule" violation is effective.
} 
type, $\theta^{7}$. The strategies of home $\left(\right.$ no $\left.{ }^{*}\right)$ and foreign $\left(^{*}\right)$ under the benchmark are:

$$
\tau_{t a}=\left\{\begin{array}{ll}
z_{a}\left(\theta_{L}\right) & \text { if } \theta_{t}=\theta_{L} \\
z_{a}\left(\theta_{H}\right) & \text { if } \theta_{t}=\theta_{H} ;
\end{array} \quad \tau_{t a}^{*}= \begin{cases}z_{a}^{*}\left(\theta_{L}\right) & \text { if } \theta_{t}=\theta_{L} \\
z_{a}^{*}\left(\theta_{H}\right) & \text { if } \theta_{t}=\theta_{H},\end{cases}\right.
$$

where $t=\{0,1, \ldots,+\infty\}$.

Since in each period, the timing of the game and the strategies under the benchmark are identical and independent over time, we can drop the subscript $t$ and only examine a one-period game. In each period, under the first best situation, home and foreign choose the import tariff, $z(\theta)$ and $z^{*}(\theta)$, to maximize the joint political welfare:

$$
\max _{z(\theta), z^{*}(\theta)} \vartheta\left(z(\theta), z^{*}(\theta), \theta\right)+\vartheta^{*}\left(z(\theta), z^{*}(\theta)\right)+w \cdot L+w^{*} \cdot L^{*}
$$

Given that the wage income in both countries are irrespective of the import tariffs, the above problem can be simplified as:

$$
\max _{z(\theta), z^{*}(\theta)} \vartheta\left(z(\theta), z^{*}(\theta), \theta\right)+\vartheta^{*}\left(z(\theta), z^{*}(\theta)\right)
$$

The politically efficient tariffs, denoted as $z^{E}(\theta)$ and $z^{* E}(\theta)$, are the solution to the above maximization problem and have the following property:

Proposition 1. Under the first-best perfect information, we have $z^{* E}\left(\theta_{H}\right)<z^{E}\left(\theta_{L}\right)=z^{*} E\left(\theta_{L}\right)<$ $z^{E}\left(\theta_{H}\right)$.

All the proofs are contained in Appendix A.

The intuition behind the proposition above is as follows. First, when $\theta$ increases from $\theta_{L}$ to $\theta_{H}$, the home producer surplus of industry $y$ carries more weight and, therefore, it accounts for a larger share in the joint political welfare. This means that the home producers in industry $y$ are more valuable as compared to the foreign producers. Also, note that an increase from the import tariff

\footnotetext{
${ }^{7}$ As will be shown later, under incomplete information, $\theta$ becomes private information of home. Then foreign will set its tariff based on home's actions in the previous stage. This might create some deadweight loss of the joint political welfare.
} 
at home makes the home producers in industry $y$ more competitive. Hence, when home is in high political pressure, it enhances the joint marginal benefit of increasing the import tariff at home. Therefore, the political pressure and the politically efficient import tariff at home are positively correlated, $z^{E}\left(\theta_{H}\right)>z^{E}\left(\theta_{L}\right)$. On the other hand, from Assumption 1, we know that the goods are strategic substitutes. Hence, when there is an increases in the import tariff from foreign in industry $x$, it will indirectly influence the home producers in industry $y$, making them less competitive. This implies that a higher weight of the home producers in industry $y$ raises the joint marginal cost of increasing the foreign import tariff. Thus, the politically efficient import tariff in foreign decreases when $\theta$ jumps from $\theta_{L}$ to $\theta_{H}$. Namely, $z^{* E}\left(\theta_{H}\right)<z^{* E}\left(\theta_{L}\right)$.

Now we are ready to consider a two-period game in which foreign has incomplete information about the home political pressure, $\theta$.

\subsection{Retaliation without Delay Mechanism}

In this subsection, we add incomplete information into the model and assume that foreign only knows the distribution and the transition probability about the home's type, $\theta$. Since $\theta$ is home's private information, it is reasonable to assume that home is the potential violator of the trade agreement while foreign is the potential punisher. Moreover, in this section, we analyze the nodelayed retaliation mechanism under which the action of increasing the import tariff by home will be punished by foreign immediately. We will first focus on the "on-schedule" violation in a twoperiod game setup. In Section 2.6, we extend it to a dynamic version and take into account the possibility of an "off-schedule" violation. As mentioned before, we assume equivalent retaliation by foreign. Namely, foreign is constrained to impose the import tariffs by the same amount as home does in the previous stage.

\subsubsection{Strategies}

The strategies of home $\left(\right.$ no*$\left.^{*}\right)$ and foreign $\left(^{*}\right)$ under the no-delayed retaliation mechanism are as follows:

$$
\tau_{t}= \begin{cases}z^{N D}\left(\theta_{L}\right) & \text { if } \theta_{t}=\theta_{L} \\ z^{N D}\left(\theta_{H}\right) & \text { if } \theta_{t}=\theta_{H}\end{cases}
$$


and

$$
\tau_{t}^{*}= \begin{cases}z^{* N D} & \text { if } \tau_{t}=z\left(\theta_{L}\right) \\ z^{N D}\left(\theta_{H}\right) & \text { if } \tau_{t}=z\left(\theta_{H}\right)\end{cases}
$$

where $t=\{1,2\}$ and the superscript letters " $N D$ " represent "no-delayed".

Observe that the strategies of home (foreign) are irrespective of the time. This makes sense because first, in terms of the home government, under the no-delayed retaliation mechanism, it sets its import tariff only based on the type in that period. Therefore, the action of home in each period should be consistent. Put differently, the home strategy must be the same across every period. On the other hand, in terms of the foreign government, according to the no-delayed retaliation strategy, foreign is constrained to match the home import tariff in the previous stage. Then, based on the observation that the action of home is consistent within the two periods, the foreign action should also be consistent. Hence, the strategies of foreign in periods 1 and 2 are the same. Nevertheless, if retaliation is delayed for one period, then although the strategies at home between the two periods are still the same, the strategies in foreign vary across time.

\subsubsection{Negotiators' Maximization Problem}

Under the retaliation without delay mechanism, the negotiators choose the import tariff scheme $\left(z^{N D}(\theta), z^{* N D}\right)$, to maximize the joint political welfare subject to the incentive compatibility conditions. Namely,

$$
\begin{aligned}
\max _{z^{N D}\left(\theta_{L}\right), z^{N D}\left(\theta_{H}\right), z^{* N D}} & \lambda\left\{\vartheta\left(z^{N D}\left(\theta_{L}\right), z^{* N D}, \theta_{L}\right)+\vartheta_{a}^{*}\left(z^{N D}\left(\theta_{L}\right), z^{* N D}, \theta_{L}\right)\right. \\
& \left.+\delta \beta\left[\vartheta\left(z^{N D}\left(\theta_{L}\right), z^{* N D}\right), \theta_{L}\right)+\vartheta^{*}\left(z^{N D}\left(\theta_{L}\right), z^{* N D}, \theta_{L}\right)\right] \\
& \left.+\delta(1-\beta)\left[\vartheta\left(z^{N D}\left(\theta_{H}\right), z^{N D}\left(\theta_{H}\right), \theta_{H}\right)+\vartheta^{*}\left(z^{N D}\left(\theta_{H}\right), z^{N D}\left(\theta_{H}\right), \theta_{L}\right)\right]\right\} \\
& +(1-\lambda)\left\{\vartheta\left(z^{N D}\left(\theta_{H}\right), z^{N D}\left(\theta_{H}\right), \theta_{H}\right)+\vartheta^{*}\left(z^{N D}\left(\theta_{H}\right), z^{N D}\left(\theta_{H}\right), \theta_{L}\right)\right. \\
& +\delta \beta\left[\vartheta\left(z^{N D}\left(\theta_{H}\right), z^{N D}\left(\theta_{H}\right), \theta_{H}\right)+\vartheta^{*}\left(z^{N D}\left(\theta_{H}\right), z^{N D}\left(\theta_{H}\right), \theta_{L}\right)\right] \\
& \left.+\delta(1-\beta)\left[\vartheta\left(z^{N D}\left(\theta_{L}\right), z^{* N D}, \theta_{L}\right)+\vartheta_{a}^{*}\left(z^{N D}\left(\theta_{L}\right), z^{* N D}, \theta_{L}\right)\right]\right\}
\end{aligned}
$$


subject to

$$
\begin{aligned}
& \vartheta\left(z^{N D}\left(\theta_{L}\right), z^{* N D}\left(\theta_{L}\right), \theta_{L}\right)+\delta \beta \vartheta\left(z^{N D}\left(\theta_{L}\right), z^{* N D}, \theta_{L}\right)+\delta(1-\beta) \vartheta\left(z^{N D}\left(\theta_{H}\right), z^{N D}\left(\theta_{H}\right), \theta_{H}\right) \geq \\
& \vartheta\left(z^{N D}\left(\theta_{H}\right), z^{N D}\left(\theta_{H}\right), \theta_{L}\right)+\delta \beta \vartheta\left(z^{N D}\left(\theta_{H}\right), z^{N D}\left(\theta_{H}\right), \theta_{L}\right)+\delta(1-\beta) \vartheta\left(z^{N D}\left(\theta_{H}\right), z^{N D}\left(\theta_{H}\right), \theta_{H}\right)
\end{aligned}
$$

and

$$
\begin{aligned}
& (1+\delta \beta) \vartheta\left(z^{N D}\left(\theta_{H}\right), z^{N D}\left(\theta_{H}\right), \theta_{H}\right)+\delta(1-\beta) \vartheta\left(z^{N D}\left(\theta_{L}\right), z^{* N D}\left(\theta_{L}\right), \theta_{L}\right) \geq \\
& (1+\delta \beta) \vartheta\left(z^{N D}\left(\theta_{L}\right), z^{* N D}\left(\theta_{L}\right), \theta_{H}\right)+\delta(1-\beta) \vartheta\left(z^{N D}\left(\theta_{L}\right), z^{* N D}\left(\theta_{L}\right), \theta_{L}\right) .
\end{aligned}
$$

Problem (3) is the unconstrained maximization problem. The first three lines represent the case where home is a high type in period 1 . The first line is the realized payoff in period 1 and the second and third lines are the expected discounted payoff in period 2, weighted by the probability, $\lambda$. The last three lines describe the payoff when home faces low pressure in period 1. It is the sum of the first period realized payoff, $\vartheta\left(z^{N D}\left(\theta_{H}\right), z^{N D}\left(\theta_{H}\right), \theta_{H}\right)+\vartheta^{*}\left(z^{N D}\left(\theta_{H}\right), z^{N D}\left(\theta_{H}\right), \theta_{L}\right)$, and the second period expected discounted payoff, $\delta \beta\left[\vartheta\left(z^{N D}\left(\theta_{H}\right), z^{N D}\left(\theta_{H}\right), \theta_{H}\right)+\vartheta^{*}\left(z^{N D}\left(\theta_{H}\right), z^{N D}\left(\theta_{H}\right), \theta_{L}\right)\right]+$ $\delta(1-\beta)\left[\vartheta\left(z^{N D}\left(\theta_{L}\right), z^{* N D}, \theta_{L}\right)+\vartheta^{*}\left(z^{N D}\left(\theta_{L}\right), z^{* N D}, \theta_{L}\right)\right]$, timed by the corresponding probability, $1-\lambda$.

Eqs.(4) and (5) are the truth-telling constraints when home is in a low type and a high type, respectively. We assume that if home misreports its type in period 1, it will also do so in period 2. The left hand side of Eq.(4) is the payoff when home reports its type truthfully and the state is low. Specifically, the first term is the payoff in period 1 while the second and third terms are the expected discounted payoff in period 2. The right hand side is the payoff if it mimics the high. It is the corresponding payoff that he can get in period 1 plus the expected discounted payoff in period 2. Eq.(4) ensures that the benefit of telling the truth is greater than the benefit of mimicking the high. Hence, it guarantees truth-telling from home when the state is low. Eq.(5) can be interpreted by following a similar argument.

Denote the solution to the unconstrained maximization problem $(3)$ as $\left(z^{N D S}(\theta), z^{* N D S}\right)$, where the superscripts "ND" represent "no-delayed" and the superscript "S" denotes "solution". The following proposition compares the best negotiated tariff scheme under the no-delayed retaliation mechanism and the political efficient tariffs: 
Proposition 2. The best negotiated import tariffs in the low state under the no-delayed equivalent retaliation mechanism are politically efficient while the best negotiated import tariff in the high state under the no-delayed equivalent retaliation mechanism is lower than the politically efficient import tariff, i.e.,

$$
z^{N D S}\left(\theta_{L}\right)=z^{E}\left(\theta_{L}\right)=z^{* N D S}=z^{* E}\left(\theta_{L}\right)<z^{N D S}\left(\theta_{H}\right)<z^{E}\left(\theta_{H}\right) .
$$

Proposition 2 shows that when home has low political pressure, the first best tariffs under the no-delayed retaliation mechanism are the same as under the benchmark. This is because home and foreign are symmetric when the state is low. Therefore, under the first best situation, they should impose the same amount of tariffs. Hence, the no-delayed equivalent retaliation strategy happens to be the politically efficient strategy. On the other hand, somewhat surprisingly, this proposition also indicates that when home suffers from high political pressure, lowering the import tariff might result in inefficiency. The intuition behind it is as follows: First, from the benchmark, we know that it is efficient for the home country to deviate and choose a high tariff when it is in a high state. Besides, recall in the benchmark, when home imposes a high tariff, the optimal action for foreign is to decrease its tariff. Nevertheless, when there is information asymmetry of the political pressure at home, to ensure truth revelation, foreign cannot lower its tariff. On the contrary, it has to retaliate for home's efficient action. Therefore, to compensate the negative effect from foreign's retaliation, home will set a tariff which is lower than the politically efficient one in the first place. This leads to the import tariff in the high state lower than the optimal one.

The next proposition provides further evidence that the no-delayed retaliation strategy in the high state is not optimal and the punishment for home's deviation might be too strong. Specifically, we verify that none of the incentive-compatibility conditions under the no-delayed retaliation mechanism is binding.

Proposition 3. Under the no-delayed equivalent retaliation mechanism, the incentive compatibility conditions (4) and (5) are slack.

Observe that if the two incentive compatibility constraints are slack, then the unconstrained solutions, $\left(z^{N D S}(\theta), z^{* N D S}\right)$, are also the solutions to the constrained maximization problem. Besides, the proposition above demonstrates that in comparison to the no-delayed equivalent retaliation 
punishment, a less sever punishment might generate higher joint political welfare. Hence, in the next section, we consider equivalent retaliation but with delay. Note that as long as the players discount their future values by a discount factor which is smaller than 1, i.e., $\delta<1$, then home will endure smaller loss from the retaliation with delay strategy by foreign.

Moreover, by comparing the markov case with the i.i.d. case in Appendix B, we can see that the maximization problems under the no-delayed retaliation mechanisms are the same. The idea here is that under the no-delayed retaliation mechanism, the strategies of the two countries are independent of how $\theta$ evolves. Hence, no matter whether $\theta$ remains the same or follows a markov process in the two-period mechanism, it has no influence on the negotiators' maximization problem.

\subsection{Retaliation with Delay Mechanism}

As mentioned in the previous section, since the truth-telling constraints are slack under the nodelayed retaliation mechanism, it can be inferred that we might allow foreign to punish too much for home's deviation. Hence, in this subpsection, we consider a trade agreement with a less severe punishment scheme. That is, instead of punishing home immediately for its increase of tariff, foreign will wait for one period and then retaliate by the same amount in the next period. We call this mechanism the delayed equivalent retaliation mechanism.

\subsubsection{Strategies}

Under the delayed equivalent retaliation mechanism, in each period, home still sets its import tariff based on its type. Unlike the previous case, however, foreign will set the retaliatory tariff in period 2 if and only if home chooses a high tariff in both periods. In other words, even if home sets a high tariff in period 1 , then as long as it decreases its tariff in period 2 , foreign will not retaliate. Namely,

$$
\begin{gathered}
\tau_{t}= \begin{cases}z^{D}\left(\theta_{L}\right) & \text { if } \theta_{t}=\theta_{L} \\
z^{D}\left(\theta_{H}\right) & \text { if } \theta_{t}=\theta_{H} ;\end{cases} \\
\tau_{1}^{*}=z^{* E}\left(\theta_{L}\right) \quad \tau_{2}^{*}= \begin{cases}z^{D}\left(\theta_{H}\right) & \text { if } \tau_{1 a}=\tau_{2 a}=z_{a}\left(\theta_{H}\right) \\
z^{* E}\left(\theta_{L}\right) & \text { otherwise },\end{cases}
\end{gathered}
$$


where $t=\{1,2\}$ and the superscript "D" represents "delayed".

Note that this retaliation strategy is consistent with the real world negotiators' problem because in most real world dispute cases, such as the US-Steel Safeguard case which is mentioned in the introduction, the complainant countries may just threaten the deviator and not impose any actual retaliation as long as the deviator decreases its tariff soon after the deviation.

However, when $\theta$ is identical between the two periods, then foreign will retaliate in period 2 for certain if home sets a high tariff in period 1 . This implies that in comparison to the case described in Appendix B, the delayed retaliation strategy under the markov case is less severe and, hence, can create more efficiency.

\subsubsection{Negotiators' Maximization Problem}

Under the retaliation with delay mechanism, the negotiators choose the import tariff scheme $\left(z^{D}\left(\theta_{L}\right), z^{D}\left(\theta_{H}\right)\right)$, to maximize the joint political welfare subject to the incentive compatibility conditions. Namely,

$$
\begin{aligned}
\max _{z^{D}\left(\theta_{L}\right), z^{D}\left(\theta_{H}\right)} & \lambda\left\{\vartheta\left(z^{D}\left(\theta_{L}\right), z^{* E}\left(\theta_{L}\right), \theta_{L}\right)+\vartheta^{*}\left(z^{D}\left(\theta_{L}\right), z^{* E}\left(\theta_{L}\right)\right)\right. \\
& +\delta \beta\left[\vartheta\left(z^{D}\left(\theta_{L}\right), z^{* E}\left(\theta_{L}\right), \theta_{L}\right)+\vartheta_{a}^{*}\left(z^{D}\left(\theta_{L}\right), z^{* E}\left(\theta_{L}\right)\right)\right] \\
& \left.+\delta(1-\beta)\left[\vartheta\left(z^{D}\left(\theta_{H}\right), z^{* E}\left(\theta_{L}\right), \theta_{H}\right)+\vartheta_{a}^{*}\left(z\left(\theta_{H}\right), z^{* E}\left(\theta_{L}\right)\right)\right]\right\} \\
& +(1-\lambda)\left\{\vartheta\left(z^{D}\left(\theta_{H}\right), z^{* E}\left(\theta_{L}\right), \theta_{H}\right)+\vartheta_{a}^{*}\left(z\left(\theta_{H}\right), z^{* E}\left(\theta_{L}\right)\right)\right. \\
& +\delta \beta\left[\vartheta\left(z^{D}\left(\theta_{H}\right), z_{a}\left(\theta_{H}\right), \theta_{H}\right)+\vartheta^{*}\left(z^{D}\left(\theta_{H}\right), z^{D}\left(\theta_{H}\right)\right)\right] \\
& \left.+\delta(1-\beta)\left[\vartheta\left(z^{D}\left(\theta_{L}\right), z^{* E}\left(\theta_{L}\right), \theta_{L}\right)+\vartheta^{*}\left(z^{D}\left(\theta_{L}\right), z^{* E}\left(\theta_{L}\right)\right)\right]\right\}
\end{aligned}
$$

subject to

$$
\begin{aligned}
& \vartheta\left(z^{D}\left(\theta_{L}\right), z^{* E}\left(\theta_{L}\right), \theta_{L}\right)+\delta \beta \vartheta\left(z^{D}\left(\theta_{L}\right), z^{* E}\left(\theta_{L}\right), \theta_{L}\right)+\delta(1-\beta) \vartheta\left(z^{D}\left(\theta_{H}\right), z^{* E}\left(\theta_{L}\right), \theta_{H}\right) \geq \\
& \vartheta\left(z^{D}\left(\theta_{H}\right), z^{* E}\left(\theta_{L}\right), \theta_{L}\right)+\delta \beta \vartheta\left(z^{D}\left(\theta_{H}\right), z^{D}\left(\theta_{H}\right), \theta_{L}\right)+\delta(1-\beta) \vartheta\left(z^{D}\left(\theta_{H}\right), z^{* E}\left(\theta_{L}\right), \theta_{H}\right)
\end{aligned}
$$


and

$$
\begin{aligned}
& \vartheta\left(z^{D}\left(\theta_{H}\right), z^{* E}\left(\theta_{L}\right), \theta_{H}\right)+\delta \beta \vartheta\left(z^{D}\left(\theta_{H}\right), z^{D}\left(\theta_{H}\right), \theta_{H}\right)+\delta(1-\beta) \vartheta\left(z^{D}\left(\theta_{L}\right), z^{* E}\left(\theta_{L}\right), \theta_{L}\right) \geq \\
& (1+\delta \beta) \vartheta\left(z^{D}\left(\theta_{L}\right), z^{* E}\left(\theta_{L}\right), \theta_{H}\right)+\delta(1-\beta) \vartheta\left(z^{D}\left(\theta_{L}\right), z^{* E}\left(\theta_{L}\right), \theta_{L}\right) .
\end{aligned}
$$

Consistent with the no-delayed retaliation mechanism, we assume that if home misreports its type in period 1, it will do that again in period 2. Problem (6) is the unconstrained maximization problem and Eqs.(7) and (8) are the truth-telling constraints in a low state and a high state, respectively. They have similar interpretations as under the no-delayed retaliation mechanism.

Denote the solution to problem (6) as $\left(z^{D S}\left(\theta_{L}\right), z^{D S}\left(\theta_{H}\right)\right)$, where the superscripts "D" and "S" denote "delayed" and "solution", respectively.

Observe that if we rearrange problem (6):

$$
\begin{aligned}
\max _{z^{D S}\left(\theta_{L}\right), z^{D S}\left(\theta_{H}\right)} & (\lambda+2 \delta \lambda \beta+\delta-\delta \beta-\delta \lambda)\left[\vartheta\left(z^{D S}\left(\theta_{L}\right), z^{* E}\left(\theta_{L}\right), \theta_{L}\right)+\vartheta^{*}\left(z^{D S}\left(\theta_{L}\right), z^{* E}\left(\theta_{L}\right)\right)\right] \\
& +(1-\lambda+\lambda \delta-\lambda \delta \beta)\left[\vartheta\left(z^{D S}\left(\theta_{H}\right) z^{* E}\left(\theta_{L}\right), \theta_{H}\right)+\vartheta^{*}\left(z^{D S}\left(\theta_{H}\right), z^{* E}\left(\theta_{L}\right)\right)\right] \\
& +(\delta \beta-\delta \lambda \beta)\left[\vartheta\left(z^{D S}\left(\theta_{H}\right), z^{D S}\left(\theta_{H}\right), \theta_{H}\right)+\vartheta_{a}^{*}\left(z_{a}^{D S}\left(\theta_{H}\right), z^{D S}\left(\theta_{H}\right)\right)\right]
\end{aligned}
$$

then $z^{D S}\left(\theta_{H}\right)$ shall satisfy the following first order condition:

$$
\begin{aligned}
& (1-\lambda+\lambda \delta-\lambda \delta \beta)\left[\vartheta_{1}\left(z^{D S}\left(\theta_{H}\right), z^{* E}\left(\theta_{L}\right), \theta_{H}\right)+\vartheta_{1}^{*}\left(z^{D S}\left(\theta_{H}\right), z^{* E}\left(\theta_{L}\right)\right)\right] \\
& +(\delta \beta-\delta \lambda \beta)\left[\vartheta_{1}\left(z^{D S}\left(\theta_{H}\right), z^{D S}\left(\theta_{H}\right), \theta_{H}\right)+\vartheta_{1}^{*}\left(z^{D S}\left(\theta_{H}\right), z^{D S}\left(\theta_{H}\right), \theta_{H}\right)\right] \\
& +(\delta \beta-\delta \lambda \beta)\left[\vartheta_{2}\left(z^{D S}\left(\theta_{H}\right), z^{D S}\left(\theta_{H}\right), \theta_{H}\right)+\vartheta_{2}^{*}\left(z^{D S}\left(\theta_{H}\right), z^{D S}\left(\theta_{H}\right), \theta_{H}\right)\right]=0 .
\end{aligned}
$$

The above equation identifies that for any given $\lambda \in(0,1)$ and $\beta \in(0,1)$, we can write $z^{D S}\left(\theta_{H}\right)$ as a function of the discount factor $\delta \in(0,1)$. Denote this function as $z^{D S}\left(\theta_{H}, \delta\right)$, where $\delta \in(0,1)$. The next proposition demonstrates that under the delayed retaliation mechanism, the best negotiated tariff in the low state is politically efficient. Besides, as opposed to the previous mechanism, the best negotiated tariff in the high state can also be politically efficient for certain parameters.

Proposition 4. Under the delayed equivalent retaliation mechanism, the best negotiated import tariff in the low state is politically efficient, i.e., $z^{D S}\left(\theta_{L}\right)=z^{E}\left(\theta_{L}\right)$ and the best negotiated import 
tariff in the high state is monotonic decreasing in the discount factor, $\delta$, i.e., $\frac{\partial z^{D S}\left(\theta_{H}, \delta\right)}{\partial \delta}<0$. Furthermore, there exists a $\delta^{E} \in(0,1)$ such that when $\delta=\delta^{E}$, the best negotiated tariff in the high state under the delayed equivalent retaliation mechanism is politically efficient, i.e., $z^{D S}\left(\theta_{H}, \delta^{E}\right)=$ $z^{E}\left(\theta_{H}\right)$.

This proposition reveals that when it is a low state, then the delayed retaliation mechanism is politically efficient. This coincides with the result under the no-delayed retaliation mechanism and the intuition behind this result is also identical to the no-delayed one. Nevertheless, when home is in a high type, in comparison to the previous mechanism, the best tariff under the delayed retaliation mechanism depends on the discount factor, $\delta$. In particular, the best tariff, $z^{D S}\left(\theta_{H}\right)$, is a decreasing function of $\delta$. Intuitively, when home suffers from a high level of political pressure, because of the delayed retaliation, the stage games between the two periods are not the same. Thus, $\delta$ cannot be cancelled out like what we did under the no-delayed case. Furthermore, when $\delta$ increases, the discounted second period joint political payoff carries more weight in the total welfare. From the property of the welfare function, we know that the joint political payoff in period 2 decreases in $z^{D S}\left(\theta_{H}\right)$. Hence, an increase in $\delta$ results in a decrease in the optimal import tariff, $z^{D S}\left(\theta_{H}\right)$. Moreover, since the politically efficient tariff, $z^{E}\left(\theta_{H}\right)$, is in between the two extreme points of $z^{M_{2}}\left(\theta_{H}\right)$, i.e., $z^{D S}\left(\theta_{H}, \delta=0\right)$ and $z^{D S}\left(\theta_{H}, \delta=1\right)$, we can find a $\delta$ such that $z^{D S}\left(\theta_{H}\right)=z^{E}\left(\theta_{H}\right)$.

The proposition below provides some useful characteristics of how the best negotiated tariff is affected by the time lag between the initial violation and the actual retaliation.

Proposition 5. The best negotiated import tariff in the low state under the no-delayed and delayed equivalent retaliation mechanisms are equal, i.e., $z^{N D S}\left(\theta_{L}\right)=z^{D S}\left(\theta_{L}\right)$, while the best negotiated import tariff in the high state under the no-delayed equivalent retaliation mechanism is lower than under the delayed equivalent retaliation mechanism i.e., $z^{N D S}\left(\theta_{H}\right)<z^{D S}\left(\theta_{H}\right)$.

Recall that the no-delayed equivalent retaliation strategy has some excessive punishment and to compensate the negative effect from foreign's inefficient retaliation, home will set a tariff which is lower than the politically efficient tariff. Now, when there is a time lag between the initial violation and the actual retaliation, it automatically makes the equivalent retaliation strategy less severe and, therefore, it reduces the negative effect from foreign's retaliation. Hence, home can choose 
a relatively higher tariff in the first place. Although it might still be lower than the politically efficient one, it is at least higher than the tariff under the no-delayed retaliation mechanism. Moreover, we can show that under certain conditions, the incentive compatibility conditions under the delayed retaliation mechanism are slack and, therefore, the solutions to the unconstrained problem (6) are incentive compatible.

Proposition 6. Under the delayed equivalent retaliation mechanism, there exists a $\hat{\delta} \in(0,1)$ and $\hat{\beta} \in(0,1)$ such that if $\delta \beta \in[\hat{\delta} \hat{\beta}, 1]$, the incentive compatibility conditions (7) and (8) are slack.

The next proposition confirms that under certain conditions, the retaliation with delay mechanism is more efficient than the retaliation without delay mechanism.

Proposition 7. Suppose that the incentive compatibility conditions under the delayed equivalent retaliation mechanism are slack, i.e., $\delta \beta \in[\hat{\delta} \hat{\beta}, 1]$. Then for any given $\lambda \in(0,1)$ and $\beta \in(0,1)$, if $\delta \in\left[\delta^{E}, 1\right)$, the delayed equivalent retaliation mechanism generates higher joint political payoff than does the no-delayed equivalent retaliation mechanism.

In deed, the range for the delayed to be more efficient than the no-delayed retaliation mechanism can be wider, if we impose more structure on the welfare function, i.e., a quadratic linear welfare function. The analysis of the welfare function in the quadratic linear form can be referred to Chapter 3.

\subsection{Dynamic Setup}

So far, we restrict our attention to the case where home only has a choice of two tariffs, which is either high or low, and ignore the possibility that it may violate the trade agreement and impose any arbitrary tariff. We now relax this assumption and examine the situation where home might set any tariff. Observe that this is a more egregious breaking of a trade agreement. We call this violation the "off-schedule" violation. We consider a dynamic version of the model and assume that the game repeats infinitely many times with the state variable evolving according to the markov process. Note that foreign could also deviate from the trade agreement and set any arbitrary tariff. 
However, when home is in a low type, home and foreign are symmetric. Hence, the analysis of the "off-schedule" violation in foreign is almost the same as at home when the type is low.

Following Bagwell-Staiger [3], we use the infinite Nash reversion as a threat to the "off-schedule" violation. Namely, when home deviates from the trade agreement, foreign will punish it by the static Nash tariff and then they will enter a trade war forever. Since an infinite reversion to the static Nash tariff is the worst scenario for the negotiators, both governments should be very cautious about imposing it. Based on this observation, we further assume that foreign will wait for one more period and then set the Nash tariff if there is an "off-schedule violation" at home.

We aim to compare the highest self-enforcing level of cooperation under incomplete information with no-delayed and delayed retaliation mechanism. However, before delving into this issue, we first characterize the static Nash tariff schemes and the bellman equations.

\subsubsection{Nash Punishment}

In this subsection, we analyze the best tariffs under the non-cooperation static game. In each period of the non-cooperation game, the governments of home and foreign set the import tariff, $z(\theta)$ and $z^{*}$, to maximize their own payoffs, respectively, i.e.,

$$
\begin{gathered}
\max _{z(\theta)} \vartheta\left(z(\theta), z^{*}, \theta\right) \\
\max _{z^{*}} \lambda \vartheta^{*}\left(z\left(\theta_{L}\right), z^{*}\right)+(1-\lambda) \vartheta^{*}\left(z\left(\theta_{H}\right), z^{*}\right) .
\end{gathered}
$$

Solving the above maximization problem yields the Nash tariff scheme, $\left(z^{N}(\theta), z^{* N}\right)$, which is given by:

$$
\begin{gathered}
z^{N}(\theta)=\underset{z(\theta)}{\operatorname{argmax}} \quad \vartheta\left(z(\theta), z^{*}, \theta\right) \\
z^{* N}=\underset{z^{*}}{\operatorname{argmax}} \lambda \vartheta^{*}\left(z\left(\theta_{L}\right), z^{*}\right)+(1-\lambda) \vartheta^{*}\left(z\left(\theta_{H}\right), z^{*}\right)
\end{gathered}
$$

Observe that the Nash tariff at home depends on the type $\theta$ while the Nash tariff in foreign does not. This idea follows by information asymmetry. Namely, $\theta$ is the private information of home. Hence, home can set its import tariff according to its type. However, foreign only knows the distribution of $\theta$. Therefore, under the non-cooperation game, it will impose the tariff to maximize its own payoff 
by taking the expectation of home's type. Besides, since the strategies are regardless of the time preferences, the static Nash tariff is independent of the discount factor, $\delta$.

\subsubsection{Bellman Equations}

Given that the state follows the markov process across time, the future values at home under the no-delayed retaliation mechanism can be captured by the following two bellman equations:

$$
\begin{aligned}
X^{N D}\left(z^{N D S}\left(\theta_{H}\right), z^{N D S}\left(\theta_{L}\right), z^{* N D S}, \theta_{L}\right) & =\vartheta\left(z^{N D S}\left(\theta_{L}\right), z^{* N D S}, \theta_{L}\right) \\
& +\delta\left[\beta \vartheta\left(z^{N D S}\left(\theta_{L}\right), z^{* N D S}, \theta_{L}\right)\right. \\
& \left.+(1-\beta) \vartheta\left(z^{N D S}\left(\theta_{H}\right), z^{N D S}\left(\theta_{H}\right), \theta_{H}\right)\right] \\
& +\delta^{2}\left\{\left[\beta^{2}\right.\right. \\
& +(1-\beta) \beta] X^{N D}\left(z^{N D S}\left(\theta_{H}\right), z^{N D S}\left(\theta_{L}\right), z^{* N D S}, \theta_{L}\right) \\
& +[(1-\beta) \beta \\
& \left.+\beta(1-\beta)] X^{N D}\left(z^{N D S}\left(\theta_{H}\right), z^{N D S}\left(\theta_{L}\right), z^{* N D S}, \theta_{H}\right)\right\}
\end{aligned}
$$

and

$$
\begin{aligned}
X^{N D}\left(z^{N D S}\left(\theta_{H}\right), z^{N D S}\left(\theta_{L}\right), z^{* N D S}, \theta_{H}\right) & =\vartheta\left(z^{N D S}\left(\theta_{H}\right), z^{N D S}\left(\theta_{H}\right), \theta_{H}\right) \\
& +\delta\left[\beta \vartheta\left(z^{N D S}\left(\theta_{H}\right), z^{N D S}\left(\theta_{H}\right), \theta_{H}\right)\right. \\
& \left.+(1-\beta) \vartheta\left(z_{a}^{N D S}\left(\theta_{L}\right), z^{* N D S}, \theta_{L}\right)\right] \\
& +\delta^{2}\left\{\left[\beta^{2}\right.\right. \\
& +(1-\beta) \beta]] X^{N D}\left(z^{N D S}\left(\theta_{H}\right), z^{N D S}\left(\theta_{L}\right), z^{* N D S}, \theta_{H}\right) \\
& +[(1-\beta) \beta \\
& \left.+\beta(1-\beta)] X^{N D}\left(z^{N D S}\left(\theta_{H}\right), z^{N D S}\left(\theta_{L}\right), z^{* N D S}, \theta_{L}\right)\right\}
\end{aligned}
$$

where $X^{N D}\left(z^{N D S}\left(\theta_{H}\right), z^{N D S}\left(\theta_{L}\right), z^{* N D S}, \theta\right)$ is the bellman equation at home under the no-delayed retaliation mechanism with the three control variables, $z^{N D S}\left(\theta_{H}\right), z^{N D S}\left(\theta_{L}\right)$ and $z^{* N D S}$, and the state variable, $\theta$.

Eq.(12) represents the future value for home if it sticks to the trade agreement and the initial 
state is low. The first four terms of the right hand side are the discounted two-period payoffs at home when the state is low at the beginning of the game. The remaining terms are the future payoff streams, $\left.\beta^{2}+(1-\beta) \beta\right] X^{N D}\left(z^{N D S}\left(\theta_{H}\right), z^{N D S}\left(\theta_{L}\right), z^{* N D S}, \theta_{L}\right)+[(1-\beta) \beta+\beta(1-$ $\beta)] X^{N D}\left(z^{N D S}\left(\theta_{H}\right), z^{N D S}\left(\theta_{L}\right), z^{* N D S}, \theta_{H}\right)$, discounted by $\delta^{2}$. We can interpret Eq.(13) by following a similar argument.

By solving the above two equations, we can express the bellman equations as a function of the best negotiated tariff scheme, $\left(z^{N S M}(\theta), z^{* N S M}\right)$, and the state variable, $\theta$.

Similarly, in terms of the delayed retaliation mechanism, the future values for home to stick to the trade agreements when it is a low state and a high state are:

$$
\begin{aligned}
X^{D}\left(z^{D S}\left(\theta_{H}\right), z^{D S}\left(\theta_{L}\right), \theta_{L}\right) & =\vartheta\left(z^{D S}\left(\theta_{L}\right), z^{* E}\left(\theta_{L}\right), \theta_{L}\right) \\
& +\delta\left[\beta \vartheta\left(z^{D S}\left(\theta_{L}\right), z^{* E}\left(\theta_{L}\right), \theta_{L}\right)\right. \\
& \left.+(1-\beta) \vartheta\left(z^{D S}\left(\theta_{H}\right), z^{* E}\left(\theta_{L}\right), \theta_{H}\right)\right] \\
& +\delta^{2}\left\{\left[\beta^{2}+(1-\beta) \beta\right] X^{D}\left(z^{D S}\left(\theta_{H}\right), z^{D S}\left(\theta_{L}\right), \theta_{L}\right)\right. \\
& \left.+[(1-\beta) \beta+\beta(1-\beta)] X^{D}\left(z^{D S}\left(\theta_{H}\right), z^{D S}\left(\theta_{L}\right), \theta_{H}\right)\right\}
\end{aligned}
$$

and

$$
\begin{aligned}
X^{D}\left(z^{D S}\left(\theta_{H}\right), z^{D S}\left(\theta_{L}\right), \theta_{H}\right) & =\vartheta\left(z^{D S}\left(\theta_{H}\right), z^{* E}\left(\theta_{L}\right), \theta_{H}\right) \\
& +\delta\left[\beta \vartheta\left(z^{D S}\left(\theta_{H}\right), z^{D S}\left(\theta_{H}\right), \theta_{H}\right)\right. \\
& \left.+(1-\beta) \vartheta\left(z^{D S}\left(\theta_{L}\right), z^{* E}\left(\theta_{L}\right), \theta_{L}\right)\right] \\
& +\delta^{2}\left\{\left[\beta^{2}+(1-\beta) \beta\right]\right] X^{D}\left(z^{D S}\left(\theta_{H}\right), z^{D S}\left(\theta_{L}\right), \theta_{H}\right) \\
& \left.+[(1-\beta) \beta+\beta(1-\beta)] X^{D}\left(z^{D S}\left(\theta_{H}\right), z^{D S}\left(\theta_{L}\right), \theta_{L}\right)\right\},
\end{aligned}
$$

respectively.

On the other hand, if home deviates from the trade agreement, then the future payoff streams when 
the initial state is low and high are:

$$
\begin{aligned}
X^{d}\left(z^{N}\left(\theta_{H}\right), z^{N}\left(\theta_{L}\right), z^{* N}, \theta_{L}\right) & =\vartheta\left(z^{N}\left(\theta_{L}\right), z^{* N}, \theta_{L}\right) \\
& +\delta\left[\beta \vartheta\left(z^{N}\left(\theta_{L}\right), z^{* N}, \theta_{L}\right)+(1-\beta) \vartheta\left(z_{a}^{N}\left(\theta_{H}\right), z^{* N}, \theta_{H}\right)\right] \\
& +\delta^{2}\left\{\left[\beta^{2}+(1-\beta) \beta\right] X^{d}\left(z^{N}\left(\theta_{H}\right), z^{N}\left(\theta_{L}\right), z^{* N}, \theta_{L}\right)\right. \\
& \left.+[(1-\beta) \beta+\beta(1-\beta)] X^{d}\left(z^{N}\left(\theta_{H}\right), z^{N}\left(\theta_{L}\right), z^{* N}, \theta_{H}\right)\right\}
\end{aligned}
$$

and

$$
\begin{aligned}
X^{d}\left(z^{N}\left(\theta_{H}\right), z^{N}\left(\theta_{L}\right), z^{* N}, \theta_{H}\right) & =\vartheta\left(z^{N}\left(\theta_{H}\right), z^{* N}, \theta_{H}\right) \\
& +\delta\left[\beta \vartheta\left(z^{N}\left(\theta_{H}\right), z^{* N}, \theta_{H}\right)+(1-\beta) \vartheta\left(z^{N}\left(\theta_{L}\right), z^{* N}, \theta_{L}\right)\right] \\
& +\delta^{2}\left\{\left[\beta^{2}+(1-\beta) \beta\right] X^{d}\left(z^{N}\left(\theta_{H}\right), z^{N}\left(\theta_{L}\right), z^{* N}, \theta_{H}\right)\right. \\
& \left.+[(1-\beta) \beta+\beta(1-\beta)] X^{d}\left(z^{N}\left(\theta_{H}\right), z^{N}\left(\theta_{L}\right), z^{* N}, \theta_{L}\right)\right\},
\end{aligned}
$$

respectively.

\subsection{3 "Off-schedule" Violation and Voluntary Participation Constraints}

Now we are ready to show the voluntary participation constraints and compare the self-enforcing levels of cooperation between the two mecahnisms. The voluntary participation constraints under the no-delayed retaliation mechanism are:

$$
\begin{aligned}
& \vartheta\left(z^{N D S}\left(\theta_{L}\right), z^{* N D S}, \theta_{L}\right) \\
& +\delta\left[\beta \vartheta\left(z^{N D S}\left(\theta_{L}\right), z_{a}^{* N D S}, \theta_{L}\right)+(1-\beta) \vartheta\left(z^{N D S}\left(\theta_{H}\right), z^{N D S}\left(\theta_{H}\right), \theta_{H}\right)\right] \\
& +\delta^{2}\left\{\left[\beta^{2}+(1-\beta) \beta\right] X^{N D}\left(z^{N D S}\left(\theta_{H}\right), z^{N D S}\left(\theta_{L}\right), z^{* N D S}, \theta_{L}\right)\right. \\
& \left.+[(1-\beta) \beta+\beta(1-\beta)] X^{N D}\left(z^{N D S}\left(\theta_{H}\right), z^{N D S}\left(\theta_{L}\right), z^{* N D S}, \theta_{H}\right)\right\} \geq \\
& \vartheta\left(z_{a}^{N D S d}\left(\theta_{L}\right), z^{* N D S}, \theta_{L}\right)+\delta\left[\beta \vartheta\left(z^{N}\left(\theta_{L}\right), z^{* N}, \theta_{L}\right)+(1-\beta) \vartheta\left(z^{N}\left(\theta_{H}\right), z^{* N}, \theta_{H}\right)\right] \\
& +\delta^{2}\left\{\left[\beta^{2}+(1-\beta) \beta\right] X^{N}\left(z^{N}\left(\theta_{H}\right), z^{N}\left(\theta_{L}\right), z^{* N}, \theta_{L}\right)\right. \\
& \left.+[(1-\beta) \beta+\beta(1-\beta)] X^{N}\left(z^{N}\left(\theta_{H}\right), z^{N}\left(\theta_{L}\right), z^{* N}, \theta_{H}\right)\right\}
\end{aligned}
$$


and

$$
\begin{aligned}
& \vartheta\left(z^{N D S}\left(\theta_{H}\right), z^{N D S}\left(\theta_{H}\right), \theta_{H}\right) \\
& +\delta\left[\beta \vartheta_{a}\left(z^{N D S}\left(\theta_{H}\right), z^{N D S}\left(\theta_{H}\right), \theta_{H}\right)+(1-\beta) \vartheta\left(z^{N D S}\left(\theta_{L}\right), z^{* N D S}, \theta_{L}\right)\right] \\
& +\delta^{2}\left\{\left[\beta^{2}+(1-\beta) \beta\right]\right] X^{N D}\left(z^{N D S}\left(\theta_{H}\right), z^{N D S}\left(\theta_{L}\right), z^{* N D S}, \theta_{H}\right) \\
& \left.+[(1-\beta) \beta+\beta(1-\beta)] X^{N D}\left(z^{N D S}\left(\theta_{H}\right), z_{a}^{N D S}\left(\theta_{L}\right), z^{* N D S}, \theta_{L}\right)\right\} \geq \\
& \vartheta\left(z_{a}^{N D S d}\left(\theta_{H}\right), z^{* N D S}, \theta_{H}\right)+\delta\left[\beta \vartheta\left(z^{N}\left(\theta_{H}\right), z^{* N}, \theta_{H}\right)+(1-\beta) \vartheta\left(z^{N}\left(\theta_{L}\right), z^{* N}, \theta_{L}\right)\right] \\
& +\delta^{2}\left\{\left[\beta^{2}+(1-\beta) \beta\right] X^{N}\left(z^{N}\left(\theta_{H}\right), z^{N}\left(\theta_{L}\right), z^{* N}, \theta_{H}\right)\right. \\
& \left.+[(1-\beta) \beta+\beta(1-\beta)] X^{N}\left(z^{N}\left(\theta_{H}\right), z^{N}\left(\theta_{L}\right), z^{* N}, \theta_{L}\right)\right\}
\end{aligned}
$$

where $z^{N D S d}(\theta)=\underset{\tau}{\operatorname{argmax}} \vartheta\left(\tau, z_{a}^{* N D S}, \theta\right)$.

The left hand side of Eq.(16) is the payoff stream of sticking to the trade-agreement. It is a combination of the current two-period payoffs and the discounted future values. The right hand side of this inequality is the discounted payoffs when the home government deviates in the current period and triggers a trade war in the next period. It is the current benefits for home's deviation plus the future payoff when both governments apply the static Nash tariff in the remaining periods. Eq.(17) describes the voluntary participation constraint when home is in a high state and it has a similar interpretation of Eq.(16).

Besides, the voluntary participation constraints under the delayed retaliation mechanism are:

$$
\begin{aligned}
& \vartheta\left(z^{D S}\left(\theta_{L}\right), z^{* E}\left(\theta_{L}\right), \theta_{L}\right) \\
& +\delta\left[\beta \vartheta\left(z^{D S}\left(\theta_{L}\right), z^{* E}\left(\theta_{L}\right), \theta_{L}\right)+(1-\beta) \vartheta\left(z^{D S}\left(\theta_{H}\right), z^{* E}\left(\theta_{L}\right), \theta_{H}\right)\right] \\
& +\delta^{2}\left\{\left[\beta^{2}+(1-\beta) \beta\right] X^{D}\left(z^{D S}\left(\theta_{H}\right), z^{D S}\left(\theta_{L}\right), \theta_{L}\right)\right. \\
& \left.+[(1-\beta) \beta+\beta(1-\beta)] X^{D}\left(z^{D S}\left(\theta_{H}\right), z^{D S}\left(\theta_{L}\right), \theta_{H}\right)\right\} \geq \\
& \vartheta\left(z^{D S d}\left(\theta_{L}\right), z^{* E}\left(\theta_{L}\right), \theta_{L}\right)+\delta\left[\beta \vartheta\left(z^{N}\left(\theta_{L}\right), z^{* N}, \theta_{L}\right)+(1-\beta) \vartheta\left(z^{N}\left(\theta_{H}\right), z^{* N}, \theta_{H}\right)\right] \\
& +\delta^{2}\left\{\left[\beta^{2}+(1-\beta) \beta\right] X\left(z^{N}\left(\theta_{H}\right), z^{N}\left(\theta_{L}\right), z^{* N}, \theta_{L}\right)\right. \\
& \left.+[(1-\beta) \beta+\beta(1-\beta)] X\left(z^{N}\left(\theta_{H}\right), z^{N}\left(\theta_{L}\right), z^{* N}, \theta_{H}\right)\right\}
\end{aligned}
$$


and

$$
\begin{aligned}
& \vartheta\left(z^{D S}\left(\theta_{H}\right), z^{* E}\left(\theta_{L}\right), \theta_{H}\right) \\
& +\delta\left[\beta \vartheta\left(z^{D S}\left(\theta_{H}\right), z^{D S}\left(\theta_{H}\right), \theta_{H}\right)+(1-\beta) \vartheta\left(z^{D S}\left(\theta_{L}\right), z^{* E}\left(\theta_{L}\right), \theta_{L}\right)\right] \\
& +\delta^{2}\left\{\left[\beta^{2}+(1-\beta) \beta\right]\right] X^{D S}\left(z^{D S}\left(\theta_{H}\right), z^{D S}\left(\theta_{L}\right), \theta_{H}\right) \\
& \left.+[(1-\beta) \beta+\beta(1-\beta)] X^{D S}\left(z^{D S}\left(\theta_{H}\right), z^{D S}\left(\theta_{L}\right), \theta_{L}\right)\right\} \geq \\
& \vartheta\left(z_{a}^{D S d}\left(\theta_{H}\right), z^{* E}\left(\theta_{L}\right), \theta_{H}\right)+\delta\left[\beta \vartheta\left(z^{N}\left(\theta_{L}\right), z^{* N}, \theta_{L}\right)+(1-\beta) \vartheta\left(z^{N}\left(\theta_{H}\right), z^{* N}, \theta_{H}\right)\right] \\
& +\delta^{2}\left\{\left[\beta^{2}+(1-\beta) \beta\right] X^{N}\left(z^{N}\left(\theta_{H}\right), z^{N}\left(\theta_{L}\right), z^{* N}, \theta_{L}\right)\right. \\
& \left.+[(1-\beta) \beta+\beta(1-\beta)] X^{N}\left(z^{N}\left(\theta_{H}\right), z^{N}\left(\theta_{L}\right), z^{* N}, \theta_{H}\right)\right\},
\end{aligned}
$$

where $z^{D S d}(\theta)=\underset{\tau}{\operatorname{argmax}} \vartheta\left(\tau, z^{* E}\left(\theta_{L}\right), \theta\right)$. The interpretation of the above two inequalities are the same as the ones under the no-delayed retaliation mechanism.

Recall Proposition 5 says that the best optimal tariff schemes in the low state are politically efficient and identical underp the no-delayed and delayed retaliation mechanisms. On the contrary, when it is a high state, if $\delta \in\left[\delta^{E}, 1\right)$, then the best import tariff under the delayed retaliation mechanism is higher than under the no-delayed case. This property, together with the voluntary participation conditions defined in Eqs.(16)-(17), further indicates that

Proposition 8. Suppose that the incentive compatibility conditions under the delayed retaliation mechanism are slack, i.e., $\delta \beta \in[\hat{\delta} \hat{\beta}, 1]$. Then for any given $\lambda \in(0,1)$ and $\beta \in(0,1)$, if $\delta \in\left[\delta^{E}, 1\right)$, the delayed equivalent retaliation mechanism supports a higher self-enforcing level of cooperation than does the no-delayed equivalent retaliation mechanism.

Proposition 8 further refines the result that the delayed retaliation mechanism is more efficient than the no-delayed retaliation mechanism. Namely, from Proposition 7, we know that under a twoperiod equivalent retaliation mechanism, when there is a time lag between the initial violation and the actual retaliation, it results in higher joint political welfare under certain conditions. Proposition 8 demonstrates that when extending the two-period model to a dynamic game, retaliation with delay mechanism is still more efficient. Intuitively, for any level of the deviation tariff, retaliation with delay reduces the current benefit of the deviation. This is because under the delayed retaliation mechanism, when it is a high state, home is allowed to increase its import tariff by a larger amount 
than under the no-delayed retaliation mechanism (Proposition 5). Hence, the benefit of deviating from the trade agreement under the delayed retaliation mechanism is smaller than under the nodelayed one. On the other hand, from the assumption, we know that the Nash punishment hurts the deviating country by the same amount under the two mechanisms, yet Proposition 5 implies that retaliation with delay raises the discounted future value of home if it sticks to the trade agreement. Thus, a retaliation with delay mechanism results in a greater loss of deviating from the trade agreement. Therefore, in comparison to a no-delayed retaliation mechanism, deviating from the trade agreement under the delayed retaliation mechanism results in a lower benefit but a higher cost. Based on this observation, it is less likely for home to deviate from the retaliation with delay mechanism. Or, retaliation with delay enhances the self-enforcing level of cooperation between the two governments. 


\section{Chapter 3: Limited Cross-retaliation and Lengthy Delays in International Dispute Settlement}

\subsection{Introduction}

International trade agreements are often viewed as contracts between two or more trading parties. They contain elements of a valid legal agreement which is enforceable by law. However, the provisions that enforcing these contracts vary from domestic tort and criminal laws in many different aspects. This chapter considers two main differences. First, in domestic laws, the injured party can receive the compensation soon after the court has made its decision to support for the complainant and, in criminal laws, if the court finds the defendant guilty, it will administer the punishment without delay. Nevertheless, when there is a violation of an international trade agreement, the Dispute Settlement Body (DSB) of the World Trade Organization (WTO) tends to wait for a certain time before applying countermeasures and entering a trade war. Second, in both contract laws and criminal laws, it seems very awkward or sometimes impracticable to charge the defendant by exactly the same harm or the same crime that they have made to the plaintiff. For example, when a medical injury is caused by the physician's negligence, the patient will be compensated by some cash payment not by ordering the physician to suffer from the same damage. Or, when a person commits a crime, instead of allowing the victim to carry out the same crime against him, the court will sentence him to jail for certain years. On the contrary, for a violation in international trade agreements, WTO limits the composition in retaliation and prefers same-sector to crosssector retaliation by saying that ".. if that party considers that it is not practical or effective to suspend concessions or other obligations with respect to the same sector(s), it may seek to suspend concessions or other obligations in other sectors under the same agreement...".

To further demonstrate these differences, we illustrate some facts in the GATT-WTO system history in Tables 1 and 2. Table 1 lists 10 retaliation claims from the members in the WTO. Inspecting the table, note that the average period of time between the date that the complaint requested for a consultation and the date that the panel made the decision is around 2-3 years. Hence, the data shows that the DSB works (unnecessarily) slowly and it further confirms that the WTO may prefer delayed retaliation. Table 2 designates the cases where the complainant governments requested for 
approvals of cross-sector retaliation by the DSB, and it shows that up till now, there have only been three out of fourteen cases where cross-retaliation has been authroized and the complainant in these three cases are mostly small countries ${ }^{8}$. Thus, the only reason that the WTO allows cross-sector

\begin{tabular}{|c|c|c|c|c|c|}
\hline Case name & Complaint & Respondent & Panel's decision & Level of suspension authorized & years \\
\hline $\begin{array}{l}\text { Brazil } \\
\text { - Export Financing Programme } \\
\text { for Aircraft }\end{array}$ & Canada & Brazil & $\begin{array}{l}\text { Support for same sector retaliation } \\
\text { and aginst cross-sector retaliation }\end{array}$ & CAN\$344.2 million (annual) & $23 / 08 / 2001$ \\
\hline $\begin{array}{l}\text { Canada } \\
\text { - Aircraft Credits and } \\
\text { Guarantees }\end{array}$ & Brazil & Canada & $\begin{array}{l}\text { Support for same sector retaliation } \\
\text { and aginst cross-sector retaliation }\end{array}$ & US\$247.8 million(annual) & $18 / 03 / 2003$ \\
\hline US - 1916 Act & EC & US & $\begin{array}{l}\text { Support for same sector retaliation } \\
\text { and aginst cross-sector retaliation }\end{array}$ & & $26 / 11 / 2004$ \\
\hline $\mathrm{US}-\mathrm{FSC}$ & US & $\mathrm{EC}$ & $\begin{array}{l}\text { Support for same sector retaliation } \\
\text { and aginst cross-sector retaliation }\end{array}$ & US $\$ 4,043$ billion (annual) & $17 / 05 / 2006$ \\
\hline $\begin{array}{l}\text { US } \\
\text {-Offset Act (Byrd Amendment) }\end{array}$ & EC & US & $\begin{array}{l}\text { Support for same sector retaliation } \\
\text { and aginst cross-sector retaliation }\end{array}$ & & $24 / 04 / 2007$ \\
\hline $\begin{array}{l}\text { EC } \\
\text { - Hormones }\end{array}$ & US & EC & $\begin{array}{l}\text { Support for same sector retaliation } \\
\text { and aginst cross-sector retaliation }\end{array}$ & US\$116.8 million (annual) & $25 / 09 / 2009$ \\
\hline EC - Bananas III & Ecuador & EC & Support for cross-sector retaliation & US\$191.4 million (annual) & $8 / 11 / 2012$ \\
\hline US - Gambling & Antigua and Barbuda & US & Support for cross-sector retaliation & US\$21 million (annual) & $28 / 01 / 2013$ \\
\hline China - Autos (US) & US & China & $\begin{array}{l}\text { Support for same sector retaliation } \\
\text { and against cross-sector retaliation }\end{array}$ & & $18 / 06 / 2014$ \\
\hline US - Upland Cotton & Brazil & US & Support for cross-sector retaliation & US\$147.3 million (annual) & $16 / 10 / 2014$ \\
\hline China - GOES & US & China & $\begin{array}{l}\text { Support for same sector retaliation } \\
\text { and against cross-sector retaliation }\end{array}$ & & $31 / 08 / 2015$ \\
\hline China - Broiler Products & US & China & $\begin{array}{l}\text { Support for same sector retaliation } \\
\text { and against cross-sector retaliation }\end{array}$ & & $22 / 06 / 2016$ \\
\hline $\begin{array}{l}\text { US } \\
\text { - Supercalendered Paper }\end{array}$ & Canada & US & $\begin{array}{l}\text { Support for same sector retaliation } \\
\text { and against cross-sector retaliation }\end{array}$ & & $31 / 08 / 2016$ \\
\hline $\begin{array}{l}\text { EU } \\
\text { - PET (Pakistan) }\end{array}$ & Pakistan & $\mathrm{EU}$ & $\begin{array}{l}\text { Support for same sector retaliation } \\
\text { and against cross-sector retaliation }\end{array}$ & & $6 / 07 / 2017$ \\
\hline
\end{tabular}

Table 2: Cases that Complainant Requests for Cross-sector Retaliation

retaliation might due to the concern that if the affected party is an extremely small scale economy, it posses little bargaining power. Then strategic same-sector retaliation may not be an effective method to secure trade laws from large countries.

For the discussion so far, the readers may have wondered why international trade agreements are different from the domestic and criminal laws and what is the rationale for the WTO to prefer delayed to no-delayed and same-sector to cross-sector retaliation?

To answer these questions, we take a dynamic mechanism design approach and analyze the welfare effect of same-sector and cross-sector retaliation under both no-delayed and delayed retaliation mechanisms. In particular, we consider a two-country, two-sector tariff-setting framework. We

\footnotetext{
${ }^{8}$ Note that in the US-Upland Cotton case, although Brazil is a large country, in comparison to the US, it has very little economic power. Hence, the WTO supports the requests for cross-sector retaliation from Brazil in this case.
} 
assume that the trade agreement is an incomplete contract and there is information asymmetry about the varying levels of political pressure that a country may face. This pressure is the country's private information and might induce the governments to increase its import tariffs to protect its domestic industry. It is assumed to take two values, which is either high or low, and evolve according to the markov process over time.

We assume equal retaliation under both cross-sector and same-sector retaliation mechanisms. Namely, the punisher is allowed to impose a retaliatory tariff only by the same amount. Note that this equal retaliation assumption is reasonable and is usually provided by GATT/WTO. For example, according to GATT Article XIX paragraph $(c)$, “...if, as a result of some unforseen developments, a contracting party takes measure inconsistent with the GATT obligations, ..., then the affected contracting party is free to suspend an equivalent concession no later than ninety days after the violation is taken." Also, GATT Article XXII paragraph (4) says that "...The level of the suspension of concessions or other obligations authorized by the DSB shall be equivalent to the level of the nullification or impairment...".

Nevertheless, this equivalent retaliation strategy might create some excessive punishment. Therefore, in Appendix C, we consider equal retaliation strategies but with delay. Note that due to this delay assumption, the equivalent retaliation strategy can have a less severe impact on the initial violator. We demonstrate formally in the previous chapter that if there is a time lag between a violation and a retaliation, then it can create more efficiency and generate a higher social welfare ${ }^{9}$. Our main goal in this chapter is to compare the efficiency between same-sector and cross-sector retaliation mechanisms. Besides, in comparison to retaliation with delay, no-delayed retaliation is less complicated. Therefore, we focus on retaliation without delay in the main part of this chapter. The analysis of the comparison between same-sector and cross-sector retaliation with delay can be referred to Appendix C.

We assume that the goods are strategic substitutes within the sector and strategically neutral across the sectors. The intuition behind this assumption follows by three layers. First, in a traditional two-good general equilibrium framework, if the goods are strategic substitutes, then an increase in foreign import tariff lowers the income at home and therefore, reduces the demand for each good

\footnotetext{
${ }^{9}$ The idea of the delayed retaliation strategies is related to Beshkar [7]. According to Beshkar [7], he argues that it would be optimal for the punisher or the WTO to impose an equivalent retaliation with certain probability.
} 
at home. This, in turn, diminishes the impact on the welfare from rasing the import tariff at home and, will, eventually, lead the optimal tariff at home to go down. Put differently, a positive strategic substitutability of the two goods results in a negative relationship between the optimal tariffs of the two countries. Or, if the goods are strategic substitutes, then the tariffs should be strategic substitutes as well. Second, our need is to analyze cross-sector retaliation and compare it with same-sector retaliation. Therefore, our model must include at least two sectors with two goods in each sector. However, if we have two sectors and four goods, then in comparison to a traditional general equilibrium model, rasing the import tariff in foreign will lead home income to float in both sectors. This will result in a quite complicated calculation and therefore, we can not solve the model analytically. Hence, to make our model analytically solvable, we reintroduce the partial equilibrium intuition by assuming that the goods across the sectors are independent. Given this partial equilibrium assumption, there is no income effect across the sectors. Thus, it dramatically simplifies the calculation. Thirdly, given that the goods are strategically neutral across the sectors, then the strategic substitutability assumption for the goods within the sector becomes a necessary assumption. This is because if the goods are strategically neutral both within and between the sectors, then there will be no income effect. Therefore, no matter whether one country raises its import tariff in sector $a$ or $b$, it will influence the other country in the same way. Then, same-sector and cross-sector retaliation must be identical.

Note that the above assumption is reasonable and realistic because in the real world, it is very common that an increase in the price of one good will stimulate the demand of some goods while have no significant effect on the demand of some other goods. For example, usually, there is a positive cross elasticity of demand between potatoes and rice or motorcycles and bicycles while there is no correlation between the price of potatoes and the demand of motorcycles. Furthermore, if we categorize the goods by their usage, then potatoes and rice are referred to the food sector while motorcycles and bicycles belong to the transportation sector. Hence, it further demonstrates the reasonableness of the assumption that the goods across the sectors are strategically neutral while the goods within the sectors are strategic substitutes.

We analyze two types of violations, the "on-schedule" and the "off-schedule" violations. An "onschedule" violation refers to the case where the country misreports its type and chooses a low tariff when it is a high type or vice versa. From the traditional tariff-setting model, we know that as long 
as the "incentive-compatibility" or "truth-telling" conditions are satisfied, then the "on-schedule" violation can be prevented. An "off-schedule" violation is a more egregious breaking of a trade agreement. It refers to the case where the country deviates from the trade agreements and chooses any arbitrary tariffs. Therefore, we use the Nash reversion strategies as a threat to this violation and focus on a dynamic version of the game. We call the conditions to prevent this "off-schedule" violations as the voluntary participation constraints.

We show that under certain conditions, the best tariffs under same-sector retaliation generate higher joint political welfare and support a higher self-enforcing level of cooperation than do the best tariffs under cross-sector retaliation. We first verify that this result holds when the retaliation happens with no delay. In Appendix $\mathrm{C}$ we specify that under certain conditions, the same-sector retaliation mechanism is still more efficient than the cross-sector retaliation mechanism even if there is a time lag between a violation and a retaliatory action of a trade agreement ${ }^{10}$.

\subsection{Basic Setup}

We consider a two-country two-sector tariff-setting political economy framework with incomplete information. It is a combination of a political economy with incomplete information in BagwellStaiger [4], Bagwell [5] and Beshkar [8], and a multi-sector tariff setting model in Chisik-Onder $[10]$.

Our model includes two countries, home and foreign, two sectors, defined as $i \in\{a, b\}$, two goods in each sector, represented by $j_{i} \in\left\{x_{i}, y_{i}\right\}$, and a numeraire good, denoted by $z$. Time is infinite and discrete (i.e., $t=0,1, \ldots)$. Home preferences are represented by:

$$
U(\cdot)=\sum_{t=0}^{\infty} \delta^{t}\left[\sum_{i=a, b} u_{i t}(\cdot)+z_{t}\right]
$$

where $\vartheta_{i t}(\cdot)$ and $z_{t}$ are the home utility from sector $i$ and the numeraire sector in period $t$, respectively. Foreign preferences, denoted by $U^{*}(\cdot)$ are given by a similar expression.

Assume that the numeraire good, $z$, is produced by both countries under constant return to scale

\footnotetext{
${ }^{10}$ In the previous chapter, we compare delayed and no-delayed retaliation. We demonstrate that under certain conditions, the best tariffs under the delayed retaliation mechanism generate a higher joint political welfare and support a higher self-enforcing level of cooperation, irrespective of whether retaliation happens in the sector where the initial violation occurs or not.
} 
and is abundant in each country ${ }^{11}$. Without loss of generality, we can normalize the price of the numeraire good, denoted by $w$, to be 1 and then the total wage income, denoted by $I_{t}$, is just equal to the total labour supply, i.e., $I_{t}=w_{t} \cdot l_{t}=l_{t}$.

Assume that $u_{i t}(\cdot, \cdot)$ is taken by the following quasi-linear function form:

$$
u_{i t}\left(q_{x_{i} t}^{d}, q_{y_{i} t}^{d}\right)=\frac{1}{1-b_{i}^{2}}\left[A\left(1+b_{i}\right)\left(q_{x_{i} t}^{d}+q_{y_{i} t}^{d}\right)-\frac{1}{2}\left(q_{x_{i} t}^{d}\right)^{2}-\frac{1}{2}\left(q_{y_{i} t}^{d}\right)^{2}-b_{i} q_{x_{i} t}^{d} q_{y_{i} t}^{d}\right]
$$

where $q_{x_{i} t}^{d}$ and $q_{y_{i} t}^{d}$ are the home demand functions of goods $x_{i}$ and $y_{i}$ in period $t$, respectively, $A>0$ is a taste parameter which measures the intensity of preferences and would be the demand choke price if the goods are neither substitutes or complement and $b_{i} \in(0,1)$ indicates the extent of substitutability between the goods.

Moveover, although our model is different from the traditional two good tariff setting framework, we can derive the same result that if the goods are strategic substitutes, then the import tariffs are strategic substitutes.

Lemma 1. Suppose that the goods within the sectors are strategic substitutes, i.e., $b_{1} \in(0,1)$ or $b_{2} \in(0,1)$, then the optimal import tariffs within the sectors are strategic substitutes.

In every period $t$, given the equilibrium prices of good $j_{i}$ in the home country, denoted as $p_{j_{i}}$, the consumer maximization problem yields the following demand functions:

$$
q_{x_{i} t}^{d}=A-p_{x_{i} t}+b_{i} p_{y_{i} t} ; \quad q_{y_{i} t}^{d}=A-p_{y_{i} t}+b_{i} p_{x_{i} t}
$$

Let $p_{j_{i} t}^{*}$ denotes the foreign equilibrium price of good $j_{i}$ in period $t$. Assume that the preference in the foreign country and period $t$, denoted as $u_{i t}^{*}$, is identical to the one of the home country. Thus, the foreign demand of good $j_{i}$ in period $t$, represented by $q_{j_{i}}^{d^{*}}$, has a similar expression of the home demand.

For the production side of the economy, in every period $t$, home $\left(\right.$ no* $\left.^{*}\right)$ and foreign $\left(^{*}\right)$ produce both

\footnotetext{
${ }^{11}$ Since the goods across the sectors are strategically neutral, we have a partial equilibrium intuition in the crosssector part. Therefore, it is not a traditional general equilibrium model. However, by introducing the numeraire good, it is still a general equilibrium model in that we can still close the model as long as the labour supply is large enough for both countries.
} 
goods $x_{i}$ and $y_{i}$ according to the cost functions:

$$
\begin{aligned}
& C_{x_{i}}\left(q_{x_{i} t}^{s}\right)=c\left(q_{x_{i} t}^{s}\right)^{2} ; \quad C_{y_{i}}\left(q_{y_{i} t}^{s}\right)=f q_{y_{i} t}^{s}+c\left(q_{y_{i} t}^{s}\right)^{2} . \\
& C_{x_{i}}\left(q_{x_{i} t}^{s^{*}}\right)=f q_{x_{a} t}^{s^{*}}+c\left(q_{x_{a} t}^{s^{*}}\right)^{2} ; \quad C_{y_{i}}\left(q_{y_{i} t}^{s^{*}}\right)=c\left(q_{y_{i} t}^{s^{*}}\right)^{2} ;
\end{aligned}
$$

where $q_{j_{i} t}^{s}$ and $q_{j_{i} t}^{s^{*}}$ are the supply functions of home and foreign in period $t$, respectively, and $f, c>0$ are parameters. Since $f>0$, the marginal cost of producing the $x \operatorname{goods}\left(x_{a}\right.$ and $\left.x_{b}\right)$ at home is lower than in foreign. Hence, home has a comparative advantage of the $x$ goods. Similarly, foreign has a comparative advantage in the $y$ goods $\left(y_{a}\right.$ and $\left.y_{b}\right)$ in that the marginal cost of the $y$ goods in foreign is lower. Therefore, home exports the $x$ goods to foreign while imports the $y$ goods from foreign. Solving the producer maximization problem derives the following supply functions of home $($ no $*)$ and foreign $(*)$ :

$$
\begin{aligned}
q_{x_{i} t}^{s} & =\frac{p_{x_{i} t}}{2 c} ; \quad q_{y_{i} t}^{s}=\frac{p_{y_{i} t}-f}{2 c} ; \\
q_{x_{i} t}^{s^{*}} & =\frac{p_{x_{i} t}^{*}-f}{2 c} ; \quad q_{y_{i} t}^{s^{*}}=\frac{p_{y_{i} t}^{*}}{2 c} .
\end{aligned}
$$

Governments in home and foreign choose a sequence of import tariffs, $\left\{\tau_{i t}\right\}_{t=0}^{\infty}$ and $\left\{\tau_{i t}^{*}\right\}_{t=0}^{\infty}$, to maximize their total welfare, respectively. In every period $t$, the tariffs create a wedge between the domestic and foreign prices. Namely,

$$
p_{x_{i} t}^{*}=p_{x_{i} t}+\tau_{i t}^{*} ; \quad p_{y_{i} t}=p_{y_{i} t}^{*}+\tau_{i t} .
$$

Following Baldwin [2], we assume that the political welfare in sector $i$ and period $t$ is a weighted sum of the country's producer surplus, consumer surplus and tariff revenues in that period. The total political welfare in sector $i$ is an infinite version of the per period one. In particular, the 
welfare of home in sector $a$ is defined as:

$$
\begin{aligned}
\vartheta_{a}\left(\tau_{a t}, \tau_{a t}^{*}, \theta_{t}\right)= & \sum_{t=0}^{\infty} \delta^{t} \vartheta_{a t}\left(\tau_{a t}, \tau_{a t}^{*}, \theta_{t}\right) \\
& =\sum_{t=0}^{\infty} \delta^{t} \vartheta_{a t}\left(p_{x_{a t}}\left(\tau_{a t}\right), p_{y_{a t}}\left(\tau_{a t}^{*}\right), \theta_{t}\right) \\
& =\sum_{t=0}^{\infty} \delta^{t}\left\{u_{a t}\left[q_{x_{a} t}^{d}\left(p_{x_{a} t}\left(\tau_{a t}\right), p_{y_{a} t}\left(\tau_{a t}^{*}\right)\right), q_{y_{a} t}^{d}\left(p_{y_{a} t}\left(\tau_{a t}^{*}\right), p_{x_{a} t}\left(\tau_{a t}\right)\right)\right]\right. \\
& \left.-p_{x_{a} t}\left(\tau_{a t}\right) q_{x_{a} t}^{d}\left(p_{x_{a} t}\left(\tau_{a t}\right), p_{y_{a} t}\left(\tau_{a t}^{*}\right)\right)-p_{y_{a} t}\left(\tau_{a t}^{*}\right) q_{y_{a} t}^{d}\left(p_{y_{a} t}\left(\tau_{a t}^{*}\right), p_{x_{a} t}\left(\tau_{a t}\right)\right)\right\} \\
& +\sum_{t=0}^{\infty} \delta^{t}\left\{p_{x_{a} t}\left(\tau_{a t}\right) q_{x_{a} t}^{s}\left(p_{x_{a} t}\left(\tau_{a t}\right)\right)-c_{x_{a} t}\left(q_{x_{a} t}^{s}\left(p_{x_{a} t}\left(\tau_{a t}\right)\right)\right)\right\} \\
& +\sum_{t=0}^{\infty} \delta^{t}\left\{\theta_{t}\left[p_{y_{a} t}\left(\tau_{a t}^{*}\right) q_{y_{a} t}^{s}\left(p_{y_{a} t}\left(\tau_{a t}^{*}\right)\right)-c_{y_{a}}\left(q_{y_{a}}^{s}\left(p_{y_{a}}\left(\tau_{a t}^{*}\right)\right)\right)\right]\right\} \\
& +\sum_{t=0}^{\infty} \delta^{t}\left\{\tau_{a t}\left[q_{y_{a} t}^{d}\left(p_{y_{a} t}\left(\tau_{a t}^{*}\right), p_{x_{a} t}\left(\tau_{a t}\right)\right)-q_{y_{a} t}^{s}\left(p_{y_{a} t}\left(\tau_{a t}^{*}\right)\right)\right]\right\}
\end{aligned}
$$

where $\theta_{t}$ is the political weight (pressure) of home producer surplus from industry $y_{i}$ in sector $a$ and period $t$.

We make the following assumptions about the political pressure at home, $\theta_{t}$. First, to capture the idea that the governments may face high political pressure, we allow $\theta_{t}$ to be greater than 1 . Specifically, it can take two values, which is either high, denoted by $\theta_{H}$, or low, denoted by $\theta_{L}$, i.e., $\theta_{t}=\left\{\theta_{L}, \theta_{H}\right\}$. Assume that $\theta_{L}=1$ and $\theta_{H}>1$. Second, we assume that $\theta_{t}$ follows the probability distribution below within the period:

$$
\theta_{t}= \begin{cases}\theta_{L} & \text { with probability } \lambda \\ \theta_{H} & \text { with probability } 1-\lambda,\end{cases}
$$

and the markov process across time:

$$
\begin{gathered}
\operatorname{prob}\left(\theta_{t+1}=\theta_{L} \mid \theta_{t}=\theta_{L}\right)=\operatorname{prob}\left(\theta_{t+1}=\theta_{H} \mid \theta_{t}=\theta_{H}\right)=\beta ; \\
\operatorname{prob}\left(\theta_{t+1}=\theta_{H} \mid \theta_{t}=\theta_{L}\right)=\operatorname{prob}\left(\theta_{t+1}=\theta_{L} \mid \theta_{t}=\theta_{H}\right)=1-\beta,
\end{gathered}
$$


where $\beta \in[0,1]$ is the transition probability.

In every period $t$, the welfare of home in sector $b$ and the welfare of foreign in each sector are the same as the one of home in sector $a$ except that the weights of the producer surplus in the import-competing industries are equal to 1 . Let $\vartheta_{b t}\left(\tau_{b t}, \tau_{b t}^{*}\right), \vartheta_{a t}^{*}\left(\tau_{a t}, \tau_{a t}^{*}\right)$ and $\vartheta_{b t}^{*}\left(\tau_{b t}, \tau_{b t}^{*}\right)$ denote the corresponding welfare, respectively.

Since $\theta_{t}$ has two possible values at home, we can add information asymmetry to the model. In particular, we assume that $\theta_{t}$ is the private information of home and foreign can only know the distribution of it. On the other hand, we assume that foreign political pressure does not change ${ }^{12}$. As alluded to in the introduction, we focus on two types of violation, the "on-schedule" and the "off-schedule". Since there are only two states, under each mechanism, we will consider two "onschedule" tariffs, a high state and a low state tariff. Note that if we only consider the "on-schedule" violations, then a one-period game is enough. However, if we allow the "off-schedule" violation, then we should consider a dynamic version of the game. We assume that under the dynamic game, the process in a one-period game repeats infinitely many times and the state evolves according to a markov process.

The timing of a per-period game is as follows. It consists of three stages. In the first stage, nature moves. It chooses a type for home, which is either high, or, low. In the second stage, home moves. It sets its import tariff in sectors $a$ and $b$ based on the realization of its type. In the third stage, foreign moves. Given the tariffs that home sets in the previous stage, foreign imposes its import tariffs in sectors $a$ and $b^{13}$.

\footnotetext{
${ }^{12}$ Although it would be straightforward to allow foreign pressure to vary as well, but the maths becomes slightly more complicated and there is no change in our results. Therefore, there is no need to have the foreign political pressure change across time.

${ }^{13}$ Indeed, as long as home sticks to the trade agreement, the game is as if home announces its type and then the tariffs are chosen simultaneously. However, we think it would be more realistic that rather than announcing the type, home would choose a tariff ro reveal its type. The readers may have wondered that if home chooses its tariff first, then it may have a first mover advantage. Nevertheless, it would not happen if the mechanism satisfies both incentive compatibility and voluntary participation conditions. Or, home does not have a first mover advantage if it has no incentive to violate the "on-schedule" and "off-schedule" violations. The reasons are as follows. First, if we only focus on the "on-schedule" violation, then home only has a couple of choice of tariffs and it cannot have a first mover advantage because if it takes the first mover advantage, then it would be an "off-schedule" violation. Second, although under a dynamic game, home can choose an "off-schedule" violation and use its first mover advantage, it will never do that in equilibrium if the threat of the "off-schedule" violation is effective.
} 


\subsection{Benchmark: Perfect Information}

To compare the attainable optimality between the same and cross-sector retaliation mechanisms under incomplete information, we first characterize the optimal trade agreements under perfect information as a benchmark. Namely, under the benchmark, we consider a first-best situation where foreign has perfect information about the political pressure faced by home and the trade agreement is under full-commitments.

Under this complete information game, both governments set their tariffs in sector $a$ based on home's type $\theta^{14}$. Since the two sectors are not related, the import tariffs of home and foreign in sector $b$ are independent of $\theta$. Hence, the strategies of home $\left(\right.$ no $\left.{ }^{*}\right)$ and foreign $\left({ }^{*}\right)$ under the benchmark are as follows:

$$
\tau_{t a}=\left\{\begin{array}{ll}
z_{a}\left(\theta_{L}\right) \quad \text { if } \theta_{t}=\theta_{L} \\
z_{a}\left(\theta_{H}\right) \quad \text { if } \theta_{t}=\theta_{H}
\end{array} \quad \tau_{t b}=z_{b} ; \quad \tau_{t a}^{*}=\left\{\begin{array}{ll}
z_{a}^{*}\left(\theta_{L}\right) \quad \text { if } \theta_{t}=\theta_{L} \\
z_{a}^{*}\left(\theta_{H}\right) \quad \text { if } \theta_{t}=\theta_{H}
\end{array} \quad \tau_{t b}^{*}=z_{b}^{*},\right.\right.
$$

where $t=\{0,1, \ldots,+\infty\}$.

Given the strategies, home and foreign choose sequences of import tariffs, $\left\{\left(z_{a t}(\theta), z_{b t}\right)\right\}_{t=0}^{\infty}$ and $\left\{\left(z_{a t}^{*}(\theta), z_{b t}^{*}\right)\right\}_{t=0}^{\infty}$, to maximize the discounted joint political welfare. Since the per-period game is the same and the strategies are independent of how the state evolves over time, the maximization problem in each period are identical. Therefore, we can drop the subscript $t$ and the maximization problem is:

$$
\begin{aligned}
\max _{z_{a}(\theta), z_{b}, z_{a}^{*}(\theta), z_{b}^{*}} & \vartheta_{a}\left(z_{a}(\theta), z_{a}^{*}(\theta), \theta_{t}\right)+\vartheta_{a}^{*}\left(z_{a}(\theta), z_{a}^{*}(\theta)\right)+\vartheta_{b}\left(z_{b}, z_{b}^{*}\right)+\vartheta_{b}^{*}\left(z_{b}, z_{b}^{*}\right) \\
& +w \cdot L+w^{*} \cdot L^{*} .
\end{aligned}
$$

Since the sectors are independent, the above maximization problem can be separated into two problems below:

$$
\max _{z_{a}(\theta), z_{a}^{*}(\theta)} \vartheta_{a}\left(z_{a}(\theta), z_{a}^{*}(\theta), \theta\right)+\vartheta_{a}^{*}\left(z_{a}(\theta), z_{a}^{*}(\theta)\right)
$$

\footnotetext{
${ }^{14}$ As will be shown later, under incomplete information, $\theta$ becomes private information of home. Then foreign will set its tariff based on home's actions in the previous stage. This might create some deadweight loss of the joint political welfare.
} 
and

$$
\max _{z_{b}, z_{b}^{*}} \vartheta_{b}\left(z_{b}, z_{b}^{*}\right)+\vartheta_{b}^{*}\left(z_{b}, z_{b}^{*}\right)
$$

Denote the solutions to problems $(25)$ and $(26)$ as $\left(z_{a}^{E}(\theta), z_{a}^{* E}(\theta)\right)$ and $\left(z_{b}^{E}, z_{b}^{* E}\right)$, respectively, where the superscript letter " $E$ "represents "politically efficient". By solving the two maximization problems, we can get the following proposition:

Proposition 9. Under the first best perfect information, we have

$$
\begin{gathered}
z_{a}^{E}\left(\theta_{L}\right)=z_{a}^{* E}\left(\theta_{L}\right)=z_{b}^{E}=z_{b}^{* E}=0 \\
z_{a}^{E}\left(\theta_{H}\right)=\frac{\left(\theta_{H}-1\right)\left(4 b_{1} c f+4 A c-4 c f-f\right)}{\left(2 b_{1} c-2 c-1\right)\left(2 b_{1}^{2} c-8 c+\theta_{H}-1\right)} \\
z_{a}^{* E}\left(\theta_{H}\right)=-\frac{b_{1}}{2} \frac{\left(\theta_{H}-1\right)\left(4 b_{1} c f+4 A c-4 c f-f\right)}{\left(2 b_{1} c-2 c-1\right)\left(2 b_{1}^{2} c-8 c+\theta_{H}-1\right)} .
\end{gathered}
$$

The proposition above indicates that the tariffs of sector $a$ in the high state depend on the production costs, $f$ and $c$, the parameter that captured the substitutability within the sector, $b_{1}$, and the taste parameter, $A$, while the tariffs of sector $a$ in the low state and the tariffs of sector $b$ are independent of all the parameters. In deed, it is optimal for the governments to impose zero tariffs in both sectors when the political pressure at home is low. The idea here is that when it is a low state, home and foreign are symmetric in all factors. Therefore, no matter how $f, c, b_{1}$ or $A$ changes, a positive import tariff in either home or foreign will lead to a deadweight loss from the total political joint welfare. Hence, it will never be optimal for either government to set a tariff which is greater than 0 . On the other hand, when home faces high political pressure, the two governments are asymmetric. The producers in home weights more in the total joint political welfare than in foreign. Hence, an increase in home import tariffs results in lower joint marginal costs than in foreign ones. Furthermore, the extent of the difference between the joint marginal costs depends on the value of the parameters, $f, c, b_{1}, A$ and $\theta_{H}$. Therefore, the two countries' optimal tariffs in a high state should depend on the parameters above. 
Proposition 10. Under the first best perfect information, if the goods in sector a are strategic substitutes, i.e., $b_{1} \in(0,1)$, then $z_{a}^{* E}\left(\theta_{H}\right)<0<z_{a}^{E}\left(\theta_{H}\right)$.

This proposition shows a very interesting result. Namely, under the first best perfect information, when home faces high political pressure, the optimal action for foreign is to serve a subsidy. Note that although a subsidy will increase the total joint political welfare, it will definitely hurt foreign. Hence, in reality, foreign will never do that unless it can receive some additional rewards for this sacrificing action. Therefore, when we add incomplete information into the game, no matter whether it is is a same-sector or cross-sector retaliation mechanism, we can never achieve the first best situation.

Propositions 9 and 10 imply that under the first-best perfect information, if the goods in sector a are strategic substitutes, i.e., $b_{1} \in(0,1)$, then the optimal import tariffs in home increases in $\theta$ while the optimal import tariffs in foreign decreases in $\theta$, i.e., $z_{a}^{* E}\left(\theta_{H}\right)<z_{a}^{E}\left(\theta_{L}\right)=z_{a}^{* E}\left(\theta_{L}\right)<z_{a}^{E}\left(\theta_{H}\right)$. Intuitively, when $\theta$ increases from $\theta_{L}$ to $\theta_{H}$, the producer surplus from industry $y$ and sector $a$ has a higher weight in home's welfare and it also accounts for a larger share in the joint political welfare. This means that the producers of home in industry $y$ are more valuable as compared to the producers of foreign in the same industry. Hence, a higher $\theta$ increases both the benefit of raising the tariff in home and the cost of imposing the tariff in foreign. Thus, when $\theta$ goes from $\theta_{L}$ to $\theta_{H}$, the efficient tariff in home increases while the efficient tariff in foreign decreases. Namely, $z_{a}^{E}\left(\theta_{L}\right)<z_{a}^{E}\left(\theta_{H}\right)$ and $z_{a}^{* E}\left(\theta_{H}\right)<z_{a}^{* E}\left(\theta_{L}\right)$.

Now let us move on to consider the situation where foreign has incomplete information about $\theta$.

\subsection{Incomplete Information with Same-sector Retaliation}

In this subsection, we assume that foreign cannot perfectly observe home's type, $\theta$, but it still has perfect information about home's previous action.

Given that the political pressure of home in sector $a$ is the only private information in this game, without loss of generality, home is assumed to be the potential violator while foreign will be the potential affected party and potential punisher for home's violation.

As mentioned in the introduction, we assume equal retaliation by foreign under both cross-sector and same-sector retaliation mechanisms. That is, foreign is constrained to match the import tariff 
of home in the previous stage.

In Sections 3.4 and 3.5, we confine our analysis to the "on-schedule" violations. Namely, we assume that home will only impose two "on-schedule" tariffs, a high state and a low state tariffs. We talk later about the possibility of "off-schedule" violations where home may deviate from the trade agreement and choose any arbitrary tariffs. As mentioned previously, if we are only concerned with "on-schedule" violations, then a per-period retaliation mechanism is enough for the comparison of the welfare under the same-sector and cross-sector retaliation mechanisms.

\subsubsection{Strategies}

In this subsection, we assume that this equivalent retaliation happens in the sector where the initial violation takes place. The strategies under the same-sector retaliation mechanism are as follows:

$$
\begin{aligned}
& \tau_{a}=\left\{\begin{array}{ll}
z_{a}^{S}\left(\theta_{L}\right) & \text { if } \theta=\theta_{L} \\
z_{a}^{S}\left(\theta_{H}\right) & \text { if } \theta=\theta_{H}
\end{array} \quad \tau_{b}^{S}=\tau_{b}^{E}=0 ;\right. \\
& \tau_{a}^{*}=\left\{\begin{array}{ll}
z_{a}^{* S} & \text { if } \tau_{a}=z_{a}^{S}\left(\theta_{L}\right) \\
z_{a}^{S}\left(\theta_{H}\right) & \text { if } \tau_{a}=z_{a}^{S}\left(\theta_{H}\right)
\end{array} \quad \tau_{b}^{*}=\tau_{b}^{* E}=0\right.
\end{aligned}
$$

where the superscript letter " $S$ " represents "same-sector".

Since home still has perfect information about its type $(\theta)$, it will set its import tariff in sector $a$ based on $\theta$. Since $\theta$ only takes two values, home only has a choice of two tariffs, i.e., $z_{a}^{S}\left(\theta_{L}\right)$ and $z_{a}^{S}\left(\theta_{H}\right)$. Given that the sectors are independent, the home import tariff in sector $b$ is independent of $\theta$. Without loss of generality, we can simply assume that it is equal to the politically efficient tariff. Under incomplete information with same sector retaliations, foriegn will retaliate by an equivalent amount in sector $a$ if home deviates and chooses a high tariff in that sector. For the same reason as explained in the the home import tariff, the foreign import tariff in sector $b$ does not depend on $\theta$ and is assumed to be politically efficient. 


\subsubsection{Negotiators's Maximization Problem}

According to the strategies above, both governments will choose the politically efficient tariffs in sector $b$. Then, since the two sectors are independent, we do not need to worry about the negotiators' maximization problem in sector $b$ and can only confine our analysis to sector a. The negotiators' maximization problem in sector $a$ is given by:

$$
\begin{aligned}
\left.\max _{z_{a}^{S}\left(\theta_{L}\right), z_{a}^{S}\left(\theta_{H}\right), z_{a}^{* S}} \lambda\left[\vartheta_{a}\left(z_{a}^{S}\left(\theta_{L}\right), z_{a}^{* S}, \theta_{L}\right)\right)+\vartheta_{a}^{*}\left(z_{a}^{S}\left(\theta_{L}\right), z_{a}^{* S}\right)\right] \\
+(1-\lambda)\left[\vartheta_{a}\left(z_{a}^{S}\left(\theta_{H}\right), z_{a}^{S}\left(\theta_{H}\right), \theta_{H}\right)+\vartheta_{a}^{*}\left(z_{a}^{S}\left(\theta_{H}\right), z_{a}^{S}\left(\theta_{H}\right)\right)\right]
\end{aligned}
$$

subject to

$$
\vartheta_{a}\left(z_{a}^{S}\left(\theta_{L}\right), z_{a}^{* S}, \theta_{L}\right) \geq \vartheta_{a}\left(z_{a}^{S}\left(\theta_{H}\right), z_{a}^{S}\left(\theta_{H}\right), \theta_{L}\right)
$$

and

$$
\vartheta_{a}\left(z_{a}^{S}\left(\theta_{H}\right), z_{a}^{S}\left(\theta_{H}\right), \theta_{H}\right) \geq \vartheta_{a}\left(z_{a}^{S}\left(\theta_{L}\right), z_{a}^{* S}, \theta_{H}\right)
$$

Problem (27) is the unconstrained maximization problem under this mechanism and it shows that the negotiators' choose the tariff scheme, $\left(z_{a}^{S}\left(\theta_{L}\right), z_{a}^{S}\left(\theta_{H}\right), z_{a}^{* S}\right)$, to maximize their expected joint political payoff. The expected payoff is composed of two parts. The first line of problem (27) is the joint payoff given that home is in low pressure. It is the probability of low pressure, $\lambda$, times the corresponding joint payoff, $\left.\vartheta_{a}\left(z_{a}^{S}\left(\theta_{L}\right), z_{a}^{* S}, \theta_{L}\right)\right)+\vartheta_{a}^{*}\left(z_{a}^{S}\left(\theta_{L}\right), z_{a}^{* S}\right)$. The second line describes the case when home faces high political pressure. It is the probability, $1-\lambda$, times the joint payoff, $\vartheta_{a}\left(z_{a}^{S}\left(\theta_{H}\right), z_{a}^{S}\left(\theta_{H}\right), \theta_{H}\right)+\vartheta_{a}^{*}\left(z_{a}^{S}\left(\theta_{H}\right), z_{a}^{S}\left(\theta_{H}\right)\right)$.

Since there is no external enforcement mechanism, to ensure truthful revelation of $\theta$, the tariff scheme needs to be incentive compatible. In particular, Eq.(28) guarantees that when home is faced with low political pressure, its payoff of telling the truth, i.e. $\vartheta_{a}\left(z_{a}^{S}\left(\theta_{L}\right), z_{a}^{* S}, \theta_{L}\right)$, is not lower than its benefit of mimicking the high type, i.e., $\vartheta_{a}\left(z_{a}^{S}\left(\theta_{H}\right), z_{a}^{S}\left(\theta_{H}\right), \theta_{L}\right)$. Similarly, Eq.(29) ensures that home has no incentive to mimic a low type when it experiences high pressure. Given that there is no information distortion in foreign, we do not need to worry about foreign's incentive compatibility conditions.

Denote the solution to the unconstrained maximization problem $(27)$ as $\left(z_{a}^{S S}(\theta), z_{a}^{* S S}\right)$, where the 
first superscript "S" represents "same-sector" and the second one represents "solutions". By solving the unconstrained maximization problem, we have

Proposition 11. Under the same-sector retaliation mechanism, the best negotiated import tariffs are as follows:

$$
z_{a}^{S S}\left(\theta_{L}\right)=z_{a}^{* S S}=0<z_{a}^{S S}\left(\theta_{H}\right)=\frac{\left(\theta_{H}-1\right)\left(4 b_{1} c f+4 A c-4 c f-f\right)}{\left(2 b_{1} c-2 c-1\right)\left(-8 b_{1} c-16 c+\theta_{H}-1\right)} .
$$

This proposition shows that the best tariffs of sector $a$ in the low state are zero and independent of the parameters, while in the high states, they depend on the production costs, $f$ and $c$, the parameter that capture the substitutability between the two goods in sector $a, b_{1}$, and the taste parameter, $A$. Intuitively, when home is in a low state, it is a traditional two-country tariff-setting model. Therefore, no matter how these parameters change, a positive import tariff will always decrease the joint political welfare. On the other hand, when it is a high state, the producer surplus at home weights more in the total joint political welfare. Besides, $f, c, b_{1}$ and $A$ can indirectly influence the home producer surplus. Therefore, it might be optimal for the home government to impose a positive tariff and this tariff should depend on the parameters, $f, c, b_{1}$ and $A$. This proposition also shows that the import tariff at home is positively correlated to its political pressure. The intuition behind this is the same as under the benchmark.

From Propositions 9 and 11, we can indicate that under the same-sector retaliation mechanism, the best unconstrained tariffs in the low state are politically efficient, i.e., $z_{a}^{S S}\left(\theta_{L}\right)=z_{a}^{E}$ and $z_{a}^{* S S}\left(\theta_{L}\right)=z_{a}^{* E}$. This implies that although we add incomplete information into the game, we can still achieve the first best outcome when the state is low. Intuitively, recall that under the complete information game, when it is a low state, the two countries have equal first best optimal import tariffs. Hence, when the state is low, the equivalent retaliation strategy under the same-sector retaliation mechanism with incomplete information happens to be the first best optimal strategy. Nevertheless, in the high state, the best unconstrained tariffs under the same-sector retaliation mechanism can never be politically efficient.

Proposition 12. Under the same-sector retaliation mechanism, the best negotiated import tariff in the high state is lower than the politically efficient tariff, i.e., $z_{a}^{S S}\left(\theta_{H}\right)<z_{a}^{E}\left(\theta_{H}\right)$. 
Although in this chapter, we only confine our model to the case where the goods are strategic substitutes within the sectors, i.e., $b_{1} \in(0,1)$, the above proposition also holds for $b_{1}=0$.

This proposition indicates that a higher import tariff is more efficient than a lower one when home faces high political pressure. Although this result seems uncommon in a traditional complete information tariff-setting model, it makes sense when there exists some incomplete information in the game. Intuitively, when home is a high type, it has to deviate and choose a high tariff. This is an efficient action because of the high $\theta$. Nevertheless, under the no-delayed and samesector retaliation mechanism, since foreign cannot perfectly observe $\theta$, when home deviates, foreign will retaliate by the same amount. On the one hand, this retaliation is inefficient because from the benchmark, when home deviates and chooses a higher tariff in the high state, then the most efficient action for the foreign government is to decrease its tariff in the next stage. On the other hand, foreign's retaliation is necessary because it ensures home to report its type truthfully. Hence, there is a tradeoff of increasing the tariffs in the high state, and to compensate the negative effect from foreign's retaliation, home should set a tariff which is lower than the optimal one in the first place.

The next proposition shows that the incentive compatibility conditions under the same-sector retaliation mechanism are slack. Therefore, the unconstrained solutions are also the solutions to the constrained maximization problem.

Proposition 13. Under the same-sector retaliation mechanism, the incentive compatibility conditions (28) and (29) are slack.

Given that none of the incentive-compatibility constraints is binding, it indicates that there is some unused enforcement capacity and this no-delayed punishment strategies might be too strong. Therefore, in Appendix C, we consider a less severe mechanism. In that case, foreign is constrained to wait for one period and then retaliate. We show that under that incomplete information game, the same-sector retaliation can still support a higher self-enforcing level of cooperation and generate higher welfare than the cross-sector retaliation under certain conditions. 


\subsection{Incomplete Information with Cross-sector Retaliation}

In Section 3.5, we consider another possible way for foreign to retaliate. Namely, when home raises its tariff in sector $a$, now foreign is constrained to retaliate by the same amount but in the other sector, i.e., sector $b$. In this section, we still focus on the "on-schedule" violation and the game is a one-period setup.

\subsubsection{Strategies}

Under this mechanism, home will still set its import tariffs in sector $a$ based on its type $\theta$ and impose the politically efficient tariff in sector $b$. Under the cross-sector retaliation pmechanism, foreign is assumed to set the politically efficient tariffs in both sectors when home imposes a low tariff in the previous stage. On the other hand, when home sets a high tariff, foreign will retaliate by the same amount in sector $b$ but still choose the politically efficient one in sector $a$. Namely,

$$
\begin{aligned}
& \tau_{a}=\left\{\begin{array}{ll}
z_{a}^{C}\left(\theta_{L}\right) & \text { if } \theta=\theta_{L} \\
z_{a}^{C}\left(\theta_{H}\right) & \text { if } \theta=\theta_{H}
\end{array} \quad \tau_{b}=z_{b}^{E}=0 ;\right. \\
& \tau_{a}^{*}=z_{a}^{* E}\left(\theta_{L}\right)=0 ; \quad \tau_{b}^{*}= \begin{cases}z_{b}^{* E}=0 & \text { if } \tau_{a}=z_{a}^{C}\left(\theta_{L}\right) \\
z_{a}^{C}\left(\theta_{H}\right) & \text { if } \tau_{a}=z_{a}^{C}\left(\theta_{H}\right),\end{cases}
\end{aligned}
$$

where the superscript letter " $C$ " represents "cross-sector".

\subsubsection{Negotiators' Maximization Problem}

Given the above strategies, the negotiators choose the tariff scheme, $\left(z_{a}^{C}\left(\theta_{L}\right), z_{a}^{C}\left(\theta_{H}\right)\right)$, to maximize the expected joint political welfare, or,

$$
\begin{aligned}
\max _{z_{a}^{C}\left(\theta_{L}\right), z_{a}^{C}\left(\theta_{H}\right)} & \lambda\left[\vartheta_{a}\left(z_{a}^{C}\left(\theta_{L}\right), 0, \theta_{L}\right)+\vartheta_{a}^{*}\left(z_{a}^{C}\left(\theta_{L}\right), 0\right)+\vartheta_{b}(0,0)+\vartheta_{b}^{*}(0,0)\right] \\
& +(1-\lambda)\left[\vartheta_{a}\left(z_{a}^{C}\left(\theta_{H}\right), 0, \theta_{H}\right)+\vartheta_{a}^{*}\left(z_{a}^{C}\left(\theta_{H}\right), 0\right)+\vartheta_{b}\left(0, z_{a}^{C}\left(\theta_{H}\right)\right)+\vartheta_{b}^{*}\left(0, z_{a}^{C}\left(\theta_{H}\right)\right)\right]
\end{aligned}
$$


subject to

$$
\vartheta_{a}\left(z_{a}^{C}\left(\theta_{L}\right), 0, \theta_{L}\right)+\vartheta_{b}(0,0) \geq \vartheta_{a}\left(z_{a}^{C}\left(\theta_{H}\right), 0, \theta_{L}\right)+\vartheta_{b}\left(0, z_{a}^{C}\left(\theta_{H}\right)\right)
$$

and

$$
\vartheta_{a}\left(z_{a}^{C}\left(\theta_{H}\right), 0, \theta_{H}\right)+\vartheta_{b}\left(0, z_{a}^{C}\left(\theta_{H}\right)\right) \geq \vartheta_{a}\left(z_{a}^{C}\left(\theta_{L}\right), 0, \theta_{H}\right)+\vartheta_{b}(0,0) .
$$

Problem (30) is the unconstrained maximization problem. The first line of problem (30) is the joint political welfare when it is a low state weighted by the probability, $\lambda$. The second line is the expected payoff in a high state. It is the probability, $1-\lambda$, times the corresponding joint political welfare, $\left.\vartheta_{a}\left(z_{a}^{C}\left(\theta_{H}\right), 0, \theta_{H}\right)+\vartheta_{a}^{*}\left(z_{a}^{C}\left(\theta_{H}\right), 0\right)+\vartheta_{b}\left(0, z_{a}^{C}\left(\theta_{H}\right)\right)+\vartheta_{b}^{*}\left(0, z_{a}^{C}\left(\theta_{H}\right)\right)\right]$. Eqs.(31) and (32) ensure that home will not misreport its type when it is a low state and a high state, respectively. The solution to the unconstrained maximization problem (30) can be written as:

$$
\begin{gathered}
z_{a}^{C S}\left(\theta_{L}\right)=\underset{z_{a}^{C}\left(\theta_{L}\right)}{\operatorname{argmax}} \vartheta_{a}\left(z_{a}^{C}\left(\theta_{L}\right), 0, \theta_{L}\right)+\vartheta_{a}^{*}\left(z_{a}^{C}\left(\theta_{L}\right), 0\right) \\
z_{a}^{C S}\left(\theta_{H}\right)=\underset{z_{a}\left(\theta_{H}\right)}{\operatorname{argmax}}
\end{gathered}
$$

where the superscript letters "C" and "S" represent "cross-sector" and "solutions", respectively. By solving the unconstrained maximization problem, we have:

Proposition 14. Under the cross-sector retaliation mechanism, the best negotiated import tariffs are as follows:

$$
z_{a}^{C S}\left(\theta_{L}\right)=0<z_{a}^{C S}\left(\theta_{H}\right)=\frac{\left(\theta_{H}-1\right)\left(4 b_{1} c f+4 A c-4 c f-f\right)}{\left(2 b_{1} c-2 c-1\right)\left(-16 c+\theta_{H}-1\right)} .
$$

This proposition says that no matter how the state of the world or the parameters change, the import tariff in the low state is always politically efficient. The idea of this is the same as the benchmark and the same-sector retaliation mechanism. This proposition also reveals that when the state is high, then the import tariff depends on the production costs, $f$ and $c$, the taste parameter, 
$A$, the value of $\theta_{L}$ and the parameter that represents the substitutability in sector $a, b_{1}$. Moreover, although now the retaliation happens in sector $b$, the substitution rate in that sector, i.e., $b_{2}$, has no influence on the best negotiated import tariff. This is due to the assumption that home is not allowed to impose any tariff in sector $b$. Since the home import tariff in sector $b$ is zero, there is no substitution effect for the retaliatory tariff imposed by foreign. Thus, the unconstrained best tariffs in the high state is independent of $b_{2}$.

From propositions 9, 11 and 14, we can verify that the best negotiated import tariffs in the low state under the same-sector and cross-sector retaliation mechanisms are politically efficient, i.e., $z_{a}^{C S}\left(\theta_{L}\right)=z_{a}^{S S}\left(\theta_{L}\right)=z_{a}^{E}\left(\theta_{L}\right)=0$. This is obvious because under incomplete information with cross-sector retaliation, foreign will set the politically efficient tariff as long as home chooses a low tariff. Therefore, the maximization problem is the same as under the first best perfect information and under incomplete information with same-sector retaliation.

Nevertheless, the next proposition says that when the state is high, the best import tariffs under the above three mechanisms are different.

Proposition 15. If the goods in sector a are strategic substitutes, i.e., $b_{1} \in(0,1)$, then the best negotiated import tariffs in the high state under the cross-sector retaliation mechanism is higher than under the same-sector retaliation mechanism while lower than under the first best perfect information, i.e., $z_{a}^{S S}\left(\theta_{H}\right)<z_{a}^{C S}\left(\theta_{H}\right)<z_{a}^{E}\left(\theta_{H}\right)$.

Intuitively, as mentioned before, when the state is high, under incomplete information, the equivalent retaliation strategies in foreign creates some inefficiency. To compensate this negative effect from foreign's retaliation, home will set a relatively lower tariff in the first place. Moreover, when the retaliation happens in the sector where the initial violation takes place, then this inefficiency is caused by both the income and substitution effects. Nevertheless, if this equivalent retaliation happens in the other sector, given that the goods across the sectors are independent, there is no income effect. Hence, in comparison to same-sector retaliation, home can have a relatively higher tariff in cross-sector retaliation. However, since the cross-sector equivalent retaliation strategy is still an inefficient action, to compensate this negative effect, home will impose an import tariff which is lower than the politically efficient one in the first place. 
Similar to the same-sector retaliation case, we can also verify that under incomplete information with cross-sector retaliation, the solutions to the unconstrained problem satisfy the incentive compatibility constraints and there might have some unused enforcement capacity.

Proposition 16. Under the cross-sector retaliation mechanism, the incentive compatibility conditions (31) and (32) are slack.

From Propositions 13 and 16, we know that the solutions to the unconstrained problems under both the same-sector and cross-sector retaliation mechanisms are incentive compatible. Based on this result, the following proposition compares the welfare under incomplete information with same-sector and cross-sector retaliation:

Proposition 17. Suppose that the goods in both sectors are strategic substitutes, i.e., $b_{1} \in(0,1)$ and $b_{2} \in(0,1)$. Then for any given $b_{1} \in(0,1)$, there exists a $b_{2}^{\prime} \in(0,1)$ such that for any $b_{2} \in\left(0, b_{2}^{\prime}\right)$, the best incentive-compatible negotiated tariffs under the same-sector retaliation mechanism generate a higher expected joint political payoff than do the best incentive-compatible negotiated tariffs under the cross-sector retaliation mechanism.

Proposition 17 implies that in comparison to same-sector retaliation, although cross-sector retaliation creates some additional efficiency in sector $a$, i.e., $z_{a}^{S S}\left(\theta_{H}\right)<z_{a}^{C S}\left(\theta_{H}\right)<z_{a}^{E}\left(\theta_{H}\right)$, the inefficiency caused by the other sector outweighs its benefits when the substitution rate in that sector is low enough.

\subsection{Dynamic Setup: "Off-schedule" Violation}

In the previous two sections, we confine our analysis to the "on-schedule" violation. Namely, we only consider the case where home may misreport its type and ignore the possibility that instead of sticking to the trade-agreement and choosing either a high or low tariff, home can deviate and set any arbitrary tariff. Now, in this section, we focus on a more egregious breaking of a trade agreement, the "off-schedule" violation. As mentioned before, to prevent this "off-schedule" violation, we consider a dynamic version of the model and assume that the one-period game repeats 
infinitely many times with the state variable evolving according to the markov process, i.e.,

$$
\operatorname{prob}\left(\theta_{t+1}=\theta_{L} \mid \theta_{t}=\theta_{L}\right)=\operatorname{prob}\left(\theta_{t+1}=\theta_{H} \mid \theta_{t}=\theta_{H}\right)=\beta
$$

and

$$
\operatorname{prob}\left(\theta_{t+1}=\theta_{H} \mid \theta_{t}=\theta_{L}\right)=\operatorname{prob}\left(\theta_{t+1}=\theta_{L} \mid \theta_{t}=\theta_{H}\right)=1-\beta,
$$

where $t \in\{0,1, \ldots\}$ and $\beta \in[0,1]$.

Note that the "off-schedule" violation requires a more sever punishment. Following Bagwell-Staiger [3], we use the infinite Nash reversion as a threat to this violation. That is, if home deviates from the initial trade agreement and chooses any arbitrary tariffs, foreign will punish home by imposing the static Nash tariff and then they will enter a trade war forever. Since an infinite reversion to the static Nash tariff is a very severe threat, foreign should be very cautious about imposing it. Thus, we assume that even if foreign observes an "off-schedule violation" in home, it will still wait for one more period and then retaliate. In particular, if home chooses the "off-schedule violation", then under same-sector retaliation, foreign will wait for one period and then retaliate by the static Nash tariff in the sector where the initial violation happens while under the cross-sector retaliation, the retaliation will still be delayed for one period but it will occur in the other sector, i.e., sector $b$. Although foreign could deviate from the trade agreement and set any arbitrary tariff, home and foreign are symmetric when it is a low state. Hence, the analysis of the "off-schedule" violation in foreign is almost the same as at home when home is in a low state.

Our focus is to compare the highest self-enforcing level of cooperation under incomplete information with same-sector and cross-sector retaliation. Before analyzing these two types of retaliation, we need to characterize the static Nash tariff schemes and the bellman equations first.

\subsubsection{Nash Punishment}

The static Nash tariffs characterize the best tariff scheme under a one-period non-cooperation game. Particularly, in the absence of cooperation, home and foreign choose the import tariff schedules, 
$\left(z_{a}^{N}(\theta), z_{b}^{N}\right)$ and $\left(z_{a}^{* N}, z_{b}^{* N}\right)$, to maximize their own payoffs, respectively. Namely,

$$
\begin{gathered}
\max _{z_{a}^{N}(\theta), z_{b}^{N}} \vartheta_{a}\left(z_{a}^{N}(\theta), z_{a}^{* N}, \theta\right)+\vartheta_{b}\left(z_{b}^{N}, z_{b}^{* N}\right) \\
\max _{z_{a}^{* N}, z_{b}^{* N}} \lambda \vartheta_{a}^{*}\left(z_{a}^{N}\left(\theta_{L}\right), z_{a}^{* N}\right)+(1-\lambda) \vartheta_{a}^{*}\left(z_{a}^{N}\left(\theta_{H}\right), z_{a}^{* N}\right)+\vartheta_{b}\left(z_{b}^{N}, z_{b}^{* N}\right) .
\end{gathered}
$$

Therefore, the static Nash tariff scheme, $\left(z_{a}^{N}(\theta), z_{b}^{N}, z_{a}^{* N}, z_{b}^{* N}\right)$, is given by

$$
\begin{gathered}
z_{a}^{N}(\theta)=\underset{z_{a}^{N}(\theta)}{\operatorname{argmax}} \vartheta_{a}\left(z_{a}^{N}(\theta), z_{a}^{* N}, \theta\right) ; \\
z_{a}^{* N}=\underset{z_{a}^{* N}}{\operatorname{argmax}} \lambda \vartheta_{a}^{*}\left(z_{a}^{N}\left(\theta_{L}\right), z_{a}^{* N}\right)+(1-\lambda) \vartheta_{a}^{*}\left(z_{a}^{N}\left(\theta_{H}\right), z_{a}^{* N}\right) ; \\
z_{b}^{N}=\underset{z_{b}^{N}}{\operatorname{argmax}} \vartheta_{b}\left(z_{b}^{N}, z_{b}^{* N}\right) ; \quad z_{b}^{* N S}=\underset{z_{b}^{* N}}{\operatorname{argmax}} \vartheta_{b}^{*}\left(z_{b}^{N}, z_{b}^{* N}\right) .
\end{gathered}
$$

Since $\theta$ is home private information, the Nash tariff at home depends on $\theta$ while the one in foreign does not. In deed, under the non-cooperation game, foreign chooses its import tariff to maximize its payoff and takes expectation of home's type.

\subsubsection{Bellman Equations}

If home sticks to the trade agreement, the future values under the same-sector retaliation mechanism can be captured by the following two bellman equations:

$$
\begin{aligned}
X^{S}\left(z_{a}^{S S}\left(\theta_{H}\right), z_{a}^{S S}\left(\theta_{L}\right), \theta_{L}\right) & =\vartheta_{a}\left(z_{a}^{S S}\left(\theta_{L}\right), 0, \theta_{L}\right)+(1+\delta) \vartheta_{b}(0,0) \\
& +\delta\left[\beta \vartheta_{a}\left(z_{a}^{S S}\left(\theta_{L}\right), 0, \theta_{L}\right)+(1-\beta) \vartheta_{a}\left(z_{a}^{S S}\left(\theta_{H}\right), z_{a}^{S S}\left(\theta_{H}\right), \theta_{H}\right)\right] \\
& +\delta^{2}\left\{\left[\beta^{2}+(1-\beta) \beta\right] X^{S}\left(z_{a}^{S S}\left(\theta_{H}\right), z_{a}^{S S}\left(\theta_{L}\right), \theta_{L}\right)\right. \\
& \left.+[(1-\beta) \beta+\beta(1-\beta)] X^{S}\left(z_{a}^{S S}\left(\theta_{H}\right), z_{a}^{S S}\left(\theta_{L}\right), \theta_{H}\right)\right\}
\end{aligned}
$$


and

$$
\begin{aligned}
X^{S}\left(z_{a}^{S S}\left(\theta_{H}\right), z_{a}^{S S}\left(\theta_{L}\right), \theta_{H}\right) & =\vartheta_{a}\left(z_{a}^{S S}\left(\theta_{H}\right), z_{a}^{S S}\left(\theta_{H}\right), \theta_{H}\right)+(1+\delta) \vartheta_{b}(0,0) \\
& +\delta\left[\beta \vartheta_{a}\left(z_{a}^{S S}\left(\theta_{H}\right), z_{a}^{S S}\left(\theta_{H}\right), \theta_{H}\right)\right. \\
& \left.+(1-\beta) \vartheta_{a}\left(z_{a}^{S S}\left(\theta_{L}\right), 0, \theta_{L}\right)\right] \\
& +\delta^{2}\left\{\left[\beta^{2}+(1-\beta) \beta\right] X^{S}\left(z_{a}^{S S}\left(\theta_{H}\right), z_{a}^{S S}\left(\theta_{L}\right), \theta_{H}\right)\right. \\
& \left.+[(1-\beta) \beta+\beta(1-\beta)] X^{S}\left(z_{a}^{S S}\left(\theta_{H}\right), z_{a}^{S S}\left(\theta_{L}\right), \theta_{L}\right)\right\}
\end{aligned}
$$

where $X^{S}\left(z_{a}^{S S}\left(\theta_{H}\right), z_{a}^{S S}\left(\theta_{L}\right), \theta\right)$ represents the bellman equation at home under the same-sector retaliation mechanism with the two control variables, $z_{a}^{S S}\left(\theta_{H}\right)$ and $z_{a}^{S S}\left(\theta_{L}\right)$, and the state variable, $\theta$.

Eq.(35) is the bellman equation when the two control variables are $z_{a}^{S S}\left(\theta_{H}\right)$ and $z_{a}^{S S}\left(\theta_{L}\right)$ and the state is low, i.e., $\theta=\theta_{L}$. The first four terms of the right hand side are the discounted two-period payoffs at home when the state is low at the beginning of the game. The remaining terms are the expected future values, $\left[\beta^{2}+(1-\beta) \beta\right] X^{S}\left(z_{a}^{S S}\left(\theta_{H}\right), z_{a}^{S S}\left(\theta_{L}\right), \theta_{H}\right)+[(1-\beta) \beta+\beta(1-$ $\beta)] X^{S}\left(z_{a}^{S S}\left(\theta_{H}\right), z_{a}^{S S}\left(\theta_{L}\right), \theta_{L}\right)$, discounted by $\delta^{2}$. We can interpret Eq.(36) by following a similar argument.

Note that by simplifying the above two equations and combing them together, we can expressed the bellman equations as a function of $\vartheta_{a}\left(z_{a}^{S S}\left(\theta_{L}\right), 0, \theta_{L}\right), \vartheta_{a}\left(z_{a}^{S S}\left(\theta_{H}\right), z_{a}^{S S}\left(\theta_{H}\right), \theta_{H}\right)$ and $\vartheta_{b}(0,0)$. Similarly, under cross-sector retaliation mechanism, the future values of sticking to the trade agreements when it is a low and high state are

$$
\begin{aligned}
X^{C}\left(z_{a}^{C S}\left(\theta_{H}\right), z_{a}^{C S}\left(\theta_{L}\right), \theta_{L}\right) & =\vartheta_{a}\left(z_{a}^{C S}\left(\theta_{L}\right), 0, \theta_{L}\right)+\vartheta_{b}(0,0) \\
& +\delta\left\{\beta \vartheta_{a}\left(z_{a}^{C S}\left(\theta_{L}\right), 0, \theta_{L}\right)+\vartheta_{b}(0,0)\right. \\
& \left.+(1-\beta)\left[\vartheta_{a}\left(z_{a}^{C S}\left(\theta_{H}\right), 0, \theta_{H}\right)+\vartheta_{b}\left(0, z_{a}^{C S}\left(\theta_{H}\right)\right)\right]\right\} \\
& +\delta^{2}\left\{\left[\beta^{2}+(1-\beta) \beta\right] X^{C}\left(z_{a}^{C S}\left(\theta_{H}\right), z_{a}^{C S}\left(\theta_{L}\right), \theta_{L}\right)\right. \\
& \left.+[(1-\beta) \beta+\beta(1-\beta)] X^{C}\left(z_{a}^{C S}\left(\theta_{H}\right), z_{a}^{C S}\left(\theta_{L}\right), \theta_{H}\right)\right\}
\end{aligned}
$$


and

$$
\begin{aligned}
X^{C}\left(z_{a}^{C S}\left(\theta_{H}\right), z_{a}^{C S}\left(\theta_{L}\right), \theta_{H}\right) & =\vartheta_{a}\left(z_{a}^{C S}\left(\theta_{H}\right), 0, \theta_{H}\right)+\vartheta_{b}\left(0, z_{a}^{C S}\left(\theta_{H}\right)\right) \\
& +\delta\left\{\beta\left[\vartheta_{a}\left(z_{a}^{C S}\left(\theta_{H}\right), 0, \theta_{H}\right)+\vartheta_{b}\left(0, z_{a}^{C S}\left(\theta_{H}\right)\right)\right]\right. \\
& \left.+(1-\beta)\left[\vartheta_{a}\left(z_{a}^{C S}\left(\theta_{L}\right), 0, \theta_{L}\right)+\vartheta_{b}(0,0)\right]\right\} \\
& +\delta^{2}\left\{\left[\beta^{2}+(1-\beta) \beta\right]\right] X^{C}\left(z_{a}^{C S}\left(\theta_{H}\right), z_{a}^{C S}\left(\theta_{L}\right), \theta_{H}\right) \\
& \left.+[(1-\beta) \beta+\beta(1-\beta)] X^{C}\left(z_{a}^{C S}\left(\theta_{H}\right), z_{a}^{C S}\left(\theta_{L}\right), \theta_{L}\right)\right\},
\end{aligned}
$$

respectively.

Furthermore, the future values for home's "off-schedule" violation under the same-sector retaliation mechanism can be represented by the following two bellman equations:

$$
\begin{aligned}
X^{S d}\left(z_{a}^{N}\left(\theta_{H}\right), z_{a}^{N}\left(\theta_{L}\right), z_{a}^{* N}, \theta_{L}\right) & =\vartheta_{a}\left(z_{a}^{N}\left(\theta_{L}\right), z_{a}^{* N}, \theta_{L}\right)+(1+\delta) \vartheta_{b}(0,0) \\
& +\delta\left[\beta \vartheta_{a}\left(z_{a}^{N}\left(\theta_{L}\right), z_{a}^{* N}, \theta_{L}\right)+(1-\beta) \vartheta_{a}\left(z_{a}^{N}\left(\theta_{H}\right), z_{a}^{* N}, \theta_{H}\right)\right] \\
& +\delta^{2}\left\{\left[\beta^{2}+(1-\beta) \beta\right] X^{S d}\left(z_{a}^{N}\left(\theta_{H}\right), z_{a}^{N}\left(\theta_{L}\right), z_{a}^{* N}, \theta_{L}\right)\right. \\
& \left.+[(1-\beta) \beta+\beta(1-\beta)] X^{S d}\left(z_{a}^{N}\left(\theta_{H}\right), z_{a}^{N}\left(\theta_{L}\right), z_{a}^{* N}, \theta_{H}\right)\right\}
\end{aligned}
$$

and

$$
\begin{aligned}
X^{S d}\left(z_{a}^{N}\left(\theta_{H}\right), z_{a}^{N}\left(\theta_{L}\right), z_{a}^{* N}, \theta_{H}\right) & =\vartheta_{a}\left(z_{a}^{N}\left(\theta_{H}\right), z_{a}^{* N}, \theta_{H}\right)+(1+\delta) \vartheta_{b}(0,0) \\
& +\delta\left[\beta \vartheta_{a}\left(z_{a}^{N}\left(\theta_{H}\right), z_{a}^{* N}, \theta_{H}\right)+(1-\beta) \vartheta_{a}\left(z_{a}^{N}\left(\theta_{L}\right), z_{a}^{* N}, \theta_{L}\right)\right] \\
& +\delta^{2}\left\{\left[\beta^{2}+(1-\beta) \beta\right] X^{S}\left(z_{a}^{N}\left(\theta_{H}\right), z_{a}^{N}\left(\theta_{L}\right), z_{a}^{* N}, \theta_{H}\right)\right. \\
& \left.+[(1-\beta) \beta+\beta(1-\beta)] X^{S}\left(z_{a}^{N}\left(\theta_{H}\right), z_{a}^{N}\left(\theta_{L}\right), z_{a}^{* N}, \theta_{L}\right)\right\} .
\end{aligned}
$$

The bellman equations for home's "off-schedule" violation under the cross-sector retaliation mechanism are:

$$
\begin{aligned}
X^{C d}\left(z_{a}^{C d}\left(\theta_{H}\right), z_{a}^{C d}\left(\theta_{L}\right), z_{b}^{N}, z_{b}^{* N}, \theta_{L}\right) & =\vartheta_{a}\left(z_{a}^{C d}\left(\theta_{L}\right), 0, \theta_{L}\right)+(1+\delta) \vartheta_{b}\left(z_{b}^{N}, z_{b}^{* N}\right) \\
& +\delta\left[\beta \vartheta_{a}\left(z_{a}^{C d}\left(\theta_{L}\right), 0, \theta_{L}\right)+(1-\beta) \vartheta_{a}\left(z_{a}^{C d}\left(\theta_{H}\right), 0, \theta_{H}\right)\right] \\
& +\delta^{2}\left\{\left[\beta^{2}+(1-\beta) \beta\right] X^{C d}\left(z_{a}^{C d}\left(\theta_{H}\right), z_{a}^{C d}\left(\theta_{L}\right), z_{b}^{N}, z_{b}^{* N}, \theta_{L}\right)\right. \\
& \left.+[(1-\beta) \beta+\beta(1-\beta)] X^{C d}\left(z_{a}^{C d}\left(\theta_{H}\right), z_{a}^{C d}\left(\theta_{L}\right), z_{b}^{N}, z_{b}^{* N}, \theta_{H}\right)\right\}
\end{aligned}
$$


and

$$
\begin{aligned}
X^{C d}\left(z_{a}^{C d}\left(\theta_{H}\right), z_{a}^{C d}\left(\theta_{L}\right), z_{b}^{N}, z_{b}^{* N}, \theta_{H}\right) & =\vartheta_{a}\left(z_{a}^{C d}\left(\theta_{H}\right), 0, \theta_{H}\right)+(1+\delta) \vartheta_{b}\left(z_{b}^{N}, z_{b}^{* N}\right) \\
& +\delta\left[\beta \vartheta_{a}\left(z_{a}^{C d}\left(\theta_{H}\right), 0, \theta_{H}\right)\right. \\
& \left.+(1-\beta) \vartheta_{a}\left(z_{a}^{C d}\left(\theta_{H}\right), 0, \theta_{H}\right)\right] \\
& +\delta^{2}\left\{\left[\beta^{2}+(1-\beta) \beta\right]\right. \\
& X^{N C}\left(z_{a}^{C d}\left(\theta_{H}\right), z_{a}^{C d}\left(\theta_{L}\right), z_{b}^{N}, z_{b}^{* N}, \theta_{H}\right) \\
& +[(1-\beta) \beta+\beta(1-\beta)] \\
& \left.X^{N C}\left(z_{a}^{C d}\left(\theta_{H}\right), z_{a}^{C d}\left(\theta_{L}\right), z_{b}^{N}, z_{b}^{* N}, \theta_{L}\right)\right\},
\end{aligned}
$$

where $z_{a}^{C d}(\theta)=\underset{\tau_{a}}{\operatorname{argmax}} \vartheta_{a}\left(\tau_{a}, 0, \theta\right)$. Note that under the cross-sector retaliation mechanism, the future value for the "off-schedule" violation depends on the deviation tariffs while under the samesector retaliation mechanism, it only depends on the Nash tariffs. This is because if the Nash reversion punishment happens in the other sector, i.e., sector $b$, then home will always choose the deviation tariff in sector $a$. However, under same-sector retaliation, foreign will impose the Nash tariff in sector $a$. Then, after deviating from the initial trade agreement, in the next period, the best option for home is to set the Nash tariff in sector $a$.

\subsection{3 "Off-schedule" Violation}

Now we are ready to show the voluntary participation constraints and compare the self-enforcing levels of cooperation between the governments under the same-sector and cross-sector retaliation mechanisms. 
The voluntary participation constraints under the same-sector retaliation mechanism are:

$$
\begin{aligned}
& \vartheta_{a}\left(z_{a}^{S S}\left(\theta_{L}\right), 0, \theta_{L}\right)+(1+\delta) \vartheta_{b}(0,0) \\
& +\delta\left[\beta \vartheta_{a}\left(z_{a}^{S S}\left(\theta_{L}\right), 0, \theta_{L}\right)+(1-\beta) \vartheta_{a}\left(z_{a}^{S S}\left(\theta_{H}\right), z_{a}^{S S}\left(\theta_{H}\right), \theta_{H}\right)\right] \\
& +\delta^{2}\left\{\left[\beta^{2}+(1-\beta) \beta\right] X^{S}\left(z_{a}^{S S}\left(\theta_{H}\right), z_{a}^{S S}\left(\theta_{L}\right), \theta_{L}\right)\right. \\
& \left.+[(1-\beta) \beta+\beta(1-\beta)] X^{S}\left(z_{a}^{S S}\left(\theta_{H}\right), z_{a}^{S S}\left(\theta_{L}\right), \theta_{H}\right)\right\} \geq \\
& \vartheta_{a}\left(z_{a}^{S d}\left(\theta_{L}\right), 0, \theta_{L}\right)+(1+\delta) \vartheta_{b}(0,0) \\
& +\delta\left[\beta \vartheta_{a}\left(z_{a}^{N}\left(\theta_{L}\right), z_{a}^{* N}, \theta_{L}\right)+(1-\beta) \vartheta_{a}\left(z_{a}^{N}\left(\theta_{H}\right), z_{a}^{* N}, \theta_{H}\right)\right] \\
& +\delta^{2}\left\{\left[\beta^{2}+(1-\beta) \beta\right] X^{S d}\left(z_{a}^{N}\left(\theta_{H}\right), z_{a}^{N}\left(\theta_{L}\right), z_{a}^{* N}, \theta_{L}\right)\right. \\
& \left.+[(1-\beta) \beta+\beta(1-\beta)] X^{S d}\left(z_{a}^{N}\left(\theta_{H}\right), z_{a}^{N}\left(\theta_{L}\right), z_{a}^{* N}, \theta_{H}\right)\right\}
\end{aligned}
$$

and

$$
\begin{aligned}
& \vartheta_{a}\left(z_{a}^{S S}\left(\theta_{H}\right), z_{a}^{S S}\left(\theta_{H}\right), \theta_{H}\right)+(1+\delta) \vartheta_{b}(0,0) \\
& +\delta\left[\beta \vartheta_{a}\left(z_{a}^{S S}\left(\theta_{H}\right), z_{a}^{S S}\left(\theta_{H}\right), \theta_{H}\right)+(1-\beta) \vartheta_{a}\left(z_{a}^{S S}\left(\theta_{L}\right), 0, \theta_{L}\right)\right] \\
& +\delta^{2}\left\{\left[\beta^{2}+(1-\beta) \beta\right]\right] X^{S}\left(z_{a}^{S S}\left(\theta_{H}\right), z_{a}^{S S}\left(\theta_{L}\right), \theta_{H}\right) \\
& \left.+[(1-\beta) \beta+\beta(1-\beta)] X^{S}\left(z_{a}^{S S}\left(\theta_{H}\right), z_{a}^{S S}\left(\theta_{L}\right), \theta_{L}\right)\right\} \geq \\
& \vartheta_{a}\left(z_{a}^{S d}\left(\theta_{H}\right), 0, \theta_{H}\right)+(1+\delta) \vartheta_{b}(0,0) \\
& +\delta\left[\beta \vartheta_{a}\left(z_{a}^{N}\left(\theta_{H}\right), z_{a}^{* N}, \theta_{H}\right)+(1-\beta) \vartheta_{a}\left(z_{a}^{N}\left(\theta_{L}\right), z_{a}^{* N}, \theta_{L}\right)\right] \\
& +\delta^{2}\left\{\left[\beta^{2}+(1-\beta) \beta\right] X^{S d}\left(z_{a}^{N}\left(\theta_{H}\right), z_{a}^{N}\left(\theta_{L}\right), z_{a}^{* N}, \theta_{H}\right)\right. \\
& \left.+[(1-\beta) \beta+\beta(1-\beta)] X^{S d}\left(z_{a}^{N}\left(\theta_{H}\right), z_{a}^{N}\left(\theta_{L}\right), z_{a}^{* N}, \theta_{L}\right)\right\}
\end{aligned}
$$

where $z_{a}^{S d}(\theta)=\underset{\tau_{a}}{\operatorname{argmax}} \vartheta_{a}\left(\tau_{a}, 0, \theta\right)$.

Eq.(41) describes the voluntary participation condition when the state is low at the beginning of the game. The left hand side is the benefits of sticking to the trade-agreement. It is the sum of the two-period discounted current values and the discounted expected future value. The right hand side is the payoffs if home deviates. It is the current benefits if home chooses any arbitrary tariffs and get punished by the Nash tariff in the next period plus the payoff stream of a static Nash reversion strategies. Eq.(42) is the voluntary participation constraint in a high state and it has a 
similar interpretation.

The voluntary participation conditions under the cross-sector retaliation mechanism are:

$$
\begin{aligned}
& \vartheta_{a}\left(z_{a}^{C S}\left(\theta_{L}\right), 0, \theta_{L}\right)+\vartheta_{b}(0,0) \\
& +\delta\left\{\beta \vartheta_{a}\left(z_{a}^{C S}\left(\theta_{L}\right), 0, \theta_{L}\right)+\vartheta_{b}(0,0)+(1-\beta)\left[\vartheta_{a}\left(z_{a}^{C S}\left(\theta_{H}\right), 0, \theta_{H}\right)+\vartheta_{b}\left(0, z_{a}^{C S}\left(\theta_{H}\right)\right)\right]\right\} \\
& +\delta^{2}\left\{\left[\beta^{2}+(1-\beta) \beta\right] X^{C}\left(z_{a}^{C S}\left(\theta_{H}\right), z_{a}^{C S}\left(\theta_{L}\right), \theta_{L}\right)\right. \\
& \left.+[(1-\beta) \beta+\beta(1-\beta)] X^{C}\left(z_{a}^{C S}\left(\theta_{H}\right), z_{a}^{C S}\left(\theta_{L}\right), \theta_{H}\right)\right\} \geq \\
& \vartheta_{a}\left(z_{a}^{C d}\left(\theta_{L}\right), 0, \theta_{L}\right)+\vartheta_{b}(0,0) \\
& +\delta\left\{\beta\left[\vartheta_{a}\left(z_{a}^{C d}\left(\theta_{L}\right), 0, \theta_{L}\right)+\vartheta_{b}\left(z_{b}^{N}, z_{b}^{* N}\right)\right]+(1-\beta)\left[\vartheta_{a}\left(z_{a}^{C d}\left(\theta_{H}\right), 0, \theta_{H}\right)+\vartheta_{b}\left(z_{b}^{N}, z_{b}^{* N}\right)\right]\right\} \\
& +\delta^{2}\left\{\left[\beta^{2}+(1-\beta) \beta\right] X^{C d}\left(z_{a}^{C d}\left(\theta_{H}\right), z_{a}^{C d}\left(\theta_{L}\right), z_{b}^{N}, z_{b}^{* N}, \theta_{L}\right)\right. \\
& \left.+[(1-\beta) \beta+\beta(1-\beta)] X^{C d}\left(z_{a}^{C d}\left(\theta_{H}\right), z_{a}^{C d}\left(\theta_{L}\right), z_{b}^{N}, z_{b}^{* N}, \theta_{H}\right)\right\}
\end{aligned}
$$

and

$$
\begin{aligned}
& \vartheta_{a}\left(z_{a}^{C S}\left(\theta_{H}\right), 0, \theta_{H}\right)+\vartheta_{b}\left(0, z_{a}^{C S}\left(\theta_{H}\right)\right) \\
& +\delta\left\{\beta\left[\vartheta_{a}\left(z_{a}^{C S}\left(\theta_{H}\right), 0, \theta_{H}\right)+\vartheta_{b}\left(0, z_{a}^{C S}\left(\theta_{H}\right)\right)\right]+(1-\beta)\left[\vartheta_{a}\left(0,0, \theta_{L}\right)+\vartheta_{b}(0,0)\right]\right\} \\
& +\delta^{2}\left\{\left[\beta^{2}+(1-\beta) \beta\right]\right] X^{C}\left(z_{a}^{C S}\left(\theta_{H}\right), z_{a}^{C S}\left(\theta_{L}\right), \theta_{H}\right) \\
& \left.+[(1-\beta) \beta+\beta(1-\beta)] X^{C}\left(z_{a}^{C S}\left(\theta_{H}\right), z_{a}^{C S}\left(\theta_{L}\right), \theta_{L}\right)\right\} \geq \\
& \vartheta_{a}\left(z_{a}^{C d}\left(\theta_{H}\right), 0, \theta_{H}\right)+\vartheta_{b}(0,0) \\
& +\delta\left\{\beta\left[\vartheta_{a}\left(z_{a}^{C d}\left(\theta_{H}\right), 0, \theta_{H}\right)+\vartheta_{b}\left(z_{b}^{N}, z_{b}^{* N}\right)\right]+(1-\beta)\left[\vartheta_{a}\left(z_{a}^{C d}\left(\theta_{L}\right), 0, \theta_{L}\right)+\vartheta_{b}\left(z_{b}^{N}, z_{b}^{* N}\right)\right]\right\} \\
& +\delta^{2}\left\{\left[\beta^{2}+(1-\beta) \beta\right] X^{C d}\left(z_{a}^{C d}\left(\theta_{H}\right), z_{a}^{C d}\left(\theta_{L}\right), z_{b}^{N}, z_{b}^{* N}, \theta_{H}\right)\right. \\
& \left.+[(1-\beta) \beta+\beta(1-\beta)] X^{C d}\left(z_{a}^{C d}\left(\theta_{H}\right), z_{a}^{C d}\left(\theta_{L}\right), z_{b}^{N}, z_{b}^{* N}, \theta_{L}\right)\right\} .
\end{aligned}
$$

We can interpret the above two equations by following a similar argument as in explaining Eq.(41). Based on the voluntary participation constraints described above, together with Propositions 11 and 14, we can derive the following result in our paper:

Proposition 18. For any given $b_{1} \in(0,1)$, there exists a $b_{2}^{*} \in(0,1)$ such that for any $b_{2} \in\left(0, b_{2}^{*}\right)$, the same-sector retaliation mechanism supports a higher self-enforcing level of cooperation than the cross-sector retaliation mechanism. 
Intuitively, since the goods across the sectors are strategically neutral, the import tariffs between the two sectors are independent. Nevertheless, cross-sector retaliation automatically link the two sectors together. Besides, under the cross-sector retaliation mechanism, an increase in $b_{2}$ results in a greater impact on the punishment for the deviating country. Hence, for any given $b_{1}$, if $b_{2}$ is sufficiently small, then for an equal deviation, the punishment hurts the deviating country by a larger amount under the same-sector retaliation mechanism and the optimal deviation is lower. Or, the same-sector retaliation strategies can support a higher self-enforcing level of cooperation. 


\section{Chapter 4: Multilateral Bargaining with Productive and Unproductive Efforts}

\subsection{Introduction}

Many situations in Economics and Political Science involve multilateral bargaining, in which two or more agents negotiate over the allocation of some surplus. For example, in international trade agreements, nations bargain over how to distribute trade benefits and seek for permissions from both the World Trade Organization (WTO) and the Contracting parties to implement their proposal. As another example, in many political institutions such as the United Nations, hierarchical organizations such as the US military army and highly-organized cooperative firms such as Google, the committee members negotiate on the distribution of funds and, depending on various voting rules, all or a fraction of committee members are needed for the implementation of a proposal. Rubinstein [21] provides the basic framework for an enormous and still growing literature in bargaining theory. His paper considers a two player non-cooperative bargaining model with alternating offers and verifies that any nonzero degree of impatience results in the existence of a unique subgame perfect equilibrium. Binmore [9] endows agents with a fixed probability of recognition. BaronFerejohn [6] study a multilateral bargaining model that extends Rubinstein's two player bargaining game to the case of $n$ players with random proposers and general voting rules. They characterize a stationary subgame perfect equilibrium (SSPE) such that the first recognized proposer compensates enough voters by their discounted future payoffs at random, the proposer collects the rest of the resources and all other members obtain zero payoffs. The closed rule Baron-Ferejohn [6] framework, where no amendment is allowed after the proposal, has been widely used not only to study multilateral legislative bargaining model but also to model many real-life economic situation that requires a group to divide certain resources. Eraslan [11] further demonstrates that with heterogeneity among the players, although the uniqueness of SSPE is ambiguous, all the equilibria yield the same payoff. Merlo-Wilson [18, 19] as well as Eraslan-Merlo [12] use a stochastic process to show that an agreement may be delayed so that more efficient contracts can be implemented by waiting. Particularly, Merlo-Wilson [18, 19] consider a sequential bargaining model with unanimity voting rule where both the size of the surplus and the identity of the proposer follow a stochas- 
tic process over time while Eraslan-Merlo [12] show that for an agreement rather than unanimity voting rule, inefficiency is induced by the fact that players accept an agreement "too soon". Most of the existing literature on multilateral bargaining restrict attention to a bargaining game where the surplus and the recognition are exogenously given or evolve stochastically over time. Recognizing that the recognition probability might be influenced by players' actions, Yildirim $[22,23]$ consider a multilateral bargaining model where agents expend costly efforts to be the proposer according to a "contest success function". On the other hand, Ali [1] analyzes a situation in which players compete for a proposer through an all-pay auction where each bidder must pay regardless of whether they win the prize and the prize is awarded to the highest bidder. He verifies that selling bargaining power make the distribution of the surplus among players extremely unequal. Specifically, if no player has veto power, then the fist proposer obtains all the resources and, if the voting rule is unanimity, then at most one other player rather than the proposer can have a positive payoff.

Yet still little consideration has been given to the case where the size of the surplus is endogenously determined by players' actions. In many negotiations, however, the size of surplus is usually created by players' contributions. Hence, the purpose of our paper is to endogenize the surplus as well as the recognition probability in a sequential bargaining model with general voting rules. Our model is based on Yildirim [22, 23]. Nevertheless, contrary to their model, instead of assuming some costly actions, we follow the literature of "Confliction" (see Skaperdas [20] and GarfinkelSkaperdas [13]) and introduce the resource constraints into the multilateral bargaining model. Particularly, we extend the Skaperadas's two-player confliction model to a multilateral bargaining model with general voting rules. We allow each player to receive a given resource. Given their resource constraints, they can allocate their own resources to productive and unproductive (or coercive) activities. The collective productive efforts determine the size of the surplus. The relative levels of unproductive efforts determine players' recognition probabilities. The players then bargain over the surplus they produced with general voting rules and realize their payoffs. Players face a trade-off between making efforts that will lead to a larger size of pie and investing to increase their recognition probabilities.

We consider both persistent effects and transitory effects to reflect how effort levels influence the bargaining process. When persistent effects are considered, the investment and recognition stage is 
separated from the bargaining stage. The effort levels have a permanent effect on the size of the pie and on players' recognition probabilities in the bargaining stage. Note that our bargaining model with persistent effects is similar to Ali [1] in that the sequential bargaining model also consists two stages: the pre-bargaining stage and the bargaining stage. Nevertheless, instead of introducing an all-pay auction in the pre-bargaining stage, we combine the sequential bargaining literature with the "contest" literature and add resource constraints into the model.

On the other hand, when transitory efforts are considered, each player receives a given player-specific and time-specific resource. In each period, players first decide how to allocate their recourses and then bargaining upon the surplus produced in the same period, and if no agreement is reached, the game continues.

In both settings, we analyze how the equilibrium outcomes would change when players vary in their patient levels or their given resources. Besides, following Skaperdas [20], we define the social loss as the difference of two types of cooperations: "full cooperation" and "partial cooperation". In "full cooperation", none of the players exert any unproductive effort. All the resources are used to produce the surplus and the surplus reaches its maximum given the total resource constraint. In "partial cooperation", some or all of the players exert some positive level of unproductive effort. These efforts determines the recognition probabilities but do not yield any direct payoff to the players. We show that in our model, "full cooperation" is not achievable by itself and "partial cooperation" is dominant for all players. Furthermore, we demonstrate that when the competition becomes less intensive (i.e., the proposal needs the consents of more players), more total resources are allocated to productive efforts and, consequently, it raises the social welfare and reduces the social loss. In the extreme case where the proposal requires all players' acceptances (i.e., unanimity rule), it can support the highest social welfare under a non-cooperation sequential bargaining model. Our model also fits into a body of research about free-rider problem in public economies. In the view of public economics, once the pie is made, it is analogous to a public good. Then free-rider problem might arise. Apart from traditional analysis of public goods, in our model the contribution of the public good is defined on a real interval, not a dichotomous signal "contribute" or "not contribute". We show that although the unanimity voting rule is more efficient than $k$-majority voting rule, it worsens the free-rider problem and incentivizes players to take a free-ride on others and contribute nothing to the social welfare. 


\subsection{Bargaining with Persistent Effects}

\subsubsection{The Model}

We first consider the case that the efforts have persistent effects in the bargaining process. We can think of this game as a two-stage bargaining game that contains the pre-bargaining and bargaining stages.

Let $N \equiv\{1,2, \ldots, n\}$ be the set of $n$ players. In the pre-bargaining stage, each player $i \in N$ receives an exogenous initial endowment, $\sigma_{i}>0$, which is not transferrable between the players. Each player $i$ simultaneously allocates his resources into two types of efforts, the productive effort, denoted by $x_{i}$, and the unproductive effort, denoted by $y_{i}$. The productive effort profile $x \equiv\left(x_{1}, \ldots, x_{n}\right)$ decides the size of the "cake", $F(x)$, and the unproductive effort profile $y \equiv\left(y_{1}, \ldots, y_{n}\right)$ determines each player's recognition probability, $p_{i}(y)$. For each $i \in N$, we assume that $x_{i}$ and $y_{i}$ are non-negative and satisfy the resource constraint:

$$
x_{i}+y_{i}=\sigma_{i}^{15}
$$

Let $X$ and $Y$ be the spaces of all feasible productive and unproductive effort profiles, respectively. Following the previous economic literature, we denote the productive and unproductive strategy profiles that exclude player $i$ 's efforts as $x_{-i}$ and $y_{-i}$, respectively. Furthermore, assume that $F(x)$ and $p_{i}(y)$ have the following properties:

Assumption 2. $F(x): X \rightarrow \mathbb{R}_{+}$is the production function, such that

(a) $F(x)$ is non-negatively valued and twice differentiable.

(b) $\frac{\partial F}{\partial x_{i}}(x)>0 ; \frac{\partial^{2} F}{\partial x_{i}^{2}}(x) \leq 0 ; \frac{\partial^{2} F}{\partial x_{i} \partial x_{j}}(x) \geq 0$, for any $x \in X$.

Assumption 3. $p_{i}(y): Y \rightarrow \mathbb{R}_{+}$is player $i$ 's recognition probability, such that for any $y \in Y$, we have

(a) $\sum_{i} p_{i}(y)=1$.

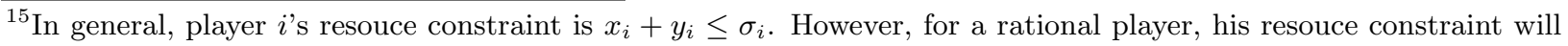
always bind in equilibrium, i.e., $x_{i}+y_{i}=\sigma_{i}$, because there is no outside options and player's expected payoff is strictly increasing in his efforts.
} 
(b) $\frac{\partial p_{i}}{\partial y_{i}}(y)>0 ; \frac{\partial^{2} p_{i}}{\partial y_{i}^{2}}(y)<0 ; \frac{\partial p_{i}}{\partial y_{j}}(y)<0 ; \frac{\partial^{2} p_{i}}{\partial y_{j}^{2}}(y)>0 ; \frac{\partial^{2} p_{i}}{\partial y_{i} \partial y_{j}}(y)>0$, where $j \neq i \in N$.

(c) $\left|\frac{\partial p_{i}}{\partial y_{i}}(y)\right| \geq\left|\frac{\partial p_{j}}{\partial y_{i}}(y)\right| ; 0<\frac{\partial^{2} p_{i}}{\partial y_{i} \partial y_{j}}(y)<\frac{\partial^{2} p_{i}}{\partial y_{j}^{2}}(y) ;\left|\frac{\partial^{2} p_{i}}{\partial y_{j} \partial y_{i}}(y)\right|<\left|\frac{\partial^{2} p_{i}}{\partial y_{i}^{2}}(y)\right|$, where $j \neq i \in N$.

(d) $0<\frac{\partial p_{k}^{2}}{\partial^{2} y_{i}}(y)<\frac{\partial^{2} p_{k}}{\partial y_{i} y_{j}}(y)$, where $k \neq i, j \in N$.

Note that many well-known concave utility functions satisfy Assumption 2, for example, $F(x)=$ $\prod_{k=1}^{n} x_{k}^{\alpha_{k}}$, where $\sum \alpha_{k}=1$. Also, the properties that we impose on the recognition probability in Assumption 3 is widely used in the rent-seeking literature, for example, $p_{i}(y)=\frac{y_{i}^{m}}{\sum_{k \in N} y_{k}^{m}}$, where $0<m \leq 1$.

Since the efforts that the players choose in the pre-bargaining stage have a persistent effect, the producer surplus, $F$, and the recognition probabilities, $\left(p_{1}, p_{2}, \ldots, p_{n}\right)$, are fixed in the bargaining stage. Hence, in the bargaining stage, the $n$ players just bargain over the allocation of the "cake", $F$, and negotiate according to the multilateral bargaining with random proposers. Namely, at the beginning of each period $t=1,2, \ldots$, player $i$ is recognized with probability $p_{i}$ to make a proposal, denoted by $s$, on how to allocate $F$. The proposal, $s$, is an element of the set of all feasible allocations, $S=\left\{s=\left(s_{1}, s_{2}, \ldots, s_{n}\right) \mid \sum_{i} s_{i} \leq F\right\}$, where $s_{i}$ is the share player $i$ receives. Then the $n$ players simultaneously decide whether to accept or reject the proposal. $F$ is shared according to the proposal if at least $k$ players (include the proposer) choose to accept it. Otherwise, the game continues to the next period where player $i$ should discount the future with the discount factor $0<\delta_{i}<1$. In this game, we will consider two types of voting rules: the unanimity rule $(k=n)$ and the simple $k$-majority rule $(k<n)$.

The timing of the game is as follows:

- At time $t=0$ (pre-bargaining stage), player $i \in N$ receives an endowment $\sigma_{i}$ and chooses the productive effort, $x_{i}$, and the unproductive effort, $y_{i}$.

- At time $t=1$, with probability $p_{i}$, player $i$ is the proposer and makes the proposal, $s$. The other players decide whether to accept it. If $k$ players (include the proposer) accept the proposal, then $F$ is shared according to this allocation. Otherwise, the game continues to period 2 .

- At time $t=2$, the process in period 1 repeats and a new proposer might be recognized. 
Next, we consider the strategy set for player $i \in N$. The action set of player $i$ in the pre-bargaining and bargaining stages can be defined by:

$$
a_{i 0} \in\left\{\left(x_{i}, y_{i}\right) \mid x_{i} \geq 0, y_{i} \geq 0, \text { and } x_{i}+y_{i}=\sigma_{i}\right\}
$$

and

$$
a_{i t} \in\left\{\begin{array}{cc}
s \in S & \text { if player } i \text { is the proposer } \\
\{\text { accept, reject }\} & \text { otherwise }
\end{array}, \text { where } \mathrm{t}=1,2,3, \ldots,\right.
$$

respectively. Assume that at each period $t=0,1, \ldots$, all past choices of the players are common knowledge and let $H_{t}$ denote the past history specifying the actions of all the players, and/or, the identity of the proposer, the proposal being made and the responses of all the players in each period before time $t$. It includes all the information available at time $t$. Then the (pure) strategy set for player $i$, denoted by $\mathbf{s}_{i}$, is a function from the history set, $H_{t}$, to the action set, $a_{i t}$. Namely, $\mathbf{s}_{i}: H_{t} \rightarrow a_{i t}$. Let $\mathbf{s}=\left(\mathbf{s}_{1}, \ldots, \mathbf{s}_{n}\right)$ be the strategy profile. A strategy profile is subgame perfect (SP) if for every history $H_{t}$, the strategy profile is a Nash equilibrium of the subgame starting from any period $t$. A strategy profile is stationary if the actions prescribed at any history does not depend on the time. In our analysis, we focus on the stationary subgame perfect equilibria (SSPE) where the strategy profile is both subgame perfect and stationary ${ }^{16}$. Now we are ready to examine the bargaining model under the unanimity voting rule with persistent effects and we relax this assumption and consider the $k$-majority voting rule $(k \neq n)$ in Section 4.2.3.

\subsubsection{Unanimity Rule}

In this subsection, we analyze the case where the productive and unproductive efforts have persistent effects on the size of the cake and the recognition process, and the proposal will be implemented if all the players accept it.

To characterize the SSPE, we use backwards induction and focus on the payoffs and the productive

\footnotetext{
${ }^{16}$ The reason that we focus on a SSPE is threefold. First, as Baron and Ferejohn (1989) point out, with more than two players, any allocation can be supported as a SPE of the game where players use history-dependent strategies with punishment. Stationary restriction significantly reduces the number of equilibria. Therefore it has been widely adopted in the multilateral bargaining literature. Second, recall the settings of the model, if no agreement is reached, the game moves to the next period with exactly the same rule, except the fact that players discount the payoff by their discount factors. Third, for analytical tractability, a SSPE is rich enough to shed light on our main conclusion.
} 
and unproductive efforts in equilibrium.

Given that $F$ and $p_{i}$ are fixed in the pre-bargaining stage, in the bargaining stage, the equilibrium payoffs, denoted by $s_{i}$, satisfies the following proposition and the proofs of all the propositions are relegated to Appendix A.

Proposition 19. If the size of "cake" is $F$ and for player $i \in N$, his discount factor is $0<\delta_{i}<1$ and recognition probability is $p_{i}$, then under the unanimity voting rule with persistent effects, there exists a unique SSPE of the bargaining stage game. In this equilibrium, agreement is immediate at the first period, and player $i$ expects to receive

$$
s_{i}\left(F, p_{i}, p_{-i}\right)=\frac{\frac{p_{i}}{1-\delta_{i}} F}{\sum_{l=1}^{n} \frac{p_{l}}{1-\delta_{l}}},
$$

where $p_{-i}$ is the players' recognition probability profile which excludes player i's recognition probability.

Proposition 19 implies that in equilibrium, one player's expected payoff increases in the size of the "cake" and his recognition probability while decreases in the other's recognition probability. Intuitively, when the size of the "cake" increases, we know that the relative proportions of the "cake" for each player do not change. However, each player is better off since the "cake" has been enlarged and each of them can get more "cake" in absolute values. In addition, a proposer can always grab a larger share of the cake than a "voter". This is because under the unanimity rule, each player knows that when he is just a "voter", he will still receive his continuation value. Therefore, if he is the proposer and after buying out every one else' votes, the remaining surplus for him is less than his continuation value, he will never make this proposal in the first place and will wait for the other player to be a proposer in the next period. Hence, to proceed in this bargaining game, the benefit of being a proposer has to be greater than being a voter. Besides, a higher recognition probability increases the chance for that player to propose while decrease the chance for the other players. Armed with these observations, we can verify that the player's expected payoff and his recognition probability are positively correlated while his expected payoff and the other's recognition probability are negatively correlated.

Furthermore, we can show that for any production function that satisfies Assumption 2 and recog- 
nition probability that satisfies Assumption 3, under the unanimity rule with persistent effects, the $\mathrm{SSPE}$ is unique.

Proposition 20. Suppose that Assumptions 2 and 3 hold. Then under the unanimity voting rule with persistent effects, if there exists a pure strategy SSPE of the bargaining stage game, then it must be unique.

Benchmark: Next we illustrate an example as a benchmark to demonstrate the properties of the optimal efforts between players $i$ and $j$. In particular, we assume that there are only two agents, i.e., $n=2$, and the production function and recognition probability are taken by the following forms:

$$
F\left(x_{1}, x_{2}\right)=\alpha_{1} x_{1}+\alpha_{2} x_{2}
$$

and

$$
p_{i}\left(y_{1}, y_{2}\right)=\left\{\begin{array}{cc}
\frac{y_{i}^{m}}{y_{1}^{m}+y_{2}^{m}} & \text { if }\left(y_{1}, y_{2}\right) \neq(0,0) \\
\frac{1}{2} & \text { if }\left(y_{1}, y_{2}\right)=(0,0)
\end{array}\right.
$$

where $\alpha_{1}>0, \alpha_{2}>0$ and $0<m \leq 1$ are constants.

The claim below characterizes the relationship of the optimal efforts between the two players in equilibrium.

Claim 1. Suppose that $n=2$, and the production and recognition probability functions are defined in Eqs. (44) and (45), respectively. Then under the unanimity voting rule with persistent effects, there is a unique equilibrium such that players will produce a positive size of "cake", and the ratio of the optimal unproductive efforts of players must satisfy:

$$
\frac{y_{2}^{*}}{y_{1}^{*}}=\left(\frac{\frac{\alpha_{1}}{1-\delta_{1}}}{\frac{\alpha_{2}}{1-\delta_{2}}}\right)^{\frac{1}{1+m}} .
$$

This claim implies that if everything is symmetric between the two players, i.e., $\delta_{1}=\delta_{2}$ and $\alpha_{1}=\alpha_{2}$, they will choose the same efforts in equilibrium. The intuition behind this results is as follows: First, $\alpha_{1}=\alpha_{2}$ indicates that two players have identical marginal benefits of producing the cake. Second, given the probability function defined in Eq.(45), under the two player bargaining 
model with unanimity voting rule, the players' marginal benefits of being recognized as a proposer are equal. Based on these, they will exert the same efforts in production and competition.

This claim also indicates that holding other factors to be the same, the less effective player in terms of producing the cake (i.e., player $i$ with a smaller $\alpha_{i}$ ) would propose with a greater probability. To see this, note that if a player is less efficient in production, it lowers his marginal benefit of producing the cake. Thus, he would focus on the recognition competition while letting the more efficient one to produce the cake.

Moreover, it shows that the less patient player (i.e., player $i$ with lower $\delta_{i}$ ) would be recognized with a higher probability. The idea here is similar to the less efficient player's case. Particularly, for a less patient player, the cake will shrink more if the proposal goes to the next period. Hence, it indirectly decreases the marginal benefit of producing the cake. Therefore, he would have lesser incentive to exert his efforts in production.

Besides, one player will exert almost no effort in production and a free-ride on the other player if his productivity or discount factor is extremely low. This is because under the unanimity voting rule, no matter whether the player makes contribution in producing the cake or not, in order to implement the proposal and get his vote, the proposer has to give him some proportion of the cake. Thus, it provides a chance for one player to take a free-ride on the other.

Now we go back to the general case. In order to make some sharp predictions, we assume that the production function $F$ and the recognition probability $p_{i}(y)$ satisfy the following assumption:

Assumption 4. (Symmetry) For any player $i, j \in N$,

(a) they are symmetric in producing the "cake", i.e., $F\left(x_{i}, x_{j}, x_{-i,-j}\right)=F\left(x_{j}, x_{i}, x_{-i,-j}\right)$, for any $\left(x_{i}, x_{j}, x_{-i,-j}\right) \in X$ and $\left(x_{j}, x_{i}, x_{-i,-j}\right) \in X$.

(b) they are symmetric in being recognized as the proposer, i.e., $p_{i}\left(y_{i}=y_{i}^{*}, y_{j}=y_{j}^{*}, y_{-i,-j}=\right.$ $\left.y_{-i,-j}^{*}\right)=p_{j}\left(y_{j}=y_{i}^{*}, y_{i}=y_{j}^{*}, y_{-i,-j}=y_{-i,-j}^{*}\right)$ for any $\left(y_{i}^{*}, y_{j}^{*}, y_{-i,-j}^{*}\right) \in Y$ and $\left(y_{j}^{*}, y_{i}^{*}, y_{-i,-j}^{*}\right) \in$ $Y$,

where $x_{-i,-j}$ and $y_{-i,-j}$ represent the productive and unproductive effort profiles which exclude the efforts of players $i$ and $j$, respectively. 
Based on the the above assumption, we can characterize the equilibrium efforts between players $i$ and $j$ under the general function forms with $n \geq 2$ players:

Proposition 21. Suppose that Assumptions 2, 3 and 4 hold. For any player $i, j \in N$, if their discount factors and their initial endowments are the same, i.e., $\delta_{i}=\delta_{j}$ and $\sigma_{i}=\sigma_{j}$, then under the unanimity voting rule with persistent effects, in equilibrium, the productive and unproductive efforts and the expected payoffs between players $i$ and $j$ are equal, i.e., $x_{i}^{*}=x_{j}^{*}, y_{i}^{*}=y_{j}^{*}$ and $s_{i}^{*}=s_{j}^{*}$.

This proposition says that under the unanimity voting rule with persistent effects, if everything is symmetric between players $i$ and $j$, they would choose the same efforts in equilibrium. This result is obvious because if the players are identical, they will have equal marginal costs and benefits of imposing unproductive and productive efforts. Hence, they will allocate the same amount of efforts in production and propose with equal probability.

Moreover, in equilibrium, it will never be the case that all the resources are wasted on competing for a proposer.

Proposition 22. Suppose that Assumptions 2, 3 and 4 hold. Then under the unanimity voting rule with persistent effects, in equilibrium, there always exist some players that will spend certain efforts in production, i.e., $x^{*}=\left(x_{1}^{*}, x_{2}^{*}, \ldots, x_{n}^{*}\right) \neq(0,0, \ldots, 0)$.

Intuitively, if no one engages in creating social welfare activities (i.e., producing the cake), then the total surplus is zero. Therefore, there is nothing left for the players to share. Hence, they would not exert all their efforts to compete in the first place.

Note that although the above proposition excludes the possibility that all resources are allocated in socially wasteful activities, it is still possible that some players will spend no efforts in production and take a free-ride on the others. The intuition behind this is the same as the benchmark.

Next we analyze how the players equilibrium efforts will change when they differ in their discount factor or initial endowments.

Proposition 23 says that all else being equal, a higher discount factor raises the player's productive efforts and expected payoff in equilibrium while Proposition 24 shows that all else being equal, the player's unproductive effort and his expected payoff are negatively correlated with his initial endowments. 
Proposition 23. Suppose that Assumptions 2, 3 and 4 hold. For any player $i, j \in N$, given that other factors are the same and their discount factors satisfy: $\delta_{i}>\delta_{j}$, then under the unanimity voting rule with persistent effects, in equilibrium, the productive and unproductive efforts and the expected payoffs between the two players must have the following relationships: $x_{i}^{*}>x_{j}^{*}, y_{i}^{*}<y_{j}^{*}$ and $s_{i}>s_{j}$, respectively.

Proposition 24. Suppose that Assumptions 2, 3 and 4 hold. For any player $i, j \in N$, given that other factors are the same and their initial endowments satisfy: $\sigma_{i}>\sigma_{j}$, then under the unanimity voting rule with persistent effects, in equilibrium, the productive and unproductive efforts and the expected payoffs between the two players must have the following relationships: $x_{i}^{*}>x_{j}^{*}, y_{i}^{*} \geq y_{j}^{*}$ and $s_{i} \geq s_{j}$, respectively.

The above two propositions demonstrate that a more patient player or a player with more initial resources will expend a greater effort to produce and, therefore, receives a higher expected payoff in equilibrium.

The idea behind Proposition 23 is as follows. Observe that under the unanimity rule, the agreement requires the approval of all players. Hence, for a more patient player, although he possesses a relatively expensive vote, he will never be excluded from the winning coalition. Thus, he has a relatively lower cost of losing the competition. However, a more patient player will suffer less from the shrink of the total surplus if the game continues to the next period. This leads him to have a higher marginal benefit of producing the cake. Based on the above two points, a higher discount factor induces the player to exert a greater effort in production under the unanimity rule. Furthermore, from the traditional bargaining model, we know that the discount factor represents one player's bargaining power in that a player with a higher one is more likely to reject the proposal. Under the unanimity rule, this bargaining power will benefit the player and result in a higher expected payoff in equilibrium. We show it later that under the $k$-majority voting rule, this may not be the case.

A similar intuition holds for a player with more initial resources (Proposition 24). Namely, for a player with some extra endowments, the cost of losing the competition under the unanimity voting rule can never be extremely high and, therefore, he will never use all his advantage (i.e., extra 
resource) to compete for a proposer. Hence, there is a positive correlation between the player's productive efforts and the initial resources.

Furthermore, we can derive an interesting insight from the two propositions above. That is, the unanimity voting rule is a relatively "fair" mechanism. This is because under the unanimity rule, a player with some initial advantage, (i.e., a higher discount factor or more initial resource) is the one who makes a greater contribution to increasing social surplus and receives a larger share of the cake from the proposer. We show it later that under the $k$-majority voting rule, this result may not always be true.

\subsection{3 k-Majority Rule}

We now consider the case where the proposal can be implemented once there are at least $k$ players accept it, where $k \neq n$. To characterize the expected equilibrium payoffs and optimal efforts, we need to introduce several new concepts.

Before the game starts, with probability $p_{i}(y)$, player $i$ will be recognized as the proposer. Similar to the previous case, the proposal will be accepted by player $j$ if and only if player $j$ is given by his continuation value, $\delta_{j} s_{j}$, where $s_{j}$ is player $j$ 's equilibrium expected payoff. However, contrary to the previous case, now to implement the proposal, player $i$ only needs the consent of $k-1$ players. Since player $i$ 's payoff increases in his own share of the cake and decreases in the others', he will pick the $k-1$ players with the "cheapest" votes, give them their continuation values and then keep the rest of the cake. Therefore, the players with the more "expensive" votes will receive nothing. Let $\psi_{i j}$ be the probability that player $i$ includes $j$ in his offer or winning coalition. Then, the total payment made by player $i$ is defined by

$$
\omega_{i} \equiv \sum_{j \neq i} \psi_{i j} \delta_{j} s_{j}
$$

Therefore, the remaining payoff that player $i$ can get is

$$
F-\omega_{i}=F-\sum_{j \neq i} \psi_{i j} \delta_{j} s_{j}
$$

On the other hand, if player $i$ is not the proposer, then he will be in player $j$ 's winning coalition 
with probability $p_{j}(y) \psi_{j i}$. It is the probability that player $j$ is the proposer, i.e., $p_{j}(y)$, times the probability that player $i$ is in player $j$ 's winning coalition, i.e., $\psi_{j i}$. By summing over all $j \neq i \in N$, we can derive the probability that player $i$ can receive his continuation value from the other players:

$$
\mu_{i}(y) \equiv \sum_{j \neq i} p_{j}(y) \psi_{j i}
$$

Then, player $i$ 's equilibrium expected payoff can be expressed as

$$
s_{i}=p_{i}\left(F-\omega_{i}\right)+\mu_{i} \delta_{i} s_{i}
$$

The first term of the right hand side is the realized payoff if player $i$ is the proposer weighted by the probability, $p_{i}$. The second term is the share that he can get if he is not the proposer and is in others' winning coalition, times the corresponding probability, $\mu_{i}$.

Since the proposal needs the acceptance of at least $k$ players (including the proposer), the proposer will buy out the $k-1$ cheapest votes. Thus, the cutoff point is the $k^{\text {th }}$ smallest continuation value, i.e., $\delta_{k} s_{k}$. Particularly, if player $i$ 's vote is cheaper than player $k$ 's, player $i$ will be in the others' winning coalition whereas if his vote is more expensive than player $k$ 's, he will always be excluded from the winning coalition. Besides, if the continuation values of players $i$ and $k$ are the same, then they will have equal probability to be bought out by the others. Hence, the probability that player $i$ is in the winning coalition, $\mu_{i}$, can be rewritten as:

$$
\mu_{i}= \begin{cases}1-p_{i} & \text { if } \delta_{i} s_{i}<\delta_{k} s_{k} \\ \frac{1-p_{i}}{t} & \text { if } \delta_{i} s_{i}=\delta_{k} s_{k} \\ 0 & \text { if } \delta_{i} s_{i}>\delta_{k} s_{k}\end{cases}
$$

where $t$ is the number of players whose continuation value is equal to $\delta_{k} s_{k}$.

Also, if player $i$ is the proposer and his vote is cheaper than player $k$ 's, then different from the total payment made by player $k$, i.e., $\omega_{k}$, player $i$ does not need to buy out his own vote, $\delta_{i} s_{i}$, but to implement the proposal, he has to give player $k$ his continuation value, $\delta_{k} s_{k}$. Namely, $\omega_{i}=\omega_{k}-\delta_{i} s_{i}+\delta_{k} s_{k}$. On the other hand, if player $i$ is the proposer but his vote is more expensive 
than or equal to player $k$ 's, then his total payment is the same as player $k$ 's, i.e., $\omega_{i}=\omega_{k}$. This is because under this situation, both players $i$ and $k$ will pick the players with the $k-1$ cheapest votes. Formally,

$$
\omega_{i}= \begin{cases}\omega_{k}+\delta_{k} s_{k}-\delta_{i} s_{i} & \text { if } \delta_{i} s_{i}<\delta_{k} s_{k} \\ \omega_{k} & \text { if } \delta_{i} s_{i} \geq \delta_{k} s_{k} .\end{cases}
$$

Now we are ready to compare the efforts and expected payoffs between players $i$ and $j$ in equilibrium. To avoid the unnecessary complication of the analysis, we assume that in equilibrium both players $i$ and $j$ have different continuation value from player $k$, i.e., $\delta_{i} s_{i} \neq \delta_{k} s_{k}$ and $\delta_{j} s_{k} \neq \delta_{k} s_{k}$, for any $i, j \neq k \in N$.

Proposition 25. Suppose that Assumptions 2, 3 and 4 hold. For any player $i, j \in N$, if their discount factors and their initial endowments are the same, i.e., $\delta_{i}=\delta_{j}$ and $\sigma_{i}=\sigma_{j}$, and they are sufficiently patient, then under the $k$-majority voting rule with persistent effects, in equilibrium, the productive and unproductive efforts and the expected payoffs between players $i$ and $j$ are equal, i.e., $x_{i}^{*}=x_{j}^{*}, y_{i}^{*}=y_{j}^{*}$ and $s_{i}=s_{j}$.

According to Proposition 25, when the two players with equal marginal costs are both in or excluded from the winning coalition, they are identical in every factor. Hence, they will choose the same allocation of efforts and receive equal expected payoffs. However, if only one player is in the others' winning coalition, then this result may not hold. Particularly, they might exert different efforts unless the two players are both sufficiently patient. This is because under the condition that only one player is in the winning coalition, it automatically makes the two players asymmetric. Nevertheless, when both players are sufficiently patient, then the costs of losing the competition will not vary too much between them. This dramatically reduces the difference between the two players and, therefore, they may still choose identical actions in equilibrium.

Besides, this proposition is consistent with the result under the unanimity rule. Recall that under the unanimity rule (Proposition 21), if every thing is symmetric between the two players, they will expend the same efforts. This similarity comes from the fact that under the $k$-majority rule, when both players are in the winning coalition, then from the views of players $i$ and $j$, the bargaining 
game with the $k$-majority voting rule is like the game with the unanimity voting rule.

Next we analyze in equilibrium, how the expected payoffs and efforts change with various parameters under the $k$-majority voting rule with persistent effect. In particular, Propositions 26 and 27 demonstrate the results when players differ in their discount factors and their initial endowments, respectively.

Proposition 26. Suppose that Assumptions 2, 3 and 4 hold. For any player $i, j \in N$, given that other factors are the same and their discount factors satisfy: $\delta_{i}>\delta_{j}$, then under the k-majority voting rule with persistent effects, if

(i) players $i$ and $j$ are in the winning coalition, i.e., $\delta_{i} s_{i}<\delta_{k} s_{k}$ and $\delta_{j} s_{j}<\delta_{k} s_{k}$, in equilibrium, the productive and unproductive efforts and the expected payoffs between the two players must have the following relationships: $x_{i}^{*}>x_{j}^{*} y_{i}^{*}<y_{j}^{*}$ and $s_{i}>s_{j}$, respectively.

(ii) players $i$ is in the winning coalition while player $j$ is excluded from the winning coalition, i.e., $\delta_{i} s_{i}<\delta_{k} s_{k}$ and $\delta_{j} s_{j}>\delta_{k} s_{k}$, in equilibrium, the productive and unproductive efforts and the expected payoffs between the two players must have the following relationships: $x_{i}^{*}>x_{j}^{*}$ $y_{i}^{*}<y_{j}^{*}$ and $s_{i}<s_{j}$, respectively.

(iii) players $i$ is excluded from the winning coalition while player $j$ is in the winning coalition, i.e., $\delta_{i} s_{i}>\delta_{k} s_{k}$ and $\delta_{j} s_{j}<\delta_{k} s_{k}$, in equilibrium, the productive and unproductive efforts between the two players must have the following relationships: $x_{i}^{*}<x_{j}^{*}$ and $y_{i}^{*}>y_{j}^{*}$, respectively.

(iv) players $i$ and $j$ are excluded from the winning coalition, i.e., $\delta_{i} s_{i}>\delta_{k} s_{k}$ and $\delta_{j} s_{j}>\delta_{k} s_{k}$, in equilibrium, the productive and unproductive efforts and the expected payoffs between the two players must have the following relationships: $x_{i}^{*}>x_{j}^{*} y_{i}^{*}<y_{j}^{*}$ and $s_{i}<s_{j}$, respectively.

Proposition 26 says that under conditions $(i)$ and $(i v)$, (i.e., both of the two players are or neither of them is in the winning coalition), the more patient one will exert greater efforts to enlarge the size of the cake. First, as mentioned before, under condition $(i)$, although it is a $k$-majority voting rule, the game is equivalent to a bargaining model with the unanimity voting rule. Hence, if condition $(i)$ is satisfied, then the result under the unanimity voting rule (Proposition 23) still holds and the intuition behind this is the same. To understand the result under condition (iv), first observe 
that under the $k$-majority voting rule, although a higher discount factor can improve the player's bargaining power and, therefore, increase his expected equilibrium payoff, unlike the unanimity voting rule, it also has a negative effect on player's equilibrium payoff. Namely, a greater extent of patient level will result in a more expensive vote and if the competition is very intense, then it increases the chance for that players to be excluded from others' winning coalition. Nevertheless, under condition $(i v)$, the two players are both excluded from the winning coalition. Hence, they will receive nothing from being a non-proposer and their costs of losing the competition are equal. Or, in comparison to the less patient player, the more patient one will not forgo a disadvantage from possessing a more expensive vote. However, by being patient, he can still obtain a greater bargaining power. This induces him to exert less efforts to propose and allocate more resources in production.

Proposition 26 also reveals that under the situation where only one of the two players is in the winning coalition, irrespective of the patient level, the player who is excluded from the winning coalition is always the one who will spend greater efforts in competition. This result follows because under the $k$-majority voting rule, an exclusion from the winning coalition will result in zero payoff from being a non-proposer. Hence, it leads the player who are excluded from the winning coalition to allocate more resources in competition, regardless of the discount factor. This result might indicate that in comparison to the unanimity voting rule, the $k$-majority voting rule is less efficient because a more patient player might use all his advantage only to engage in social wasteful activities (i.e., competing for a proposer).

To further demonstrate this point, we analyze the case where players are endowed with different initial resource.

Proposition 27. Suppose that Assumptions 2, 3 and 4 hold. For any player $i, j \in N$, given that other factors are the same and their initial endowments satisfy: $\sigma_{i}>\sigma_{j}$, then under the $k$-majority voting rule with persistent effects, if

(i) players $i$ and $j$ are in the winning coalition, i.e., $\delta_{i} s_{i}<\delta_{k} s_{k}$ and $\delta_{j} s_{j}<\delta_{k} s_{k}$, in equilibrium, the productive and unproductive efforts and the expected payoffs between the two players must have the following relationships: $x_{i}^{*}>x_{j}^{*} y_{i}^{*}>y_{j}^{*}$ and $s_{i}>s_{j}$.

(ii) player $i$ is in the winning coalition while player $j$ is excluded from the winning coalition, i.e., 
$\delta_{i} s_{i}<\delta_{k} s_{k}<\delta_{j} s_{j}$, in equilibrium, the productive and unproductive efforts and the expected payoffs between the two players must have the following relationships: $x_{i}^{*}>x_{j}^{*} y_{i}^{*} \geq y_{j}^{*}$ and $s_{i}<s_{j}$.

(iii) player $i$ is excluded from the winning coalition while player $j$ is in the winning coalition, i.e., $\delta_{i} s_{i}>\delta_{k} s_{k}>\delta_{j} s_{j}$, in equilibrium, the productive and unproductive efforts and the expected payoffs between the two players must have the following relationships: $y_{i}^{*}>y_{j}^{*}$ and $s_{i}>s_{j}$.

(iv) players $i$ and $j$ are excluded from the winning coalition, i.e., $\delta_{i} s_{i}>\delta_{k} s_{k}$ and $\delta_{j} s_{j}>\delta_{k} s_{k}$, in equilibrium, the productive and unproductive efforts and the expected payoffs between the two players must have the following relationships: $x_{i}^{*}>x_{j}^{*} y_{i}^{*}>y_{j}^{*}$ and $s_{i}>s_{j}$.

According to Proposition 27, under either of the four conditions above, a player with more initial endowments will always allocate greater efforts to be a proposer while whether he would spend more efforts in production varies across different situations. Particularly, under conditions $(i),(i i)$ and $(i v)$, he will exert some of his extra resources to enlarge the size of the cake while in his worst scenario (i.e., condition (iii)), he will use all his advantage to compete for a proposer. This result is in sharp contrast to the case under the unanimity voting rule. Recall that from Proposition 24, under the unanimity voting rule with persistent effects, the productive efforts and initial resources are always positively correlated. This is because under the $k$-majority rule, by being given some additional endowments, that player's vote is less desirable to buy out and therefore, it increases the chance of receiving nothing from losing the competition. Based on this, that player will never use all his advantage in creating social welfare activities and will retain some of his advantage to compete for a proposer.

Overall, the discussion so far suggests that the $k$-majority rule might be less efficient than the unanimity rule in that it induces the players to exert greater efforts in social wasteful activities. The next proposition further confirms this intuition and provides more additional insight about the social welfare under the unanimity rule and the $k$-majority rule.

To distinguish the two voting rules, we denote the efforts under the unanimity voting rule as $\left(x_{i}^{U}, y_{i}^{U}\right)$ and the efforts under the $k$-majority rule as $\left(x_{i}^{k}, y_{i}^{k}\right)$, where the superscript " $U$ " and " $k$ " represent "unanimity" and " $k$-majority", respectively. Before proceeding to our next proposition, 
we first observe that for each player, the level of his unproductive effort reduces when the voting rule changes from majority to unanimity rule.

Lemma 2. Suppose that Assumptions 2 and 3 hold. For any player $i \in N$, given that other factors are the same, under the bargaining model with persistent effects, in comparison to the $k$ majority voting rule, player $i$ will exert more productive effort and less unproductive effort under the unanimity voting rule, i.e., $y_{i}^{* U}<y_{i}^{* k}$ and $x_{i}^{* U}>x_{i}^{* k}$.

Next, by following Skaperdas [20], we define "full cooperation" as the case where players allocate all their resources to productive effects. Under this case, the largest size of the cake, denoted as $F^{S}$, can be produced, where

$$
F^{S}=F\left(\sigma_{1}, \sigma_{2}, \ldots \sigma_{n}\right)
$$

We refer "partial cooperation" to the situation where each player maximizes his own expected payoff and positive unproductive efforts are made. The social cost, represented by $C\left(y_{1}, y_{2}, \ldots, y_{n}\right)$, is the difference of the surplus under "full cooperation" and "partial cooperation". Therefore, for all $y \in Y$, we have

$$
C\left(y_{1}, y_{2}, \ldots, y_{n}\right)=F^{S}-F\left(\sigma_{1}-y_{1}, \sigma_{2}-y_{2}, \ldots, \sigma_{n}-y_{n}\right)
$$

Now we are ready to compare the two voting rules in terms of social welfare:

Proposition 28. Suppose that Assumptions 2 and 3 hold. Then in comparison to the $k$-majority voting rule with persistent effects, the unanimity voting rule with persistent effects generates a greater social surplus and forgoes a smaller social cost.

Proposition 28 follows because under the unanimity voting rule, a proposal requires the consent of all the players and each will receive their continuation value from being a non-proposer. Nevertheless, if the voting rule changes to majority rule, some of the players will receive nothing if they lose the competition. This indirectly intensify the competition and consequently lead each player to exert greater effort to propose and less effort to enlarge the total surplus.

A similar line of argument discloses that when the voting rule becomes more inclusive (i.e., $k$ increases), it will improve the social welfare and reduce wasteful social activities. 
Lemma 3. Suppose that Assumptions 2 and 3 hold. For any player $i \in N$, given that other factors are the same, under the $k$-majority voting rule with persistent effects, his unproductive effort, $y_{i}^{*}$, weakly decreases in $k$ while his productive effort, $x_{i}^{*}$, weakly increases in $k$, where $k=\{1,2, \ldots, n-1\}$.

After observing the above properties, we can characterize how the social cost and social surplus will vary when the competition becomes more intense.

Proposition 29. Suppose that Assumptions 2 and 3 hold. Then under the $k$-majority voting rule with persistent effects, the social cost decreases in $k$ while the social surplus increases in $k$.

The intuition behind the above result is the same as Proposition 28. Particularly, an increase in $k$ has a similar impact as of a change from a majority to a unanimity rule. That is, they both will make the competition less intensive. Therefore, each player will behave more cooperatively and exert less efforts to fight and more efforts to produce.

\subsection{Bargaining with Transitory Effects}

\subsubsection{The Model}

As before, let $N \equiv\{1,2, \ldots, n\}$ be the set of $n$ players. We now consider a game where players produce a "cake" and share it among themselves in each period. Time is still infinite and discrete but there is no pre-bargaining stage, i.e., $t=1,2, \ldots$ At the beginning of every period, each player $i \in N$ receives $\sigma_{i}>0$ units of resources which are not transferable between the players nor between different periods. Similar to the bargaining with persistent effects, player $i$ can still divide his individual resources into two types of efforts, the productive effort, denoted by $x_{i}$ and unproductive effort, denoted by $y_{i}$. The productive effort profile $x \equiv\left(x_{1}, \ldots, x_{n}\right)$ decides the size of the "cake", denoted by $F(x)$, and the unproductive effort profile $y \equiv\left(y_{1}, \ldots, y_{n}\right)$ determines each player's recognition probability, represented by $p_{i}(y)$. We still assume that for each $i \in N, x_{i}$ and $y_{i}$ are nonnegative and satisfy the resource constraint:

$$
x_{i}+y_{i}=\sigma_{i}
$$


Furthermore, the production function, $F(x)$, and the recognition probability, $p_{i}(y)$, satisfy Assumptions 2 and 3, respectively.

The timing of the game is as follows: At the beginning of period $t(t=1,2, \ldots)$ if the game has not ended, players simultaneously choose their own allocations between productive and unproductive efforts. Once the efforts are chosen, the size of the "cake" is determined by the production function and one player is recognized as the proposer. The proposer proposes an allocation, denoted by $s=\left(s_{1}, s_{2}, \ldots, s_{n}\right)$, to all the players. The proposal must satisfy $s_{i} \geqslant 0$ for all $i$ and $\sum_{k \in N} s_{k} \leqslant F(x)$. All players then respond by either accepting or rejecting it. Depending on the rules of the game, the proposer needs the consent of $k$ players (including the proposer) for his proposal to be agreed upon. If $k$ players accept the offer then the proposal is implemented and the game ends. Otherwise the game repeats to the next period $t+1$. The "cake" produced in period $t$ diminishes and the recognition probability vanishes in $t+1$. The players choose their efforts again and a new player is recognized. This process continues until an allocation is accepted. Game ends if a proposal is made. We assume no exit option for the players until game ends. We consider two voting rules: $k$-majority and unanimity.

We next describe the strategy set from which the players can choose and specify the equilibrium concept that we will use. The action that a player can take at period $t$ is $\left(x_{i t}, y_{i t}, a_{i t}\right)$, where $x_{i t}$ is the productive effort, $y_{i t}$ is the unproductive effort and

$$
a_{i t} \in\left\{\begin{array}{cc}
\mathrm{s} & \text { if player } i \text { is the proposer } \\
\{\text { accept, reject }\} & \text { otherwise }
\end{array} .\right.
$$

Let $H_{t}$ denote the past history specifying the effort levels of all the players, the identity of the proposer, the propose being made and the response of all the players in each period before time $t$. It includes all the information available at time $t$. A (pure) strategy $\mathbf{s}_{i}$ for player $i$ is a sequence of actions $\left\{a_{i t}\left(H_{t}\right)\right\}_{t=0}^{\infty}$. Again, in our analysis below, we still focus on SSPE.

\subsubsection{Unanimity Rule}

In this section we analyze the case where the players adopt unanimity rule. Suppose a proposal needs the consent of all the $n$ players. We denote the expected equilibrium payoff for player $i$ in 
period $t$ as $v_{i t}$, where $i=1, \ldots, n$ and $t=1, \ldots, \infty$. Note that it is the expected payoff for player $i$ before the efforts are chosen and the identity of the proposer is revealed. It is a real number, not a function of other choice variables. Since we confine our focus on stationary strategy profiles only, we can drop the subscripts $t$ so that $v_{i t}=v_{i}$ for all $t$. To guarantee the existence of such SSPE, we further assume that a voter will accept any proposal whenever she is offered any share of the "cake" that is equal to the expected payoff he can get if he rejects the current offer and continues to the next period. To induce acceptance and maximize his own share, any proposer will offer all the other players their continuation payoff, $\delta_{i} v_{i}$.

Therefore, the dynamic problem for player $i \in N$ is:

$$
v_{i}=\max _{x_{i}+y_{i}=\sigma_{i} ; x_{i}, y_{i} \geq 0}\left\{p_{i}(y)\left(F(x)-\sum_{l \neq i} \delta_{l} v_{l}\right)+\left(1-p_{i}(y)\right) \delta_{i} v_{i}\right\}
$$

Or,

$$
v_{i}=\max _{x_{i}+y_{i}=\sigma_{i} ; x_{i}, y_{i} \geq 0}\left\{\frac{p_{i}(y)}{1-\delta_{i}}\left(F(x)-\sum_{l=1}^{n} \delta_{l} v_{l}\right)\right\} .
$$

The following proposition shows that under the unanimity rule with transitory effects, if there exists a SSPE, then it must be unique. Namely,

Proposition 30. Suppose that Assumptions 2 and 3 hold. Then under the unanimity voting rule with transitory effects, if there exists a pure strategy SSPE, then it must be unique.

Benchmark: Next we illustrate an example as a benchmark to demonstrate the properties of the optimal efforts between players $i$ and $j$ under the unanimity rule with transitory effects. We assume that there are only two agents, i.e., $n=2$, and the production function and recognition probability are taken by the same forms as in the benchmark with persistent effects.

Now we can derive the following nice properties of the optimal efforts between the two players in equilibrium .

Claim 2. Suppose that $n=2$, and the production and recognition probability functions are defined in Eqs. (44) and (45), respectively. Then under the unanimity voting rule with transitory effects, there is a unique equilibrium such that players will produce a positive size of "cake", and the ratio 
of the optimal unproductive efforts of players must satisfy:

$$
\frac{y_{2}^{*}}{y_{1}^{*}}=\left(\frac{\alpha_{1}}{\alpha_{2}}\right)^{\frac{1}{1+m}}
$$

The above claim demonstrates that under this two player bargaining model with unanimity voting rule and transitory effects, the player's productivity and optimal unproductive efforts are negatively correlated. This is because under the unanimity rule with the probability function defined in Eq.(45), a more productive player possess a greater marginal benefit of producing the cake while the marginal cost of losing the competition remains the same. Based on these, a higher productivity will induce the player to exert greater efforts to produce and consequently, reduce the level of unproductive efforts in equilibrium.

Moreover, surprisingly, the above proposition also shows that in comparison to a unanimity voting rule with persistent effects, when the efforts have no long-lasting effect on player's recognition probability and total surplus, the two players' optimal efforts are irrespective of their discount factors. The intuition behind this result follows by three layers: First, observe that under both persistent and transitory effects, the two players have equal net benefits of being recognized as a proposer. Particularly, the net benefit is the remaining surplus that one player can get after buying out other players' votes minus the payoff he can receive from being a non proposer. In the benchmark, the net benefit is

$$
F-\delta_{1} v_{1}-\delta_{2} v_{2}
$$

which is equal across the two players. Second, the productivity levels, $\alpha_{1}$ and $\alpha_{2}$, represent the marginal benefits of increasing the total surplus and are independent of the discount factors. Thirdly, when efforts are transitory, by the definition of a SSPE, the equilibrium strategy and the expected equilibrium payoff are irrespective of time period $t$. Hence, this game is more like a repeated game and the discount factor plays no role on player's equilibrium payoff. On the contrary, when efforts have a persistent effect, the game is more like a one-shot game and the actions that made in the pre-bargaining stage have a long-lasting effect. Therefore, although the marginal benefits of both winning the competition and increasing the total surplus are independent of the discount factor, the patient level will still influence their continuation payoff and therefore, have an 
impact on their equilibrium optimal choice.

Now we go back to the general case and as before, we assume that the production function $F$ and the recognition probability $p_{i}$ satisfy Assumptions 2, 3 and 4.

By solving the dynamic problem (50), we can derive the following relationships of the efforts and the expected payoffs between players $i$ and $j$ :

Proposition 31. Suppose that Assumptions 2, 3 and 4 hold. For any player $i, j \in N$, if their discount factors and their initial endowments are the same, i.e., $\delta_{i}=\delta_{j}$ and $\sigma_{i}=\sigma_{j}$, then under the unanimity voting rule with transitory effects, the productive and unproductive efforts and the expected payoffs between players $i$ and $j$ are equal, i.e., $x_{i}^{*}=x_{j}^{*}, y_{i}^{*}=y_{j}^{*}$ and $v_{i}=v_{j}$.

The proposition above has a similar interpretation as the corresponding situation with persistent effects (Proposition 21).

The next proposition is also consistent with the result under the unanimity voting rule with persistent effect (Proposition 22). It shows that under the unanimity voting rule with persistent effects, it will never be an equilibrium such that all initial resources are used in wasteful social activities.

Proposition 32. Suppose that Assumptions 2, 3 and 4 hold. Then under the unanimity voting rule with transitory effects, in equilibrium, there always exist some players that will spend their efforts in production, i.e., $x^{*}=\left(x_{1}^{*}, x_{2}^{*}, \ldots, x_{n}^{*}\right) \neq(0,0, \ldots, 0)$.

Still, as mentioned before, we can not exclude the possibility for some players to exert zero efforts in production and take a free-ride on other players.

Next we consider the two cases where players differ in their discount factor and their initial endowments and analyze how these will influence their optimal efforts and expected equilibrium payoff under the unanimity voting rule with transitory effects.

The following proposition strengthens the result in the benchmark and verifies that players' productive and unproductive efforts are independent of how they discount their future values while the more patient player can receive a higher expected equilibrium payoff.

Proposition 33. Suppose that Assumptions 2, 3 and 4 hold. For any player $i, j \in N$, given that other factors are the same, then under the unanimity voting rule with transitory effects, no 
matter how they discount their future values, in equilibrium, the productive and unproductive efforts between players $i$ and $j$ must satisfy: $x_{i}^{*}=x_{j}^{*}$ and $y_{i}^{*}=y_{j}^{*}$, respectively. Furthermore, given that other factors are the same, then the discount factors and the expected equilibrium payoffs between the two players must have the following relationship: $\left(1-\delta_{i}\right) v_{i}=\left(1-\delta_{j}\right) v_{j}$.

The proposition above is contrary to the case under the persistent effects. Remember that under the unanimity rule with persistent effects (Proposition 23), the more patient players will exert greater efforts to produce and propose with a smaller probability. However, under the transitory effects, a higher discount factor will not change the allocations of the efforts. As alluded to in the benchmark, this makes sense because under the unanimity rule with transitory effects, the net benefit of being a proposer is equal to the payoff that he can get if he is the proposer, i.e., $F-\sum_{l \neq i} \delta_{i} v_{i}$, minus, the opportunity cost if he is not the proposer, i.e., $\delta_{i} v_{i}$. In other words, the residual surplus is equal to $F-\sum_{l=1}^{n} \delta_{l} v_{l}$. Besides, as opposed to the persistent effect model, now the expected equilibrium payoff $v_{i}$ is independent of the optimal efforts. Therefore, no matter how the players discount their future values, the residual surplus does not vary among players. Put differently, the player's marginal benefits of winning the competition are equal. Furthermore, although the gains of exerting one more unit of productive efforts may vary among the players, they are irrespective of the players' patient level. Hence, regardless of the discount factors, players will have equal marginal benefits of both producing the cake and being recognized as a proposer. Based on these, the players will allocate their resource in the same way, irrespective of their patient levels.

Nevertheless, the proposition also shows that although the players choose the same actions in equilibrium, they will end up with different equilibrium expected payoff. Particularly, by being patient, players will not suffer too much if the proposal is rejected in the current period. Hence, a more patient player possesses more bargaining power and therefore, he will be given a larger proportion of the cake and can end up with a higher expected equilibrium payoff. This results in a positive correlation between the player's discount factor and his equilibrium payoff. Furthermore, this proposition also provides an interesting new insight of the model. That is, under the unanimity voting rule with transitory effects, an increase of the player's patient level will not create any additional social surplus but it will make each player better off from their expected 
equilibrium payoff.

Now we assume that there exists some heterogeneity among the players' initial endowment. Specifically, we reveal that holding other factors fixed, the player with a greater endowment will allocate his excess resources in both productive and unproductive efforts and can receive a higher expected equilibrium payoff.

Proposition 34. Suppose that Assumptions 2, 3 and 4 hold. For any player $i, j \in N$, given that other factors are the same and their initial endowments satisfy: $\sigma_{i}>\sigma_{j}$, then under the unanimity voting rule with transitory effects, the productive and unproductive efforts and the expected payoffs between the two players have the following relationships: $x_{i}^{*}>x_{j}^{*}, y_{i}^{*}>y_{j}^{*}$ and $v_{i}>v_{j}$, respectively.

The above proposition is consistent with the result under the unanimity voting rule with persistent effects (Proposition 24). Both results show that the productive efforts as well as the expected equilibrium payoff are positively correlated with the players' initial resources while the unproductive efforts and the initial resources are negatively correlated. The intuitions behind these two results are the same. We can end up with the same conclusion that the unanimity voting rule is a relatively "fair" mechanism.

However, the result under the transitory effects is still slightly different from Proposition 24 in that the inequality of the unproductive effort becomes strict when there is an increase in player's initial endowments. This difference is due to the fact that under the transitory effects, in each period, the player has a chance to reallocate his resources. Since we only confine our analysis to a SSPE, players will choose the same action in each period. Hence, in every period, the player will suffer from the same cost of losing the competition. However, when the efforts have a persistent effect, the game is a one-shot game and the cost is just a one-time loss. Therefore, in comparison to the persistent effects, the bargaining model with transitory effects increases the cost of being a nonproposer and, hence, indirectly heats up the competition. Thus, the player will never allocate all his advantage (i.e., excess resource) to increase the total surplus in a transitory effect bargaining model. 


\subsection{3 k-Majority Rule}

Now we consider the game where the proposal only needs the consent of at least $k$ players, where $k<n$. To facilitate our analysis, we introduce some new notations. As before, we still use $\psi_{i j}$ to denote the probability that player $i$ includes $j$ in his offer or winning coalition. Then, if player $i$ is the proposer, to implement the proposal, the total payment he needs to pay is:

$$
\omega_{i} \equiv \sum_{j \neq i} \psi_{i j} \delta_{j} v_{j}
$$

If player $i$ is not recognized, the probability that he will be in the proposer's winning coalition can be written as:

$$
\mu_{i}(y) \equiv \sum_{j \neq i} p_{j}(y) \varphi_{j i}
$$

Hence, player $i$ 's dynamic problem can be expressed as:

$$
v_{i}=\max _{x_{i}+y_{i}=\sigma_{i} ; x_{i}, y_{i} \geq 0}\left\{p_{i}(y)\left[F(x)-\omega_{i}\right]+\mu_{i}(y) \delta_{i} v_{i}\right\}
$$

Again, without loss of generality, we can renumber the players by their continuation values so that if $i<j$, we have $\delta_{i} v_{i} \leq \delta_{j} v_{j}$. Then $\mu_{i}$ and $\omega_{i}$ can be rewritten as,

$$
\begin{gathered}
\mu_{i}= \begin{cases}1-p_{i} & \text { if } \delta_{i} v_{i}<\delta_{k} v_{k} \\
\frac{1-p_{i}}{t} & \text { if } \delta_{i} v_{i}=\delta_{k} v_{k} \\
0 & \text { if } \delta_{i} v_{i}^{*}>\delta_{k} v_{k}\end{cases} \\
\omega_{i}= \begin{cases}\omega_{k}+\delta_{k} v_{k}-\delta_{i} v_{i} & \text { if } \delta_{i} v_{i} \leq \delta_{k} v_{k} \\
\omega_{k} & \text { if } \delta_{i} v_{i} \geq \delta_{k} v_{k},\end{cases}
\end{gathered}
$$

where $t$ is the number of players whose continuation value is equal to $\delta_{k} v_{k}$. As to the $k$-majority rule with persistent effects, to avoid the unnecessary complication of the analysis, we assume that in equilibrium both players $i$ and $j$ have different continuation value from player $k$, i.e., $\delta_{i} s_{i} \neq \delta_{k} s_{k}$ and $\delta_{j} s_{k} \neq \delta_{k} s_{k}$, for any $i, j \neq k \in N$. 
The following proposition says that the solution to player $i$ 's dynamic problem is unique.

Proposition 35. Suppose that Assumptions 2 and 3 hold. Then under the $k$-majority voting rule with transitory effects, if there exists a SSPE, it must be unique.

Based on this observation, the following proposition characterizes the efforts and expected payoffs between the two players in equilibrium.

Proposition 36. Suppose that Assumptions 2, 3 and 4 hold. For any $i, j \in N$, if their discount factors and their initial endowments are the same, i.e., $\delta_{i}=\delta_{j}$ and $\sigma_{i}=\sigma_{j}$, and players are sufficiently patient, then under the $k$-majority voting rule with transitory effects, in equilibrium, the productive and unproductive efforts and the expected payoff between players $i$ and $j$ are equal, i.e., $x_{i}^{*}=x_{j}^{*}, y_{i}^{*}=y_{j}^{*}$ and $v_{i}=v_{j}$.

The intuition behind this result is similar to the $k$-majority voting rule with persistent effect. That is, if the two players are in the winning coalition or excluded from the winning coalition, then they are identical in all the factors. Therefore, their marginal benefits of producing the cake or winning the competition are equal. Hence, they would choose the same efforts and receive the same expected payoff. Nevertheless, if only one of the two players is in the winning coalition, then the player in the winning coalition has a lower marginal cost of losing the competition and, therefore, the two players are asymmetric. However, this difference is smaller as the players become more patient. In the extreme case, this difference is almost zero.

The proposition below further specifies that under the $k$-majority voting rule with transitory effects, it can never be an equilibrium such that all the social resources will be allocated in social wasteful activities. However, it is still possible that some of the players might exert zero effort in production and take a free-ride on others. The intuition behind this is consistent with the ones under the unanimity voting rule (Propositions 22 and 32).

Proposition 37. Suppose that Assumptions 2, 3 and 4 hold. Then under the k-majority voting rule with transitory effects, in equilibrium, there always exist some players that will spend their efforts in production, i.e., $x^{*}=\left(x_{1}^{*}, x_{2}^{*}, \ldots, x_{n}^{*}\right) \neq(0,0, \ldots, 0)$. 
Now we investigate how the equilibrium outcomes will change when we add heterogeneity into the bargaining model. Specifically, Propositions 38 and 39 demonstrate the impact of an increase from one player's discount factor and initial endowment on the optimal efforts and the equilibrium expected outcome, respectively.

Proposition 38 designates that when players are symmetric in all the other factors, then no matter how they discount their future values, they will exert the same efforts while the more patient player can receive a higher expected equilibrium payoff.

Proposition 38. Suppose that Assumptions 2, 3 and 4 hold. For any player $i, j \in N$, given that other factors are the same and their discount factors satisfy: $\delta_{i}>\delta_{j}$, then under the $k$-majority voting rule with transitory effects, if

(i) players $i$ and $j$ are in the winning coalition, i.e., $\delta_{i} v_{i}<\delta_{k} v_{k}$ and $\delta_{j} v_{j}<\delta_{k} v_{k}$, then no matter how they discount their future values, in equilibrium, their productive and unproductive efforts must satisfy: $x_{i}^{*}=x_{j}^{*}$ and $y_{i}^{*}=y_{j}^{*}$, respectively, and the discount factors and the expected equilibrium payoffs between the two players have the following relationship: $\left(1-\delta_{i}\right) v_{i}=$ $\left(1-\delta_{j}\right) v_{j}$.

(ii) players $i$ is in the winning coalition while player $j$ is excluded from the winning coalition, i.e., $\delta_{i} v_{i}<\delta_{k} v_{k}<\delta_{j} v_{j}$, in equilibrium, the productive and unproductive efforts and the expected payoffs between the two players must have the following relationships: $x_{i}^{*}>x_{j}^{*} y_{i}^{*}<y_{j}^{*}$ and $v_{i}<v_{j}$, respectively

(iii) players $i$ is excluded from the winning coalition while player $j$ is in the winning coalition, i.e., $\delta_{i} v_{i}>\delta_{k} v_{k}>\delta_{j} v_{j}$, in equilibrium, the productive and unproductive efforts between the two players must have the following relationships: $x_{i}^{*}<x_{j}^{*}$ and $y_{i}^{*}>y_{j}^{*}$, respectively.

(iv) players $i$ and $j$ are excluded from the winning coalition, i.e., $\delta_{i} v_{i}>\delta_{k} v_{k}$ and $\delta_{j} v_{j}>\delta_{k} v_{k}$, then no matter how they discount their future values, in equilibrium, their productive and unproductive efforts must satisfy: $x_{i}^{*}=x_{j}^{*}$ and $y_{i}^{*}=y_{j}^{*}$, respectively and the discounted factors and the expected equilibrium payoffs between the two players have the following relationship: $\left(1-\delta_{i}\right) v_{i}=\left(1-\delta_{j}\right) v_{j}$ 
The result and the idea behind the above proposition are directly comparable to the case under the persistent effect (Proposition 26). First, when both players are in the winning coalition or neither of them is in the winning coalition, they have equal marginal benefits of increasing either productive or unproductive efforts. Hence, they would choose the same efforts and these efforts are independent of how they discount their future values. Nevertheless, since the discount factor improves the player's bargaining power, by being patient, he can earn a larger proportion of the "cake" from being a non proposer. This in turn will eventually raise his expected equilibrium payoff. Second, if only one of them is in the winning coalition (i.e., conditions $(i i)$ and (iii)), then regardless of the patient level, the player who are excluded from the winning coalition will exert greater efforts to compete for a proposer because he has a higher cost of losing the competition. The next result specifies how the equilibrium outcomes change when the initial endowments vary across agents.

Proposition 39. Suppose that Assumptions 2, 3 and 4 hold. For any player $i, j \in N$, given that other factors are the same and their initial endowments satisfy: $\sigma_{i}>\sigma_{j}$, then under the $k$-majority voting rule with transitory effects, if

(i) players $i$ and $j$ are in the winning coalition, i.e., $\delta_{i} v_{i}<\delta_{k} v_{k}$ and $\delta_{j} v_{j}<\delta_{k} v_{k}$, in equilibrium, the productive and unproductive efforts and the expected payoffs between the two players must have the following relationships: $x_{i}^{*}>x_{j}^{*} y_{i}^{*}>y_{j}^{*}$ and $v_{i}>v_{j}$, respectively.

(ii) players $i$ is in the winning coalition while player $j$ is excluded from the winning coalition, i.e., $\delta_{i} v_{i}<\delta_{k} v_{k}<\delta_{j} v_{j}$, in equilibrium, the productive efforts and the expected payoffs between the two players must have the following relationships: $x_{i}^{*}>x_{j}^{*}$ and $v_{i}<v_{j}$, respectively.

(iii) players $i$ is excluded from the winning coalition while player $j$ is in the winning coalition, i.e., $\delta_{i} v_{i}>\delta_{k} v_{k}>\delta_{j} v_{j}$, in equilibrium, the unproductive efforts and the expected payoffs between the two players must have the following relationships: $y_{i}^{*}>y_{j}^{*}$ and $v_{i}>v_{j}$, respectively.

(iv) players $i$ and $j$ are excluded from the winning coalition, i.e., $\delta_{i} v_{i}>\delta_{k} v_{k}$ and $\delta_{j} v_{j}>\delta_{k} v_{k}$, in equilibrium, the productive and unproductive efforts and the expected payoffs between the two players must have the following relationships: $x_{i}^{*}>x_{j}^{*} y_{i}^{*}>y_{j}^{*}$ and $v_{i}>v_{j}$, respectively. 
Proposition 39 coincides with the bargaining model under persistent effects (Proposition 27). Namely, they both reveal that as opposed to the unanimity voting rule, the $k$-majority voting rule results in a positive correlation between the players unproductive efforts and initial endowments. The idea behind these are the same.

Nevertheless, Proposition 39 is still slightly different from the persistent effect. That is, under the $k$-majority voting rule with transitory effects, if the player with more initial resources is in his best scenario (condition $(i i)$ ), he may use all his advantage to increase the size of the cake. This difference comes from the fact that under the transitory effect, the game is more like a repeated game and the benefits of being a nonproposer is the discounted payoff stream of the corresponding benefits under the persistent effects. Hence, for a player with some extra endowments, under condition (ii), it is possible that he will use all his extra resource in production.

Note that this difference might suggest that under the bargaining model with $k$-majority voting rule, if the efforts only has a transitory effect on the total surplus and recognition probability, it can reduce social wasteful activities and restore some of the inefficiency.

To further analyze the issue of social welfare, as before, we introduce the concept of social cost, denoted as $C\left(y_{1}, \ldots, y_{n}\right)$. It refers to the difference of the surplus between "full cooperation" and "partial cooperation" under the bargaining model with transitory effects. Namely, for any $y \in Y$, we have

$$
C\left(y_{1}, \ldots, y_{n}\right)=F^{S}-F\left(\sigma_{1}-y_{1}, \sigma_{2}-y_{2}, \ldots \sigma_{n}-y_{n}\right)
$$

The following lemma provides some useful characteristics of how the optimal efforts are affected by the two different voting rules. As before, we denote the efforts under the unanimity voting rule as $\left(x_{i}^{U}, y_{i}^{U}\right)$ and the efforts under the $k$-majority rule as $\left(x_{i}^{k}, y_{i}^{k}\right)$, where the superscript " $\mathrm{U}$ " and " $\mathrm{k}$ " represent "unanimity" and " $k$-majority", respectively.

Lemma 4. Suppose that Assumptions 2 and 3 hold. For any player $i \in N$, given that other factors are the same, under the bargaining model with transitory effects, in comparison to the $k$ majority voting rule, player $i$ will exert more productive effort and less unproductive effort under the unanimity voting rule, i.e., $y_{i}^{* U}<y_{i}^{* k}$ and $x_{i}^{* U}>x_{i}^{* k}$.

Then we can show that in comparison to the $k$-majority voting rule, the unanimity voting rule 
enhances more social welfare creating activities while reduces more social wasteful activities.

Proposition 40. Suppose that Assumptions 2 and 3 hold. Then in comparison to the k-majority voting rule with persistent effects, the unanimity voting rule with persistent effects generates a greater social surplus and forgoes a smaller social cost.

This proposition implies that under the bargaining model with transitory effects, the unanimity voting rule is more efficient than the $k$-majority voting rule in that players will exert more efforts to produce and less efforts to propose. This is consistent with the persistent effect case. The ideas behind them are also the same. Intuitively, under the $k$-majority voting rule, for players with high continuation values, their votes are more expensive and less desirable for other players to buy out. Therefore, they will be excluded from the winning coalition and receive nothing if they lose the competition. Nevertheless, under the unanimity voting rule, they will still be given their continuation values from being a non proposer. Hence, the $k$-majority voting rule heats up the competition and induce players to exert greater efforts to engage in social wasteful activities. Therefore, the $k$-majority voting rule is less efficient than the unanimity voting rule.

Moreover, when the majority rule requires less affirmant votes, it will also intensify the competition and consequently reduce social surplus and raise social cost. This intuition will be confirmed by Proposition 41.

Before proceeding to the result, we observe the following lemma:

Lemma 5. Suppose that Assumptions 2 and 3 hold. For any player $i \in N$, given that other factors are the same, under the $k$-majority voting rule with transitory effects, his unproductive effort, $y_{i}^{*}$, weakly decreases in $k$ while his productive effort, $x_{i}^{*}$, weakly increases in $k$, where $k=\{1,2, \ldots, n-1\}$.

Now we are ready to designate the result that an increase in $k$ creates more social surplus under the $k$-majority voting rule with transitory effects.

Proposition 41. Suppose that Assumptions 2 and 3 hold. Then under the $k$-majority voting rule with transitory effects, the social cost decreases in $k$ while the social surplus increases in $k$. 


\section{A Appendix A: Proof}

Proposition 1. Under the first-best perfect information, we have $z^{* E}\left(\theta_{H}\right)<z^{*} E\left(\theta_{L}\right)=z^{E}\left(\theta_{L}\right)<$ $z^{E}\left(\theta_{H}\right)$.

Proof: First, when $\theta=\theta_{L}$, home and foreign are symmetric. Thus, it is obvious that $z^{E}\left(\theta_{L}\right)=$ $z^{* E}\left(\theta_{L}\right)$.

Next, to show that $\left.z^{E}\left(\theta_{L}\right)<z^{E}\left(\theta_{H}\right)\right)$ and $z^{* E}\left(\theta_{H}\right)<z^{*} E\left(\theta_{L}\right)$, observe that $z^{E}(\theta)$ and $z^{* E}(\theta)$ must satisfy the following first order conditions for the maximization problem (2):

$$
\begin{gathered}
\vartheta_{1}\left(z\left(\theta_{L}\right), z^{*}\left(\theta_{L}\right), \theta_{L}\right)+\vartheta_{1}^{*}\left(z\left(\theta_{L}\right), z^{*}\left(\theta_{L}\right)\right)=0, \\
\vartheta_{2}\left(z\left(\theta_{L}\right), z^{*}\left(\theta_{L}\right), \theta_{L}\right)+\vartheta_{2}^{*}\left(z\left(\theta_{L}\right), z^{*}\left(\theta_{L}\right)\right)=0, \\
\vartheta_{1}\left(z\left(\theta_{H}\right), z^{*}\left(\theta_{H}\right), \theta_{H}\right)+\vartheta_{1}^{*}\left(z\left(\theta_{H}\right), z^{*}\left(\theta_{H}\right)\right)=0, \\
\vartheta_{2}\left(z\left(\theta_{H}\right), z^{*}\left(\theta_{H}\right), \theta_{H}\right)+\vartheta_{2}^{*}\left(z\left(\theta_{H}\right), z^{*}\left(\theta_{H}\right)\right)=0,
\end{gathered}
$$

where the numbers 1 and 2 in subscript represent the first order partial derivative of the welfare function with respect to its first and second argument, respectively. From Eq.(54) and the welfare function defined in Eq.(1), it indicates that

$$
\vartheta_{1}\left(z^{E}\left(\theta_{L}\right), z^{* E}\left(\theta_{L}\right), \theta_{H}\right)+\vartheta_{1}^{*}\left(z^{E}\left(\theta_{L}\right), z^{* E}\left(\theta_{L}\right)\right)>0
$$

Then, in order for Eq.(56) to hold, we must have $z^{E}\left(\theta_{H}\right)>z^{E}\left(\theta_{L}\right)$.

Besides, Eq.(1) also implies that $\theta$ plays no role in Eq.(55). Therefore, we have

$$
\vartheta_{2}\left(z^{E}\left(\theta_{L}\right), z^{* E}\left(\theta_{L}\right), \theta_{H}\right)+\vartheta_{2}^{*}\left(z^{E}\left(\theta_{L}\right), z^{* E}\left(\theta_{L}\right)\right)=0
$$

Moreover, it has been verified that $z^{E}\left(\theta_{H}\right)>z^{E}\left(\theta_{L}\right)$. Therefore, in order for Eq.(57) to be satisfied, we must have $z^{* E}\left(\theta_{L}\right)>z^{* E}\left(\theta_{H}\right)$. This completes the proof that the best tariffs under perfect information must satisfy: $z^{* E}\left(\theta_{H}\right)<z^{*} E\left(\theta_{L}\right)=z^{E}\left(\theta_{L}\right)<z^{E}\left(\theta_{H}\right)$.

Proposition 2. The best negotiated import tariffs in the low state under the no-delayed equivalent 
retaliation mechanism are politically efficient while the best negotiated import tariff in the high state under the no-delayed equivalent retaliation mechanism is lower than the politically efficient import tariff, i.e.,

$$
z^{N D S}\left(\theta_{L}\right)=z^{E}\left(\theta_{L}\right)=z^{* N D S}=z^{* E}\left(\theta_{L}\right)<z^{N D S}\left(\theta_{H}\right)<z^{E}\left(\theta_{H}\right)
$$

Proof: Problem (3) can be simplified as,

$$
\begin{aligned}
\max _{z^{N D}\left(\theta_{L}\right), z^{N D}\left(\theta_{H}\right), z^{* N D}} & (\lambda+2 \delta \lambda \beta+\delta-\delta \beta-\delta \lambda)\left[\vartheta\left(z^{N D}\left(\theta_{L}\right), z^{* N D}, \theta_{L}\right)+\vartheta^{*}\left(z^{N D}\left(\theta_{L}\right), z^{* N D}\right)\right] \\
& +(1-\lambda-2 \delta \lambda \beta+\delta \beta+\delta \lambda)\left[\vartheta\left(z^{N D}\left(\theta_{H}\right), z^{N D}\left(\theta_{H}\right), \theta_{H}\right)\right. \\
& \left.+\vartheta^{*}\left(z^{N D}\left(\theta_{H}\right), z^{N D}\left(\theta_{H}\right)\right)\right] .
\end{aligned}
$$

Then, the solutions can be written as:

$$
\begin{gathered}
z^{N D S}\left(\theta_{L}\right)=\underset{z^{N D}\left(\theta_{L}\right)}{\operatorname{argmax}} \quad(\lambda+2 \delta \lambda \beta+\delta-\delta \beta-\delta \lambda)\left[\vartheta\left(z^{N D}\left(\theta_{L}\right), z^{* N D}, \theta_{L}\right)+\vartheta^{*}\left(z^{N D}\left(\theta_{L}\right), z^{* N D}\right)\right] ; \\
z^{* N D S}\left(\theta_{L}\right)=\underset{z^{* N D}}{\operatorname{argmax}} \quad(\lambda+2 \delta \lambda \beta+\delta-\delta \beta-\delta \lambda)\left[\vartheta\left(z^{N D}\left(\theta_{L}\right), z^{* N D}, \theta_{L}\right)+\vartheta^{*}\left(z^{N D}\left(\theta_{L}\right), z^{* N D}\right)\right] ; \\
z^{N D S}\left(\theta_{H}\right)=\underset{z^{N D}\left(\theta_{H}\right)}{\operatorname{argmax}} \\
\left.+\vartheta^{* N D}\left(z^{N D}\left(\theta_{H}\right), z^{N D}\left(\theta_{H}\right)\right)\right] .
\end{gathered}
$$

Since $\lambda+2 \delta \lambda \beta+\delta-\delta \beta-\delta \lambda>0$ and $1-\lambda-2 \delta \lambda \beta+\delta \beta+\delta \lambda>0$ are parameters, the above expressions can be reduced to:

$$
\begin{aligned}
& z^{N D S}\left(\theta_{L}\right)=\underset{z^{N D}\left(\theta_{L}\right)}{\operatorname{argmax}} \vartheta\left(z^{N D}\left(\theta_{L}\right), z^{* N D}, \theta_{L}\right)+\vartheta^{*}\left(z^{N D}\left(\theta_{L}\right), z^{* N D}\right) \\
& z^{* N D S}\left(\theta_{L}\right)=\underset{z^{* N D}\left(\theta_{L}\right)}{\operatorname{argmax}} \vartheta\left(z^{N D}\left(\theta_{L}\right), z^{* N D}, \theta_{L}\right)+\vartheta^{*}\left(z^{N D}\left(\theta_{L}\right), z^{* N D}\right) ; \\
& z^{N D S}\left(\theta_{H}\right)=\underset{z^{N D}\left(\theta_{H}\right)}{\operatorname{argmax}} \vartheta\left(z^{N D}\left(\theta_{H}\right), z^{N D}\left(\theta_{H}\right), \theta_{H}\right)+\vartheta^{* N D}\left(z^{N D}\left(\theta_{H}\right), z^{N D}\left(\theta_{H}\right)\right) .
\end{aligned}
$$


Hence, $z^{N D S}(\theta)$ and $z^{* N D S}$ must satisfy:

$$
\begin{gathered}
\vartheta_{1}\left(z^{N D S}\left(\theta_{L}\right), z^{* N D S}, \theta_{L}\right)+\vartheta_{1}^{*}\left(z^{N D S}\left(\theta_{L}\right), z^{* N D S}\right)=0 ; \\
\vartheta_{2}\left(z^{N D S}\left(\theta_{L}\right), z^{* N D S}, \theta_{L}\right)+\vartheta_{2}^{*}\left(z^{N D S}\left(\theta_{L}\right), z^{* N D S}\right)=0 ; \\
\vartheta_{1}\left(z^{N D S}\left(\theta_{H}\right), z^{N D S}\left(\theta_{H}\right), \theta_{H}\right)+\vartheta_{1}^{*}\left(z^{N D S}\left(\theta_{H}\right), z^{N D S}\left(\theta_{H}\right)\right) \\
+\vartheta_{2}\left(z^{N D S}\left(\theta_{H}\right), z^{N D S}\left(\theta_{H}\right), \theta_{H}\right)+\vartheta_{2}^{*}\left(z^{N D S}\left(\theta_{H}\right), z^{N D S}\left(\theta_{H}\right)\right)=0 .
\end{gathered}
$$

Since Eqs.(58) and (59) coincide with the first order conditions for the low state import tariff under perfect information, i.e., Eqs. (54) and (55), it implies that $z^{E}\left(\theta_{L}\right)=z^{N D S}\left(\theta_{L}\right)=z^{* E}\left(\theta_{L}\right)=$ $z^{* N D S}$. Therefore, we have shown that the best tariffs in the low state under the no-delayed retaliation mechanism are politically efficient.

Next, we verify that $z^{N D S}\left(\theta_{L}\right)<z^{N D S}\left(\theta_{H}\right)$. Adding Eqs.(58) and (59) yields:

$$
\begin{aligned}
& \vartheta_{1}\left(z^{N D S}\left(\theta_{L}\right), z^{* N D S}, \theta_{L}\right)+\vartheta_{1}^{*}\left(z^{N D S}\left(\theta_{L}\right), z^{* N D S}\right)+ \\
& \vartheta_{2}\left(z^{N D S}\left(\theta_{L}\right), z^{* N D S}, \theta_{L}\right)+\vartheta_{2}^{*}\left(z^{N D S}\left(\theta_{L}\right), z^{* N D S}\right)=0 .
\end{aligned}
$$

Given the welfare function defined in Eq.(1) and $z^{N D S}\left(\theta_{L}\right)=z^{* N D S}\left(\theta_{L}\right)$, in order for the equation above and Eq.(60) to hold, the best tariffs of home between the two states under the no-delayed retaliation mechanism must satisfy: $z^{N D S}\left(\theta_{L}\right)<z^{N D S}\left(\theta_{H}\right)$.

Finally, to demonstrate that $z^{N D S}\left(\theta_{H}\right)<z^{E}\left(\theta_{H}\right)$, recall the first order conditions for the import tariffs in the high state under perfect information are:

$$
\begin{aligned}
& \vartheta_{1}\left(z^{E}\left(\theta_{H}\right), z^{* E}\left(\theta_{H}\right), \theta_{H}\right)+\vartheta_{1}^{*}\left(z^{E}\left(\theta_{H}\right), z^{* E}\left(\theta_{H}\right)\right)=0 ; \\
& \vartheta_{2}\left(z^{E}\left(\theta_{H}\right), z^{* E}\left(\theta_{H}\right), \theta_{H}\right)+\vartheta_{2}^{*}\left(z^{E}\left(\theta_{H}\right), z^{* E}\left(\theta_{H}\right)\right)=0 .
\end{aligned}
$$

Summing up the two equations above, we have

$$
\begin{aligned}
& \vartheta_{1}\left(z^{E}\left(\theta_{H}\right), z^{* E}\left(\theta_{H}\right), \theta_{H}\right)+\vartheta_{1}^{*}\left(z^{E}\left(\theta_{H}\right), z^{* E}\left(\theta_{H}\right)\right) \\
& +\vartheta_{2}\left(z^{E}\left(\theta_{H}\right), z^{* E}\left(\theta_{H}\right), \theta_{H}\right)+\vartheta_{2}^{*}\left(z^{E}\left(\theta_{H}\right), z^{* E}\left(\theta_{H}\right)\right)=0
\end{aligned}
$$


Besides, from proposition 1, we have $z^{E}\left(\theta_{H}\right)>z^{* E}\left(\theta_{H}\right)$. Together with the welfare function defined in Eq.(1), it can be shown that Eq.(60) holds $i . f . f$

$$
z^{* E}\left(\theta_{H}\right)<z^{D S M}\left(\theta_{H}\right)<z^{E}\left(\theta_{H}\right)
$$

Proposition 3. Under the no-delayed equivalent retaliation mechanism, the incentive compatibility conditions (4) and (5) are slack.

Proof: By simplifying the incentive compatibility conditions (4) and (5), we can get:

$$
\vartheta\left(z^{N D}\left(\theta_{L}\right), z^{* N D}, \theta_{L}\right) \geq \vartheta\left(z^{N D}\left(\theta_{H}\right), z^{N D}\left(\theta_{H}\right), \theta_{L}\right)
$$

and

$$
\vartheta\left(z^{N D}\left(\theta_{H}\right), z^{N D}\left(\theta_{H}\right), \theta_{H}\right) \geq \vartheta\left(z^{N D}\left(\theta_{L}\right), z^{* N D}, \theta_{H}\right)
$$

Since the two countries are symmetric when $\theta=\theta_{L}$, Proposition 2 implies that $z^{N D S}\left(\theta_{L}\right)$ and $z^{* N D S}$ are the maximizers of both the joint payoff, i.e., $\vartheta\left(\tau, \tau^{*}, \theta_{L}\right)+\vartheta^{*}\left(\tau, \tau^{*}\right)$, and the payoff for each country, i.e., $\vartheta\left(\tau, \tau^{*}, \theta_{L}\right)$ and $\vartheta^{*}\left(\tau, \tau^{*}, \theta_{L}\right)$. Therefore, $\vartheta\left(z^{N D}\left(\theta_{L}\right), z^{* N D}, \theta_{L}\right) \geq \vartheta\left(z^{N D}\left(\theta_{H}\right), z^{N D}\left(\theta_{H}\right), \theta_{L}\right)$. Hence, condition (4) is slack.

To prove that condition (5) is not binding, let $\hat{\tau}=\operatorname{argmax} \quad \vartheta\left(\tau, \tau, \theta_{H}\right)$. Note that $\hat{\tau}$ is the maximizer of the home political payoff and $z^{N D S}\left(\theta_{H}\right)$ is the maximizer of the joint political payoff, i.e., $z^{N D S}\left(\theta_{H}\right)=\operatorname{argmax} \vartheta\left(\tau, \tau, \theta_{H}\right)+\vartheta^{*}(\tau, \tau)$. Besides, from the welfare function defined in Eq.(1), we know that $\vartheta_{1}\left(\tau, \tau^{*}, \theta\right)+\vartheta_{1}^{*}\left(\tau, \tau^{*}\right)<0$. Hence, the maximizer of the joint political welfare must be smaller than the maximizer of the home political payoff, i.e., $\hat{\tau}>z^{N D S}\left(\theta_{H}\right)$. Proposition 2 says that $z^{N D S}\left(\theta_{L}\right)=z^{* N D S}<z^{N D S}\left(\theta_{H}\right)$. Since the welfare function is concave, $z^{N D S}\left(\theta_{L}\right)=z^{* N D S}<$ $z^{N D S}\left(\theta_{H}\right)<\hat{\tau}$ indicates that $\vartheta\left(z^{N D S}\left(\theta_{H}\right), z^{N D S}\left(\theta_{H}\right), \theta_{H}\right) \geq \vartheta\left(z^{N D S}\left(\theta_{L}\right), z^{* N D S}, \theta_{H}\right)$. Therefore, condition (5) is slack.

Proposition 4. Under the delayed equivalent retaliation mechanism, the best negotiated import tariff in the low state is politically efficient, i.e., $z^{D S}\left(\theta_{L}\right)=z^{E}\left(\theta_{L}\right)$ and the best negotiated import tariff in the high state is monotonic decreasing in the discount factor, $\delta$, i.e., $\frac{\partial z^{D S}\left(\theta_{H}, \delta\right)}{\partial \delta}<0$. 
Furthermore, there exists a $\delta^{E} \in(0,1)$ such that when $\delta=\delta^{E}$, the best negotiated tariff in the high state under the delayed equivalent retaliation mechanism is politically efficient, i.e., $z^{D S}\left(\theta_{H}, \delta^{E}\right)=$ $z^{E}\left(\theta_{H}\right)$

Proof: First, from the maximization problem (9), we know that $z^{D S}\left(\theta_{L}\right)$ can be written as:

$$
\left.z^{D S}\left(\theta_{L}\right)=\underset{z^{D}\left(\theta_{L}\right)}{\operatorname{argmax}}(\lambda+2 \delta \lambda \beta+\delta-\delta \beta-\delta \lambda) \vartheta\left(z^{D}\left(\theta_{L}\right), z^{* E}\left(\theta_{L}\right), \theta_{L}\right)+\vartheta^{*}\left(z^{D}\left(\theta_{L}\right), z_{a}^{*}\right)\right)
$$

Since $\lambda+2 \delta \lambda \beta+\delta-\delta \beta-\delta \lambda>0$ is constant, we have

$$
\left.z^{D S}\left(\theta_{L}\right)=\underset{z^{D}\left(\theta_{L}\right)}{\operatorname{argmax}} \vartheta\left(z^{D}\left(\theta_{L}\right), z^{* E}\left(\theta_{L}\right), \theta_{L}\right)+\vartheta^{*}\left(z^{D}\left(\theta_{L}\right), z_{a}^{*}\right)\right)
$$

Hence, $z^{D S}\left(\theta_{L}\right)$ shall satisfy:

$$
\left.\vartheta_{1}\left(z^{D}\left(\theta_{L}\right), z^{* E}\left(\theta_{L}\right), \theta_{L}\right)+\vartheta_{1}^{*}\left(z^{D}\left(\theta_{L}\right), z_{a}^{*}\right)\right)=0
$$

Note that the above equation coincides with Eq.(54). Hence, it indicates that $z^{D S}\left(\theta_{L}\right)=z^{E}\left(\theta_{L}\right)$. Now we verify that there exists a $\delta^{E} \in(0,1)$ such that $z^{D S}\left(\theta_{H}, \delta^{E}\right)=z^{E}\left(\theta_{H}\right)$. To prove this, we first show that $z^{D S}\left(\theta_{H}\right)$ is monotonic decreasing in $\delta$. The proof of this monotonic argument is followed by a contradiction. Suppose not. Namely, $\frac{\partial z^{D S}\left(\theta_{H}, \delta\right)}{\partial \delta}>0$, or $\frac{\partial z^{D S}\left(\theta_{H}, \delta\right)}{\partial \delta}=0$. Observe that $z^{D S}\left(\theta_{H}\right)$ solves the first order condition from the maximization problem (9):

$$
\begin{aligned}
& (1-\lambda+\lambda \delta-\lambda \delta \beta)\left[\vartheta_{1}\left(z^{D S}\left(\theta_{H}\right), z^{* E}\left(\theta_{L}\right), \theta_{H}\right)+\vartheta_{1}^{*}\left(z^{D S}\left(\theta_{H}\right), z^{* E}\left(\theta_{L}\right)\right)\right] \\
& +(\delta \beta-\delta \lambda \beta)\left[\vartheta_{1}\left(z^{D S}\left(\theta_{H}\right), z^{D S}\left(\theta_{H}\right), \theta_{H}\right)+\vartheta_{1}^{*}\left(z^{D S}\left(\theta_{H}\right), z^{D S}\left(\theta_{H}\right)\right)\right. \\
& \left.+\vartheta_{2}\left(z^{D S}\left(\theta_{H}\right), z^{D S}\left(\theta_{H}\right), \theta_{H}\right)+\vartheta_{2}^{*}\left(z^{D S}\left(\theta_{H}\right), z^{D S}\left(\theta_{H}\right)\right)\right]=0
\end{aligned}
$$

Define

$$
g\left(z^{D S}\left(\theta_{H}\right)\right)=\vartheta_{1}\left(z^{D S}\left(\theta_{H}\right), z^{* E}\left(\theta_{L}\right), \theta_{H}\right)+\vartheta_{1}^{*}\left(z^{D S}\left(\theta_{H}\right), z^{* E}\left(\theta_{L}\right)\right)
$$


and

$$
\begin{aligned}
f\left(z^{D S}\left(\theta_{H}\right)\right)= & \vartheta_{1}\left(z^{D S}\left(\theta_{H}\right), z^{D S}\left(\theta_{H}\right), \theta_{H}\right)+\vartheta_{1}^{*}\left(z^{D S}\left(\theta_{H}\right), z^{D S}\left(\theta_{H}\right)\right) \\
& +\vartheta_{2}\left(z^{D S}\left(\theta_{H}\right), z^{D S}\left(\theta_{H}\right), \theta_{H}\right)+\vartheta_{2}^{*}\left(z^{D S}\left(\theta_{H}\right), z^{D S}\left(\theta_{H}\right)\right) .
\end{aligned}
$$

Hence, if $\frac{\partial z^{D S}\left(\theta_{H}, \delta\right)}{\partial \delta}>0$, then by the welfare function defined in Eq.(1), we have $g$ and $f$ decrease in $z^{D S}\left(\theta_{H}\right)$. Thus, an increase in $\delta$ will lead to a decrease in $g$ and $f$. Besides, Eq.(1) also implies that $\left|\frac{\partial g}{\partial z^{M_{2} I}\left(\theta_{H}\right)}\right|<\left|\frac{\partial f}{\partial z^{M_{2} I}\left(\theta_{H}\right)}\right|$. Therefore, there does not exist any $z^{D S}\left(\theta_{H}\right)$ that satisfies Eq. (62). If $\frac{\partial z^{D S}\left(\theta_{H}, \delta\right)}{\partial \delta}=0$, it is obvious that Eq. (62) does not hold. Hence, when $\delta$ increases, in order for Eq. (62) to be satisfied, $z^{D S}\left(\theta_{H}\right)$ must decrease. That is, $\frac{\partial z^{D S}\left(\theta_{H}, \delta\right)}{\partial \delta}<0$.

Next, since $z^{* E}\left(\theta_{L}\right)<z^{* E}\left(\theta_{H}\right)$ (from Proposition 1), together with Eqs.(61) and (62), it implies that $z^{D S}\left(\theta_{H}, 0\right)>z^{E}\left(\theta_{H}\right)$. On the other hand, when $\delta=1$, if $z^{D S}\left(\theta_{H}, 1\right) \geq z^{E}\left(\theta_{H}\right)$, then we have $g\left(z^{D S}\left(\theta_{H}\right)\right)>0$ and $f\left(z^{D S}\left(\theta_{H}\right)\right)>0$, implying that Eq.(62) doesn't hold. Therefore, $z^{D S}\left(\theta_{H}, 1\right) \geq$ $z^{E}\left(\theta_{H}\right)$ cannot be the case. Or, $z^{D S}\left(\theta_{H}, 1\right)<z^{E}\left(\theta_{H}\right)$.

Hence, $z^{D S}\left(\theta_{H}, \delta\right)$ is monotonic decreasing in $\delta$ and at the two extreme points of $\delta$, we have $z^{D S}\left(\theta_{H}, 0\right)>z^{E}\left(\theta_{H}\right)$ and $z^{D S}\left(\theta_{H}, 1\right)<z^{E}\left(\theta_{H}\right)$. Armed with these observations, we can show that for any given $\lambda \in(0,1)$ and $\beta \in(0,1)$, there exists a $\delta^{E}$ such that $z^{D S}\left(\theta_{H}, \delta^{E}\right)=z^{E}\left(\theta_{H}\right)$.

Proposition 5. The best negotiated import tariff in the low state under the no-delayed and delayed equivalent retaliation mechanisms are equal, i.e., $z^{N D S}\left(\theta_{L}\right)=z^{D S}\left(\theta_{L}\right)$, while the best negotiated import tariff in the high state under the no-delayed equivalent retaliation mechanism is lower than under the delayed equivalent retaliation mechanism, i.e., $z^{N D S}\left(\theta_{H}\right)<z^{D S}\left(\theta_{H}\right)$.

Proof: From Proposition 2, we have $z^{N D S}\left(\theta_{L}\right)=z^{E}\left(\theta_{L}\right)$ and from Proposition 4, we have $z^{D S}\left(\theta_{L}\right)=z^{E}\left(\theta_{L}\right)$. Hence, it is obvious that $z^{N D S}\left(\theta_{L}\right)=z^{D S}\left(\theta_{L}\right)$.

To prove that $z^{N D S}\left(\theta_{H}\right)<z^{D S}\left(\theta_{H}\right)$, from the previous proof, we know that $z^{N D S}\left(\theta_{H}\right)$ and $z^{D S}\left(\theta_{H}\right)$ require:

$$
\begin{aligned}
& \vartheta_{1}\left(z^{N D S}\left(\theta_{H}\right), z^{N D S}\left(\theta_{H}\right), \theta_{H}\right)+\vartheta_{1}^{*}\left(z^{N D S}\left(\theta_{H}\right), z^{N D S}\left(\theta_{H}\right)\right) \\
& +\vartheta_{2}\left(z^{N D S}\left(\theta_{H}\right), z^{N D S}\left(\theta_{H}\right), \theta_{H}\right)+\vartheta_{2}^{*}\left(z^{N D S}\left(\theta_{H}\right), z^{N D S}\left(\theta_{H}\right)\right)=0
\end{aligned}
$$


and

$$
\begin{aligned}
& (1-\lambda+\lambda \delta-\lambda \delta \beta)\left[\vartheta_{1}\left(z^{D S}\left(\theta_{H}\right), z^{* E}\left(\theta_{L}\right), \theta_{H}\right)+\vartheta_{1}^{*}\left(z^{D S}\left(\theta_{H}\right), z^{* E}\left(\theta_{L}\right)\right)\right] \\
& +(\delta \beta-\delta \lambda \beta)\left[\vartheta_{1}\left(z^{D S}\left(\theta_{H}\right), z^{D S}\left(\theta_{H}\right), \theta_{H}\right)+\vartheta_{1}^{*}\left(z^{D S}\left(\theta_{H}\right), z^{D S}\left(\theta_{H}\right)\right)\right. \\
& \left.+\vartheta_{2}\left(z^{D S}\left(\theta_{H}\right), z^{D S}\left(\theta_{H}\right), \theta_{H}\right)+\vartheta_{2}^{*}\left(z^{D S}\left(\theta_{H}\right), z^{D S}\left(\theta_{H}\right)\right)\right]=0
\end{aligned}
$$

respectively. By Assumption 1, we know that

$$
\vartheta_{1}\left(z^{D S}\left(\theta_{H}\right), z^{* E}\left(\theta_{L}\right), \theta_{H}\right)+\vartheta_{1}^{*}\left(z^{D S}\left(\theta_{H}\right), z^{* E}\left(\theta_{L}\right)\right)<0 .
$$

Hence,

$$
\begin{aligned}
& \vartheta_{1}\left(z^{D S}\left(\theta_{H}\right), z^{D S}\left(\theta_{H}\right), \theta_{H}\right)+\vartheta_{1}^{*}\left(z^{D S}\left(\theta_{H}\right), z^{D S}\left(\theta_{H}\right)\right) \\
& +\vartheta_{2}\left(z^{D S}\left(\theta_{H}\right), z^{D S}\left(\theta_{H}\right), \theta_{H}\right)+\vartheta_{2}^{*}\left(z^{D S}\left(\theta_{H}\right), z^{D S}\left(\theta_{H}\right)\right)>0 .
\end{aligned}
$$

Given that the welfare function is defined in Eq.(1), Eq.(63) and the above equation imply that $z^{N D S}\left(\theta_{H}\right)<z^{D S}\left(\theta_{H}\right)$.

Proposition 6. Under the delayed equivalent retaliation mechanism, there exists a $\hat{\delta} \in(0,1)$ and $\hat{\beta} \in(0,1)$ such that if $\delta \beta \in[\hat{\delta} \hat{\beta}, 1]$, the incentive compatibility conditions (7) and (8) are slack.

Proof: Simplify the incentive compatibility constraints (7) and (8):

$$
\begin{aligned}
& \vartheta\left(z^{D}\left(\theta_{L}\right), z^{* E}\left(\theta_{L}\right), \theta_{L}\right)+\delta \beta \vartheta\left(z^{D}\left(\theta_{L}\right), z^{* E}\left(\theta_{L}\right), \theta_{L}\right) \\
& \geq \vartheta\left(z^{D}\left(\theta_{H}\right), z^{* E}\left(\theta_{L}\right), \theta_{L}\right)+\delta \beta \vartheta\left(z^{D}\left(\theta_{H}\right), z^{D}\left(\theta_{H}\right), \theta_{L}\right)
\end{aligned}
$$

and

$$
\vartheta\left(z^{D}\left(\theta_{H}\right), z^{* E}\left(\theta_{L}\right), \theta_{H}\right)+\delta \beta \vartheta\left(z^{D}\left(\theta_{H}\right), z^{D}\left(\theta_{H}\right), \theta_{H}\right) \geq(1+\delta \beta) \vartheta\left(z^{D}\left(\theta_{L}\right), z^{* E}\left(\theta_{L}\right), \theta_{H}\right) .
$$

Let $\delta \beta=A \in[0,1]$. Then, we have

$$
\begin{aligned}
& \vartheta\left(z^{D}\left(\theta_{L}\right), z^{* E}\left(\theta_{L}\right), \theta_{L}\right)+A \vartheta\left(z^{D}\left(\theta_{L}\right), z^{* E}\left(\theta_{L}\right), \theta_{L}\right) \\
& \geq \vartheta\left(z^{D}\left(\theta_{H}\right), z^{* E}\left(\theta_{L}\right), \theta_{L}\right)+A \vartheta\left(z^{D}\left(\theta_{H}\right), z^{D}\left(\theta_{H}\right), \theta_{L}\right)
\end{aligned}
$$


and

$$
\vartheta\left(z^{D}\left(\theta_{H}\right), z^{* E}\left(\theta_{L}\right), \theta_{H}\right)+A \vartheta\left(z^{D}\left(\theta_{H}\right), z^{D}\left(\theta_{H}\right), \theta_{H}\right) \geq(1+A) \vartheta\left(z^{D}\left(\theta_{L}\right), z^{* E}\left(\theta_{L}\right), \theta_{H}\right) .
$$

Let

$$
G(A)=(1+A) \vartheta\left(z^{D}\left(\theta_{L}\right), z^{* E}\left(\theta_{L}\right), \theta_{L}\right)-\vartheta\left(z^{D}\left(\theta_{H}\right), z^{* E}\left(\theta_{L}\right), \theta_{L}\right)-A\left(z^{D}\left(\theta_{H}\right), z^{D}\left(\theta_{H}\right), \theta_{L}\right) .
$$

Since $z^{D S}\left(\theta_{L}\right)=z^{E}\left(\theta_{L}\right), \partial z^{D S}\left(\theta_{H}\right) / \partial \delta<0, \partial z^{D S}\left(\theta_{H}\right) / \partial \beta<0$ and

$$
\begin{aligned}
& \left|\frac{d\left[\vartheta\left(z^{D S}\left(\theta_{L}\right), z^{* E}\left(\theta_{L}\right), \theta_{L}\right)-\vartheta\left(z^{D S}\left(\theta_{H}\right), z^{* E}\left(\theta_{L}\right), \theta_{L}\right)\right]}{d z^{D S}\left(\theta_{H}\right)}\right| \\
& >\delta\left|\frac{d\left[\vartheta\left(z^{D S}\left(\theta_{L}\right), z^{* E}\left(\theta_{L}\right), \theta_{L}\right)-\vartheta\left(z^{D S}\left(\theta_{H}\right), z^{D S}\left(\theta_{H}\right), \theta_{L}\right)\right]}{d z^{D S}\left(\theta_{H}\right)}\right|,
\end{aligned}
$$

we have $\frac{d G}{d A}>0$. Observe that $G(0)<0$ and $G(1)>0$. Hence, there exists a cutoff point $\hat{A} \in[0,1]$ such that if $A \in[\hat{A}, 1]$, the incentive compatibility condition (7) is slack. Equivalently, there exist some parameters $\delta^{\prime} \in[0,1]$ and $\beta^{\prime} \in[0,1]$ such that if $\delta \beta \in\left[\delta^{\prime} \beta^{\prime}, 1\right]$, condition (7) is slack.

To show that condition (7) is not binding, let

$$
H(A)=\vartheta\left(z^{D}\left(\theta_{H}\right), z^{* E}\left(\theta_{L}\right), \theta_{H}\right)+A\left(z^{D}\left(\theta_{H}\right), z^{D}\left(\theta_{H}\right), \theta_{H}\right)-(1+A) \vartheta\left(z^{D}\left(\theta_{L}\right), z^{* E}\left(\theta_{L}\right), \theta_{H}\right) .
$$

Since $z^{D S}\left(\theta_{L}\right)=z^{E}\left(\theta_{L}\right), \partial z^{D S}\left(\theta_{H}\right) / \partial \delta<0, \partial z^{D S}\left(\theta_{H}\right) / \partial \beta<0$ and

$$
\begin{aligned}
& \left|\frac{d\left[\vartheta\left(z^{D S}\left(\theta_{H}\right), z^{* E}\left(\theta_{L}\right), \theta_{H}\right)-\vartheta\left(z^{D S}\left(\theta_{L}\right), z^{* E}\left(\theta_{L}\right), \theta_{H}\right)\right]}{d z^{D S}\left(\theta_{H}\right)}\right| \\
& >\delta\left|\frac{d\left[\vartheta\left(z^{D S}\left(\theta_{H}\right), z^{D S}\left(\theta_{H}\right), \theta_{H}\right)-\vartheta\left(z^{D S}\left(\theta_{L}\right), z^{* E}\left(\theta_{L}\right), \theta_{H}\right)\right]}{d z^{D S}\left(\theta_{H}\right)}\right|,
\end{aligned}
$$

we have $\frac{d H}{d A}<0$. Besides, $z^{D S}\left(\theta_{H}\right)>z^{N D S}\left(\theta_{H}\right)$ (by Proposition 5) and $z^{N D S}\left(\theta_{H}\right)>z^{N D S}\left(\theta_{L}\right)$ (by Proposition 2) indicate that $z^{D S}\left(\theta_{H}\right)>z^{* E}\left(\theta_{L}\right)=z^{E}\left(\theta_{L}\right)$. Hence, $H(1)>0$. Therefore, condition (8) is not binding.

Overall, when $\delta \beta \in\left[\delta^{\prime} \beta^{\prime}, 1\right]$, then the incentive compatibility conditions (7) and (8) are both slack. 
Proposition 7. Suppose that the incentive compatibility conditions under the delayed equivalent retaliation mechanism are slack, i.e., $\delta \beta \in[\hat{\delta} \hat{\beta}, 1]$. Then for any given $\lambda \in(0,1)$ and $\beta \in(0,1)$, if $\delta \in\left[\delta^{E}, 1\right)$, the delayed equivalent retaliation mechanism generates higher joint political payoff than does the no-delayed equivalent retaliation mechanism.

Proof: Proposition 4 says that when $\delta \in\left[\delta^{E}, 1\right]$, then $z^{D S}\left(\theta_{H}\right) \leq z^{E}\left(\theta_{H}\right)$. Proposition 2 shows that $z^{N D S}\left(\theta_{H}\right)<z^{E}\left(\theta_{H}\right)$. Proposition 5 verifies that $z^{N D S}\left(\theta_{H}\right)<z^{D S}\left(\theta_{H}\right)$. Hence, it is obvious that when $\delta \in\left[\delta^{E}, 1\right)$, we have $z^{E}\left(\theta_{H}\right)-z^{N D S}\left(\theta_{H}\right)<z^{E}\left(\theta_{H}\right)-z^{D S}\left(\theta_{H}\right)$. Besides, $z^{N D S}\left(\theta_{H}\right)>z^{* E}\left(\theta_{H}\right)$ (by Proposition 2). Therefore, $z^{* E}\left(\theta_{H}\right)<z^{N D S}\left(\theta_{H}\right)<z^{D S}\left(\theta_{H}\right)<z^{E}\left(\theta_{H}\right)$. Given that $\theta_{H}>\theta_{L}=1$ and the concavity assumption of the utility function (Assumption 1), the inefficiency created from increasing the import tariff from $z^{N D S}\left(\theta_{H}\right)$ to $z^{D S}\left(\theta_{H}\right)$ can never exceed its benefit. Hence, the delayed retaliation mechanism generates higher joint political payoff for any $\delta \in\left[\delta^{E}, 1\right]$.

Proposition 8. Suppose that the incentive compatibility conditions under the delayed equivalent retaliation mechanism are slack, i.e., $\delta \beta \in[\hat{\delta} \hat{\beta}, 1]$. Then for any given $\lambda \in(0,1)$ and $\beta \in(0,1)$, if $\delta \in\left[\delta^{E}, 1\right)$, the delayed equivalent retaliation mechanism supports a higher self-enforcing level of cooperation than does the no-delayed equivalent retaliation mechanism.

Proof: To prove that the delayed retaliation mechanism supports more cooperation, it is equivalent to show that in comparison to the no-delayed retaliation mechanism, the voluntary participation conditions under the delayed retaliation mechanism are less likely to bind.

From Proposition 5, we know that if $\delta \in\left[\delta^{E}, 1\right]$, then we have $z^{N D S}\left(\theta_{H}\right)<z^{D S}\left(\theta_{H}\right)$ and $z^{N D S}\left(\theta_{L}\right)=$ $z^{N D}\left(\theta_{L}\right)$. Thus, the current benefit of deviating from the delayed same-sector retaliation mechanism is smaller than from the no-delayed same-sector one. Furthermore, $z^{N D S}\left(\theta_{H}\right)<z^{D S}\left(\theta_{H}\right)$ also implies that the future value of sticking to the agreements in a high state under the delayed one is greater. Namely,

$$
X^{N D S}\left(z^{N D S}\left(\theta_{H}\right), z^{N D S}\left(\theta_{L}\right), z^{* N D S}(\theta), \theta_{H}\right)<X^{D S}\left(z^{D S}\left(\theta_{H}\right), z^{D S}\left(\theta_{L}\right), \theta_{H}\right) .
$$

Besides, the payoff stream of a static Nash reversion strategies under the retaliation without delayed mechanism is equal to the one under retaliation with delay mechanism. Therefore, the future cost of deviating from the delayed retaliation mechanism is greater. Hence, the voluntary participation 
conditions under the delayed one is looser and, consequently, when the punishment has been delayed for one period, it enhances more cooperation between the two governments.

Lemma 1. Suppose that the goods within the sectors are strategic substitutes, i.e., $b_{1} \in(0,1)$ or $b_{2} \in(0,1)$, then the optimal import tariffs within the sectors are strategic substitutes.

Proof: The proof of Lemma 1 is based on the following two lemmas which characterize some useful properties for the per-period utility and the per-period price functions. Since now our analysis is confined to a one-period game, we drop the subscript letter $t$.

Lemma 6. For any given $\tau_{a} \in[0,+\infty)$, we have

$$
\begin{gathered}
p_{y_{a}}=\frac{1}{2} \frac{-2 b_{1} c \tau_{a}+4 A c+2 c \tau_{a}+f+\tau_{a}}{1-2 b_{1} c+2 c} \\
q_{y_{a}}^{s}=\frac{1}{4 c}\left(\tau_{a}+\frac{4 A c+f}{1+2 c-2 b_{1} c}\right)-\frac{f}{2 c} .
\end{gathered}
$$

Proof: The trade is balanced in equilibrium. Therefore, we have

$$
q_{y_{a}}^{s}-q_{y_{a}}^{d}=q_{y_{a}}^{* d}-q_{y_{a}}^{* s} ; \quad q_{x_{a}}^{* s}-q_{x_{a}}^{* d}=q_{x_{a}}^{d}-q_{x_{a}}^{s}
$$

Besides, for any given $\tau_{a}, \tau_{a}^{*} \in[0 .+\infty)$, the domestic and foreign prices have the following relationship:

$$
p_{x_{a}}^{*}=p_{x_{a}}+\tau_{a}^{*} ; \quad p_{y_{i}}=p_{y_{a}}^{*}+\tau_{a} .
$$

Then, together with the demand functions defined in Eq.(21) and supply functions defined in Eq.(23), we can show that

$$
p_{y_{a}}=\frac{1}{2} \frac{-2 b_{1} c \tau_{a}+4 A c+2 c \tau_{a}+f+\tau_{a}}{1-2 b_{1} c+2 c} .
$$

Substituting the above equation into Eq.(23), we have

$$
q_{y_{a}}^{s}=\frac{1}{4 c}\left(\tau_{a}+\frac{4 A c+f}{1+2 c-2 b_{1} c}\right)-\frac{f}{2 c} .
$$

This completes the proof of Lemma 6 . 
Lemma 7. Given that the utility function is defined in Eq.(20) and the cost function is defined in Eq.(22), we have

$$
\begin{aligned}
& \frac{\partial \vartheta_{a}\left(\tau_{a}, \tau_{a}^{*}, \theta\right)}{\partial \tau_{a}}=\frac{1}{2}\left[\theta q_{y_{a}}^{s}\left(p_{y_{a}}\right)-q_{y_{a}}^{d}\left(p_{y_{a}}, p_{x_{a}}\right)\right]+M_{a}-\tau_{a} ; \\
& \frac{\partial \vartheta_{a}\left(\tau_{a}, \tau_{a}^{*}, \theta\right)}{\partial \tau_{a}^{*}}=-\frac{1}{2} M_{a}^{*}-\frac{1}{2} b_{1} \tau_{a} ; \quad \frac{\partial \vartheta_{i}^{*}\left(\tau_{i}^{*}, \tau_{i}\right)}{\partial \tau_{i}^{*}}=\frac{1}{2} M_{i}^{*}-\tau_{i}^{*} ; \quad \frac{\partial \vartheta_{i}^{*}\left(\tau_{i}^{*}, \tau_{i}\right)}{\partial \tau_{i}}=-\frac{1}{2} M_{i}^{*}-\frac{1}{2} b_{i} \tau_{i}^{*} ; \\
& \frac{\partial \vartheta_{b}\left(\tau_{b}, \tau_{b}^{*}\right)}{\partial \tau_{b}}=\frac{1}{2} M_{b}-\tau_{b} ; \quad \frac{\partial \vartheta_{b}\left(\tau_{b}, \tau_{b}^{*}\right)}{\partial \tau_{b}^{*}}=-\frac{1}{2} M_{b}^{*}-\frac{1}{2} b_{2} \tau_{b} ; \\
& \frac{\partial \vartheta_{a}\left(\tau_{a}, \tau_{a}^{*}, \theta\right)}{\partial \tau_{a}}+\frac{\partial \vartheta_{a}^{*}\left(\tau_{a}^{*}, \tau_{a}\right)}{\partial \tau_{a}}=\frac{1}{2}(\theta-1) \frac{p_{y_{a}}-F}{2 c}-\tau_{a}-\frac{1}{2} b_{1} \tau_{a}^{*} ; \\
& \frac{\partial \vartheta_{a}\left(\tau_{a}, \tau_{a}^{*}, \theta\right)}{\partial \tau_{a}^{*}}+\frac{\partial \vartheta_{a}^{*}\left(\tau_{a}^{*}, \tau_{a}\right)}{\partial \tau_{a}^{*}}=-\frac{1}{2} b_{1} \tau_{a}-\tau_{a}^{*} ; \\
& \frac{\partial \vartheta_{b}\left(\tau_{b}, \tau_{b}^{*}\right)}{\partial \tau_{b}}+\frac{\partial \vartheta_{b}^{*}\left(\tau_{b}^{*}, \tau_{b}\right)}{\partial \tau_{b}}=-\tau_{b}-\frac{1}{2} b_{2} \tau_{b}^{*} ; \quad \frac{\partial \vartheta_{b}\left(\tau_{b}, \tau_{b}^{*}\right)}{\partial \tau_{b}^{*}}+\frac{\partial \vartheta_{b}^{*}\left(\tau_{b}^{*}, \tau_{b}\right)}{\partial \tau_{b}^{*}}=-\tau_{b}^{*}-\frac{1}{2} b_{2} \tau_{b}
\end{aligned}
$$

where $M_{a} \equiv q_{y_{a}}^{d}\left(p_{y_{a}}, p_{x_{a}}\right)-q_{y_{a}}^{s}\left(p_{y_{a}}\right)$ and $M_{i}^{*} \equiv q_{x_{i}}^{d^{*}}\left(p_{x_{i}}^{*}, p_{y_{i}}^{*}\right)-q_{x_{i}}^{s^{*}}\left(p_{x_{i}}^{*}\right)$.

Proof: To prove that

$$
\frac{\partial \vartheta_{a}\left(\tau_{a}, \tau_{a}^{*}, \theta\right)}{\partial \tau_{a}}=\frac{1}{2}\left[\theta q_{y_{a}}^{s}\left(p_{y_{a}}\right)-q_{y_{a}}^{d}\left(p_{y_{a}}, p_{x_{a}}\right)\right]+M_{a}-\tau_{a}
$$

and

$$
\frac{\partial \vartheta_{a}\left(\tau_{a}, \tau_{a}^{*}, \theta\right)}{\partial \tau_{a}^{*}}=-\frac{1}{2} M_{a}^{*}-\frac{1}{2} b_{1} \tau_{a}
$$

we first take the first order condition of $\vartheta_{a}$ and $\vartheta_{a}^{*}$ with respect to $\tau_{a}$ and $\tau_{a}^{*}$, respectively:

$$
\begin{aligned}
& \frac{\partial \vartheta_{a}\left(\tau_{a}, \tau_{a}^{*}, \theta\right)}{\partial \tau_{a}}=\frac{\partial p_{y_{a}}}{\partial \tau_{a}}\left[q_{x_{a 2}}^{d}\left(u_{1}-p_{x_{a}}\right)+q_{y_{a 1}}^{d}\left(u_{2}-p_{y_{a}}\right)+\theta q_{y_{a 1}}^{s}\left(p_{y_{a}}-c_{y_{a}}^{\prime}\right)\right] \\
& +\theta \frac{\partial p_{y_{a}}}{\partial \tau_{a}} q_{y_{a}}^{s}\left(p_{y_{a}}\right)-\frac{\partial p_{y_{a}}}{\partial \tau_{a}} q_{y_{a}}^{d}\left(p_{y_{a}}, p_{x_{a}}\right)+\tau_{a} \frac{\partial M_{a}}{\partial \tau_{a}}+M_{a} ; \\
& \frac{\partial \vartheta_{a}^{*}\left(\tau_{a}, \tau_{a}^{*}, \theta\right)}{\partial \tau_{a}}=\frac{\partial p_{y_{a}}^{*}}{\partial \tau_{a}}\left[q_{x_{a 2}}^{d^{*}}\left(u_{1}^{*}-p_{x_{a}}^{*}\right)+q_{y_{a 1}}^{d^{*}}\left(u_{2}^{*}-p_{y_{a}}^{*}\right)+q_{y_{a 1}}^{s^{*}}\left(p_{y_{a}}^{*}-c_{y_{a}}^{* \prime}\right)\right] \\
& \frac{\partial p_{y_{a}}^{*}}{\partial \tau_{a}}\left[q_{y_{a}}^{s^{*}}\left(p_{y_{a}}\right)-q_{y_{a}}^{d^{*}}\left(p_{y_{a}}^{*}, p_{x_{a}}^{*}\right)\right]+\tau_{a}^{*} \frac{\partial q_{y_{a}}^{d^{*}}\left(p_{y_{a}}^{*}, p_{x_{a}}^{*}\right)}{\partial p_{y_{a}}^{*}} \frac{\partial p_{y_{a}}^{*}}{\partial \tau_{a}} .
\end{aligned}
$$

Then, by the first order conditions from the producer and consumer maximization problem and 
the Envelope Theorem, we have

$$
q_{x_{a 2}}^{d}\left(u_{1}-p_{x_{a}}\right)+q_{y_{a 1}}^{d}\left(u_{2}-p_{y_{a}}\right)+\theta q_{y_{a 1}}^{s}\left(p_{y_{a}}-c_{y_{a}}^{\prime}\right)=0 .
$$

and

$$
q_{x_{a 2}}^{d^{*}}\left(u_{1}^{*}-p_{x_{a}}^{*}\right)+q_{y_{a 1}}^{d^{*}}\left(u_{2}^{*}-p_{y_{a}}^{*}\right)+q_{y_{a 1}}^{s^{*}}\left(p_{y_{a}}^{*}-c_{y_{a}}^{* \prime}\right)=0 .
$$

Hence, Eqs.(65) and (66) can be simplified as:

$$
\frac{\partial \vartheta_{a}\left(\tau_{a}, \tau_{a}^{*}, \theta\right)}{\partial \tau_{a}}=\theta \frac{\partial p_{y_{a}}}{\partial \tau_{a}} q_{y_{a}}^{s}\left(p_{y_{a}}\right)-\frac{\partial p_{y_{a}}}{\partial \tau_{a}} q_{y_{a}}^{d}\left(p_{y_{a}}, p_{x_{a}}\right)+\tau_{a} \frac{\partial M_{a}}{\partial \tau_{a}}+M_{a}
$$

and

$$
\frac{\partial \vartheta_{a}^{*}\left(\tau_{a}^{*}, \tau_{a}\right)}{\partial \tau_{a}}=\frac{\partial p_{y_{a}}^{*}}{\partial \tau_{a}}\left[q_{y_{a}}^{s^{*}}\left(p_{y_{a}}\right)-q_{y_{a}}^{d^{*}}\left(p_{y_{a}}^{*}, p_{x_{a}}^{*}\right)\right]+\tau_{a}^{*} \frac{\partial q_{y_{a}}^{d^{*}}\left(p_{y_{a}}^{*}, p_{x_{a}}^{*}\right)}{\partial p_{y_{a}}^{*}} \frac{\partial p_{y_{a}}^{*}}{\partial \tau_{a}}
$$

respectively.

Besides, since trade is balanced in equilibrium, i.e., $q_{y_{a}}^{d}-q_{y_{a}}^{s}=q_{y_{a}}^{s^{*}}-q_{y_{a}}^{d^{*}}, q_{x_{a}}^{d^{*}}-q_{x_{a}}^{s^{*}}=q_{x_{a}}^{s}-q_{x_{a}}^{d}$, and the tariffs create a wedge between domestic and foreign equilibrium prices, i.e., $p_{x_{i}}^{*}=p_{x_{i}}+\tau_{i}^{*}$, $p_{y_{i}}=p_{y_{i}}^{*}+\tau_{i}$, together with the demand functions defined in Eq.(21) and the supply functions defined in Eq.(23), we can show that:

$$
\begin{aligned}
& \frac{\partial p_{x_{a}}}{\partial \tau_{a}}=\frac{\partial p_{y_{a}}}{\partial \tau_{a}^{*}}=1 / 2 ; \quad \frac{\partial p_{x_{a}}}{\partial \tau_{a}^{*}}=\frac{\partial p_{y_{a}}^{*}}{\partial \tau_{a}}=-1 / 2 \\
& \frac{\partial q_{y_{a}}^{d}\left(p_{y_{a}}, p_{x_{a}}\right)}{\partial p_{x_{a}}}=\frac{\partial q_{y_{a}}^{d^{*}}\left(p_{y_{a}}^{*}, p_{x_{a}}^{*}\right)}{\partial p_{y_{a}}^{*}}=b_{1} ; \quad \frac{\partial M_{a}}{\partial \tau_{a}}=\frac{\partial M_{a}^{*}}{\partial \tau_{a}^{*}}=-1 .
\end{aligned}
$$

Substituting the above equations into Eqs.(67) and (68) yields:

$$
\frac{\partial \vartheta_{a}\left(\tau_{a}, \tau_{a}^{*}, \theta\right)}{\partial \tau_{a}}=\frac{1}{2}\left[\theta q_{y_{a}}^{s}\left(p_{y_{a}}\right)-q_{y_{a}}^{d}\left(p_{y_{a}}, p_{x_{a}}\right)\right]+M_{a}-\tau_{a}
$$

and

$$
\frac{\partial \vartheta_{a}^{*}\left(\tau_{a}^{*}, \tau_{a}\right)}{\partial \tau_{a}}=-\frac{1}{2} M_{a}-\frac{1}{2} b_{1} \tau_{a}^{*}
$$


Adding the above two equations, together with the supply function $q_{y_{a}}^{s}=\frac{p_{y_{a}}-f}{2 c}$, we have

$$
\frac{\partial \vartheta_{a}\left(\tau_{a}, \tau_{a}^{*}, \theta\right)}{\partial \tau_{a}}+\frac{\partial \vartheta_{a}^{*}\left(\tau_{a}^{*}, \tau_{a}\right)}{\partial \tau_{a}}=\frac{1}{2}(\theta-1) \frac{p_{y_{a}}-f}{2 c}-\tau_{a}-\frac{1}{2} b_{1} \tau_{a}^{*}
$$

By following a similar argument, we can verify that:

$$
\begin{aligned}
& \frac{\partial \vartheta_{a}\left(\tau_{a}, \tau_{a}^{*}, \theta\right)}{\partial \tau_{a}^{*}}=-\frac{1}{2} M_{a}^{*}-\frac{1}{2} b_{1} \tau_{a} ; \quad \frac{\partial \vartheta_{i}^{*}\left(\tau_{i}^{*}, \tau_{i}\right)}{\partial \tau_{i}^{*}}=\frac{1}{2} M_{i}^{*}-\tau_{i}^{*} ; \\
& \frac{\partial \vartheta_{i}^{*}\left(\tau_{i}^{*}, \tau_{i}\right)}{\partial \tau_{i}}=-\frac{1}{2} M_{i}^{*}-\frac{1}{2} b_{i} \tau_{i}^{*} ; \quad \frac{\partial \vartheta_{b}\left(\tau_{b}, \tau_{b}^{*}\right)}{\partial \tau_{b}}=\frac{1}{2} M_{b}-\tau_{b} ; \quad \frac{\partial \vartheta_{b}\left(\tau_{b}, \tau_{b}^{*}\right)}{\partial \tau_{b}^{*}}=-\frac{1}{2} M_{b}^{*}-\frac{1}{2} b_{2} \tau_{b} ; \\
& \frac{\partial \vartheta_{a}\left(\tau_{a}, \tau_{a}^{*}, \theta\right)}{\partial \tau_{a}^{*}}+\frac{\partial \vartheta_{a}^{*}\left(\tau_{a}^{*}, \tau_{a}\right)}{\partial \tau_{a}^{*}}=-\frac{1}{2} b_{1} \tau_{a}-\tau_{a}^{*} ; \\
& \frac{\partial \vartheta_{b}\left(\tau_{b}, \tau_{b}^{*}\right)}{\partial \tau_{b}}+\frac{\partial \vartheta_{b}^{*}\left(\tau_{b}^{*}, \tau_{b}\right)}{\partial \tau_{b}}=-\tau_{b}-\frac{1}{2} b_{2} \tau_{b}^{*} ; \quad \frac{\partial \vartheta_{b}\left(\tau_{b}, \tau_{b}^{*}\right)}{\partial \tau_{b}^{*}}+\frac{\partial \vartheta_{b}^{*}\left(\tau_{b}^{*}, \tau_{b}\right)}{\partial \tau_{b}^{*}}=-\tau_{b}^{*}-\frac{1}{2} b_{2} \tau_{b} .
\end{aligned}
$$

This completes the proof of Lemma 7.

Now we are ready to prove Lemma 1. From Eq.(69), we know that $\frac{\partial p_{x_{a}}}{\partial \tau_{a}^{*}}=-1 / 2$ and $\frac{\partial q_{y_{a}}^{d}\left(p_{y_{a}}, p_{x_{a}}\right)}{\partial p_{x_{a}}}=$ $b_{1}$. Hence, $b_{1} \in(0,1)$ implies that there is a negative correlation between $\tau_{a}^{*}$ and $q_{y_{a}}^{d}$. On the other hand, Lemma 6 says that

$$
q_{y_{a}}^{s}=\frac{1}{4 c}\left(\tau_{a}+\frac{4 A c+f}{1+2 c-2 b_{1} c}\right)-\frac{f}{2 c} .
$$

Therefore, $q_{y_{a}}^{s}$ is independent of $\tau_{a}^{*}$. Furthermore, Eq.(64) reveals that the optimal tariff, $\tau_{a}$, requires:

$$
\frac{1}{2}\left[\theta q_{y_{a}}^{s}\left(p_{y_{a}}\right)-q_{y_{a}}^{d}\left(p_{y_{a}}, p_{x_{a}}\right)\right]+q_{y_{a}}^{d}\left(p_{y_{a}}, p_{x_{a}}\right)-q_{y_{a}}^{s}\left(p_{y_{a}}\right)=\tau_{a} .
$$

Then, based on the previous proof that when there is an increase in $\tau_{a}^{*}$, it lowers the demand at home, i.e., $q_{y_{a}}^{s}$ while the supply at home remains the same, i.e., $q_{y_{a}}^{s}\left(p_{y_{a}}\right)$, the above equation demonstrates that $\tau_{a}^{*}$ and $\tau_{a}$ must be negatively correlated.

By following similar steps, we can show that if $b_{2} \in(0,1)$, then there is a negative correlation between $\tau_{b}$ and $\tau_{b}^{*}$. This completes the proof of Lemma 1 .

Proposition 9. Under the first best perfect information, we have

$$
z_{a}^{E}\left(\theta_{L}\right)=z_{a}^{* E}\left(\theta_{L}\right)=z_{b}^{E}=z_{b}^{* E}=0
$$




$$
\begin{gathered}
z_{a}^{E}\left(\theta_{H}\right)=\frac{\left(\theta_{H}-1\right)\left(4 b_{1} c f+4 A c-4 c f-f\right)}{\left(2 b_{1} c-2 c-1\right)\left(2 b^{2} c-8 c+\theta_{H}-1\right)} \\
z_{a}^{* E C}\left(\theta_{H}\right)=-\frac{b_{1}}{2} \frac{\left(\theta_{H}-1\right)\left(4 b_{1} c f+4 A c-4 c f-f\right)}{\left(2 b_{1} c-2 c-1\right)\left(2 b_{1}^{2} c-8 c+\theta_{H}-1\right)} .
\end{gathered}
$$

Proof: Since $\left(z_{a}^{E}(\theta), z_{a}^{* E}(\theta)\right)$ and $\left(z_{b}^{E}, z_{b}^{* E}\right)$ are the solutions to the maximization problems (25) and (26), respectively, they can be written as:

$$
\begin{gathered}
z_{a}^{E}(\theta)=\underset{z_{a}(\theta)}{\operatorname{argmax}} \vartheta_{a}\left(z_{a}(\theta), z_{a}^{*}(\theta), \theta\right)+\vartheta_{a}^{*}\left(z_{a}(\theta), z_{a}^{*}(\theta)\right) ; \\
z_{a}^{* E}(\theta)=\underset{z_{a}^{*}(\theta)}{\operatorname{argmax}} \vartheta_{a}\left(z_{a}(\theta), z_{a}^{*}(\theta), \theta\right)+\vartheta_{a}^{*}\left(z_{a}(\theta), z_{a}^{*}(\theta)\right) ; \\
z_{b}^{E}=\underset{z_{b}}{\operatorname{argmax}} \vartheta_{b}\left(z_{b}, z_{b}^{*}\right)+\vartheta_{b}^{*}\left(z_{b}, z_{b}^{*}\right) ; \\
z_{b}^{* E}=\underset{z_{b}^{*}}{\operatorname{argmax}} \vartheta_{b}\left(z_{b}, z_{b}^{*}\right)+\vartheta_{b}^{*}\left(z_{b}, z_{b}^{*}\right) .
\end{gathered}
$$

From Lemma 7, we have

$$
\begin{gathered}
\frac{\partial \vartheta_{a}\left(\tau_{a}, \tau_{a}^{*}, \theta\right)}{\partial \tau_{a}}+\frac{\partial \vartheta_{a}^{*}\left(\tau_{a}^{*}, \tau_{a}\right)}{\partial \tau_{a}}=\frac{1}{2}(\theta-1) \frac{p_{y_{a}}-f}{2 c}-\tau_{a}-\frac{1}{2} b_{1} \tau_{a}^{*} \\
\frac{\partial \vartheta_{a}\left(\tau_{a}, \tau_{a}^{*}, \theta\right)}{\partial \tau_{a}^{*}}+\frac{\partial \vartheta_{a}^{*}\left(\tau_{a}^{*}, \tau_{a}\right)}{\partial \tau_{a}^{*}}=-\frac{1}{2} b_{1} \tau_{a}-\tau_{a}^{*}
\end{gathered}
$$

and

$$
\frac{\partial \vartheta_{b}\left(\tau_{b}, \tau_{b}^{*}\right)}{\partial \tau_{b}^{*}}+\frac{\partial \vartheta_{b}^{*}\left(\tau_{b}^{*}, \tau_{b}\right)}{\partial \tau_{b}^{*}}=-\tau_{b}^{*}-\frac{1}{2} b_{2} \tau_{b}
$$

Hence,

$$
\begin{gathered}
\frac{1}{2}\left[\theta q_{y_{a}}^{s}\left(p_{y_{a}}\right)-q_{y_{a}}^{d}\left(p_{y_{a}}, p_{x_{a}}\right)\right]+\frac{1}{2} M_{a}-z_{a}^{E}(\theta)-\frac{1}{2} b_{1} z_{a}^{* E}(\theta)=0 \\
-\frac{1}{2} b_{1} z_{a}^{E}(\theta)-z_{a}^{* E}(\theta)=0 \\
-z_{b}^{E}-\frac{1}{2} b_{1} z_{b}^{* E}=0 \\
-\frac{1}{2} b_{2} z_{b}^{E}-z_{b}^{*} E=0
\end{gathered}
$$


Solving these equations derives the solutions to problem (24):

$$
\begin{aligned}
& z_{a}^{E}\left(\theta_{L}\right)=z_{a}^{* E}\left(\theta_{L}\right)=z_{b}^{E}=z_{b}^{* E}=0 \\
& z_{a}^{E}\left(\theta_{H}\right)=\frac{2}{4-b_{1}^{2}}\left(\theta_{H}-1\right) \frac{p_{y_{a}}-f}{2 c} \\
& z_{a}^{* E}\left(\theta_{H}\right)=\frac{b_{1}}{b_{1}^{2}-4}\left(\theta_{H}-1\right) \frac{p_{y_{a}}-f}{2 c}
\end{aligned}
$$

From lemma 6, we know that

$$
\begin{aligned}
p_{y_{a}} & =\frac{1}{2} \frac{-2 b c \tau+4 A c+2 c \tau+f+\tau}{1-2 b c+2 c} \\
& =\frac{1}{2} \frac{-2 b c z_{a}^{E C}\left(\theta_{H}\right)+4 A c+2 c z_{a}^{E C}\left(\theta_{H}\right)+f+z_{a}^{E C}\left(\theta_{H}\right)}{1-2 b c+2 c} .
\end{aligned}
$$

Substituting it into Eqs.(70) and (71), we have $z_{a}^{E}\left(\theta_{H}\right)=\frac{\left(\theta_{H}-1\right)\left(4 b_{1} c f+4 A c-4 c f-f\right)}{\left(2 b_{1} c-2 c-1\right)\left(2 b_{1}^{2} c-8 c+\theta_{H}-1\right)}, z_{a}^{* E}\left(\theta_{H}\right)=$ $-\frac{b}{2} \frac{\left(\theta_{H}-1\right)\left(4 b_{1} c f+4 A c-4 c f-f\right)}{\left(2 b_{1} c-2 c-1\right)\left(2 b_{1}^{2} c-8 c+\theta_{H}-1\right)}$.

Proposition 10. Under the first best perfect information, if the goods in sector a are strategic substitutes, i.e., $b_{1} \in(0,1)$, then $z_{a}^{* E}\left(\theta_{H}\right)<0<z_{a}^{E}\left(\theta_{H}\right)$.

Proof: From the proof of Proposition 9, we know that

$$
z_{a}^{E}\left(\theta_{H}\right)=\frac{2}{4-b_{1}^{2}}\left(\theta_{H}-1\right) \frac{p_{y_{a}}-f}{2 c} ; \quad z_{a}^{* E}\left(\theta_{H}\right)=\frac{b_{1}}{b_{1}^{2}-4}\left(\theta_{H}-1\right) \frac{p_{y_{a}}-f}{2 c} .
$$

Note that

$$
\frac{p_{y_{a}}-f}{2 c}=q_{y_{a}}^{s}>0
$$

for all $\tau, \tau^{*} \in[0,+\infty)$. Therefore, together with $b_{1} \in(0,1)$, it is obvious that $z_{a}^{E C}\left(\theta_{H}\right)>0>$ $z_{a}^{* E C}\left(\theta_{H}\right)$

Proposition 11. Under the same-sector retaliation mechanism, the best negotiated import tariffs are as follows:

$$
z_{a}^{S S}\left(\theta_{L}\right)=z_{a}^{* S S}=0<z_{a}^{S S}\left(\theta_{H}\right)=\frac{\left(\theta_{H}-1\right)\left(4 b_{1} c f+4 A c-4 c f-f\right)}{\left(2 b_{1} c-2 c-1\right)\left(-8 b_{1} c-16 c+\theta_{H}-1\right)} .
$$


Proof: The solutions to the unconstrained maximization problem (27) must satisfy the following equations:

$$
\begin{gathered}
\vartheta_{a 1}\left(z_{a}^{S S}\left(\theta_{L}\right), z_{a}^{* S S}, \theta_{L}\right)+\vartheta_{a 1}^{*}\left(z_{a}^{S S}\left(\theta_{L}\right), z_{a}^{* S S}\right)=0 \\
\vartheta_{a 1}\left(z_{a}^{S S}\left(\theta_{H}\right), z_{a}^{S S}\left(\theta_{H}\right), \theta_{H}\right)+\vartheta_{a 1}^{*}\left(z_{a}^{S S}\left(\theta_{H}\right), z_{a}^{S S}\left(\theta_{H}\right)\right) \\
+\vartheta_{a 2}\left(z_{a}^{S S}\left(\theta_{H}\right), z_{a}^{S S}\left(\theta_{H}\right), \theta_{H}\right)+\vartheta_{a 2}^{*}\left(z_{a}^{S S}\left(\theta_{H}\right), z_{a}^{S S}\left(\theta_{H}\right)\right)=0 \\
\vartheta_{a 2}\left(z_{a}^{S S}\left(\theta_{L}\right), z_{a}^{* S S}, \theta_{L}\right)+\vartheta_{a 2}^{*}\left(z_{a}^{S S}\left(\theta_{L}\right), z_{a}^{* S S}\right)=0 .
\end{gathered}
$$

Together with Eq.(64) and the supply function $q_{y}^{s}\left(p_{y}\right)=\frac{p_{y_{a}}-f}{2 c}$, we have

$$
\begin{gathered}
-z_{a}^{S S}\left(\theta_{L}\right)-\frac{1}{2} b_{1} z_{a}^{* S S}=0 ; \\
\frac{1}{2}\left[\theta_{H} q_{y}^{s}\left(p_{y}\right)-q_{y}^{d}\left(p_{y}, p_{x}\right)\right]+M_{a}-z_{a}^{S S}\left(\theta_{H}\right)-\frac{1}{2} M_{a}^{*} \\
-\frac{1}{2} b_{1} z_{a}^{S S}\left(\theta_{H}\right)-\frac{1}{2} M_{a}-\frac{1}{2} b_{1} z_{a}^{S S}\left(\theta_{H}\right) \frac{1}{2} M_{a}^{*}-z_{a}^{S S}\left(\theta_{H}\right)=0 ; \\
-\frac{1}{2} b_{1} z_{a}^{S S}\left(\theta_{L}\right)-z_{a}^{* S S}=0 .
\end{gathered}
$$

Solving the above equations yields the solution to problem (27):

$$
\begin{gathered}
z_{a}^{S S}\left(\theta_{L}\right)=z_{a}^{* S S}=0 \\
z_{a}^{S S}\left(\theta_{H}\right)=\frac{1}{4+2 b_{1}}\left(\theta_{H}-1\right) \frac{p_{y_{a}}-f}{2 c} .
\end{gathered}
$$

From Lemma 6, we have

$$
p_{y_{a}}=\frac{1}{2} \frac{-2 b c \tau+4 A c+2 c \tau+f+\tau}{1-2 b c+2 c} .
$$

Substitute $\tau=z_{a}^{S S}\left(\theta_{H}\right)$ into it:

$$
p_{y_{a}}=\frac{1}{2} \frac{-2 b_{1} c z_{a}^{S S}\left(\theta_{H}\right)+4 A c+2 c z_{a}^{S S}\left(\theta_{H}\right)+f+z_{a}^{S S}\left(\theta_{H}\right)}{1-2 b_{1} c+2 c} .
$$


Together with Eq.(72), we have

$$
z_{a}^{S S}\left(\theta_{H}\right)=\frac{\left(\theta_{H}-1\right)\left(4 b_{1} c f+4 A c-4 c f-f\right)}{\left(2 b_{1} c-2 c-1\right)\left(-8 b_{1} c-16 c+\theta_{H}-1\right)} .
$$

Next to show that $z_{a}^{S S}\left(\theta_{H}\right)>0$, first given that the supply function $q_{y_{a}}^{s}\left(p_{y_{a}}\right)=\frac{p_{y_{a}}-f}{2 c}>0$, Eq.(72) can be rewritten as:

$$
z_{a}^{S S}\left(\theta_{H}\right)=\frac{1}{4+2 b_{1}} q_{y_{a}}^{s}\left(p_{y_{a}}\right)
$$

Then, $b_{1} \in(0,1)$ implies that $\frac{1}{4+2 b_{1}}>0$. Together with $\theta>1$, we can verify that $z_{a}^{S S}\left(\theta_{H}\right)>0$.

Proposition 12. If the goods in sector a are strategic substitutes, i.e., $b_{1} \in(0,1)$, then under the same-sector retaliation mechanism, the best negotiated import tariff in the high state is lower than the politically efficient tariff, i.e., $z_{a}^{S S}\left(\theta_{H}\right)<z_{a}^{E}\left(\theta_{H}\right)$.

Proof: From Lemma 6, we have $p_{y_{a}}=\frac{1}{2} \frac{-2 b_{1} c \tau+4 A c+2 c \tau+f+\tau}{1-2 b_{1} c+2 c}$. Note that $p_{y_{a}}>0$ for all $\tau \in[0,+\infty)$. Thus, when $\tau=0$, we must have

$$
p_{y_{a}}=\frac{1}{2} \frac{4 A c+f}{1-2 b_{1} c+2 c}>0 .
$$

Then, by the assumption, we have $A>0, c>0$, and $f>0$. Therefore, $4 A c+f>0$. This implies that $1-2 b_{1} c+2 c>0$.

Furthermore, from Lemma 6, we know that

$$
q_{y_{a}}^{s}=\frac{1}{4 c}\left(\tau+\frac{4 A c+f}{1+2 c-2 b_{1} c}\right)-\frac{f}{2 c} .
$$

Note that $q_{y_{a}}^{s}>0$ for all $\tau \in[0,+\infty)$. Hence, when $\tau=0$, we must have

$$
\begin{aligned}
q_{y_{a}}^{s} & =\frac{1}{4 c}\left(\frac{4 A c+f}{1+2 c-2 b_{1} c}\right)-\frac{f}{2 c} \\
& =\frac{4 A c+f-2 f\left(1+2 c-2 b_{1} c\right)}{4 c\left(1+2 c-2 b_{1} c\right)} \\
& =\frac{4 A c-f-4 c f+4 b_{1} c f}{4 c\left(1+2 c-2 b_{1} c\right)}>0 .
\end{aligned}
$$

Together with $c>0$ and $1-2 b_{1} c+2 c>0$, it implies that $4 b_{1} c f+4 A c-4 c f-f>0$. 
Besides, given that $b_{1} \in(0,1)$ and $c>0$, we have

$$
-8 b_{1} c-16 c+\theta_{H}-1<2 b_{1}^{2} c-8 c+\theta_{H}-1 .
$$

Then recall from Proposition 9, we have $z_{a}^{E}\left(\theta_{H}\right)=\frac{\left(\theta_{H}-1\right)\left(4 b_{1} c f+4 A c-4 c f-f\right)}{\left(2 b_{1} c-2 c-1\right)\left(2 b_{1}^{2} c-8 c+\theta_{H}-1\right)}$ and from Proposition 11 , we have $z_{a}^{S S}\left(\theta_{H}\right)=\frac{\left(\theta_{H}-1\right)\left(4 b_{1} c f+4 A c-4 c f-f\right)}{\left(2 b_{1} c-2 c-1\right)\left(-8 b_{1} c-16 c+\theta_{H}-1\right)}$. Together with the assumption that $\theta_{H}>1$, it implies that $z_{a}^{E}\left(\theta_{H}\right)>z_{a}^{S S}\left(\theta_{H}\right)$.

Proposition 13. Under the same-sector retaliation mechanism, the incentive compatibility conditions (28) and (29) are slack.

Proof: Let

$$
\hat{\tau_{a}}(\theta)=\underset{\tau_{a}}{\operatorname{argmax}} \vartheta_{a}\left(\tau_{a}, \tau_{a}, \theta\right)
$$

Together with Eq.(64), we have

$$
\begin{gathered}
\frac{1}{2} M_{a}-\hat{\tau_{a}}\left(\theta_{L}\right)-\frac{1}{2} M_{a}^{*}-\frac{1}{2} b_{1} \hat{\tau_{a}}\left(\theta_{L}\right)=0 ; \\
\frac{1}{2}\left[\theta_{H} q_{y}^{s}\left(p_{y}\right)-q_{y}^{d}\left(p_{y}, p_{x}\right)\right]+M_{a}-\hat{\tau}\left(\theta_{H}\right)-\frac{1}{2} M_{a}^{*}-\frac{1}{2} b_{1} \hat{\tau}\left(\theta_{H}\right)=0 .
\end{gathered}
$$

When home has low political pressure, home and foreign are symmetric. Hence, $M_{a}=M_{a}^{*}$. Then by Eq.(73), we know that $\hat{\tau_{a}}\left(\theta_{L}\right)=0$. From Proposition 11, we have $z_{a}^{S S}\left(\theta_{L}\right)=z_{a}^{* S S}=0 \neq z_{a}^{S S}\left(\theta_{H}\right)$. This indicates that

$$
\vartheta_{a}\left(z_{a}^{S S}\left(\theta_{L}\right), z_{a}^{* S S}, \theta_{L}\right)=\vartheta_{a}\left(\hat{\tau_{a}}\left(\theta_{L}\right), \hat{\tau_{a}}\left(\theta_{L}\right), \theta_{L}\right)>\vartheta_{a}\left(z_{a}^{S S}\left(\theta_{H}\right), z_{a}^{S S}\left(\theta_{H}\right), \theta_{L}\right) .
$$

Thus, condition (28) is not binding.

To show that condition (29) is slack, recall from the proof of Proposition 11, we know that $z_{a}^{S S}\left(\theta_{H}\right)$ must satisfy:

$$
\begin{aligned}
& \frac{1}{2}\left[\theta_{H} q_{y}^{s}\left(p_{y}\right)-q_{y}^{d}\left(p_{y}, p_{x}\right)\right]+M_{a}-z_{a}^{S S}\left(\theta_{H}\right)-\frac{1}{2} M_{a}^{*} \\
& -\frac{1}{2} b_{1} z_{a}^{S S}\left(\theta_{H}\right)-\frac{1}{2} M_{a}-\frac{1}{2} b_{1} z_{a}^{S S}\left(\theta_{H}\right) \frac{1}{2} M_{a}^{*}-z_{a}^{S S}\left(\theta_{H}\right)=0
\end{aligned}
$$


Let

$$
G(\tau)=\frac{1}{2}\left[\theta_{H} q_{y}^{s}\left(p_{y}\right)-q_{y}^{d}\left(p_{y}, p_{x}\right)\right]+M_{a}-\tau-\frac{1}{2} M_{a}^{*}-\frac{1}{2} b_{1} \tau .
$$

Then Eqs.(74) and (75) can be rewritten as $G(\tau)=0$ and

$$
G(\tau)=\frac{1}{2} M_{a}+\frac{1}{2} b_{1} \tau \frac{1}{2} M_{a}^{*}+\tau
$$

respectively. Since $\frac{1}{2} M_{a}+\frac{1}{2} b_{1} \tau \frac{1}{2} M_{a}^{*}+\tau>0$ and $\frac{\partial G(\tau)}{\partial \tau}<0$, Eqs.(74) and (75) indicate that $\hat{\tau}\left(\theta_{H}\right)>z_{a}^{S S}\left(\theta_{H}\right)$. Hence, $z_{a}^{S S}\left(\theta_{H}\right)>z_{a}^{S S}\left(\theta_{L}\right)=z_{a}^{* S S}\left(\theta_{L}\right)$ (from Proposition 11) implies that $\vartheta_{a}\left(z_{a}^{S S}\left(\theta_{H}\right), z_{a}^{S S}\left(\theta_{H}\right), \theta_{H}\right) \geq \vartheta_{a}\left(z_{a}^{S S}\left(\theta_{L}\right), z_{a}^{* S S}, \theta_{H}\right)$ and condition (29) is slack.

Proposition 14. Under the cross-sector retaliation mechanism, the best negotiated import tariffs are as follows:

$$
z_{a}^{C S}\left(\theta_{L}\right)=0<z_{a}^{C S}\left(\theta_{H}\right)=\frac{\left(\theta_{H}-1\right)\left(4 b_{1} c f+4 A c-4 c f-f\right)}{\left(2 b_{1} c-2 c-1\right)\left(-16 c+\theta_{H}-1\right)} .
$$

Proof: By going through similar steps as in deriving Propositions 9 and 11, substituting Eq.(64) and the price function

$$
\begin{aligned}
p_{y_{a}} & =\frac{1}{2} \frac{-2 b c \tau+4 A c+2 c \tau+f+\tau}{1-2 b c+2 c} \\
& =\frac{1}{2} \frac{-2 b_{1} c z_{a}^{D S C}\left(\theta_{H}\right)+4 A c+2 c z_{a}^{D S C}\left(\theta_{H}\right)+f+z_{a}^{D S C}\left(\theta_{H}\right)}{1-2 b_{1} c+2 c} .
\end{aligned}
$$

into Eqs. (33)-(34) yields: $z_{a}^{C S}\left(\theta_{L}\right)=0$ and $z_{a}^{C S}\left(\theta_{H}\right)=\frac{1}{4}\left(\theta_{H}-1\right) \frac{p_{y_{a}}-f}{2 c}=\frac{\left(\theta_{H}-1\right)\left(4 b_{1} c f+4 A c-4 c f-f\right)}{\left(2 b_{1} c-2 c-1\right)\left(-16 c+\theta_{H}-1\right)}$. Besides, given that the supply function $q_{y_{a}}^{s}=\frac{p_{y_{a}}-f}{2 c}>0$, and $\theta_{H}>1$, it is obvious that $z_{a}^{C S}\left(\theta_{H}\right)>0$.

Proposition 15. If the goods in sector a are strategic substitutes, i.e., $b_{1} \in(0,1)$, then the best negotiated import tariffs in the high state under the cross-sector retaliation mechanism is higher than under the same-sector retaliation mechanism while lower than under the first best perfect information, i.e., $z_{a}^{S S}\left(\theta_{H}\right)<z_{a}^{C S}\left(\theta_{H}\right)<z_{a}^{E}\left(\theta_{H}\right)$. 
Proof: From Proposition 9, we have

$$
z_{a}^{E}\left(\theta_{H}\right)=\frac{\left(\theta_{H}-1\right)\left(4 b_{1} c f+4 A c-4 c f-f\right)}{\left(2 b_{1} c-2 c-1\right)\left(2 b_{1}^{2} c-8 c+\theta_{H}-1\right)},
$$

from Proposition 11, we have

$$
z_{a}^{S S}\left(\theta_{H}\right)=\frac{\left(\theta_{H}-1\right)\left(4 b_{1} c f+4 A c-4 c f-f\right)}{\left(2 b_{1} c-2 c-1\right)\left(-8 b_{1} c-16 c+\theta_{H}-1\right)}
$$

and from Proposition 14, we have

$$
z_{a}^{C S}\left(\theta_{H}\right)=\frac{\left(\theta_{H}-1\right)\left(4 b_{1} c f+4 A c-4 c f-f\right)}{\left(2 b_{1} c-2 c-1\right)\left(-16 c+\theta_{H}-1\right)} .
$$

Since $b_{1} \in(0,1)$, it implies that

$$
-8 b_{1} c-16 c+\theta_{H}-1<-16 c+\theta_{H}-1<2 b_{1}^{2} c-8 c+\theta_{H}-1
$$

From the proof of Proposition 12, we know that

$$
2 b_{1} c-2 c-1<0 ; \quad 4 b_{1} c f+4 A c-4 c f-f>0 .
$$

Together with $\theta_{H}>1$, it is obvious that

$$
z_{a}^{S S}\left(\theta_{H}\right)<z_{a}^{C S}\left(\theta_{H}\right)<z_{a}^{E}\left(\theta_{H}\right)
$$

Proposition 16. Under the cross-sector retaliation mechanism, the incentive compatibility conditions (31) and (32) are slack.

Proof: The proof is followed by similar steps as in deriving Proposition 13.

To show that

$$
\vartheta_{a}\left(z_{a}^{C S}\left(\theta_{L}\right), 0, \theta_{L}\right)+\vartheta_{b}(0,0) \geq \vartheta_{a}\left(z_{a}^{C S}\left(\theta_{H}\right), 0, \theta_{L}\right)+\vartheta_{b}\left(0, z_{a}^{C S}\left(\theta_{H}\right)\right)
$$


first note that $z_{a}^{C S}\left(\theta_{L}\right)=z_{a}^{E}\left(\theta_{L}\right)<z_{a}^{C S}\left(\theta_{H}\right)$ (from Proposition 14). Hence,

$$
\vartheta_{a}\left(z_{a}^{C S}\left(\theta_{L}\right), 0, \theta_{L}\right)>\vartheta_{a}\left(z_{a}^{C S}\left(\theta_{H}\right), 0, \theta_{L}\right)
$$

Besides, Proposition 9 says that $z_{b}^{* E}=z_{b}^{E}=0<z_{a}^{C S}\left(\theta_{H}\right)$. Thus, $\vartheta_{b}(0,0)>\vartheta_{b}\left(0, z_{a}^{C S}\left(\theta_{H}\right)\right)$. Therefore, condition (31) is slack.

To prove that condition (32) is slack, first from Eq.(64), we know that $\frac{\partial \vartheta_{a}\left(\tau_{a}, 0, \theta_{H}\right)}{\partial \tau_{a}}>-\frac{\partial \vartheta_{b}\left(0, \tau_{b}^{*}\right)}{\partial \tau_{b}^{*}}$. Together with $z_{a}^{C S}\left(\theta_{L}\right)=0<z_{a}^{C S}\left(\theta_{H}\right)$ (from Proposition 14), it indicates that

$$
\vartheta_{a}\left(z_{a}^{C S}\left(\theta_{H}\right), 0, \theta_{H}\right)-\vartheta_{a}\left(z_{a}^{C S}\left(\theta_{L}\right), 0, \theta_{H}\right)>\vartheta_{b}(0,0)-\vartheta_{b}\left(0, z_{a}^{C S}\left(\theta_{H}\right)\right)
$$

Hence, condition (32) is slack.

Proposition 17. Suppose that the goods in both sectors are strategic substitutes, i.e., $b_{1} \in(0,1)$ and $b_{2} \in(0,1)$. Then for any given $b_{1} \in(0,1)$, there exists a $b_{2}^{\prime} \in(0,1)$ such that for any $b_{2} \in\left(0, b_{2}^{\prime}\right)$, the best incentive-compatible negotiated tariffs under the same-sector retaliation mechanism generate a higher expected joint political payoff than do the best incentive-compatible negotiated tariffs under the cross-sector retaliation mechanism.

Proof: First, recall from Propositions 13 and 16, the incentive compatibility conditions under these two mechanisms are slack. Therefore, the solutions to the unconstrained maximization problem (27) and (30) are incentive compatible.

Note that the best tariffs under the cross-sector retaliation mechanism are different from the politically efficient tariffs in both sectors. Hence, it creates the deadweight losses (DWL) of the joint payoffs in both sectors. Specifically, the DWL of the joint payoffs in sectors $a$ and $b$ are

$$
\begin{aligned}
& \vartheta_{a}\left(z_{a}^{E}\left(\theta_{H}\right), z_{a}^{* E}\left(\theta_{H}\right), \theta_{H}\right)+\vartheta_{a}^{*}\left(z_{a}^{E}\left(\theta_{H}\right), z_{a}^{* E}\left(\theta_{H}\right)\right) \\
& -\vartheta_{a}\left(z_{a}^{C S}\left(\theta_{H}\right), z_{a}^{* E}\left(\theta_{L}\right), \theta_{H}\right)-\vartheta_{a}^{*}\left(z_{a}^{C S}\left(\theta_{H}\right), z_{a}^{* E}\left(\theta_{L}\right)\right)
\end{aligned}
$$

and

$$
\vartheta_{b}\left(z_{b}^{E}, z_{b}^{* E}\right)+\vartheta_{b}^{*}\left(z_{b}^{E}, z_{b}^{* E}\right)-\vartheta_{b}\left(z_{b}^{E}, z_{a}^{C S}\left(\theta_{H}\right)\right)-\vartheta_{b}^{*}\left(z_{b}^{E}, z_{a}^{C S}\left(\theta_{H}\right)\right)
$$

respectively. 
On the other hand, under same-sector retaliation, the difference between the negotiated tariffs and the politically efficient tariffs is only from sector $a$. Hence, the DWL of the joint payoff under this mechanism is

$$
\begin{aligned}
& \vartheta_{a}\left(z_{a}^{E}\left(\theta_{H}\right), z_{a}^{* E}\left(\theta_{H}\right), \theta_{H}\right)+\vartheta_{a}^{*}\left(z_{a}^{E}\left(\theta_{H}\right), z_{a}^{* E}\left(\theta_{H}\right)\right) \\
& -\vartheta_{a}\left(z_{a}^{S S}\left(\theta_{H}\right), z_{a}^{S S}\left(\theta_{H}\right), \theta_{H}\right)-\vartheta_{a}^{*}\left(z_{a}^{S S}\left(\theta_{H}\right), z_{a}^{S S}\left(\theta_{H}\right)\right) .
\end{aligned}
$$

Therefore, to prove that the negotiated tariffs under the same-sector retaliation mechanism generates a higher expected political payoff, it is equivalent to show that

DWL under the same-sector retaliation mechanism in sector $a$

- DWL under the cross-sector retaliation mechanism in sector $a$

$<$ DWL under the cross-sector retaliation mechanism in sector $b$.

Namely,

$$
\begin{aligned}
& \vartheta_{a}\left(z_{a}^{E}\left(\theta_{H}\right), z_{a}^{* E}\left(\theta_{H}\right), \theta_{H}\right)+\vartheta_{a}^{*}\left(z_{a}^{E}\left(\theta_{H}\right), z_{a}^{* E}\left(\theta_{H}\right)\right) \\
& -\vartheta_{a}\left(z_{a}^{S S}\left(\theta_{H}\right), z_{a}^{S S}\left(\theta_{H}\right), \theta_{H}\right)-\vartheta_{a}^{*}\left(z_{a}^{S S}\left(\theta_{H}\right), z_{a}^{S S}\left(\theta_{H}\right)\right) \\
& -\left[\vartheta_{a}\left(z_{a}^{E}\left(\theta_{H}\right), z_{a}^{* E}\left(\theta_{H}\right), \theta_{H}\right)+\vartheta_{a}^{*}\left(z_{a}^{E}\left(\theta_{H}\right), z_{a}^{* E}\left(\theta_{H}\right)\right)\right. \\
& \left.-\vartheta_{a}\left(z_{a}^{C S}\left(\theta_{H}\right), z_{a}^{C S}\left(\theta_{H}\right), \theta_{H}\right)-\vartheta_{a}^{*}\left(z_{a}^{C S}\left(\theta_{H}\right), z_{a}^{C S}\left(\theta_{H}\right)\right)\right] \\
& <\vartheta_{b}\left(z_{b}^{E}, z_{b}^{* E}\right)+\vartheta_{b}^{*}\left(z_{b}^{E}, z_{b}^{* E}\right)-\vartheta_{b}\left(z_{b}^{E}, z_{a}^{C S}\left(\theta_{H}\right)\right)-\vartheta_{b}^{*}\left(z_{b}^{E}, z_{a}^{C S}\left(\theta_{H}\right)\right)
\end{aligned}
$$

Substituting $z_{a}^{E}\left(\theta_{L}\right)=z_{a}^{* E}\left(\theta_{L}\right)=z_{b}^{E}=z_{b}^{* E}=0$ (from Proposition 9) into the above equation and simplifying it, we have

$$
\begin{aligned}
& \vartheta_{a}\left(z_{a}^{C S}\left(\theta_{H}\right), 0, \theta_{H}\right)+\vartheta_{a}^{*}\left(z_{a}^{C S}\left(\theta_{H}\right), 0\right)-\vartheta_{a}\left(z_{a}^{S S}\left(\theta_{H}\right), z_{a}^{S S}\left(\theta_{H}\right), \theta_{H}\right)-\vartheta_{a}^{*}\left(z_{a}^{S S}\left(\theta_{H}\right), z_{a}^{S S}\left(\theta_{H}\right)\right) \\
& -\vartheta_{b}(0,0)-\vartheta_{b}^{*}(0,0)+\vartheta_{b}\left(0, z_{a}^{N C C}\left(\theta_{H}\right)\right)+\vartheta_{b}^{*}\left(0, z_{a}^{N C C}\left(\theta_{H}\right)\right)<0 .
\end{aligned}
$$

From Propositions 11 and 14, we know that $z_{a}^{C S}\left(\theta_{H}\right)$ and $z_{a}^{C C}\left(\theta_{H}\right)$ are independent of $b_{2}$. Together with the utility function defined in Eq.(20), it is easy to verify that the left hand side of Eq.(76) decreases in $b_{2}$. Therefore, given that $b_{1}$ is fixed, the left hand side can be expressed as a function 
of $b_{2}$, i.e.,

$$
\begin{aligned}
G\left(b_{2}\right)= & \vartheta_{a}\left(z_{a}^{C S}\left(\theta_{H}\right), 0, \theta_{H}\right)+\vartheta_{a}^{*}\left(z_{a}^{C S}\left(\theta_{H}\right), 0\right) \\
& -\vartheta_{a}\left(z_{a}^{S S}\left(\theta_{H}\right), z_{a}^{S S}\left(\theta_{H}\right), \theta_{H}\right)-\vartheta_{a}^{*}\left(z_{a}^{S S}\left(\theta_{H}\right), z_{a}^{S S}\left(\theta_{H}\right)\right) \\
& -\vartheta_{b}(0,0)-\vartheta_{b}^{*}(0,0)+\vartheta_{b}\left(0, z_{a}^{N C C}\left(\theta_{H}\right)\right)+\vartheta_{b}^{*}\left(0, z_{a}^{N C C}\left(\theta_{H}\right)\right) .
\end{aligned}
$$

Moreover, at the extreme point where $b_{2}=1$, we have $G\left(b_{2}\right)=-\infty$. At another extreme point where $b_{2}=0$, given that $b_{1} \in(0,1)>b_{2}=0$ and $\theta_{H}>1$, it is obvious that $G\left(b_{2}\right)>0$. Therefore, for any given $b_{1} \in(0,1)$, there exists a cutoff point $b_{2}^{\prime} \in(0,1)$ such that for any $b_{2} \in\left(0, b_{2}^{\prime}\right)$, Eq.(76) holds. Hence, the tariffs under the same-sector retaliation mechanism generate a higher joint political payoff than under the cross-sector one when $b_{2} \in\left(0, b_{2}^{\prime}\right)$.

Proposition 18. For any given $b_{1} \in(0,1)$, there exists a $b_{2}^{*} \in(0,1)$ such that for any $b_{2} \in\left(0, b_{2}^{*}\right)$, the same-sector retaliation mechanism supports a higher self-enforcing level of cooperation than the cross-sector retaliation mechanism.

Proof: Note that Eqs.(41) and (42) can be simplified as:

$$
\begin{aligned}
& \vartheta_{a}\left(z_{a}^{S S}\left(\theta_{L}\right), 0, \theta_{L}\right) \\
& +\delta\left[\beta \vartheta_{a}\left(z_{a}^{S S}\left(\theta_{L}\right), 0, \theta_{L}\right)+(1-\beta) \vartheta_{a}\left(z_{a}^{S S}\left(\theta_{H}\right), z_{a}^{S S}\left(\theta_{H}\right), \theta_{H}\right)\right] \\
& +\delta^{2}\left\{\left[\beta^{2}+(1-\beta) \beta\right] X^{S}\left(z_{a}^{S S}\left(\theta_{H}\right), z_{a}^{S S}\left(\theta_{L}\right), \theta_{L}\right)\right. \\
& \left.+[(1-\beta) \beta+\beta(1-\beta)] X^{S}\left(z_{a}^{S S}\left(\theta_{H}\right), z_{a}^{S S}\left(\theta_{L}\right), \theta_{H}\right)\right\} \geq \\
& \vartheta_{a}\left(z_{a}^{S d}\left(\theta_{L}\right), 0, \theta_{L}\right) \\
& +\delta\left[\beta \vartheta_{a}\left(z_{a}^{N}\left(\theta_{L}\right), z_{a}^{* N}, \theta_{L}\right)+(1-\beta) \vartheta_{a}\left(z_{a}^{N}\left(\theta_{H}\right), z_{a}^{* N}, \theta_{H}\right)\right] \\
& +\delta^{2}\left\{\left[\beta^{2}+(1-\beta) \beta\right] X^{S d}\left(z_{a}^{N}\left(\theta_{H}\right), z_{a}^{N}\left(\theta_{L}\right), z_{a}^{* N}, \theta_{L}\right)\right. \\
& \left.+[(1-\beta) \beta+\beta(1-\beta)] X^{S d}\left(z_{a}^{N}\left(\theta_{H}\right), z_{a}^{N}\left(\theta_{L}\right), z_{a}^{* N}, \theta_{H}\right)\right\}
\end{aligned}
$$


and

$$
\begin{aligned}
& \vartheta_{a}\left(z_{a}^{S S}\left(\theta_{H}\right), z_{a}^{S S}\left(\theta_{H}\right), \theta_{H}\right) \\
& +\delta\left[\beta \vartheta_{a}\left(z_{a}^{S S}\left(\theta_{H}\right), z_{a}^{S S}\left(\theta_{H}\right), \theta_{H}\right)+(1-\beta) \vartheta_{a}\left(z_{a}^{S S}\left(\theta_{L}\right), 0, \theta_{L}\right)\right] \\
& +\delta^{2}\left\{\left[\beta^{2}+(1-\beta) \beta\right]\right] X^{S}\left(z_{a}^{S S}\left(\theta_{H}\right), z_{a}^{S S}\left(\theta_{L}\right), \theta_{H}\right) \\
& \left.+[(1-\beta) \beta+\beta(1-\beta)] X^{S}\left(z_{a}^{S S}\left(\theta_{H}\right), z_{a}^{S S}\left(\theta_{L}\right), \theta_{L}\right)\right\} \geq \\
& \vartheta_{a}\left(z_{a}^{S d}\left(\theta_{H}\right), 0, \theta_{H}\right) \\
& +\delta\left[\beta \vartheta_{a}\left(z_{a}^{N}\left(\theta_{H}\right), z_{a}^{* N}, \theta_{H}\right)+(1-\beta) \vartheta_{a}\left(z_{a}^{N}\left(\theta_{L}\right), z_{a}^{* N}, \theta_{L}\right)\right] \\
& +\delta^{2}\left\{\left[\beta^{2}+(1-\beta) \beta\right] X^{S d}\left(z_{a}^{N}\left(\theta_{H}\right), z_{a}^{N}\left(\theta_{L}\right), z_{a}^{* N}, \theta_{H}\right)\right. \\
& \left.+[(1-\beta) \beta+\beta(1-\beta)] X^{S d}\left(z_{a}^{N}\left(\theta_{H}\right), z_{a}^{N}\left(\theta_{L}\right), z_{a}^{* N}, \theta_{L}\right)\right\}
\end{aligned}
$$

respectively. Given that the sectors are independent, the voluntary participation conditions under the same-sector retaliation mechanism do not depend on the substitution rate, $b_{2}$.

We next show that in a low state, the same-sector retaliation has a higher self-enforcing level of cooperation when $b_{2}$ is sufficiently low. Note that this is equivalent to show that there exists a $b_{2}^{L} \in(0,1)$ such that if $b_{2} \in\left(0, b_{2}^{L}\right)$ and Eq.(42) binds, then Eq.(43) will bind. Or, the equation below holds for any given $b_{2} \in\left(0, b_{2}^{L}\right)$. 


$$
\begin{aligned}
& \vartheta_{a}\left(z_{a}^{S S}\left(\theta_{L}\right), 0, \theta_{L}\right) \\
& +\delta\left[\beta \vartheta_{a}\left(z_{a}^{S S}\left(\theta_{L}\right), 0, \theta_{L}\right)+(1-\beta) \vartheta_{a}\left(z_{a}^{S S}\left(\theta_{H}\right), z_{a}^{S S}\left(\theta_{H}\right), \theta_{H}\right)\right] \\
& +\delta^{2}\left\{\left[\beta^{2}+(1-\beta) \beta\right] X^{S}\left(z_{a}^{S S}\left(\theta_{H}\right), z_{a}^{S S}\left(\theta_{L}\right), \theta_{L}\right)\right. \\
& \left.+[(1-\beta) \beta+\beta(1-\beta)] X^{S}\left(z_{a}^{S S}\left(\theta_{H}\right), z_{a}^{S S}\left(\theta_{L}\right), \theta_{H}\right)\right\}-\vartheta_{a}\left(z_{a}^{S d}\left(\theta_{L}\right), 0, \theta_{L}\right) \\
& -\delta\left[\beta \vartheta_{a}\left(z_{a}^{N}\left(\theta_{L}\right), z_{a}^{* N}, \theta_{L}\right)+(1-\beta) \vartheta_{a}\left(z_{a}^{N}\left(\theta_{H}\right), z_{a}^{* N}, \theta_{H}\right)\right] \\
& -\delta^{2}\left\{\left[\beta^{2}+(1-\beta) \beta\right] X_{a}^{S d}\left(z_{a}^{N}\left(\theta_{H}\right), z_{a}^{N}\left(\theta_{L}\right), z_{a}^{* N}, \theta_{L}\right)\right. \\
& \left.-[(1-\beta) \beta+\beta(1-\beta)] X_{a}^{S d}\left(z_{a}^{N}\left(\theta_{H}\right), z_{a}^{N}\left(\theta_{L}\right), z_{a}^{* N}, \theta_{H}\right)\right\} \\
& -\vartheta_{a}\left(z_{a}^{C S}\left(\theta_{L}\right), 0, \theta_{L}\right)-\vartheta_{b}(0,0) \\
& -\delta\left\{\beta \vartheta_{a}\left(z_{a}^{C S}\left(\theta_{L}\right), 0, \theta_{L}\right)+\vartheta_{b}(0,0)+(1-\beta)\left[\vartheta_{a}\left(z_{a}^{C S}\left(\theta_{H}\right), 0, \theta_{H}\right)+\vartheta_{b}\left(0, z_{a}^{C S}\left(\theta_{H}\right)\right)\right]\right\} \\
& -\delta^{2}\left\{\left[\beta^{2}+(1-\beta) \beta\right] X^{C}\left(z_{a}^{C S}\left(\theta_{H}\right), z_{a}^{C S}\left(\theta_{L}\right), \theta_{L}\right)\right. \\
& \left.+[(1-\beta) \beta+\beta(1-\beta)] X^{C}\left(z_{a}^{C S}\left(\theta_{H}\right), z_{a}^{C S}\left(\theta_{L}\right), \theta_{H}\right)\right\} \\
& -\vartheta_{a}\left(z_{a}^{C d}\left(\theta_{L}\right), 0, \theta_{L}\right)-\vartheta_{b}(0,0) \\
& -\delta\left\{\beta\left[\vartheta_{a}\left(z_{a}^{C d}\left(\theta_{L}\right), 0, \theta_{L}\right)+\vartheta_{b}\left(z_{b}^{N}, z_{b}^{* N}\right)\right]+(1-\beta)\left[\vartheta_{a}\left(z_{a}^{C d}\left(\theta_{H}\right), 0, \theta_{H}\right)+\vartheta_{b}\left(z_{b}^{N}, z_{b}^{* N}\right)\right]\right\} \\
& -\delta^{2}\left\{\left[\beta^{2}+(1-\beta) \beta\right] X^{C d}\left(z_{a}^{C d}\left(\theta_{H}\right), z_{a}^{C d}\left(\theta_{L}\right), z_{b}^{N}, z_{b}^{* N}, \theta_{L}\right)\right. \\
& \left.+[(1-\beta) \beta+\beta(1-\beta)] X^{C d}\left(z_{a}^{C d}\left(\theta_{H}\right), z_{a}^{C d}\left(\theta_{L}\right), z_{b}^{N}, z_{b}^{* N}, \theta_{H}\right)\right\} \geq 0 . \\
&
\end{aligned}
$$

Let $A=$ the left hand side of Eq.(79). From Propositions 11 and 14, we know that $z_{a}^{S S}(\theta)$ and $z_{a}^{C S}(\theta)$ do not depend on the substitution rate, $b_{2}$. Therefore, for any given $b_{1} \in(0,1)$, when $b_{2}$ increases, it has no impact on the enforceability constraint under the same-sector retaliation mechanism while it makes the enforceability constraint under the cross-sector retaliation mechanism looser. Thus, if $b_{1}$ is fixed, $A$ can be expressed as a function of $b_{2}$, denoted as $A\left(b_{2}\right)$, and it is strictly decreasing in $b_{2}$. Then, since $A\left(b_{2}=0\right)>0$ and $A\left(b_{2}=1\right)=-\infty$, there exists a $b_{2}^{L}$ such that $A\left(b_{2}^{L}\right)=0$. Therefore, for any $b_{2} \in\left(0, b_{2}^{L}\right]$, we have $A\left(b_{2}\right) \geq 0$. Hence, for any $b_{2} \in\left[0, b_{2}^{L}\right)$, the same-sector retaliation mechanism can support a higher self-enforcing level of cooperation when the state is low.

By following a similar argument, we can show that when the state is high, there also exists such a 
$b_{2}^{H} \in(0,1)$. Let $b_{2}^{*}=\min \left\{b_{2}^{H}, b_{2}^{L}\right\}$. Then, for any $b_{2} \in\left(0, b_{2}^{*}\right)$, the same-sector retaliation mechanism can have a higher self-enforcing level of cooperation than the cross-sector retaliation mechanism under both states.

Note that the following two lemmas hold under Assumptions 2, 3 and 4:

Lemma 8. Suppose that $x^{*}=\left(x_{i}^{*}, x_{j}^{*}, x_{-i,-j}^{*}\right)$ is a productive effort profile such that $x_{i}^{*}>x_{j}^{*}$. Under Assumptions 2, 3 and 4, we have $\frac{\partial F}{\partial x_{i}}\left(x^{*}\right) \leq \frac{\partial F}{\partial x_{j}}\left(x^{*}\right)$.

Proof: Assumption $2(\mathrm{~b})$ says that $\frac{\partial F}{\partial x_{i}}(x) \geq 0$ and $\frac{\partial^{2} F}{\partial x_{i}^{2}}(x) \leq 0$, for all $x \in X$. Therefore, given that $x_{i}^{*}>x_{j}^{*}$, we can show that

$$
\frac{\partial F}{\partial x_{i}}\left(x_{i}=x_{i}^{*}, x_{j}=x_{j}^{*}, x_{-i,-i}=x_{-i,-j}^{*}\right) \leq \frac{\partial F}{\partial x_{i}}\left(x_{i}=x_{j}^{*}, x_{j}=x_{j}^{*}, x_{-i,-i}=x_{-i,-j}^{*}\right) .
$$

Similarly, we know that $\frac{\partial F}{\partial x_{i}}(x) \geq 0$ and $\frac{\partial^{2} F}{\partial x_{i} \partial x_{j}}(x) \geq 0$, for all $x \in X$, by Assumption 2(b). Thus, $x_{i}^{*}>x_{j}^{*}$ also indicates that

$$
\frac{\partial F}{\partial x_{i}}\left(x_{i}=x_{j}^{*}, x_{j}=x_{j}^{*}, x_{-i,-i}=x_{-i,-j}^{*}\right) \leq \frac{\partial F}{\partial x_{i}}\left(x_{i}=x_{j}^{*}, x_{j}=x_{i}^{*}, x_{-i,-i}=x_{-i,-j}^{*}\right) .
$$

Finally, by Assumption 4, we have

$$
\frac{\partial F}{\partial x_{i}}\left(x_{i}=x_{j}^{*}, x_{j}=x_{i}^{*}, x_{-i,-i}=x_{-i,-j}^{*}\right)=\frac{\partial F}{\partial x_{j}}\left(x_{i}=x_{i}^{*}, x_{j}=x_{j}^{*}, x_{-i,-i}=x_{-i,-j}^{*}\right) .
$$

Therefore,

$$
\frac{\partial F}{\partial x_{i}}\left(x_{i}=x_{i}^{*}, x_{j}=x_{j}^{*}, x_{-i,-i}=x_{-i,-j}^{*}\right) \leq \frac{\partial F}{\partial x_{j}}\left(x_{i}=x_{i}^{*}, x_{j}=x_{j}^{*}, x_{-i,-i}=x_{-i,-j}^{*}\right) .
$$

This completes the proof.

Lemma 9. Suppose that $y^{*}=\left(y_{i}^{*}, y_{j}^{*}, y_{-i,-j}^{*}\right)$ is an unproductive effort profile such that $y_{i}^{*}>y_{j}^{*}$. Under Assumptions 2, 3 and 4, we have $p_{i}\left(y^{*}\right)>p_{j}\left(y^{*}\right), \frac{\partial p_{i}}{\partial y_{i}}\left(y^{*}\right)<\frac{\partial p_{j}}{\partial y_{j}}\left(y^{*}\right), \frac{\partial p_{i}}{\partial y_{j}}\left(y^{*}\right)>\frac{\partial p_{j}}{\partial y_{i}}\left(y^{*}\right)$, $\frac{\partial p_{i}}{\partial y_{i}}\left(y^{*}\right)-\frac{\partial p_{i}}{\partial y_{j}}\left(y^{*}\right)>\frac{\partial p_{j}}{\partial y_{j}}\left(y^{*}\right)-\frac{\partial p_{j}}{\partial y_{i}}\left(y^{*}\right)$ and $\frac{\partial p_{l}}{\partial y_{i}}\left(y^{*}\right)>\frac{\partial p_{l}}{\partial y_{j}}\left(y^{*}\right)$, for any $l \neq i, j \in N$. 
Proof: Assumption $3(b)$ says that $\frac{\partial p_{i}}{\partial y_{i}}(y)>0$, for all $y \in Y$. Thus, if $y_{i}^{*}>y_{j}^{*}$, we have

$$
p_{i}\left(y_{i}=y_{i}^{*}, y_{j}=y_{j}^{*}, y_{-i,-j}=y_{-i,-j}^{*}\right)>p_{i}\left(y_{i}=y_{j}^{*}, y_{j}=y_{j}^{*}, y_{-i,-j}=y_{-i,-j}^{*}\right)
$$

Also, from Assumption 3(b), we know that $\frac{\partial p_{i}}{\partial y_{j}}(y)<0$, for all $y \in Y$. Hence, we have

$$
p_{i}\left(y_{i}=y_{j}^{*}, y_{j}=y_{j}^{*}, y_{-i,-j}=y_{-i,-j}^{*}\right)>p_{i}\left(y_{i}=y_{j}^{*}, y_{j}=y_{i}^{*}, y_{-i,-j}=y_{-i,-j}^{*}\right) .
$$

Furthermore, from Assumption 4, it is clear that

$$
p_{i}\left(y_{i}=y_{j}^{*}, y_{j}=y_{i}^{*}, y_{-i,-j}=y_{-i,-j}^{*}\right)=p_{j}\left(y_{i}=y_{i}^{*}, y_{j}=y_{j}^{*}, y_{-i,-j}=y_{-i,-j}^{*}\right)
$$

Therefore,

$$
p_{i}\left(y_{i}=y_{i}^{*}, y_{j}=y_{j}^{*}, y_{-i,-j}=y_{-i,-j}^{*}\right)>p_{j}\left(y_{j}=y_{j}^{*}, y_{i}=y_{i}^{*}, y_{-i,-j}=y_{-i,-j}^{*}\right) .
$$

We have now shown that $p_{i}\left(y^{*}\right)>p_{j}\left(y^{*}\right)$, for any unproductive strategy profile $y^{*}=\left(y_{i}^{*}, y_{j}^{*}, y_{-i,-j}^{*}\right)$, where $y_{i}^{*}>y_{j}^{*}$.

We next show that $\frac{\partial p_{i}}{\partial y_{i}}\left(y^{*}\right)<\frac{\partial p_{j}}{\partial y_{j}}\left(y^{*}\right)$. We know that $\frac{\partial^{2} p_{i}}{\partial y_{i}^{2}}(y)<0$, for all $y \in Y$, by Assumption $3(b)$. Hence, $y_{i}^{*}>y_{j}^{*}$ indicates that

$$
\frac{\partial p_{i}}{\partial y_{i}}\left(y_{i}=y_{i}^{*}, y_{j}=y_{j}^{*}, y_{-i,-j}=y_{-i,-j}^{*}\right)<\frac{\partial p_{i}}{\partial y_{i}}\left(y_{i}=y_{j}^{*}, y_{j}=y_{j}^{*}, y_{-i,-j}=y_{-i,-j}^{*}\right)
$$

Assumption 3(b) also says that $\frac{\partial^{2} p_{i}}{\partial y_{i} \partial y_{j}}(y)>0$, for all $y \in Y$. Therefore, if $y_{i}^{*}>y_{j}^{*}$, we also have

$$
\frac{\partial p_{i}}{\partial y_{i}}\left(y_{i}=y_{j}^{*}, y_{j}=y_{j}^{*}, y_{-i,-j}=y_{-i,-j}^{*}\right)<\frac{\partial p_{i}}{\partial y_{i}}\left(y_{i}=y_{j}^{*}, y_{j}=y_{i}^{*}, y_{-i,-j}=y_{-i,-j}^{*}\right)
$$

Then by Assumption 4, we know that

$$
\frac{\partial p_{i}}{\partial y_{i}}\left(y_{i}=y_{j}^{*}, y_{j}=y_{i}^{*}, y_{-i,-j}=y_{-i,-j}^{*}\right)=\frac{\partial p_{j}}{\partial y_{j}}\left(y_{i}=y_{i}^{*}, y_{j}=y_{j}^{*}, y_{-i,-j}=y_{-i,-j}^{*}\right)
$$


Thus,

$$
\frac{\partial p_{i}}{\partial y_{i}}\left(y_{i}=y_{i}^{*}, y_{j}=y_{j}^{*}, y_{-i,-j}=y_{-i,-j}^{*}\right)<\frac{\partial p_{j}}{\partial y_{j}}\left(y_{i}=y_{i}^{*}, y_{j}=y_{j}^{*}, y_{-i,-j}=y_{-i,-j}^{*}\right) .
$$

This completes the proof that $\frac{\partial p_{i}}{\partial y_{i}}\left(y^{*}\right)<\frac{\partial p_{j}}{\partial y_{j}}\left(y^{*}\right)$, for any unproductive effort profile $y^{*}=\left(y_{i}^{*}, y_{j}^{*}, y_{-i,-j}^{*}\right)$, where $y_{i}^{*}>y_{j}^{*}$.

Next, to show that $\frac{\partial p_{i}}{\partial y_{j}}\left(y^{*}\right)>\frac{\partial p_{j}}{\partial y_{i}}\left(y^{*}\right)$, first from Assumption $3(c)$, we have $0<\frac{\partial^{2} p_{i}}{\partial y_{i} \partial y_{j}}(y)<\frac{\partial^{2} p_{i}}{\partial y_{j}^{2}}(y)$.

Thus, $y_{i}^{*}>y_{j}^{*}$ indicates that

$$
\frac{\partial p_{i}}{\partial y_{j}}\left(y_{i}=y_{i}^{*}, y_{j}=y_{j}^{*}, y_{-i,-j}=y_{-i,-j}^{*}\right)>\frac{\partial p_{i}}{\partial y_{j}}\left(y_{i}=y_{j}^{*}, y_{j}=y_{i}^{*}, y_{-i,-j}=y_{-i,-j}^{*}\right)
$$

Then by Assumption $4, y_{i}^{*}>y_{j}^{*}$ also implies that

$$
\frac{\partial p_{i}}{\partial y_{j}}\left(y_{i}=y_{j}^{*}, y_{j}=y_{i}^{*}, y_{-i,-j}=y_{-i,-j}^{*}\right)=\frac{\partial p_{j}}{\partial y_{i}}\left(y_{j}=y_{j}^{*}, y_{i}=y_{i}^{*}, Y_{-i,-j}=Y_{-i,-j}^{*}\right)
$$

Hence,

$$
\frac{\partial p_{i}}{\partial y_{j}}\left(y_{i}=y_{i}^{*}, y_{j}=y_{j}^{*}, y_{-i,-j}=y_{-i,-j}^{*}\right)>\frac{\partial p_{j}}{\partial y_{i}}\left(y_{j}=y_{j}^{*}, y_{i}=y_{i}^{*}, Y_{-i,-j}=Y_{-i,-j}^{*}\right)
$$

This complete the proof that $\frac{\partial p_{i}}{\partial y_{j}}\left(y^{*}\right)>\frac{\partial p_{j}}{\partial y_{i}}\left(y^{*}\right)$, for any unproductive effort profile $y^{*}=\left(y_{i}^{*}, y_{j}^{*}, y_{-i,-j}^{*}\right)$, where $y_{i}^{*}>y_{j}^{*}$.

To prove that $\frac{\partial p_{i}}{\partial y_{i}}\left(y^{*}\right)-\frac{\partial p_{i}}{\partial y_{j}}\left(y^{*}\right)>\frac{\partial p_{j}}{\partial y_{j}}\left(y^{*}\right)-\frac{\partial p_{j}}{\partial y_{i}}\left(y^{*}\right)$, first from Assumption $3(c)$, we have $0<$ $\frac{\partial^{2} p_{i}}{\partial y_{i} \partial y_{j}}(y)<\frac{\partial^{2} p_{i}}{\partial y_{j}^{2}}(y)$. Therefore, $y_{i}^{*}>y_{j}^{*}$ implies that

$$
\begin{aligned}
& \frac{\partial p_{i}}{\partial y_{i}}\left(y_{i}=y_{i}^{*}, y_{j}=y_{j}^{*}, y_{-i,-j}=y_{-i,-j}^{*}\right)-\frac{\partial p_{i}}{\partial y_{j}}\left(y_{i}=y_{i}^{*}, y_{j}=y_{j}^{*}, y_{-i,-j}=y_{-i,-j}^{*}\right) \\
& >\frac{\partial p_{i}}{\partial y_{i}}\left(y_{i}=y_{i}^{*}, y_{j}=y_{i}^{*}, y_{-i,-j}=y_{-i,-j}^{*}\right)-\frac{\partial p_{i}}{\partial y_{j}}\left(y_{i}=y_{i}^{*}, y_{j}=y_{i}^{*}, y_{-i,-j}=y_{-i,-j}^{*}\right) .
\end{aligned}
$$

Assumption 3(c) also says that $\left|\frac{\partial^{2} p_{i}}{\partial y_{j} \partial y_{i}}(y)\right|<\left|\frac{\partial^{2} p_{i}}{\partial y_{i}^{2}}(y)\right|$. Hence, we have

$$
\begin{aligned}
& \frac{\partial p_{i}}{\partial y_{i}}\left(y_{i}=y_{i}^{*}, y_{j}=y_{i}^{*}, y_{-i,-j}=y_{-i,-j}^{*}\right)-\frac{\partial p_{i}}{\partial y_{j}}\left(y_{i}=y_{i}^{*}, y_{j}=y_{i}^{*}, y_{-i,-j}=y_{-i,-j}^{*}\right) \\
& >\frac{\partial p_{i}}{\partial y_{i}}\left(y_{i}=y_{j}^{*}, y_{j}=y_{i}^{*}, y_{-i,-j}=y_{-i,-j}^{*}\right)-\frac{\partial p_{i}}{\partial y_{j}}\left(y_{i}=y_{j}^{*}, y_{j}=y_{i}^{*}, y_{-i,-j}=y_{-i,-j}^{*}\right) .
\end{aligned}
$$


Furthermore, by Assumption 4, we have

$$
\begin{aligned}
& \frac{\partial p_{i}}{\partial y_{i}}\left(y_{i}=y_{j}^{*}, y_{j}=y_{i}^{*}, y_{-i,-j}=y_{-i,-j}^{*}\right)-\frac{\partial p_{i}}{\partial y_{j}}\left(y_{i}=y_{j}^{*}, y_{j}=y_{i}^{*}, y_{-i,-j}=y_{-i,-j}^{*}\right) \\
& =\frac{\partial p_{j}}{\partial y_{j}}\left(y_{j}=y_{j}^{*}, y_{i}=y_{i}^{*}, y_{-i,-j}=y_{-i,-j}^{*}\right)-\frac{\partial p_{j}}{\partial y_{i}}\left(y_{j}=y_{j}^{*}, y_{i}=y_{i}^{*}, y_{-i,-j}=y_{-i,-j}^{*}\right) .
\end{aligned}
$$

Therefore,

$$
\begin{aligned}
& \frac{\partial p_{i}}{\partial y_{i}}\left(y_{i}=y_{i}^{*}, y_{j}=y_{i}^{*}, y_{-i,-j}=y_{-i,-j}^{*}\right)-\frac{\partial p_{i}}{\partial y_{j}}\left(y_{i}=y_{i}^{*}, y_{j}=y_{i}^{*}, y_{-i,-j}=y_{-i,-j}^{*}\right) \\
& >\frac{\partial p_{j}}{\partial y_{j}}\left(y_{j}=y_{j}^{*}, y_{i}=y_{i}^{*}, y_{-i,-j}=y_{-i,-j}^{*}\right)-\frac{\partial p_{j}}{\partial y_{i}}\left(y_{j}=y_{j}^{*}, y_{i}=y_{i}^{*}, y_{-i,-j}=y_{-i,-j}^{*}\right)
\end{aligned}
$$

This completes the proof that $\frac{\partial p_{i}}{\partial y_{i}}\left(y^{*}\right)-\frac{\partial p_{i}}{\partial y_{j}}\left(y^{*}\right)>\frac{\partial p_{j}}{\partial y_{j}}\left(y^{*}\right)-\frac{\partial p_{j}}{\partial y_{i}}\left(y^{*}\right)$, for any unproductive effort profile $y^{*}=\left(y_{i}^{*}, y_{j}^{*}, y_{-i,-j}^{*}\right)$, where $y_{i}^{*}>y_{j}^{*}$.

Finally, we show that $\frac{\partial p_{l}}{\partial y_{i}}\left(y^{*}\right)>\frac{\partial p_{l}}{\partial y_{j}}\left(y^{*}\right)$, for any $l \neq i, j \in N$. We know that $0<\frac{\partial p_{l}^{2}}{\partial^{2} y_{i}}(y)<\frac{\partial^{2} p_{l}}{\partial y_{i} y_{j}}(y)$, where $l \neq i, j \in N$, for all $y \in Y$, by Assumption 3(d). Thus, we can show that for any $l \neq i, j \in N$,

$$
\frac{\partial p_{l}}{\partial y_{i}}\left(y_{i}=y_{i}^{*}, y_{j}=y_{j}^{*}, y_{-i,-j}=y_{-i,-j}^{*}\right)>\frac{\partial p_{l}}{\partial y_{j}}\left(y_{i}=y_{j}^{*}, y_{j}=y_{i}^{*}, y_{-i,-j}=y_{-i,-j}^{*}\right)
$$

Then by Assumption 4, we have

$$
p_{i}\left(y_{i}=y_{i}^{*}, y_{j}=y_{j}^{*}, y_{-i,-j}=y_{-i,-j}^{*}\right)=p_{j}\left(y_{j}=y_{i}^{*}, y_{i}=y_{j}^{*}, y_{-i,-j}=y_{-i,-j}^{*}\right)
$$

for any $\left(y_{i}^{*}, y_{j}^{*}, y_{-i,-j}^{*}\right) \in Y$ and $\left(y_{j}^{*}, y_{i}^{*}, y_{-i,-j}^{*}\right) \in Y$. Therefore, for any $l \neq i, j \in N$,

$$
\frac{\partial p_{l}}{\partial y_{i}}\left(y_{i}=y_{i}^{*}, y_{j}=y_{j}^{*}, y_{-i,-j}=y_{-i,-j}^{*}\right)>\frac{\partial p_{l}}{\partial y_{j}}\left(y_{j}=y_{j}^{*}, y_{i}=y_{i}^{*}, y_{-i,-j}=y_{-i,-j}^{*}\right)
$$

This completes the proof that $\frac{\partial p_{l}}{\partial y_{i}}\left(y^{*}\right)>\frac{\partial p_{l}}{\partial y_{j}}\left(y^{*}\right)$, for any $l \neq i, j \in N$ and for any unproductive effort profile $y^{*}=\left(y_{i}^{*}, y_{j}^{*}, y_{-i,-j}^{*}\right)$, where $y_{i}^{*}>y_{j}^{*}$.

Proposition 19. If the size of "cake" is $F$ and for player $i \in N$, his discount factor is $0<\delta_{i}<1$ and recognition probability is $p_{i}$, then under the unanimity voting rule with persistent effects, there exists a unique SSPE of the bargaining stage game. In this equilibrium, agreement is immediate at 
the first period, and player $i$ expects to receive

$$
s_{i}\left(F, p_{i}, p_{-i}\right)=\frac{\frac{p_{i}}{1-\delta_{i}} F}{\sum_{l=1}^{n} \frac{p_{l}}{1-\delta_{l}}},
$$

where $p_{-i}$ is the players' recognition probability profile which excludes player i's recognition probability.

Proof: We first show that in any stationary equilibrium, in the bargaining stage, if it is player $i$ 's chance to propose, it is the best option to offer player $j \delta_{j} s_{j}\left(F, p_{j}, p_{i}\right)$ so that player $j$ would accept this proposal and player $i$ could keep the rest. Hence, when player $i$ is the proposer, to make the proposal acceptable by all other players, player $i$ has to give $\sum_{j \neq i} \delta_{j} s_{j}\left(F, p_{j}, p_{-j}\right)$ to the other players, but retain the rest of the surplus, $F-\sum_{j \neq i} \delta_{j} s_{j}\left(F, p_{j}, p_{-j}\right)$. On the other hand, if he is not the proposer, then he will be given by his continuation payoff, $\delta_{i} s_{i}$. Thus, the expected equilibrium payoff for player $i$ can be expressed as

$$
s_{i}=p_{i}\left(F-\sum_{j \neq i} \delta_{j} s_{j}\right)+\left(1-p_{i}\right) \delta_{i} s_{i}
$$

This is to say,

$$
s_{i}=\frac{p_{i}}{1-\delta_{i}}\left(F-\sum_{l=1}^{n} \delta_{l} s_{l}\right) .
$$

Multiplying both sides of the above equation by $\delta_{i}$, and summing over $i \in N$ give us

$$
\sum_{l=1}^{n} \delta_{l} s_{l}=\frac{\sum_{l=1}^{n} \frac{\delta_{l} p_{l}}{1-\delta_{l}} F}{1+\sum_{l=1}^{n} \frac{\delta_{l} p_{l}}{1-\delta_{l}}}
$$

where $s_{l} \equiv s_{l}\left(F, p_{l}, p_{-l}\right)$. Combining the two equations above, and noting that $\sum_{l=1}^{n} \frac{\delta_{l} p_{l}}{1-\delta_{l}}=$ $\sum_{l=1}^{n} \frac{p_{l}}{1-\delta_{l}}-1$, we can now obtain Eq.(80).

Proposition 20. Suppose that Assumptions 2 and 3 hold. Then under the unanimity voting rule with persistent effects, if there exists a pure strategy SSPE of the bargaining stage game, then it must be unique.

Proof: By backwards induction, we know that in the pre-bargaining stage, each player $i \in N$ chooses the unproductive effort, $y_{i}$, and the productive effort, $x_{i}$, to maximize his expected payoff, 
$s_{i}$, or,

$$
\max _{x_{i}, y_{i}} s_{i}\left(F(x), p_{i}(y), p_{j}(y)\right)
$$

subject to the resource constraint:

$$
x_{i}+y_{i}=\sigma_{i} .
$$

Recall from Proposition 19, we have $s_{i}\left(F, p_{i}, p_{j}\right)=\frac{\frac{p_{i}}{1-\delta_{i}} F}{\sum_{l=1}^{n} \frac{p_{l}}{1-\delta_{l}}}$. Substituting it into the maximization problem (81) yields:

$$
\max _{x_{i}, y_{i}} \frac{\frac{p_{i}(y)}{1-\delta_{i}} F(x)}{\sum_{l=1}^{n} \frac{p_{l}}{1-\delta_{l}}} .
$$

Together with $x_{i}+y_{i}=\sigma_{i}$, agent $i$ 's maximization problem becomes:

$$
\max _{y_{i}} \frac{\frac{p_{i}}{1-\delta_{i}} F\left(x_{1}, x_{2}, \sigma_{i}-x_{i}, \ldots, x_{n}\right)}{\sum_{l=1}^{n} \frac{p_{l}}{1-\delta_{l}}} .
$$

Since $\frac{1}{1-\delta_{i}}>0$ is constant, it can be reduced to:

$$
\max _{x_{i}} \frac{F\left(x_{1}, x_{2}, \sigma_{i}-x_{i}, \ldots, x_{n}\right)}{\sum_{l=1}^{n} \frac{p_{l}}{1-\delta_{l}}} .
$$

The first order condition for the above problem is given by:

$$
\frac{1}{\left[\sum_{l=1}^{n} \frac{p_{l}}{1-\delta_{l}}\right]^{2}}\left\{\left[-\frac{\partial p_{i}}{\partial y_{i}} F(x)+p_{i} \frac{\partial F}{\partial x_{i}}\right] \sum_{l=1}^{n} \frac{p_{l}}{1-\delta_{l}}+p_{i} F(x) \sum_{l=1}^{n} \frac{1}{1-\delta_{l}} \frac{\partial p_{l}}{\partial y_{i}}\right\}=0,
$$

which provides the solution for player $i$ 's optimal unproductive effort, $y_{i}^{*}$. Rearrange it:

$$
\frac{1}{\left[\sum_{l=1}^{n} \frac{p_{l}}{1-\delta_{l}}\right]^{2}}\left\{F(x)\left[\frac{\partial p_{i}}{\partial y_{i}} \sum_{l=1}^{n} \frac{p_{l}}{1-\delta_{l}}-p_{i} \sum_{l=1}^{n} \frac{1}{1-\delta_{l}} \frac{\partial p_{l}}{\partial y_{i}}\right]-p_{i} \frac{\partial F}{\partial x_{i}} \sum_{l=1}^{n} \frac{p_{l}}{1-\delta_{l}}\right\}=0 .
$$

Then, simplifying it derives:

$$
F(x)\left[\sum_{l=1}^{n} \frac{1}{1-\delta_{l}}\left(p_{l} \frac{\partial p_{i}}{\partial y_{i}}-p_{i} \frac{\partial p_{l}}{\partial y_{i}}\right)\right]-p_{i} \frac{\partial F}{\partial x_{i}} \sum_{l=1}^{n} \frac{p_{l}}{1-\delta_{l}}=0 .
$$


Note that when $l=i$, we have $p_{l} \frac{\partial p_{i}}{\partial y_{i}}-p_{i} \frac{\partial p_{l}}{\partial y_{i}}=0$. Therefore, the above equation is equivalent to:

$$
F(x)\left[\sum_{l \neq i}^{n} \frac{1}{1-\delta_{l}}\left(p_{l} \frac{\partial p_{i}}{\partial y_{i}}-p_{i} \frac{\partial p_{l}}{\partial y_{i}}\right)\right]-p_{i} \frac{\partial F}{\partial x_{i}} \sum_{l=1}^{n} \frac{p_{l}}{1-\delta_{l}}=0 .
$$

From Assumption 2(b), we know that $\frac{\partial F}{\partial x_{i}}(x) \geq 0$, for any $x \in X$, from the resource constraint, we have $x_{i}+y_{i}=\sigma_{i}$, and from Assumption 3, we know that $\frac{\partial p_{i}}{\partial y_{j}}(y)<0, \frac{\partial^{2} p_{i}}{\partial y_{i}^{2}}(y)<0, \frac{\partial p_{i}}{\partial y_{i}}(y)>0$ and $\frac{\partial^{2} p_{i}}{\partial y_{j}^{2}}(y)>0$, for any $y \in Y$. Hence, $F(x)$ and $\sum_{l \neq i}^{n} \frac{1}{1-\delta_{l}}\left(p_{l} \frac{\partial p_{i}}{\partial y_{i}}-p_{i} \frac{\partial p_{l}}{\partial y_{i}}\right)$ are both decreasing in $y_{i}$. Besides, $\frac{\partial F}{\partial x_{i}}$ increases in $y_{i}$ because $x_{i}+y_{i}=\sigma_{i}$, by the resource constraint and $\frac{\partial^{2} F}{\partial x_{i}^{2}}(x) \leq 0$, for any $x \in X$, by Assumption 2(b). $p_{i} \sum_{l=1}^{n} \frac{p_{l}}{1-\delta_{l}}$ also increases in $y_{i}$ since Assumption 3(c) says that for any $y \in Y,\left|\frac{\partial p_{i}}{\partial y_{i}}(y)\right| \geq\left|\frac{\partial p_{j}}{\partial y_{i}}(y)\right|$ and $\frac{\partial p_{i}}{\partial y_{i}}(y)>0$. Hence, the left hand side of Eq.(82) is strictly decreasing in $y_{i}$. Since the right hand side is constant, then if there exists a SSPE, it must be unique. This completes the proof of uniqueness.

Proposition 21. Suppose that Assumptions 2, 3 and 4 hold. For any player $i, j \in N$, if their discount factors and their initial endowments are the same, i.e., $\delta_{i}=\delta_{j}$ and $\sigma_{i}=\sigma_{j}$, then under the unanimity voting rule with persistent effects, in equilibrium, the productive and unproductive efforts and the expected payoffs between players $i$ and $j$ are equal, i.e., $x_{i}^{*}=x_{j}^{*}, y_{i}^{*}=y_{j}^{*}$ and $s_{i}^{*}=s_{j}^{*}$.

Proof: From the proof of Proposition 20, we know that the optimal efforts for player $i$ must satisfy

$$
F(x)\left[\frac{\partial p_{i}}{\partial y_{i}} \sum_{l=1}^{n} \frac{p_{l}}{1-\delta_{l}}-p_{i} \sum_{l=1}^{n} \frac{1}{1-\delta_{l}} \frac{\partial p_{l}}{\partial y_{i}}\right]=p_{i} \frac{\partial F}{\partial x_{i}} \sum_{l=1}^{n} \frac{p_{l}}{1-\delta_{l}} .
$$

Since Assumption 4 says that players $i$ and $j$ are symmetric in producing the size of the cake and being recognized as a proposer, player $j$ 's optimal efforts have a similar expression. Namely, it shall solve the first order condition from player $j$ 's maximization problem:

$$
F(x)\left[\frac{\partial p_{j}}{\partial y_{j}} \sum_{k \in N} \frac{p_{k}}{1-\delta_{k}}-p_{j} \sum_{k \in N} \frac{1}{1-\delta_{k}} \frac{\partial p_{k}}{\partial y_{j}}\right]=p_{j} \frac{\partial F}{\partial x_{j}} \sum_{k \in N} \frac{p_{k}}{1-\delta_{k}}
$$

Taking the ratio of the above two equations derives:

$$
\frac{\frac{\partial p_{i}}{\partial y_{i}} \sum_{l=1}^{n} \frac{p_{l}}{1-\delta_{l}}-p_{i} \sum_{l=1}^{n} \frac{1}{1-\delta_{l}} \frac{\partial p_{l}}{\partial y_{i}}}{\frac{\partial p_{j}}{\partial y_{j}} \sum_{l=1}^{n} \frac{p_{l}}{1-\delta_{l}}-p_{j} \sum_{l=1}^{n} \frac{1}{1-\delta_{l}} \frac{\partial p_{l}}{\partial y_{j}}}=\frac{p_{i}}{p_{j}} \frac{\frac{\partial F}{\partial x_{i}}}{\frac{\partial F}{\partial x_{j}}}
$$


Rearranging yields:

$$
\frac{\sum_{l=1}^{n} \frac{1}{1-\delta_{l}}\left(p_{l} \frac{\partial p_{i}}{\partial y_{i}}-p_{i} \frac{\partial p_{l}}{\partial y_{i}}\right)}{\sum_{l=1}^{n} \frac{1}{1-\delta_{l}}\left(p_{l} \frac{\partial p_{j}}{\partial y_{j}}-p_{j} \frac{\partial p_{k}}{\partial y_{j}}\right)}=\frac{p_{i}}{p_{j}} \frac{\frac{\partial F}{\partial x_{i}}}{\frac{\partial F}{\partial x_{j}}} .
$$

Hence, for any player $i, j \in N$, in equilibrium, their efforts must satisfy Eq.(83).

We next show that $x_{i}^{*}=x_{j}^{*}$. Suppose not. Namely, $x_{i}^{*}<x_{j}^{*}$ or $x_{i}^{*}>x_{j}^{*}$.

If $x_{i}^{*}<x_{j}^{*}$, then Lemma 8 indicates that $\frac{\partial F}{\partial x_{i}}\left(x^{*}\right) \geq \frac{\partial F}{\partial x_{j}}\left(x^{*}\right)$. Also, if $x_{i}^{*}<x_{j}^{*}$, then we have $y_{i}^{*}>y_{j}^{*}$ because the initial endowments between the two players are the same, i.e., $\sigma_{i}=\sigma_{j}$, and for any $\left(x_{i}, y_{i}\right)$ and $\left(x_{j}, y_{j}\right)$, we have $x_{i}+y_{i}=\sigma_{i}$ and $x_{j}+y_{j}=\sigma_{j}$. Then by Lemma 9 , we have $p_{i}\left(y^{*}\right)>p_{j}\left(y^{*}\right)$. Hence, the right hand side of Eq.(83) is greater than 1.

For the left hand side of Eq.(83), Lemma 9 says that if $y_{i}^{*}>y_{j}^{*}$, then we have $p_{i}\left(y^{*}\right)>p_{j}\left(y^{*}\right)$, $\frac{\partial p_{i}}{\partial y_{i}}\left(y^{*}\right)<\frac{\partial p_{j}}{\partial y_{j}}\left(y^{*}\right)$ and $\frac{\partial p_{k}}{\partial y_{i}}\left(y^{*}\right)>\frac{\partial p_{k}}{\partial y_{j}}\left(y^{*}\right)$, where $k \neq i, j$. These imply that for any $l \neq i, j \in N$, we have

$$
\frac{1}{1-\delta_{l}}\left[p_{l}\left(y^{*}\right) \frac{\partial p_{i}}{\partial y_{i}}\left(y^{*}\right)-p_{i}\left(y^{*}\right) \frac{\partial p_{l}}{\partial y_{i}}\left(y^{*}\right)\right]<\frac{1}{1-\delta_{l}}\left[p_{l}\left(y^{*}\right) \frac{\partial p_{j}}{\partial y_{j}}\left(y^{*}\right)-p_{j}\left(y^{*}\right) \frac{\partial p_{l}}{\partial y_{j}}\left(y^{*}\right)\right]
$$

Summing over $l \neq i, j \in N$ derives:

$$
\begin{aligned}
& \sum_{l \neq i, j} \frac{1}{1-\delta_{l}}\left[p_{l}\left(y^{*}\right) \frac{\partial p_{i}}{\partial y_{i}}\left(y^{*}\right)-p_{i}\left(y^{*}\right) \frac{\partial p_{l}}{\partial y_{i}}\left(y^{*}\right)\right] \\
& <\sum_{l \neq i, j} \frac{1}{1-\delta_{l}}\left[p_{l}\left(y^{*}\right) \frac{\partial p_{j}}{\partial y_{j}}\left(y^{*}\right)-p_{j}\left(y^{*}\right) \frac{\partial p_{l}}{\partial y_{j}}\left(y^{*}\right)\right] .
\end{aligned}
$$

Then, as long as we can show that for $l=i, j \in N$, the following equation holds,

$$
\begin{aligned}
& \sum_{l=i, j} \frac{1}{1-\delta_{l}}\left[p_{l}\left(y^{*}\right) \frac{\partial p_{i}}{\partial y_{i}}\left(y^{*}\right)-p_{i}\left(y^{*}\right) \frac{\partial p_{l}}{\partial y_{i}}\left(y^{*}\right)\right] \\
& <\sum_{l=i, j} \frac{1}{1-\delta_{l}}\left[p_{l}\left(y^{*}\right) \frac{\partial p_{j}}{\partial y_{j}}\left(y^{*}\right)-p_{j}\left(y^{*}\right) \frac{\partial p_{l}}{\partial y_{j}}\left(y^{*}\right)\right]
\end{aligned}
$$

we can end up with the conclusion that the left hand side of Eq.(83) $<1<$ the right hand side of Eq.(83). Therefore, $x_{i}^{*}<x_{j}^{*}$ cannot be the case.

Note that Eq.(84) can be simplified as:

$$
\frac{1}{1-\delta_{j}}\left[p_{j}\left(y^{*}\right) \frac{\partial p_{i}}{\partial y_{i}}\left(y^{*}\right)-p_{i}\left(y^{*}\right) \frac{\partial p_{j}}{\partial y_{i}}\left(y^{*}\right)\right]<\frac{1}{1-\delta_{i}}\left[p_{i}\left(y^{*}\right) \frac{\partial p_{j}}{\partial y_{j}}\left(y^{*}\right)-p_{j}\left(y^{*}\right) \frac{\partial p_{i}}{\partial y_{j}}\left(y^{*}\right)\right]
$$


Also, by Lemma 9, we know that if $y_{i}^{*}>y_{j}^{*}$, then $p_{j}\left(y^{*}\right)<p_{i}\left(y^{*}\right), \frac{\partial p_{i}}{\partial y_{i}}\left(y^{*}\right)<\frac{\partial p_{j}}{\partial y_{j}}\left(y^{*}\right)$ and $\frac{\partial p_{j}}{\partial y_{i}}\left(y^{*}\right)<$ $\frac{\partial p_{i}}{\partial y_{j}}\left(y^{*}\right)$. Thus, the above equation is satisfied. Hence, we have that the left hand side of Eq.(83) $<1<$ the right hand side of Eq.(83), a contradiction.

By following a similar argument, we can show that if $x_{i}^{*}>x_{j}^{*}$, Eq.(83) does not hold.

Therefore, for any $i, j \in N$, if $\delta_{i}=\delta_{j}$ and $\sigma_{i}=\sigma_{j}$, then in equilibrium, the efforts between players $i$ and $j$ must satisfy $x_{i}^{*}=x_{j}^{*}$ and $y_{i}^{*}=y_{j}^{*}$. Together with the expected equilibrium payoff derived in Eq.(80), it can be shown that $s_{i}^{*}=s_{j}^{*}$. This completes the proof.

Claim 1. Suppose that $n=2$, and the production and recognition probability functions are defined in Eqs. (44) and (45), respectively. Then under the unanimity voting rule with persistent effects, there is a unique equilibrium such that players will produce a positive size of "cake", and the ratio of the optimal unproductive efforts of players must satisfy:

$$
\frac{y_{2}^{*}}{y_{1}^{*}}=\left(\frac{\frac{\alpha_{1}}{1-\delta_{1}}}{\frac{\alpha_{2}}{1-\delta_{2}}}\right)^{\frac{1}{1+m}} .
$$

Proof: The proof is followed by backwards induction. From the proof of Proposition 19, we know that in the pre-bargaining stage, player 1 chooses the efforts, $\left(x_{1}, y_{1}\right)$, to maximize his expected payoff, or,

$$
\max _{x_{1}, y_{1}} \frac{\frac{p_{1}(y)}{1-\delta_{1}} F(x)}{\frac{p_{1}}{1-\delta_{1}}+\frac{p_{2}}{1-\delta_{2}}}
$$

subject to the resource constraint:

$$
x_{1}+y_{1}=\sigma_{1} \text {. }
$$

Substitute $x_{1}=\sigma_{1}-y_{1}$ into problem $(86)$ :

$$
\max _{y_{1}} \frac{\frac{p_{1}(y)}{1-\delta_{1}} F\left(\sigma_{1}-y_{1}\right)}{\frac{p_{1}}{1-\delta_{1}}+\frac{p_{2}}{1-\delta_{2}}} .
$$

Given that $\frac{1}{1-\delta_{1}}>0$ is constant, the above problem can be reduced to:

$$
\max _{y_{1}} \frac{p_{1}(y) F\left(\sigma_{1}-y_{1}\right)}{\frac{p_{1}}{1-\delta_{1}}+\frac{p_{2}}{1-\delta_{2}}}
$$


By the monotonicity of the utility function, it is equivalent to

$$
\max _{y_{1}}\left\{\ln p_{1}(y)+\ln F\left(\sigma_{1}-y_{1}\right)-\ln \left(\frac{p_{1}}{1-\delta_{1}}+\frac{p_{2}}{1-\delta_{2}}\right)\right\}
$$

Then by substituting the production function defined in Eq.(44) and the recognition probability defined in Eq.(45), we have

$$
\max _{y_{1}}\left\{\ln \frac{y_{1}^{m}}{y_{1}^{m}+y_{2}^{m}}+\ln \left[\alpha_{1}\left(\sigma_{1}-y_{1}\right)+\alpha_{2}\left(\sigma_{2}-y_{2}\right)\right]-\ln \left(\frac{y_{1}^{m}}{y_{1}^{m}+y_{2}^{m}} \frac{1}{1-\delta_{1}}+\frac{y_{2}^{m}}{y_{1}^{m}+y_{2}^{m}} \frac{1}{1-\delta_{2}}\right)\right\}
$$

Simplifying it yields:

$$
\max _{y_{1}} \ln y_{1}^{m}+\ln \left[\alpha_{1}\left(\sigma_{1}-y_{1}\right)+\alpha_{2}\left(\sigma_{2}-y_{2}\right)\right]-\ln \left(\frac{y_{1}^{m}}{1-\delta_{1}}+\frac{y_{2}^{m}}{1-\delta_{2}}\right)
$$

Hence, player 1's optimal unproductive effort, $y_{1}^{*}$, must satisfy the first order condition for the above maximization problem:

$$
\frac{m y_{1}^{m-1}}{y_{1}^{m}}-\frac{\alpha_{1}}{\alpha_{1}\left(\sigma_{1}-y_{1}\right)+\alpha_{2}\left(\sigma_{2}-y_{2}\right)}-\frac{\frac{m y_{1}^{m-1}}{1-\delta_{1}}}{\frac{y_{1}^{m}}{1-\delta_{1}}+\frac{y_{2}^{m}}{1-\delta_{2}}}=0
$$

Simplify and rearrange it:

$$
\alpha_{1}\left(\sigma_{1}-y_{1}\right)+\alpha_{2}\left(\sigma_{2}-y_{2}\right)=\frac{\alpha_{1}}{m} y_{1} \frac{\frac{y_{1}^{m}}{1-\delta_{1}}+\frac{y_{2}^{m}}{1-\delta_{2}}}{\frac{y_{2}^{m}}{1-\delta_{2}}}
$$

Similarly, for player 2, we have

$$
\alpha_{1}\left(\sigma_{1}-y_{1}\right)+\alpha_{2}\left(\sigma_{2}-y_{2}\right)=\frac{\alpha_{2}}{m} y_{2} \frac{\frac{y_{1}^{m}}{1-\delta_{1}}+\frac{y_{2}^{m}}{1-\delta_{2}}}{\frac{y_{1}^{m}}{1-\delta_{1}}}
$$

Combining Eqs.(88) and (89) and simplifying it yield:

$$
\frac{y_{2}}{y_{1}}=\left(\frac{\frac{\alpha_{1}}{1-\delta_{1}}}{\frac{\alpha_{2}}{1-\delta_{2}}}\right)^{\frac{1}{1+m}}
$$

Thus, in equilibrium, players' optimal unproductive efforts, $y_{1}^{*}$ and $y_{2}^{*}$ must satisfy the above 
equation. This completes the proof.

Proposition 22. Suppose that Assumptions 2, 3 and 4 hold. Then under the unanimity voting rule with persistent effects, in equilibrium, there always exist some players that will spend certain efforts in production, i.e., $x^{*}=\left(x_{1}^{*}, x_{2}^{*}, \ldots, x_{n}^{*}\right) \neq(0,0, \ldots, 0)$.

Proof: The proof is followed by a contradiction. Suppose not, i.e., $x^{*}=\left(x_{1}^{*}, x_{2}^{*}, \ldots ., x_{n}^{*}\right)=$ $(0,0, \ldots, 0)$. Then, from the proof of Proposition 20, we know that in equilibrium, the following equation must hold for any player $i \in N$ :

$$
F(x)\left[\frac{\partial p_{i}}{\partial y_{i}} \sum_{l=1}^{n} \frac{p_{l}}{1-\delta_{l}}-p_{i} \sum_{l=1}^{n} \frac{1}{1-\delta_{l}} \frac{\partial p_{l}}{\partial y_{i}}\right]=p_{i} \frac{\partial F}{\partial x_{i}} \sum_{l=1}^{n} \frac{p_{l}}{1-\delta_{l}}
$$

Since $x^{*}=(0,0, \ldots, 0)$ implies that $F\left(x^{*}\right)=0$, the left hand side of the above equation is 0 . Besides, from Assumption 2, we know that for any $x \in X, \frac{\partial F}{\partial x_{i}}(x)>0$. From the budget constraint, we have $x_{i}+y_{i}=\sigma_{i}$, for any $i \in N$. Therefore, $x_{i}=0$ implies that $y_{i}=\sigma_{i}>0$. Hence, $p_{i}>0$, for any $i \in N$ and the right hand side of the above equation is greater than 0 , a contradiction.

Proposition 23. Suppose that Assumptions 2, 3 and 4 hold. For any player $i, j \in N$, given that other factors are the same and their discount factors satisfy: $\delta_{i}>\delta_{j}$, then under the unanimity voting rule with persistent effects, in equilibrium, the productive and unproductive efforts and the expected payoffs between the two players must have the following relationships: $x_{i}^{*}>x_{j}^{*}, y_{i}^{*}<y_{j}^{*}$ and $s_{i}>s_{j}$, respectively.

Proof: From the proof of Proposition 21, we know that the equilibrium efforts for some $i, j \in N$ must satisfy Eq.(83). Namely,

$$
\frac{\sum_{l=1}^{n} \frac{1}{1-\delta_{l}}\left(p_{l} \frac{\partial p_{i}}{\partial y_{i}}-p_{i} \frac{\partial p_{l}}{\partial y_{i}}\right)}{\sum_{l=1}^{n} \frac{1}{1-\delta_{l}}\left(p_{l} \frac{\partial p_{j}}{\partial y_{j}}-p_{j} \frac{\partial p_{l}}{\partial y_{j}}\right)}=\frac{p_{i}}{p_{j}} \frac{\frac{\partial F}{\partial x_{i}}}{\frac{\partial F}{\partial x_{j}}}
$$

Then the proof is followed by a contradiction. Suppose not. Namely, $x_{i}^{*} \leq x_{j}^{*}$. Since the initial endowments of players $i$ and $j$ are the same, i.e., $\sigma_{i}=\sigma_{j}$ and for any $\left(x_{i}, y_{i}\right),\left(x_{j}, y_{j}\right)$, we have $x_{i}+y_{i}=\sigma_{i}, x_{j}+y_{j}=\sigma_{j}, x_{i}^{*}<x_{j}^{*}$ implies that $y_{i}^{*} \geq y_{j}^{*}$. Together with Lemmas 8 and 9 , we can show that $\frac{\partial F}{\partial x_{i}}\left(x^{*}\right) \geq \frac{\partial F}{\partial x_{j}}\left(x^{*}\right)$ and $p_{i}\left(y^{*}\right)>p_{j}\left(y^{*}\right)$. Therefore, the right hand of Eq.(83) $\geq 1$.

Regarding the left hand side of Eq.(83), similar to the proof of Proposition 21, since $x_{i}^{*} \leq x_{j}^{*}$ and 
$y_{i}^{*} \geq y_{j}^{*}$, it can be verified that

$$
\begin{aligned}
& \sum_{l \neq i, j} \frac{1}{1-\delta_{l}}\left[p_{l}\left(y^{*}\right) \frac{\partial p_{i}}{\partial y_{i}}\left(y^{*}\right)-p_{i}\left(y^{*}\right) \frac{\partial p_{l}}{\partial y_{i}}\left(y^{*}\right)\right] \\
& <\sum_{l \neq i, j} \frac{1}{1-\delta_{l}}\left[p_{l}\left(y^{*}\right) \frac{\partial p_{j}}{\partial y_{j}}\left(y^{*}\right)-p_{j}\left(y^{*}\right) \frac{\partial p_{l}}{\partial y_{j}}\left(y^{*}\right)\right] .
\end{aligned}
$$

For $l=i, j \in N$, from Lemma 9, we know that if $y_{i}^{*} \geq y_{j}^{*}$, then $p_{j}\left(y^{*}\right) \leq p_{i}\left(y^{*}\right), \frac{\partial p_{i}}{\partial y_{i}}\left(y^{*}\right) \leq \frac{\partial p_{j}}{\partial y_{j}}\left(y^{*}\right)$ and $\frac{\partial p_{j}}{\partial y_{i}}\left(y^{*}\right) \leq \frac{\partial p_{i}}{\partial y_{j}}\left(y^{*}\right)$. Therefore, we can show that

$$
p_{j}\left(y^{*}\right) \frac{\partial p_{i}}{\partial y_{i}}\left(y^{*}\right)-p_{i}\left(y^{*}\right) \frac{\partial p_{j}}{\partial y_{i}}\left(y^{*}\right) \leq p_{i}\left(y^{*}\right) \frac{\partial p_{j}}{\partial y_{j}}\left(y^{*}\right)-p_{j}\left(y^{*}\right) \frac{\partial p_{i}}{\partial y_{j}}\left(y^{*}\right)
$$

Then $\delta_{i}>\delta_{j}$ implies that

$$
\frac{1}{1-\delta_{j}}\left[p_{j}\left(y^{*}\right) \frac{\partial p_{i}}{\partial y_{i}}\left(y^{*}\right)-p_{i}\left(y^{*}\right) \frac{\partial p_{j}}{\partial y_{i}\left(y^{*}\right)}\right]<\frac{1}{1-\delta_{i}}\left[p_{i}\left(y^{*}\right) \frac{\partial p_{j}}{\partial y_{j}}\left(y^{*}\right)-p_{j}\left(y^{*}\right) \frac{\partial p_{i}}{\partial y_{j}}\left(y^{*}\right)\right]
$$

By adding the term, $\frac{1}{1-\delta_{i}}\left[p_{i}\left(y^{*}\right) \frac{\partial p_{i}}{\partial y_{i}}\left(y^{*}\right)-p_{i}\left(y^{*}\right) \frac{\partial p_{i}}{\partial y_{i}}\left(y^{*}\right)\right]$, to the left hand side, and, the term, $\frac{1}{1-\delta_{j}}\left[p_{j}\left(y^{*}\right) \frac{\partial p_{j}}{\partial y_{j}}\left(y^{*}\right)-p_{j}\left(y^{*}\right) \frac{\partial p_{j}}{\partial y_{j}}\left(y^{*}\right)\right]$, to the right hand side, the above equation can be rewritten as

$$
\begin{aligned}
& \sum_{l=i, j} \frac{1}{1-\delta_{l}}\left[p_{l}\left(y^{*}\right) \frac{\partial p_{i}}{\partial y_{i}}\left(y^{*}\right)-p_{i}\left(y^{*}\right) \frac{\partial p_{l}}{\partial y_{i}}\left(y^{*}\right)\right] \\
& <\sum_{l=i, j} \frac{1}{1-\delta_{l}}\left[p_{l}\left(y^{*}\right) \frac{\partial p_{j}}{\partial y_{j}}\left(y^{*}\right)-p_{j}\left(y^{*}\right) \frac{\partial p_{l}}{\partial y_{j}}\left(y^{*}\right)\right]
\end{aligned}
$$

Combining Eqs.(90) and (91) yields:

$$
\begin{aligned}
& \sum_{l=1}^{n} \frac{1}{1-\delta_{k}}\left[p_{k}\left(y^{*}\right) \frac{\partial p_{i}}{\partial y_{i}}\left(y^{*}\right)-p_{i}\left(y^{*}\right) \frac{\partial p_{k}}{\partial y_{i}}\left(y^{*}\right)\right] \\
& <\sum_{l=1}^{n} \frac{1}{1-\delta_{k}}\left[p_{k}\left(y^{*}\right) \frac{\partial p_{j}}{\partial y_{j}}\left(y^{*}\right)-p_{j}\left(y^{*}\right) \frac{\partial p_{k}}{\partial y_{j}}\left(y^{*}\right)\right] .
\end{aligned}
$$

Hence, the left hand side of of Eq.(83) $<1 \leq$ the right hand side of Eq.(83), a contradiction. Thus, we have shown that for any player $i, j \in N$, if $\delta_{i}>\delta_{j}$, then in equilibrium the optimal efforts must satisfy $x_{i}^{*}>x_{j}^{*}$ and $y_{i}^{*}<y_{j}^{*}$. 
Finally, to prove that $s_{i}>s_{j}$, first, from the proof of Proposition 21, we know that the equilibrium efforts for some $i, j \in N$ must satisfy Eq.(83). Namely,

$$
\frac{\sum_{l=1}^{n} \frac{1}{1-\delta_{l}}\left(p_{l} \frac{\partial p_{i}}{\partial y_{i}}-p_{i} \frac{\partial p_{l}}{\partial y_{i}}\right)}{\sum_{l=1}^{n} \frac{1}{1-\delta_{l}}\left(p_{l} \frac{\partial p_{j}}{\partial y_{j}}-p_{j} \frac{\partial p_{l}}{\partial y_{j}}\right)}=\frac{p_{i}}{p_{j}} \frac{\frac{\partial F}{\partial x_{i}}}{\frac{\partial F}{\partial x_{j}}}
$$

Rearrange, we have

$$
\frac{\sum_{l=1}^{n} \frac{1}{1-\delta_{l}}\left(p_{l} \frac{\partial p_{i}}{\partial y_{i}}-p_{i} \frac{\partial p_{l}}{\partial y_{i}}\right)}{\sum_{l=1}^{n} \frac{1}{1-\delta_{l}}\left(p_{l} \frac{\partial p_{j}}{\partial y_{j}}-p_{j} \frac{\partial p_{l}}{\partial y_{j}}\right)} \frac{\frac{\partial F}{\partial x_{i}}}{\frac{\partial F}{\partial x_{j}}}=\frac{p_{i}}{p_{j}}
$$

Then, from the previous proof, we know that $\frac{\frac{\partial F}{\partial x_{j}}\left(x^{*}\right)}{\frac{\partial F}{\partial x_{i}}\left(x^{*}\right)}>1, \frac{p_{i}\left(y^{*}\right)}{p_{j}\left(y^{*}\right)}<1$,

$$
\frac{\sum_{l \neq i, j} \frac{1}{1-\delta_{l}}\left[p_{l}\left(y^{*}\right) \frac{\partial p_{i}}{\partial y_{i}}\left(y^{*}\right)-p_{i}\left(y^{*}\right) \frac{\partial p_{l}}{\partial y_{i}}\left(y^{*}\right)\right]}{\sum_{l \neq i, j} \frac{1}{1-\delta_{l}}\left[p_{l}\left(y^{*}\right) \frac{\partial p_{j}}{\partial y_{j}}\left(y^{*}\right)-p_{j}\left(y^{*}\right) \frac{\partial p_{l}}{\partial y_{j}}\left(y^{*}\right)\right]}>1
$$

and

$$
p_{j}\left(y^{*}\right) \frac{\partial p_{i}}{\partial y_{i}}\left(y^{*}\right)-p_{i}\left(y^{*}\right) \frac{\partial p_{j}}{\partial y_{i}}\left(y^{*}\right)>p_{i}\left(y^{*}\right) \frac{\partial p_{j}}{\partial y_{j}}\left(y^{*}\right)-p_{j}\left(y^{*}\right) \frac{\partial p_{i}}{\partial y_{j}}\left(y^{*}\right)
$$

Therefore, in order for the left hand side of Eq.(92) to be less than 1, we must have

$$
\frac{\sum_{l=1}^{n} \frac{1}{1-\delta_{l}}\left[p_{l}\left(y^{*}\right) \frac{\partial p_{i}}{\partial y_{i}}\left(y^{*}\right)-p_{i}\left(y^{*}\right) \frac{\partial p_{l}}{\partial y_{i}}\left(y^{*}\right)\right]}{\sum_{l=1}^{n} \frac{1}{1-\delta_{l}}\left[p_{l}\left(y^{*}\right) \frac{\partial p_{j}}{\partial y_{j}}\left(y^{*}\right)-p_{j}\left(y^{*}\right) \frac{\partial p_{l}}{\partial y_{j}}\left(y^{*}\right)\right]} \frac{\frac{\partial F}{\partial x_{j}}\left(x^{*}\right)}{\frac{\partial F}{\partial x_{i}}\left(x^{*}\right)}>\frac{1-\delta_{i}}{1-\delta_{j}}
$$

Or, $\frac{p_{i}\left(y^{*}\right)}{p_{j}\left(y^{*}\right)}>\frac{1-\delta_{i}}{1-\delta_{j}}$.

Besides, from Proposition 19, we know that

$$
s_{i}=\frac{\frac{p_{i}\left(y^{*}\right)}{1-\delta_{i}} F}{\sum_{l=1}^{n} \frac{p_{l}\left(y^{*}\right)}{1-\delta_{l}}} ; \quad s_{j}=\frac{\frac{p_{j}\left(y^{*}\right)}{1-\delta_{j}} F}{\sum_{l=1}^{n} \frac{p_{l}\left(y^{*}\right)}{1-\delta_{l}}} .
$$

Therefore,

$$
\frac{s_{i}}{s_{j}}=\frac{p_{i}\left(y^{*}\right)}{p_{j}\left(y^{*}\right)} \frac{1-\delta_{j}}{1-\delta_{i}}>\frac{1-\delta_{i}}{1-\delta_{j}} \frac{1-\delta_{j}}{1-\delta_{i}}=1
$$

This completes the proof that if $\delta_{i}>\delta_{j}$, then we must have $s_{i}>s_{j}$. 
Proposition 24. Suppose that Assumptions 2, 3 and 4 hold. For any player $i, j \in N$, given that other factors are the same and their initial endowments satisfy: $\sigma_{i}>\sigma_{j}$, then under the unanimity voting rule with persistent effects, in equilibrium, the productive and unproductive efforts and the expected payoffs between the two players must have the following relationships: $x_{i}^{*}>x_{j}^{*}, y_{i}^{*} \geq y_{j}^{*}$ and $s_{i} \geq s_{j}$, respectively.

Proof: Suppose not, i.e., $y_{i}^{*}<y_{j}^{*}$, or $y_{i}^{*}>y_{j}^{*}$ and $x_{i}^{*} \leq x_{j}^{*}$. Note that in equilibrium, the efforts for players $i$ and $j$ must still satisfy Eq.(83).

Then, if $y_{i}^{*}<y_{j}^{*}$, given that $\sigma_{i}>\sigma_{j}, x_{i}^{*}+y_{i}^{*}=\sigma_{i}$ and $x_{j}^{*}+y_{j}^{*}=\sigma_{j}$, it indicates that $x_{i}^{*}>x_{j}^{*}$. By Lemma 8, we have $\frac{\partial F}{\partial x_{i}}\left(x^{*}\right) \leq \frac{\partial F}{\partial x_{j}}\left(x^{*}\right)$ and by Lemma 9 , we have $p_{i}\left(y^{*}\right)<p_{j}\left(y^{*}\right)$. Thus, the right hand side of Eq. $(83)<1$. Then by following similar steps as in deriving Proposition 21, we can show that if $x_{i}^{*}>x_{j}^{*}, y_{i}^{*}<y_{j}^{*}$ and $\delta_{i}=\delta_{j}$, we have

$$
\begin{aligned}
& \sum_{l=1}^{n} \frac{1}{1-\delta_{l}}\left[p_{l}\left(y^{*}\right) \frac{\partial p_{i}}{\partial y_{i}}\left(y^{*}\right)-p_{i}\left(y^{*}\right) \frac{\partial p_{l}}{\partial y_{i}}\left(y^{*}\right)\right] \\
& >\sum_{l=1}^{n} \frac{1}{1-\delta_{l}}\left[p_{l}\left(y^{*}\right) \frac{\partial p_{j}}{\partial y_{j}}\left(y^{*}\right)-p_{j}\left(y^{*}\right) \frac{\partial p_{l}}{\partial y_{j}}\left(y^{*}\right)\right] .
\end{aligned}
$$

It implies that the right hand side of Eq.(83) is less than 1. Thus, the left hand side of Eq.(83) $>1>$ the right hand side of Eq.(83), a contradiction.

Similarly, if $y_{i}^{*}>y_{j}^{*}$ and $x_{i}^{*} \leq x_{j}^{*}$, then we can show that the left hand side of Eq. $(83)<1<$ the right hand side of Eq.(83), a contradiction. This completes the proof that if $\sigma_{i}>\sigma_{j}$, then the equilibrium efforts between players $i$ and $j$ must satisfy $x_{i}^{*}>x_{j}^{*}$ and $y_{i}^{*} \geq y_{j}^{*}$.

Finally, we show that if $\sigma_{i}>\sigma_{j}$, then $s_{i} \geq s_{j}$. From Proposition 19, we know that the expected equilibrium payoffs of players $i$ and $j$ are

$$
s_{i}=\frac{\frac{p_{i}}{1-\delta_{i}} F}{\sum_{l=1}^{n} \frac{p_{l}}{1-\delta_{l}}}
$$

and

$$
s_{j}=\frac{\frac{p_{j}}{1-\delta_{j}} F}{\sum_{l=1}^{n} \frac{p_{l}}{1-\delta_{l}}},
$$

respectively. Besides, $y_{i}^{*} \geq y_{j}^{*}$ implies that $p_{i} \geq p_{j}$. Hence, $s_{i} \geq s_{j}$. This completes the proof. 
Proposition 25. Suppose that Assumptions 2, 3 and 4 hold. For any player $i, j \in N$, if their discount factors and their initial endowments are the same, i.e., $\delta_{i}=\delta_{j}$ and $\sigma_{i}=\sigma_{j}$, and they are sufficiently patient, then under the $k$-majority voting rule with persistent effects, in equilibrium, the productive and unproductive efforts and the expected payoffs between players $i$ and $j$ are equal, i.e., $x_{i}^{*}=x_{j}^{*}, y_{i}^{*}=y_{j}^{*}$ and $s_{i}=s_{j}$.

Proof: We start by proving the following lemma. It characterizes the relationship between one player's unproductive effort and the cost that he has to spend when being recognized as a proposer.

Lemma 10. Suppose that Assumptions 2, 3 and 4 hold and $y^{*}=\left(y_{i}^{*}, y_{j}^{*}, y_{-i,-j}^{*}\right)$ is an unproductive effort profile such that $y_{i}^{*}>y_{j}^{*}$. Then under the unanimity voting rule with persistent effects, we have

$$
\frac{\partial s_{l}}{\partial y_{i}}\left(y^{*}\right)>\frac{\partial s_{l}}{\partial y_{j}}\left(y^{*}\right)
$$

where $l \neq i, j \in\{1,2, \ldots, k\}$.

Proof: By Eqs.(47), (48) and (49), we know that for any player $l$, where $l=\{1,2, \ldots, k\}$, the expected equilibrium payoff can be expressed as follows:

$$
s_{l}=p_{l}\left(F-\omega_{k}-\delta_{k} s_{k}+\delta_{l} s_{l}\right)+\left(1-p_{l}\right) \delta_{l} s_{l}
$$

Rearranging it, we have

$$
s_{l}=\frac{p_{l}}{1-\delta_{l}}\left(F-\omega_{k}-\delta_{k} s_{k}\right)
$$

Substitute $\omega_{k}^{\prime}=\sum_{l=1}^{k} \delta_{l} s_{l}$ into the above equation,

$$
s_{l}=\frac{p_{l}}{1-\delta_{l}}\left(F-\omega_{k}^{\prime}\right)
$$

Therefore, for any $y^{*}=\left(y_{i}^{*}, y_{j}^{*}, y_{-i,-j}^{*}\right) \in Y$ such that $y_{i}^{*}>y_{j}^{*}$, the following equation must hold:

$$
s_{l}\left(y^{*}\right)=\frac{p_{l}\left(y^{*}\right)}{1-\delta_{l}}\left(F\left(y^{*}\right)-\omega_{k}^{\prime}\left(y^{*}\right)\right)
$$

From the resource constrains, we know that for any $i \in N$, we have $x_{i}+y_{i}=\sigma_{i}$. Substituting the 
resource constraint into it and then totally differentiating it with respect to $y_{i}^{*}$ and $y_{j}^{*}$, we have

$$
\frac{\partial s_{l}}{\partial y_{i}^{*}}\left(y^{*}\right)=\frac{1}{1-\delta_{l}}\left\{\frac{\partial p_{l}}{\partial y_{i}^{*}}\left(y^{*}\right)+p_{l}\left(y^{*}\right)\left[-\frac{\partial F}{\partial x_{i}^{*}}\left(x^{*}\right)-\frac{\partial \omega_{k}^{\prime}}{\partial y_{i}^{*}}\left(y^{*}\right)\right]\right\}
$$

and

$$
\frac{\partial s_{l}}{\partial y_{j}^{*}}\left(y^{*}\right)=\frac{1}{1-\delta_{l}}\left\{\frac{\partial p_{l}}{\partial y_{j}^{*}}\left(y^{*}\right)+p_{l}\left(y^{*}\right)\left[-\frac{\partial F}{\partial x_{j}^{*}}\left(x^{*}\right)-\frac{\partial \omega_{k}^{\prime}}{\partial y_{j}^{*}}\left(y^{*}\right)\right]\right\},
$$

respectively. Take the ratio of the above two equations,

$$
\frac{\frac{\partial s_{l}}{\partial y_{i}^{*}}\left(y^{*}\right)}{\frac{\partial s_{l}}{\partial y_{j}^{*}}\left(y^{*}\right)}=\frac{\frac{\partial p_{l}}{\partial y_{i}^{*}}\left(y^{*}\right)+p_{l}\left(y^{*}\right)\left[-\frac{\partial F}{\partial x_{i}^{*}}\left(x^{*}\right)-\frac{\partial \omega_{k}^{\prime}}{\partial y_{i}^{*}}\left(y^{*}\right)\right]}{\frac{\partial p_{l}}{\partial y_{j}^{*}}\left(y^{*}\right)+p_{l}\left(y^{*}\right)\left[-\frac{\partial F}{\partial x_{j}^{*}}\left(x^{*}\right)-\frac{\partial \omega_{k}^{\prime}}{\partial y_{j}^{*}}\left(y^{*}\right)\right]}
$$

From Lemmas 8 and 9 , we know that for any $x_{i}^{*}=\left(x_{i}^{*}, x_{j}^{*}, x_{-i,-j}^{*}\right)$ such that $x_{i}^{*}<x_{j}^{*}, y_{i}^{*}=$ $\left(y_{i}^{*}, y_{j}^{*}, y_{-i,-j}^{*}\right)$ such that $y_{i}^{*}>y_{j}^{*}$, and $l \neq i, j$, we have $\frac{\partial F\left(x^{*}\right)}{\partial x_{i}^{*}}<\frac{\partial F\left(x^{*}\right)}{\partial x_{j}^{*}}, \frac{p_{l}\left(y^{*}\right)}{\partial y_{i}^{*}}>\frac{p_{l}\left(y^{*}\right)}{\partial y_{j}^{*}}$. Together with $\omega_{k}^{\prime}=\sum_{l=1}^{k} \delta_{k} s_{k}$, in order for the above equation to hold, we must have $\frac{\partial s_{l}}{\partial y_{i}}>\frac{\partial s_{l}}{\partial y_{j}}$. This completes the proof of Lemma 3.

The next step of proving Proposition 25 is followed by a contradiction. Suppose not. Namely, $s_{i} \neq s_{j}$. Since players $i$ and $j$ are symmetric in all the factors, without loss of generality, assume that $s_{i}<s_{j}$.

Baraon and Ferejohn [6] show that under an infinite sequential bargaining model with $k$-majority voting rule, the game ends in period 1. Note that the model described in Baraon and Ferejohn [6] is equivalent to our model in the bargaining stage under the $k$-majority rule with persistent effects. Hence, in our bargaining model, the "cake" will be shared according to the proposal in period 1 . To show that $s_{i} \neq s_{j}$ cannot be the case, we now consider three possible equilibrium paths.

Equilibrium path 1: Suppose that in period 1, players $i$ and $j$ are in the winning coalition, i.e., $\delta_{i} s_{i}<\delta_{j} s_{j}<\delta_{k} s_{k}$.

Substituting Eqs.(48) and (49) into Eq.(47) derives player $i$ 's expected equilibrium payoff as follows:

$$
s_{i}=p_{i}\left(F-\omega_{k}-\delta_{k} s_{k}+\delta_{i} s_{i}\right)+\left(1-p_{i}\right) \delta_{i} s_{i} .
$$


Rearranging it, we have

$$
s_{i}=\frac{p_{i}}{1-\delta_{i}}\left(F-\omega_{k}-\delta_{k} s_{k}\right)
$$

In the pre-bargaining stage, player $i$ solves the following maximization problem:

$$
\max _{x_{i}, y_{i}} \frac{p_{i}}{1-\delta_{i}}\left(F-\omega_{k}-\delta_{k} s_{k}\right)
$$

subject to the recourse constraint:

$$
x_{i}+y_{i}=\sigma_{i} .
$$

Substituting the resource constraint $x_{i}+y_{i}=\sigma_{i}$ into it, we have

$$
\max _{y_{i}} \frac{p_{i}}{1-\delta_{i}}\left[F\left(x_{1}, \ldots, \sigma_{i}-y_{i}, \ldots x_{n}\right)-\omega_{k}-\delta_{k} s_{k}\right]
$$

Solving the above maximization problem derives player $i$ 's optimal unproductive effort, $y_{i}^{*}$, which satisfies the following equation:

$$
\frac{\partial p_{i}}{\partial y_{i}}\left[F-\omega_{k}-\delta_{k} s_{k}\right]+p_{i}\left[-\frac{\partial F}{\partial x_{i}}-\frac{\partial}{\partial y_{i}}\left(\omega_{k}+\delta_{k} s_{k}\right)\right]=0 .
$$

Rearrange,

$$
\frac{\partial p_{i}}{\partial y_{i}}\left[F-\omega_{k}-\delta_{k} s_{k}\right]=p_{i}\left[\frac{\partial F}{\partial x_{i}}+\frac{\partial}{\partial y_{i}}\left(\omega_{k}+\delta_{k} s_{k}\right)\right]
$$

For player $j$ 's maximization problem, from Assumption 4, we know that players $i$ and $j$ are symmetric in producing the cake and being recognized as a proposer. Therefore, player $j$ 's optimal unproductive effort, $y_{j}^{*}$, has a similar expression and must satisfy the following first order condition:

$$
\frac{\partial p_{j}}{\partial y_{j}}\left[F-\omega_{k}-\delta_{k} s_{k}\right]=p_{j}\left[\frac{\partial F}{\partial x_{j}}+\frac{\partial}{\partial y_{j}}\left(\omega_{k}+\delta_{k} s_{k}\right)\right]
$$

Take the ratio of Eqs.(96) and (97) and simplify it:

$$
\frac{\frac{\partial p_{i}}{\partial y_{i}}}{\frac{\partial p_{j}}{\partial y_{j}}}=\frac{p_{i}}{p_{j}} \frac{\frac{\partial F}{\partial x_{i}}+\frac{\partial}{\partial y_{i}}\left(\omega_{k}+\delta_{k} s_{k}\right)}{\frac{\partial F}{\partial x_{j}}+\frac{\partial}{\partial y_{j}}\left(\omega_{k}+\delta_{k} s_{k}\right)} .
$$

Therefore, in equilibrium, the efforts between players $i$ and $j$ shall have the relationship above. 
Then, we show that in order for the above equation to hold, we must have: $y_{i}^{*}=y_{j}^{*}$. Suppose not, i.e., $y_{i}^{*}<y_{j}^{*}$ or $y_{i}^{*}>y_{j}^{*}$. If $y_{i}^{*}<y_{j}^{*}$, then we have $x_{i}^{*}>x_{j}^{*}$ because for any $\left(x_{i}, y_{i}\right)$ and $\left(x_{j}, y_{j}\right)$, we have $x_{i}+y_{i}=\sigma_{i}, x_{j}+y_{j}=\sigma_{j}$, and the initial endowments between players $i$ and $j$ are the same, i.e., $\sigma_{i}=\sigma_{j}$. Then by Lemma $9, y_{i}^{*}<y_{j}^{*}$ implies that $\frac{\partial p_{i}}{\partial y_{i}}\left(y^{*}\right)>\frac{\partial p_{j}}{\partial y_{j}}\left(y^{*}\right)$ and $p_{i}\left(y^{*}\right)<p_{j}\left(y^{*}\right)$, by Lemma $8, x_{i}^{*}>x_{j}^{*}$ indicates that $\frac{\partial F}{\partial x_{i}}\left(x^{*}\right)<\frac{\partial F}{\partial x_{j}}\left(x^{*}\right)$ and by Lemma $10, y_{i}^{*}<y_{j}^{*}$ shows that $\frac{\partial}{\partial y_{i}}\left(\sum_{l \neq i, j}^{k-1} \delta_{l} s_{l} s_{l}\left(y^{*}\right)+\delta_{k} s_{k} s_{l}\left(y^{*}\right)\right)<\frac{\partial}{\partial y_{j}}\left(\sum_{l \neq i, j}^{k-1} \delta_{l} s_{l} s_{l}\left(y^{*}\right)+\delta_{k} s_{k} s_{l}\left(y^{*}\right)\right)$. Then as long as we can show that for $l=i, j$, we have

$$
\frac{\partial}{\partial y_{i}} \delta_{l} s_{l}\left(y^{*}\right)<\frac{\partial}{\partial y_{j}} \delta_{l} s_{l}\left(y^{*}\right)
$$

the left hand side $>1>$ the right hand side of Eq.(98), a contradiction. To show this, first we totally differentiate player $i$ 's expected equilibrium payoff with respect to $y_{j}$ and player $j^{\prime}$ s expected equilibrium payoff with respect to $y_{i}$, respectively:

$$
\begin{aligned}
& \frac{\partial s_{i}}{\partial y_{j}}=\frac{1}{1-\delta_{i}}\left[\frac{\partial p_{i}}{\partial y_{j}}\left(F-\omega_{k}-\delta_{k} s_{k}\right)+p_{i} \frac{\partial}{\partial y_{j}}\left(F-\omega_{k}-\delta_{k} s_{k}\right)\right] \\
& \frac{\partial s_{j}}{\partial y_{i}}=\frac{1}{1-\delta_{j}}\left[\frac{\partial p_{j}}{\partial y_{i}}\left(F-\omega_{k}-\delta_{k} s_{k}\right)+p_{i} \frac{\partial}{\partial y_{i}}\left(F-\omega_{k}-\delta_{k} s_{k}\right)\right] .
\end{aligned}
$$

Take the ratio of them:

$$
\frac{\frac{\partial s_{i}}{\partial y_{j}}}{\frac{\partial s_{j}}{\partial y_{i}}}=\frac{1-\delta_{j}}{1-\delta_{i}} \frac{\frac{\partial p_{i}}{\partial y_{j}}\left(F-\omega_{k}-\delta_{k} s_{k}\right)+p_{i} \frac{\partial}{\partial y_{j}}\left(F-\omega_{k}-\delta_{k} s_{k}\right)}{\left.\partial-\omega_{k}-\delta_{k} s_{k}\right)+p_{j} \frac{\partial}{\partial y_{i}}\left(F-\omega_{k}-\delta_{k} s_{k}\right)} .
$$

Note that this equation must hold for any $y \in Y$. From Lemmas 8, 9 and 10, we know that $\frac{\partial p_{i}}{\partial y_{j}}\left(y^{*}\right)<\frac{\partial p_{j}}{\partial y_{i}}\left(y^{*}\right), p_{i}\left(y^{*}\right)<p_{j}\left(y^{*}\right), \frac{\partial F}{\partial y_{i}}\left(y^{*}\right)<\frac{\partial F}{\partial y_{j}}\left(y^{*}\right)$ and $\frac{\partial s_{l \neq i, j}}{\partial y_{i}}\left(y^{*}\right)>\frac{\partial s_{l \neq i, j}}{\partial y_{j}}\left(y^{*}\right)$. Together with $\delta_{i}=\delta_{j}$, we must have $\frac{\partial s_{i}}{\partial y_{j}}\left(y^{*}\right)<\frac{\partial s_{j}}{\partial y_{i}}\left(y^{*}\right)$. Besides, in equilibrium, we have $\frac{\partial s_{i}}{\partial y_{i}}=\frac{\partial s_{j}}{\partial y_{j}}=0$. Therefore, it can be verified that for any $l=i, j \in\{1,2, \ldots, k-1\}$, we have

$$
\frac{\partial}{\partial y_{i}} \delta_{l} s_{l}\left(y^{*}\right)<\frac{\partial}{\partial y_{j}} \delta_{l} s_{l}\left(y^{*}\right)
$$

Hence, as mentioned previously, it implies that the left hand side $>1>$ the right hand side of Eq.(98), a contradiction.

By following a similar argument, we can show that $y_{i}^{*}>y_{j}^{*}$ cannot be the case, either. Therefore, 
if both players are in the winning coalition, then in equilibrium, we have $x_{i}^{*}=x_{j}^{*}$ and $y_{i}^{*}=y_{j}^{*}$. However, recall that the expected equilibrium payoffs for players $i$ and $j$ are:

$$
s_{i}=\frac{p_{i}}{1-\delta_{i}}\left(F-\omega_{k}-\delta_{k} s_{k}\right) ; \quad s_{j}=\frac{p_{j}}{1-\delta_{j}}\left(F-\omega_{k}-\delta_{k} s_{k}\right)
$$

Given that $\delta_{i}=\delta_{j}, x_{i}^{*}=x_{j}^{*}$ and $y_{i}^{*}=y_{j}^{*}$, we have $s_{i}=s_{j}$, a contradiction. Hence, under equilibrium path 1 , the expected equilibrium payoffs between players $i$ and $j$ are equal: $s_{i}=s_{j}$.

Equilibrium Path 2: Suppose that in period 1, player $i$ is in the winning coalition while player $j$ is not. Namely, $\delta_{i} s_{i}<\delta_{k} s_{k}<\delta_{j} s_{j}$. Then, by Eqs.(47)-(49), we have

$$
s_{i}=\frac{p_{i}}{1-\delta_{i}}\left(F-\omega_{k}-\delta_{k} s_{k}\right) ; \quad s_{j}=p_{j}\left(F-\omega_{k}\right)
$$

Given that $\delta_{i}=\delta_{j}$ is sufficiently large, $s_{i}>s_{j}$, a contradiction. Therefore, we have shown that $\delta_{i} s_{i}<\delta_{k} s_{k}<\delta_{j} s_{j}$ does not hold, either.

Equilibrium Path 3: Suppose that in period 1, neither player $i$ nor $j$ is in the winning coalition. Namely, $\delta_{k} s_{k}<\delta_{i} s_{i}<\delta_{j} s_{j}$. Since $\delta_{i} s_{i}>\delta_{k} s_{k}$, player $i$ 's expected equilibrium payoff is:

$$
s_{i}=p_{i}\left(F-\omega_{k}\right) .
$$

In the pre-bargaining stage, player $i$ solves the following maximization problem:

$$
\max _{x_{i}, y_{i}} p_{i}\left(F-\omega_{k}\right)
$$

subject to the resource constraint:

$$
x_{i}+y_{i}=\sigma_{i} .
$$

Substitute the resource constraint into problem (99):

$$
\max _{y_{i}} \quad p_{i}\left\{F\left(x_{1}, \ldots \sigma_{i}-y_{i}, \ldots, x_{n}\right)-\omega_{k}\right]
$$

Solving the above maximization problem derives player $i$ 's optimal unproductive effort, $y_{i}^{*}$, which 
must satisfy:

$$
\frac{\partial p_{i}}{\partial y_{i}}\left[F-\omega_{k}\right]=p_{i}\left[\frac{\partial F}{\partial x_{i}}+\frac{\partial \omega_{k}}{\partial y_{i}}\right]
$$

Similarly, player $j$ 's optimal unproductive effort, $y_{j}^{*}$ shall satisfy:

$$
\frac{\partial p_{j}}{\partial y_{j}}\left[F-\omega_{k}\right]=p_{j}\left[\frac{\partial F}{\partial x_{j}}+\frac{\partial \omega_{k}}{\partial y_{j}}\right]
$$

Take the ratio of them:

$$
\frac{\frac{\partial p_{i}}{\partial y_{i}}}{\frac{\partial p_{j}}{\partial y_{j}}}=\frac{p_{i}}{p_{j}} \frac{\frac{\partial F}{\partial x_{i}}+\frac{\partial \omega_{k}}{\partial y_{i}}}{\frac{\partial F}{\partial x_{j}}+\frac{\partial \omega_{k}}{\partial y_{j}}} .
$$

Then by following a similar argument as in deriving the properties of the equilibrium efforts under path 1 , we can show that in equilibrium path 3 , we have $x_{i}^{*}=x_{j}^{*}$ and $y_{i}^{*}=y_{j}^{*}$. Finally, recall that

$$
s_{i}=p_{i}\left(F-\omega_{k}\right) ; \quad s_{j}=p_{j}\left(F-\omega_{k}\right)
$$

Hence, $s_{i}=s_{j}$, a contradiction. Therefore, if neither players is in the winning coalition, we must have $s_{i}=s_{j}$.

To sum up, the three possible equilibrium paths reveal that if $\delta_{i}=\delta_{j}, \sigma_{i}=\sigma_{j}$ and the two players are sufficiently patient, then the expected equilibrium payoffs between the two players are equal, i.e., $s_{i}=s_{j}$. Therefore, the three possible equilibrium paths reduce to two. Namely, both players are in the winning coalition, i.e., $\delta_{i} s_{i}=\delta_{j} s_{j}<\delta_{k} s_{k}$ or both players are excluded from the winning coalition, i.e., $\delta_{i} s_{i}=\delta_{j} s_{j}>\delta_{k} s_{k}$. From the previous proof, we know that under these two cases, the equilibrium efforts must satisfy:

$$
\frac{\frac{\partial p_{i}}{\partial y_{i}}}{\frac{\partial p_{j}}{\partial y_{j}}}=\frac{p_{i}}{p_{j}} \frac{\frac{\partial F}{\partial x_{i}}+\frac{\partial}{\partial y_{i}}\left(\omega_{k}+\delta_{k} s_{k}\right)}{\frac{\partial F}{\partial x_{j}}+\frac{\partial}{\partial y_{j}}\left(\omega_{k}+\delta_{k} s_{k}\right)}
$$

and

$$
\frac{\frac{\partial p_{i}}{\partial y_{i}}}{\frac{\partial p_{j}}{\partial y_{j}}}=\frac{p_{i}}{p_{j}} \frac{\frac{\partial F}{\partial x_{i}}+\frac{\partial \omega_{k}}{\partial y_{i}}}{\frac{\partial F}{\partial x_{j}}+\frac{\partial \omega_{k}}{\partial y_{j}}},
$$

respectively, and the equilibrium productive and unproductive efforts shall satisfy: $x_{i}^{*}=x_{j}^{*}$ and $y_{i}^{*}=y_{j}^{*}$. This completes the proof. 
Proposition 26. Suppose that Assumptions 2, 3 and 4 hold. For any player $i, j \in N$, given that other factors are the same and their discount factors satisfy: $\delta_{i}>\delta_{j}$, then under the $k$-majority voting rule with persistent effects, if

(i) players $i$ and $j$ are in the winning coalition, i.e., $\delta_{i} s_{i}<\delta_{k} s_{k}$ and $\delta_{j} s_{j}<\delta_{k} s_{k}$, in equilibrium, the productive and unproductive efforts and the expected payoffs between the two players must have the following relationships: $x_{i}^{*}>x_{j}^{*} y_{i}^{*}<y_{j}^{*}$ and $s_{i}>s_{j}$, respectively.

(ii) players $i$ is in the winning coalition while player $j$ is excluded from the winning coalition, i.e., $\delta_{i} s_{i}<\delta_{k} s_{k}$ and $\delta_{j} s_{j}>\delta_{k} s_{k}$, in equilibrium, the productive and unproductive efforts and the expected payoffs between the two players must have the following relationships: $x_{i}^{*}>x_{j}^{*}$ $y_{i}^{*}<y_{j}^{*}$ and $s_{i}<s_{j}$, respectively.

(iii) players $i$ is excluded from the winning coalition while player $j$ is in the winning coalition, i.e., $\delta_{i} s_{i}>\delta_{k} s_{k}$ and $\delta_{j} s_{j}<\delta_{k} s_{k}$, in equilibrium, the productive and unproductive efforts between the two players must have the following relationships: $x_{i}^{*}<x_{j}^{*}$ and $y_{i}^{*}>y_{j}^{*}$, respectively.

(iv) players $i$ and $j$ are excluded from the winning coalition, i.e., $\delta_{i} s_{i}>\delta_{k} s_{k}$ and $\delta_{j} s_{j}>\delta_{k} s_{k}$, in equilibrium, the productive and unproductive efforts and the expected payoffs between the two players must have the following relationships: $x_{i}^{*}>x_{j}^{*} y_{i}^{*}<y_{j}^{*}$ and $s_{i}<s_{j}$, respectively.

Proof: As mentioned before, the game ends in period 1.

Under condition $(i)$, we know that in period 1 , both players $i$ and $j$ are in the winning coalition. Namely, $\delta_{i} s_{i}<\delta_{k} s_{k}$ and $\delta_{j} s_{j}<\delta_{k} s_{k}$. To show that under this case, $x_{i}^{*}>x_{j}^{*} y_{i}^{*}<y_{j}^{*}$ and $s_{i}>s_{j}$, suppose not, i.e., $y_{i}^{*} \geq y_{j}^{*}$. Then from the resource constraints, $y_{i}^{*} \geq y_{j}^{*}$ and $\sigma_{i}=\sigma_{j}$ implies that $x_{i}^{*} \leq x_{j}^{*}$.

Given that both players are in the winning coalition, from the proof of Proposition 25, in equilibrium, the optimal unproductive efforts of players $i$ and $j$ must satisfy:

$$
\frac{\frac{\partial p_{i}}{\partial y_{i}}}{\frac{\partial p_{j}}{\partial y_{j}}}=\frac{p_{i}}{p_{j}} \frac{\frac{\partial F}{\partial x_{i}}+\frac{\partial}{\partial y_{i}}\left(\omega_{k}+\delta_{k} s_{k}\right)}{\frac{\partial F}{\partial x_{j}}+\frac{\partial}{\partial y_{j}}\left(\omega_{k}+\delta_{k} s_{k}\right)} .
$$

Also, Lemma 9 says that if $y_{i}^{*} \geq y_{j}^{*}$, then $\frac{\partial p_{i}}{\partial y_{i}}\left(y^{*}\right) \leq \frac{\partial p_{j}}{\partial y_{j}}\left(y^{*}\right)$. Thus, the left hand side of the above equation is less than 1 . 
For the right hand side of Eq.(100), from Lemma $8, x_{i}^{*} \leq x_{j}^{*}$ indicates that $\frac{\partial F}{\partial x_{i}}\left(x^{*}\right)>\frac{\partial F}{\partial x_{j}}\left(x^{*}\right)$ and from Lemma $9, y_{i}^{*} \geq y_{j}^{*}$ implies that $p_{i}\left(y^{*}\right) \geq p_{j}\left(y^{*}\right)$. Hence, as long as we can show that

$$
\frac{\partial}{\partial y_{i}}\left(\omega_{k}\left(y^{*}\right)+\delta_{k} s_{k}\left(y^{*}\right)\right)>\frac{\partial}{\partial y_{j}}\left(\omega_{k}\left(y^{*}\right)+\delta_{k} s_{k}\left(y^{*}\right)\right)
$$

or

$$
\frac{\partial}{\partial y_{i}} \sum_{l=1}^{k} \delta_{l} s_{l}\left(y^{*}\right)>\frac{\partial}{\partial y_{j}} \sum_{l=1}^{k} \delta_{l} s_{l}\left(y^{*}\right)
$$

then the right hand side of Eq.(100) $>1 \geq$ the left hand side of Eq.(100), a contradiction. To show that Eq.(101) holds, note that by Lemma 10, if $y_{i}^{*} \geq y_{j}^{*}$, then

$$
\frac{\partial}{\partial y_{i}} \sum_{l \neq i, j} \delta_{l} s_{l}\left(y^{*}\right)>\frac{\partial}{\partial y_{j}} \sum_{l \neq i, j} \delta_{l} s_{l}\left(y^{*}\right)
$$

Besides, from the proof of Proposition 25, we know that

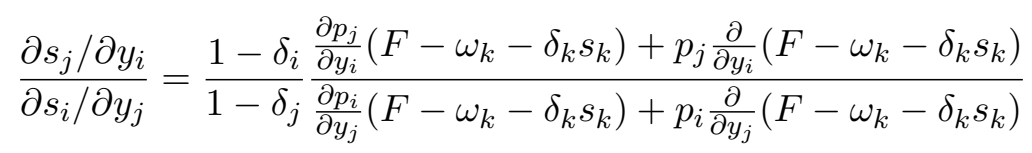

From Lemmas 8, 9 and 10, if $y_{i}^{*} \geq y_{j}^{*}$ and $x_{i}^{*} \leq x_{j}^{*}$, then $\frac{\partial p_{i}}{\partial y_{j}}\left(y^{*}\right) \geq \frac{\partial p_{j}}{\partial y_{i}}\left(y^{*}\right), p_{i}\left(y^{*}\right) \geq p_{j}\left(y^{*}\right)$, $\frac{\partial F}{\partial y_{i}}\left(y^{*}\right) \geq \frac{\partial F}{\partial y_{j}}\left(y^{*}\right)$ and $\frac{\partial s_{l \neq i, j}\left(y^{*}\right)}{\partial y_{i}} \leq \frac{\partial s_{l \neq i, j}}{\partial y_{j}}$. Together with $\delta_{i}>\delta_{j}$, it implies that

$$
\frac{\partial s_{j}}{\partial y_{i}}\left(y^{*}\right)>\frac{\partial s_{i}}{\partial y_{j}}\left(y^{*}\right)
$$

Also, in equilibrium, we have $\frac{\partial s_{i}}{\partial y_{i}}=\frac{\partial s_{j}}{\partial y_{j}}=0$. Therefore, it can be verified that for any $l=i, j \in$ $\{1,2, \ldots, k-1\}$, we have

$$
\frac{\partial}{\partial y_{i}} \delta_{l} s_{l}\left(y^{*}\right)>\frac{\partial}{\partial y_{j}} \delta_{l} s_{l}\left(y^{*}\right)
$$

This implies that Eq.(101) holds and the right hand side of Eq.(100) $>1 \geq$ the left hand side of Eq.(100), a contradiction. Hence, when players $i$ and $j$ are in the winning coalition and $\delta_{i}>\delta_{j}$, then the equilibrium optimal efforts shall satisfy: $y_{i}^{*}<y_{j}^{*}$, and $x_{i}^{*}>x_{j}^{*}$.

Now we show that under condition $(i), s_{i}>s_{j}$. From the previous proof, $y_{i}^{*}<y_{j}^{*}$ indicates that 


$$
\begin{aligned}
& \frac{\frac{\partial s_{j}}{\partial y_{i}}\left(y^{*}\right)}{\frac{\partial s_{i}}{\partial y_{j}}\left(y^{*}\right)}<1 \text {. Therefore, Eq.(102) implies that } \\
& \qquad \frac{1-\delta_{i}}{1-\delta_{j}} \frac{\frac{\partial p_{j}}{\partial y_{i}}\left(F-\omega_{k}-\delta_{k} s_{k}\right)+p_{j} \frac{\partial}{\partial y_{i}}\left(F-\omega_{k}-\omega_{k} s_{k}\right)+\delta_{i} \frac{\partial}{\partial y_{j}}\left(F-\omega_{k}-\delta_{k} s_{k}\right)}{2}<1 .
\end{aligned}
$$

Moreover, from Lemmas 8 and 10 and the previous proof, we know that if $y_{i}^{*}<y_{j}^{*}$ and $x_{i}^{*}>x_{j}^{*}$, then $\frac{\partial p_{i}}{\partial y_{j}}\left(y^{*}\right) \leq \frac{\partial p_{j}}{\partial y_{i}}\left(y^{*}\right), p_{i}\left(y^{*}\right) \leq p_{j}\left(y^{*}\right), \frac{\partial F}{\partial y_{i}}\left(y^{*}\right) \leq \frac{\partial F}{\partial y_{j}}\left(y^{*}\right)$ and $\frac{\partial s_{l \neq i, j}}{\partial y_{i}}\left(y^{*}\right) \geq \frac{\partial s_{l \neq i, j}}{\partial y_{j}}\left(y^{*}\right)$. Thus,

$$
\begin{aligned}
& \frac{1-\delta_{i}}{1-\delta_{j}} \frac{p_{j}\left(y^{*}\right)}{p_{i}\left(y^{*}\right)} \\
& <\frac{1-\delta_{i}}{1-\delta_{j}} \frac{\frac{\partial p_{j}}{\partial y_{i}}\left(y^{*}\right)\left[F\left(x^{*}\right)-\omega_{k}\left(y^{*}\right)-\delta_{k} s_{k}\left(y^{*}\right)\right]+p_{j}\left(y^{*}\right) \frac{\partial}{\partial y_{i}}\left[F\left(y^{*}\right)-\omega_{k}\left(y^{*}\right)-\delta_{k} s_{k}\left(y^{*}\right)\right)+p_{i}\left(y^{*}\right) \frac{\partial}{\partial y_{j}}\left[F\left(y^{*}\right)-\omega_{k}\left(y^{*}\right)-\delta_{k} s_{k}\left(y^{*}\right)\right]}{}
\end{aligned}
$$$$
<1 \text {. }
$$

Given that players $i$ and $j$ are in the winning coalition, their expected equilibrium payoffs are

$$
s_{i}=\frac{p_{i}}{1-\delta_{i}}\left(F-\omega_{k}-\delta_{k} s_{k}\right) ; \quad s_{j}=\frac{p_{j}}{1-\delta_{j}}\left(F-\omega_{k}-\delta_{k} s_{k}\right)
$$

Taking the ratio of them, we have

$$
\frac{s_{i}}{s_{j}}=\frac{1-\delta_{j}}{1-\delta_{i}} \frac{p_{i}}{p_{j}}
$$

Since in equilibrium, $\frac{1-\delta_{i}}{1-\delta_{j}} \frac{p_{j}\left(y^{*}\right)}{p_{i}\left(y^{*}\right)}<1$, we must have $\frac{s_{i}}{s_{j}}>1$. This completes the proof that under condition $(i)$, the equilibrium efforts and expected payoffs between players $i$ and $j$ shall satisfy: $x_{i}^{*}>x_{j}^{*} y_{i}^{*}<y_{j}^{*}, s_{i}>s_{j}$,

We next show that under condition $(i i)$, if $\delta_{i}>\delta_{j}$, then $x_{i}^{*}>x_{j}^{*}, y_{i}^{*}<y_{j}^{*}$, and $s_{i}<s_{j}$. First, under condition (ii), $s_{i}<s_{j}$ because $\delta_{i} s_{i}<\delta_{k} s_{k}<\delta_{j} s_{j}$ and $\delta_{i}>\delta_{j}$. The expected equilibrium payoffs for players $i$ and $j$ can be expressed as:

$$
s_{i}=\frac{p_{i}}{1-\delta_{i}}\left(F-\omega_{k}-\delta_{k} s_{k}\right) ; \quad s_{j}=p_{j}\left(F-\omega_{k}\right) .
$$


Hence, the optimal unproductive efforts of players $i$ and $j$ must satisfy:

$$
\frac{\partial p_{i}}{\partial y_{i}}\left[F-\omega_{k}-\delta_{k} s_{k}\right]=p_{i}\left[\frac{\partial F}{\partial x_{i}}+\frac{\partial}{\partial y_{i}}\left(\omega_{k}+\delta_{k} s_{k}\right)\right]
$$

and

$$
\frac{\partial p_{j}}{\partial y_{j}}\left[F-\omega_{k}\right]=p_{j}\left[\frac{\partial F}{\partial x_{j}}+\frac{\partial \omega_{k}}{\partial y_{j}}\right]
$$

respectively. Take the ratio of them:

$$
\frac{\frac{\partial p_{i}}{\partial y_{i}}}{\frac{\partial p_{j}}{\partial y_{j}}} \frac{F-\omega_{k}-\delta_{k} s_{k}}{F-\omega_{k}}=\frac{p_{i}}{p_{j}} \frac{\frac{\partial F}{\partial x_{i}}+\frac{\partial}{\partial y_{i}}\left(\omega_{k}+\delta_{k} s_{k}\right)}{\frac{\partial F}{\partial x_{j}}+\frac{\partial \omega_{k}}{\partial y_{j}}}
$$

Then by following similar steps as in condition $(i)$, we can show that if $y_{i}^{*} \geq y_{j}^{*}, x_{i}^{*} \leq x_{j}^{*}$ and $\delta_{i}>\delta_{j}$, the left hand side of the above equation $<1 \leq$ the right hand side, a contradiction. This verifies that if $\delta_{i} s_{i}<\delta_{k} s_{k}<\delta_{j} s_{j}$ and $\delta_{i}>\delta_{j}$, the optimal efforts must satisfy: $x_{i}^{*}>x_{j}^{*}$ and $y_{i}^{*}<y_{j}^{*}$.

The proof of condition ( $i i i)$ is followed by a similar argument. We can show that the optimal unproductive efforts of players $i$ and $j$ must satisfy:

$$
\frac{\frac{\partial p_{i}}{\partial y_{i}}}{\frac{\partial p_{j}}{\partial y_{j}}} \frac{F-\omega_{k}}{F-\omega_{k}-\delta_{k} s_{k}}=\frac{p_{i}}{p_{j}} \frac{\frac{\partial F}{\partial x_{i}}+\frac{\partial \omega_{k}}{\partial y_{i}}}{\frac{\partial F}{\partial x_{j}}+\frac{\partial}{\partial y_{j}}\left(\omega_{k}+\delta_{k} s_{k}\right)} .
$$

and, therefore, $y_{i}^{*} \leq y_{j}^{*}$ and $x_{i}^{*} \geq x_{j}^{*}$ cannot be the case. Thus, under this condition, we must have $x_{i}^{*}<x_{j}^{*}$ and $y_{i}^{*}>y_{j}^{*}$.

Finally, we show that $x_{i}^{*}>x_{j}^{*}, y_{i}^{*}<y_{j}^{*}$ and $s_{i}<s_{j}$ under condition $(i v)$. In this case, the game ends in period 1 where neither player $i$ or $j$ is in the winning coalition. Namely, $\delta_{i} s_{i}>\delta_{k} s_{k}$ and $\delta_{j} s_{j}>\delta_{k} s_{k}$. Similar to the previous proof, we can show that the optimal unproductive efforts of players $i$ and $j$ must satisfy:

$$
\frac{\frac{\partial p_{i}}{\partial y_{i}}}{\frac{\partial p_{j}}{\partial y_{j}}}=\frac{p_{i}}{p_{j}} \frac{\frac{\partial F}{\partial x_{i}}+\frac{\partial}{\partial y_{i}}\left(\omega_{k}+\delta_{k} s_{k}\right)}{\frac{\partial F}{\partial x_{j}}+\frac{\partial}{\partial y_{j}}\left(\omega_{k}+\delta_{k} s_{k}\right)} .
$$

Note that the above condition is the same as under condition $(i)$. Therefore, we must have $y_{i}^{*}<y_{j}^{*}$ and $x_{i}^{*}>x_{j}^{*}$. Then since

$$
s_{i}=p_{i}\left(F-\omega_{k}\right) ; \quad s_{j}=p_{j}\left(F-\omega_{k}\right)
$$


the equilibrium expected payoffs shall satisfy: $s_{i}<s_{j}$. This completes the proof under condition $(i v)$.

Proposition 27. Suppose that Assumptions 2, 3 and 4 hold. For any player $i, j \in N$, given that other factors are the same and their initial endowments satisfy: $\sigma_{i}>\sigma_{j}$, then under the $k$-majority voting rule with persistent effects, if

(i) players $i$ and $j$ are in the winning coalition, i.e., $\delta_{i} s_{i}<\delta_{k} s_{k}$ and $\delta_{j} s_{j}<\delta_{k} s_{k}$, in equilibrium, the productive and unproductive efforts and the expected payoffs between the two players must have the following relationships: $x_{i}^{*}>x_{j}^{*} y_{i}^{*}>y_{j}^{*}$ and $s_{i}>s_{j}$.

(ii) player $i$ is in the winning coalition while player $j$ is excluded from the winning coalition, i.e., $\delta_{i} s_{i}<\delta_{k} s_{k}<\delta_{j} s_{j}$, in equilibrium, the productive and unproductive efforts and the expected payoffs between the two players must have the following relationships: $x_{i}^{*}>x_{j}^{*} y_{i}^{*} \geq y_{j}^{*}$ and $s_{i}<s_{j}$.

(iii) player $i$ is excluded from the winning coalition while player $j$ is in the winning coalition, i.e., $\delta_{i} s_{i}>\delta_{k} s_{k}>\delta_{j} s_{j}$, in equilibrium, the unproductive efforts and the expected payoffs between the two players must have the following relationships: $y_{i}^{*}>y_{j}^{*}$ and $s_{i}>s_{j}$.

(iv) players $i$ and $j$ are excluded from the winning coalition, i.e., $\delta_{i} s_{i}>\delta_{k} s_{k}$ and $\delta_{j} s_{j}>\delta_{k} s_{k}$, in equilibrium, the productive and unproductive efforts and the expected payoffs between the two players must have the following relationships: $x_{i}^{*}>x_{j}^{*} y_{i}^{*}>y_{j}^{*}$ and $s_{i}>s_{j}$.

Proof: By the previous proof, we know that under conditions $(i)$ and $(i v)$, the optimal unproductive efforts of players $i$ and $j$, i.e., $y_{i}^{*}$ and $y_{j}^{*}$, must satisfy the following equation:

$$
\frac{\frac{\partial p_{i}}{\partial y_{i}}}{\frac{\partial p_{j}}{\partial y_{j}}}=\frac{p_{i}}{p_{j}} \frac{\frac{\partial F}{\partial x_{i}}+\frac{\partial}{\partial y_{i}}\left(\omega_{k}+\delta_{k} s_{k}\right)}{\frac{\partial F}{\partial x_{j}}+\frac{\partial}{\partial y_{j}}\left(\omega_{k}+\delta_{k} s_{k}\right)},
$$

if $y_{i}^{*}<y_{j}^{*}$ and $x_{i}^{*}>x_{j}^{*}$, the left hand side of the above equation $>1>$ the right hand side, and, if $y_{i}^{*}=y_{j}^{*}$ and $x_{i}^{*}>x_{j}^{*}$, the left hand side of the above equation $=1>$ the right hand side. Thus, we have shown that if both players are in the winning coalition or are excluded from the winning coalition, together with $\sigma_{i}>\sigma_{j}$, then in equilibrium, we must have $y_{i}^{*}>y_{j}^{*}$ and $x_{i}^{*}>x_{j}^{*}$. 
Besides, since $y_{i}^{*}>y_{j}^{*}$ and the equilibrium expected payoff satisfies Eq.(80), we have: $s_{i}>s_{j}$. This completes the proof under conditions $(i)$ and $(i v)$.

To show that under condition $(i i), x_{i}^{*}>x_{j}^{*} y_{i}^{*} \geq y_{j}^{*}$ and $s_{i}<s_{j}$. Given that $\delta_{i}=\delta_{j}$ and $\delta_{i} s_{i}<$ $\delta_{k} s_{k}<\delta_{j} s_{j}$, it is obvious that $s_{i}<s_{j}$. Then to prove that $x_{i}^{*}>x_{j}^{*} y_{i}^{*} \geq y_{j}^{*}$, suppose not, i.e., $x_{i}^{*} \leq x_{j}^{*}$ or $x_{i}^{*}>x_{j}^{*}$ and $y_{i}^{*}<y_{j}^{*}$. Note that $x_{i}^{*} \leq x_{j}^{*}$ implies that $y_{i}^{*}>y_{j}^{*}$ because $\sigma_{i}>\sigma_{j}$ and $x_{l}+y_{l}=\sigma_{l}$, for any $l \in N$. By the proof of Proposition 26, in equilibrium, we have

$$
\frac{\frac{\partial p_{i}}{\partial y_{i}}}{\frac{\partial p_{j}}{\partial y_{j}}} \frac{F-\omega_{k}-\delta_{k} s_{k}}{F-\omega_{k}}=\frac{p_{i}}{p_{j}} \frac{\frac{\partial F}{\partial x_{i}}+\frac{\partial}{\partial y_{i}}\left(\omega_{k}+\delta_{k} s_{k}\right)}{\frac{\partial F}{\partial x_{j}}+\frac{\partial \omega_{k}}{\partial y_{j}}} .
$$

Observe that if $x_{i}^{*} \leq x_{j}^{*}$ and $y_{i}^{*}>y_{j}^{*}$ or $x_{i}^{*}>x_{j}^{*}$ and $y_{i}^{*}<y_{j}^{*}$, then the above equation does not hold, a contradiction. Therefore, under condition $(i i)$, we must have $x_{i}^{*}>x_{j}^{*} y_{i}^{*} \geq y_{j}^{*}$ and $s_{i}<s_{j}$. Finally, to verify that under condition $(i i i)$, we have $y_{i}^{*}>y_{j}^{*}, s_{i}>s_{j}$. Note that $\delta_{i}=\delta_{j}$ and $\delta_{i} s_{i}>\delta_{k} s_{k}>\delta_{j} s_{j}$ imply that $s_{i}>s_{j}$. From the proof of Proposition 26, we know that

$$
\frac{\partial p_{i} / \partial y_{i}}{\partial p_{j} / \partial y_{j}} \frac{F-\omega_{k}}{F-\omega_{k}-\delta_{k} s_{k}}=\frac{p_{i}}{p_{j}} \frac{\partial F / \partial x_{i}+\partial \omega_{k} / \partial y_{i}}{\frac{\partial F}{\partial x_{j}}+\frac{\partial}{\partial y_{j}}\left(\omega_{k}+\delta_{k} s_{k}\right)}
$$

Similar to the proof under condition $(i i)$, in order for the above equation to be satisfied, in equilibrium, we must have $y_{i}^{*}>y_{j}^{*}$. This completes the proof that under condition $(i i i)$, the equilibrium unproductive efforts and expected payoff shall satisfy: $y_{i}^{*}>y_{j}^{*}, s_{i}>s_{j}$.

Lemma 2. Suppose that Assumptions 2 and 3 hold. For any player $i \in N$, given that other factors are the same, under the bargaining model with persistent effects, in comparison to the $k$ majority voting rule, player $i$ will exert more productive effort and less unproductive effort under the unanimity voting rule, i.e., $y_{i}^{* U}<y_{i}^{* k}$ and $x_{i}^{* U}>x_{i}^{* k}$.

Proof: Suppose not, i.e., $y_{i}^{* U} \geq y_{i}^{* k}$. If $y_{i}^{* U} \geq y_{i}^{* k}$, then $x_{i}^{* U} \leq x_{i}^{* k}$, because the initial endowments are the same under both voting rules and for any $\left(x_{i}, y_{i}\right)$, we must have $x_{i}+y_{i}=\sigma_{i}$. As mentioned previously, we know that the games ends in period 1. Now we consider two possible equilibrium paths in the first period.

Equilibrium path 1: Suppose that in period 1, player $i$ is in the winning coalition. From proof of 
Proposition 19, we know that under the unanimity voting rule, the expected equilibrium payoff is

$$
s_{i}=\frac{p_{i}}{1-\delta_{i}}\left(F-\sum_{l=1}^{n} \delta_{l} s_{l}\right)
$$

Then totally differentiate the above equation w.r.t. $y_{i}$,

$$
\frac{\partial s_{i}}{\partial y_{i}}=\frac{1}{1-\delta_{i}}\left[\frac{\partial p_{i}}{\partial y_{i}}\left(F-\sum_{l=1}^{n} \delta_{l} s_{l}\right)+p_{i}\left(-\frac{\partial F}{\partial x_{i}}-\sum_{l=1}^{n} \delta_{l} \frac{\partial s_{l}}{\partial y_{i}}\right)\right]
$$

Note that for any $x_{i}, y_{i}$, we must have $x_{i}+y_{i}=\sigma_{i}$ and in equilibrium, $y^{* U}$ shall satisfy $\frac{\partial s_{i}}{\partial y_{i}}\left(y^{* U}\right)=0$. Substitute them into the above equation and rearrange:

$$
\frac{\partial p_{i}}{\partial y_{i}}\left(y^{* U}\right)\left[F\left(x^{* U}\right)-\sum_{l=1}^{n} \delta_{l} s_{l}\left(y^{* U}\right)\right]=p_{i}\left(y^{* U}\right)\left[\frac{\partial F}{\partial x_{i}}\left(x^{* U}\right)+\sum_{l=1}^{n} \delta_{l} \frac{\partial s_{l}}{\partial y_{i}}\left(y^{* U}\right)\right] .
$$

From the proof of Proposition 25, we know that the equilibrium unproductive effort, $y_{i}^{* k}$, must satisfy:

$$
\frac{\partial p_{i}}{\partial y_{i}}\left(y^{* k}\right)\left[F\left(x^{* k}\right)-\sum_{l=1}^{k} \delta_{l} s_{l}\left(y^{* k}\right)\right]=p_{i}\left(y^{* k}\right)\left[\frac{\partial F}{\partial x_{i}}\left(x^{* k}\right)+\sum_{l=1}^{k} \delta_{l} \frac{\partial s_{l}}{\partial y_{i}}\left(y^{* k}\right)\right] .
$$

Take the ratio of them, we have

$$
\frac{\frac{\partial p_{i}}{\partial y_{i}}\left(y^{* U}\right)}{\frac{\partial p_{i}}{\partial y_{i}}\left(y^{* k}\right)} \frac{F\left(x^{* U}\right)-\sum_{l=1}^{n} \delta_{l} s_{l}\left(y^{* U}\right)}{F\left(x^{* k}\right)-\sum_{l=1}^{k} \delta_{l} s_{l}\left(y^{* k}\right)}=\frac{p_{i}\left(y^{* U}\right)}{p_{i}\left(y^{* k}\right)} \frac{\frac{\partial F}{\partial x_{i}}\left(x^{* U}\right)+\sum_{l=1}^{n} \delta_{l} \frac{\partial s_{l}}{\partial y_{i}}\left(y^{* U}\right)}{\frac{\partial F}{\partial x_{i}}\left(x^{* k}\right)+\sum_{l=1}^{k} \delta_{l} \frac{\partial s_{l}}{\partial y_{i}}\left(y^{* k}\right)}
$$

By Assumptions 2 and 3, if $y_{i}^{* U}>y_{i}^{* K}$, then

$$
\frac{\partial p_{i}}{\partial y_{i}}\left(y^{* U}\right)<\frac{\partial p_{i}}{\partial y_{i}}\left(y^{* k}\right) ; \quad F\left(x^{* U}\right)<F\left(x^{* k}\right) ; \quad p_{i}\left(y^{* U}\right)>p_{i}\left(y^{* k}\right)
$$

Hence, the left hand side of Eq.(103) $<1$ the right hand side of Eq.(103), a contradiction. Thus, we must have $y_{i}^{* k}>y_{i}^{* U}$ under equilibrium path 1 .

Equilibrium path 2: Suppose that in period 1, player $i$ is excluded from the winning coalition. 
Then from the previous proof, we know that $y_{i}^{* U}$ and $y_{i}^{* k}$ must satisfy:

$$
\frac{\partial p_{i}}{\partial y_{i}}\left(y^{* U}\right)\left[F\left(x^{* U}\right)-\sum_{l=1}^{n} \delta_{l} s_{l}\left(y^{* U}\right)\right]=p_{i}\left(y^{* U}\right)\left[\frac{\partial F}{\partial x_{i}}\left(x^{* U}\right)+\sum_{l=1}^{n} \delta_{l} \frac{\partial s_{l}}{\partial y_{i}}\left(y^{* U}\right)\right]
$$

and

$$
\frac{\partial p_{i}}{\partial y_{i}}\left(y^{* k}\right)\left[F\left(x^{* k}\right)-\sum_{l=1}^{k-1} \delta_{l} s_{l}\left(y^{* k}\right)\right]=p_{i}\left(y^{* k}\right)\left[\frac{\partial F}{\partial x_{i}}\left(x^{* k}\right)+\sum_{l=1}^{k-1} \delta_{l} \frac{\partial s_{l}}{\partial y_{i}}\left(y^{* k}\right)\right] .
$$

respectively. Then by following a similar argument, we can show that if $y_{i}^{* U} \geq y_{i}^{* k}$ and $x_{i}^{* U} \leq x_{i}^{* k}$, then at least one of the above equations does not satisfy. Therefore, we must have $y_{i}^{* U} \leq y_{i}^{* k}$ and $x_{i}^{* U} \geq x_{i}^{* k}$.

To sum up, the two possible equilibrium paths reveal that $y_{i}^{* U} \leq y_{i}^{* k}$ and $x_{i}^{* U} \geq x_{i}^{* k}$. This completes the proof.

Proposition 28. Suppose that Assumptions 2 and 3 hold. Then in comparison to the k-majority voting rule with persistent effects, the unanimity voting rule with persistent effects generates a greater social surplus and forgoes a smaller social cost.

Proof: From Lemma 2, we know that holding other factors to be the same, for any player $i \in N$, we have $y_{i}^{* U}>y_{i}^{* k}$, and $x_{i}^{* U}<x_{i}^{* k}$. Hence, Assumption 2 implies that $F\left(x^{* k}\right)<F\left(x^{* U}\right)$. Therefore, $C\left(y^{* k}\right)>C\left(y^{* U}\right)$. This completes the proof.

Lemma 3. Suppose that Assumptions 2 and 3 hold. For any player $i \in N$, given that other factors are the same, under the $k$-majority voting rule with persistent effects, his unproductive effort, $y_{i}^{*}$, weakly decreases in $k$ while his productive effort, $x_{i}^{*}$, weakly increases in $k$, where $k=\{1,2, \ldots, n-1\}$.

Proof: Suppose not. Namely, $y_{i}^{*}$ increases in $k$. This implies that $x_{i}^{*}$ decreases in $k$ because for any $\left(x_{i}, y_{i}\right)$, we have $x_{i}+y_{i}=\sigma_{i}$. Then, as mentioned before, the bargaining game ends in period 1. We next consider three possible equilibrium paths in period 1.

Equilibrium Path 1: Suppose that in period 1, player $i$ is in the winning coalition. Then, the equilibrium payoff is

$$
s_{i}=\frac{p_{i}}{1-\delta_{i}}\left(F-\omega_{k}-\delta_{k} s_{k}\right)
$$


Substitute the resource constraint into it and then take the first order condition w.r.t $y_{i}$ :

$$
\frac{\partial p_{i}}{\partial y_{i}}\left(F-\omega_{k}-\delta_{k} s_{k}\right)=p_{i}\left(\frac{\partial F}{\partial x_{i}}+\sum_{l=1}^{k} \delta_{l} \frac{\partial s_{l}}{\partial y_{i}}\right)
$$

Note that the above equation holds for any $k \in\{1,2, \ldots, n-1\}$. Now suppose that $k$ increases from $p$ to $p+q$, where $p \in\{1,2, \ldots, n-1\}$ and $q=\{1,2, \ldots, n-p-1\}$. Then $\omega_{k}+\delta_{k} s_{k}$ weakly increases because by definition, $\omega_{k}=\sum_{l=1}^{k-1} \delta_{l} s_{l}$ and $\delta_{k} s_{k}$ are weakly increasing functions of $k$. Then from Assumption 3, we have $\frac{\partial p_{i}}{\partial y_{i}}(y)>0, \frac{\partial p_{i}^{2}}{\partial y_{i}^{2}}(y)<0$ for any $y \in Y$ and from Assumption 2 we have $\frac{\partial F}{\partial x_{i}}(x)>0$ and $\frac{\partial F^{2}}{\partial x_{i}^{2}}(x)<0$ for any $x \in X$. Thus, if an increase in $k$ results in an increase in $y_{i}$ and a decrease in $x_{i}$, then we have the left hand side of Eq.(104) decreases while the right hand side of Eq.(104) increases. Hence, for any $k=p+q$, Eq.(104) does not hold in equilibrium, a contradiction. This verifies that under equilibrium path $1, y_{i}^{*}$ decreases in $k$ and $x_{i}^{*}$ increases in $k$ weakly.

Equilibrium path 2: Suppose that in period 1, player $i$ is excluded from the winning coalition. Then, the equilibrium payoff is

$$
s_{i}=p_{i}\left(F-\omega_{k}\right)
$$

Substitute the resource constraint into it and then take the first order condition w.r.t $y_{i}$ :

$$
\frac{\partial p_{i}}{\partial y_{i}}\left(F-\omega_{k}\right)=p_{i}\left(\frac{\partial F}{\partial x_{i}}+\sum_{l=1}^{k-1} \delta_{l} \frac{\partial s_{l}}{\partial y_{i}}\right)
$$

Then the proof follows by similar steps as in equilibrium path 1 .

To conclude, the two possible equilibrium paths show that in equilibrium the productive efforts increases in $k$ while the unproductive efforts decreases in $k$.

Proposition 29. Suppose that Assumptions 2 and 3 hold. Then under the $k$-majority voting rule with persistent effects, the social cost decreases in $k$ while the social surplus increases in $k$.

Proof: The proof is the same as in Proposition 28.

Proposition 30. Suppose that Assumptions 2 and 3 hold. Then under the unanimity voting rule with transitory effects, if there exists a pure strategy SSPE, then it must be unique. 
Proof: Player $i$ 's optimal productive effort, $x_{i}^{*}$, solves for the first order condition from the maximization problem (50):

$$
0=\frac{1}{1-\delta_{i}}\left(-\frac{\partial p_{i}}{\partial y_{i}}\right)\left[F-\sum_{l=1}^{n} \delta_{l} v_{l}\right]+\frac{1}{1-\delta_{i}} p_{i} \frac{\partial F}{\partial x_{i}}
$$

By simplifying and rearranging it, we have

$$
\frac{\partial p_{i}}{\partial y_{i}}\left[F-\sum_{l=1}^{n} \delta_{l} v_{l}\right]-p_{i} \frac{\partial F}{\partial x_{i}}=0
$$

From Assumption 2(b), we know that $\frac{\partial F}{\partial x_{i}}(x) \geq 0$, for any $x \in X$, from the resource constraint, we have $x_{i}+y_{i}=\sigma_{i}$, and from Assumption 3, we know that $\frac{\partial^{2} p_{i}}{\partial y_{i}^{2}}(y)<0$ and $\frac{\partial p_{i}}{\partial y_{i}}(y)>0$, for any $y \in Y$. Hence, $F(x)$ and $\frac{\partial p_{i}}{\partial y_{i}}$ are both increasing in $x_{i}$ while $p_{i}$ and $\frac{\partial F}{\partial x_{i}}$ decrease in $x_{i}$. Besides, as mentioned before, $\sum_{l=1}^{n} \delta_{l} v_{l}$ is nothing but a constant. Therefore, the left hand side of the above equation is strictly increasing in $x_{i}$. Since the right hand side is constant, then if there exists a SSPE, it must be unique. This completes the proof of uniqueness.

Claim 2. Suppose that $n=2$, and the production and recognition probability functions are defined in Eqs. (44) and (45), respectively. Then under the unanimity voting rule with transitory effects, there is a unique equilibrium such that players will produce a positive size of "cake", and the ratio of the optimal unproductive efforts of players must satisfy:

$$
\frac{y_{2}^{*}}{y_{1}^{*}}=\left(\frac{\alpha_{1}}{\alpha_{2}}\right)^{\frac{1}{1+m}}
$$

Proof: From the proof of Proposition 30, we know that the optimal efforts of players 1 and 2 require:

$$
\frac{\partial p_{1}}{\partial y_{1}}\left[F-\sum_{l=1}^{2} \delta_{l} v_{l}\right]-p_{1} \frac{\partial F}{\partial x_{1}}=0
$$

and

$$
\frac{\partial p_{2}}{\partial y_{2}}\left[F-\sum_{l=1}^{2} \delta_{l} v_{l}\right]-p_{2} \frac{\partial F}{\partial x_{2}}=0
$$


respectively. Take the ratio of them,

$$
\frac{\partial p_{1} / \partial y_{1}}{\partial p_{2} / \partial y_{2}}=\frac{p_{1}}{p_{2}} \frac{\partial F / \partial x_{1}}{\partial F / \partial x_{2}}
$$

Substituting Eqs.(44) and (45) into it, we have

$$
\frac{\frac{m y_{1}^{m-1}\left(y_{1}^{m}+y_{2}^{m}\right)-y_{1}^{m} m y_{1}^{m-1}}{\left[y_{1}^{m}+y_{2}^{m}\right]^{2}}}{\frac{m y_{2}^{m-1}\left(y_{1}^{m}+y_{2}^{m}\right)-y_{2}^{m} m y_{2}^{m-1}}{\left[y_{1}^{m}+y_{2}^{m}\right]^{2}}}=\frac{\frac{y_{1}^{m}}{y_{1}^{m}+y_{2}^{m}}}{\frac{y_{2}^{m}}{y_{1}^{m}+y_{2}^{m}}} \frac{\alpha_{1}}{\alpha_{2}} .
$$

Simplifying it derives:

$$
\frac{y_{2}^{*}}{y_{1}^{*}}=\left(\frac{\alpha_{1}}{\alpha_{2}}\right)^{\frac{1}{1+m}} .
$$

Hence, in equilibrium, players' optimal unproductive efforts, $y_{1}^{*}$ and $y_{2}^{*}$ must satisfy the above equation. This completes the proof.

Proposition 31. Suppose that Assumptions 2, 3 and 4 hold. For any player $i, j \in N$, if their discount factors and their initial endowments are the same, i.e., $\delta_{i}=\delta_{j}$ and $\sigma_{i}=\sigma_{j}$, then under the unanimity voting rule with transitory effects, the productive and unproductive efforts and the expected payoffs between players $i$ and $j$ are equal, i.e., $x_{i}^{*}=x_{j}^{*}, y_{i}^{*}=y_{j}^{*}$ and $v_{i}=v_{j}$.

Proof: From Eq.(105), we know that

$$
\frac{\partial p_{i}}{\partial y_{i}}\left[F-\sum_{l=1}^{n} \delta_{l} s_{l}\right]=p_{i} \frac{\partial F}{\partial x_{i}} .
$$

Since Assumption 4 says that players $i$ and $j$ are symmetric in producing the size of the cake and being recognized as a proposer, player $j$ 's optimal productive effort, $x_{j}^{*}$, has a similar expression. Namely, it shall solve the first order condition from player $j$ 's maximization problem:

$$
\frac{\partial p_{j}}{\partial y_{j}}\left[F-\sum_{l=1}^{n} \delta_{l} s_{l}\right]=p_{j} \frac{\partial F}{\partial x_{j}} .
$$

Take the ratio of the above two equations:

$$
\frac{\frac{\partial p_{i}}{\partial y_{i}}}{\frac{\partial p_{j}}{\partial y_{j}}}=\frac{p_{i}}{p_{j}} \frac{\frac{\partial F}{\partial x_{i}}}{\frac{\partial F}{\partial x_{j}}}
$$


Hence, in equilibrium, $x_{i}^{*}$ and $x_{j}^{*}$ must satisfy Eq.(107).

Then the proof is followed by a contradiction. Suppose not, i.e., $x_{i}^{*}<x_{j}^{*}$ or $x_{i}^{*}>x_{j}^{*}$. If $x_{i}^{*}<x_{j}^{*}$, then Lemma 8 indicates that $\frac{\partial F}{\partial x_{i}}\left(x^{*}\right) \geq \frac{\partial F}{\partial x_{j}}\left(x^{*}\right)$. Also, if $x_{i}^{*}<x_{j}^{*}$, then we have $y_{i}^{*}>y_{j}^{*}$ because the initial endowments between the two players are the same, i.e., $\sigma_{i}=\sigma_{j}$, and for any $\left(x_{i}, y_{i}\right)$ and $\left(x_{j}, y_{j}\right)$, we have $x_{i}+y_{i}=\sigma_{i}$ and $x_{j}+y_{j}=\sigma_{j}$. Then by Lemma 9 , we have $p_{i}\left(y^{*}\right)>p_{j}\left(y^{*}\right)$. Hence, the right hand side of Eq.(107) is greater than 1. Also, Lemma 9 says that if $y_{i}^{*}>y_{j}^{*}$, then $\frac{\partial p_{i}}{\partial y_{i}}\left(y^{*}\right)<\frac{\partial p_{j}}{\partial y_{j}}\left(y^{*}\right)$. Therefore, the left hand side of Eq.(107) is less than 1 and $x_{i}^{*}<x_{j}^{*}$ cannot be the case.

By following a similar argument, we can show that $x_{i}^{*}>x_{j}^{*}$ cannot be the case, either. Therefore, in equilibrium, we must have $x_{i}^{*}=x_{j}^{*}$ and $y_{i}^{*}=y_{j}^{*}$. Then, together with Eq.(105), it implies that $v_{i}=v_{j}$. This completes the proof.

Proposition 32. Suppose that Assumptions 2, 3 and 4 hold. Then under the unanimity voting rule with transitory effects, in equilibrium, there always exist some players that will spend their efforts in production, i.e., $x^{*}=\left(x_{1}^{*}, x_{2}^{*}, \ldots, x_{n}^{*}\right) \neq(0,0, \ldots, 0)$.

Proof: The proof is followed by a contradiction. Suppose not, i.e., $x^{*}=\left(x_{1}^{*}, x_{2}^{*}, \ldots, x_{n}^{*}\right)=$ $(0,0, \ldots, 0)$. Then, from the proof of Proposition 30, we know that in equilibrium, the following equation must hold for any player $i \in N$ :

$$
\frac{\partial p_{i}}{\partial y_{i}}\left[F-\sum_{l=1}^{n} \delta_{l} v_{l}\right]-p_{i} \frac{\partial F}{\partial x_{i}}=0
$$

Rearrange the above equation,

$$
\frac{\partial p_{i}}{\partial y_{i}} F=\frac{\partial p_{i}}{\partial y_{i}} \sum_{l=1}^{n} \delta_{l} v_{l}+p_{i} \frac{\partial F}{\partial x_{i}} .
$$

Since $x^{*}=(0,0, \ldots, 0)$ implies that $F\left(x^{*}\right)=0$, the left hand side of the above equation is 0 . Besides, from Assumption 2, we know that for any $x \in X, \frac{\partial F}{\partial x_{i}}(x)>0$. From the budget constraint, we have $x_{i}+y_{i}=\sigma_{i}$, for any $i \in N$. Therefore, $x_{i}=0$ implies that $y_{i}=\sigma_{i}>0$. Hence, $p_{i}>0$, for any $i \in N$ and the right hand side of the above equation is greater than 0 , a contradiction.

Proposition 33. Suppose that Assumptions 2, 3 and 4 hold. For any player $i, j \in N$, given 
that other factors are the same, then under the unanimity voting rule with transitory effects, no matter how they discount their future values, in equilibrium, the productive and unproductive efforts between players $i$ and $j$ must satisfy: $x_{i}^{*}=x_{j}^{*}$ and $y_{i}^{*}=y_{j}^{*}$, respectively. Furthermore, given that other factors are the same, then the discount factors and the expected equilibrium payoffs between the two players must have the following relationship: $\left(1-\delta_{i}\right) v_{i}=\left(1-\delta_{j}\right) v_{j}$.

Proof: From the previous proof, we know that in equilibrium, the optimal efforts between players $i$ and $j$ must satisfy:

$$
\frac{\frac{\partial p_{i}}{\partial y_{i}}}{\frac{\partial p_{j}}{\partial y_{j}}}=\frac{p_{i}}{p_{j}} \frac{\frac{\partial F}{\partial x_{i}}}{\frac{\partial F}{\partial x_{j}}}
$$

Since the above equation is independent of the discount factors, $\delta_{i}$ and $\delta_{j}$, Proposition 31 still holds. Hence, we have shown that if $\delta_{i}>\delta_{j}$, then $x_{i}^{*}=x_{j}^{*}$ and $y_{i}^{*}=y_{j}^{*}$.

Next, we show that in equilibrium, we have $\left(1-\delta_{i}\right) v_{i}=\left(1-\delta_{j}\right) v_{j}$. From Eq.(50), we know that the expected equilibrium payoffs for players $i$ and $j$ are as follows:

$$
v_{i}=\frac{p_{i}}{1-\delta_{i}}\left[F-\sum_{l=1}^{n} \delta_{l} s_{l}\right] ; \quad v_{j}=\frac{p_{j}}{1-\delta_{j}}\left[F-\sum_{l=1}^{n} \delta_{l} s_{l}\right]
$$

Rearrange them:

$$
\left(1-\delta_{i}\right) v_{i}=\frac{p_{i}\left(x^{*}\right)}{1-\delta_{i}}\left[F-\sum_{l=1}^{n} \delta_{l} s_{l}\right] ; \quad\left(1-\delta_{j}\right) v_{j}=\frac{p_{j}\left(x^{*}\right)}{1-\delta_{j}}\left[F-\sum_{l=1}^{n} \delta_{l} s_{l}\right]
$$

Since $y_{i}^{*}=y_{j}^{*}$, we have $p_{i}=p_{j}$. Therefore, it is obvious that $\left(1-\delta_{i}\right) v_{i}=\left(1-\delta_{j}\right) v_{j}$. This completes the proof.

Proposition 34. Suppose that Assumptions 2, 3 and 4 hold. For any player $i, j \in N$, given that other factors are the same and their initial endowments satisfy: $\sigma_{i}>\sigma_{j}$, then under the unanimity voting rule with transitory effects, the productive and unproductive efforts and the expected payoffs between the two players have the following relationships: $x_{i}^{*}>x_{j}^{*}, y_{i}^{*}>y_{j}^{*}$ and $v_{i}>v_{j}$, respectively.

Proof: First, we show that if $\sigma_{i}>\sigma_{j}$, then $y_{i}^{*}>y_{j}^{*}$ and $x_{i}^{*}>x_{j}^{*}$. Suppose not. Namely, $y_{i}^{*} \leq y_{j}^{*}$, or $y_{i}^{*}>y_{j}^{*}$ and $x_{i}^{*}<x_{j}^{*}$. If $y_{i}^{*} \leq y_{j}^{*}$, then $x_{i}^{*}>x_{j}^{*}$ since $\sigma_{i}>\sigma_{j}$, and for any $\left(x_{i}, y_{i}\right)$ and $\left(x_{j}, y_{j}\right)$, we have $x_{i}+y_{i}=\sigma_{i}$ and $x_{j}+y_{j}=\sigma_{j}$. Then from the previous proof, we know that the left hand side of Eq.(107) $\geq 1>$ the right hand side of Eq.(107), a contradiction. Similarly, if $y_{i}^{*}>y_{j}^{*}$ and $x_{i}^{*}<x_{j}^{*}$, 
then we can verify that the left hand side of Eq.(107) $<1<$ the right hand side of Eq.(107), a contradiction. Thus, if $\sigma_{i}>\sigma_{j}$, in equilibrium, we must have $x_{i}^{*}>x_{j}^{*}$ and $y_{i}^{*}>y_{j}^{*}$.

Next, given that $y_{i}^{*}>y_{j}^{*}$, together with the expected equilibrium payoff derived in Eq.(50) and the production function defined in Assumption 3, it is obvious that in equilibrium, the expected payoff shall satisfy: $v_{i}>v_{j}$. This completes the proof.

Proposition 35. Suppose that Assumptions 2 and 3 hold. Then under the k-majority voting rule with transitory effects, if there exists a SSPE, it must be unique.

Proof: To show that there exists a unique SSPE, we consider the following two possible equilibrium paths. First, suppose that player $i$ 's vote is cheaper than player $k$ 's. Namely, $\delta_{i} v_{i}<\delta_{k} v_{k}$. Then, substituting Eqs.(52) and (53) into player $i$ 's dynamic problem, we have:

$$
v_{i}=\max _{x_{i} \in\left[0, \sigma_{i}\right]}\left\{\frac{p_{i}}{1-\delta_{i}}\left[F(x)-\omega_{k}-\delta_{k} v_{k}\right]\right\}
$$

Taking the first order derivative w.r.t. $x_{i}$ yields the first-order condition:

$$
\frac{1}{1-\delta_{i}}\left\{-\partial p_{i} / \partial y_{i}\left[F(x)-\omega_{k}-\delta_{k} v_{k}\right]+p_{i} \partial F / \partial x_{i}\right\}=0
$$

Or,

$$
\partial p_{i} / \partial y_{i}\left[F(x)-\omega_{k}-\delta_{k} v_{k}\right]-p_{i} \partial F / \partial x_{i}=0
$$

Then, by following the same steps as in deriving the uniqueness under the unanimity rule with persistent effects, it can be shown that the left hand side of the above equation increases in $x_{i}$. Besides, since the right hand side is constant, then if there exists a SSPE, it must be unique.

Next, suppose that player $i$ 's vote is more expensive than player $k^{\prime}$ s, i.e., $\delta_{i} v_{i}>\delta_{k} v_{k}$. Then by Eqs.(52) and (53), player $i$ 's dynamic problem becomes:

$$
v_{i}=\max _{x_{i} \in\left[0, \sigma_{i}\right]}\left\{p_{i}\left[F(x)-\omega_{k}\right]\right\}
$$

Taking the first order derivative w.r.t. $x_{i}$ yields the first-order condition:

$$
-\frac{\partial p_{i}}{\partial y_{i}}\left[F(x)-\omega_{k}\right]+p_{i} \frac{\partial F}{\partial x_{i}}=0
$$


Rearranging it, we have

$$
\frac{\partial p_{i}}{\partial y_{i}}\left[F(x)-\omega_{k}\right]-p_{i} \frac{\partial F}{\partial x_{i}}=0
$$

Similar to the previous proof, we can verify that the left hand side of the above equation is monotonic in $x_{i}$ while the right hand side remains constant. Hence, the SSPE is unique.

To sum up, the two possible equilibrium paths reveal that the solution to player $i$ 's dynamic problem under the $k$-majority voting rule with transitory effects is unique.

Proposition 36. Suppose that Assumptions 2, 3 and 4 hold. For any $i, j \in N$, if their discount factors and their initial endowments are the same, i.e., $\delta_{i}=\delta_{j}$ and $\sigma_{i}=\sigma_{j}$, and players are sufficiently patient, then under the $k$-majority voting rule with transitory effects, in equilibrium, the productive and unproductive efforts and the expected payoff between players $i$ and $j$ are equal, i.e., $x_{i}^{*}=x_{j}^{*}, y_{i}^{*}=y_{j}^{*}$ and $v_{i}=v_{j}$.

Proof: We first show that given that everything is symmetric between the two players, then their expected equilibrium payoffs are equal, i.e., $v_{i}=v_{j}$. The proof is followed by a contradiction. Suppose not. Namely, $v_{i} \neq v_{j}$. Since players $i$ and $j$ are symmetric in all the factors, without loss of generality, assume that player $i$ has a smaller continuation value than player $j$, i.e., $\delta_{i} v_{i}<\delta_{j} v_{j}$. Now we consider three possible equilibrium paths.

Equilibrium path 1: Suppose that in equilibrium, we have $\delta_{i} v_{i}<\delta_{j} v_{j}<\delta_{k} v_{k}$. From Eq.(109), we know that $x_{i}^{*}$ must satisfy the following first order condition:

$$
\frac{\partial p_{i}}{\partial y_{i}}\left[F(x)-\omega_{k}-\delta_{k} v_{k}\right]=p_{i} \frac{\partial F}{\partial x_{i}} .
$$

Besides, Assumption 4 says that players $i$ and $j$ are symmetric in producing the size of the "cake" and being recognized as a proposer. Hence, we can derive a similar expression of player $j$ ' optimal productive effort:

$$
\frac{\partial p_{j}}{\partial y_{j}}\left[F(x)-\omega_{k}-\delta_{k} v_{k}\right]=p_{j} \frac{\partial F}{\partial x_{j}}
$$

Taking the ratio of the above two equations yields

$$
\frac{\frac{\partial p_{i}}{\partial y_{i}}}{\frac{\partial p_{j}}{\partial y_{j}}}=\frac{p_{i}}{p_{j}} \frac{\frac{\partial F}{\partial x_{i}}}{\frac{\partial F}{\partial x_{j}}}
$$


Then, from the proof of Proposition 31, we know that in order for the above equation to hold, in equilibrium, we must have $x_{i}^{*}=x_{j}^{*}$ and $y_{i}^{*}=y_{j}^{*}$. However, by Eq.(108), we know that the expected equilibrium payoff for players $i$ and $j$ are:

$$
v_{i}=\frac{p_{i}}{1-\delta_{i}}\left[F(x)-\omega_{k}-\delta_{k} v_{k}\right] ; \quad v_{j}=\frac{p_{j}}{1-\delta_{j}}\left[F(x)-\omega_{k}-\delta_{k} v_{k}\right]
$$

Since $\delta_{i}=\delta_{j}, x_{i}^{*}=x_{j}^{*}$ and $y_{i}^{*}=y_{j}^{*}$, then $v_{i}=v_{j}$, a contradiction. Hence, we have shown that under equilibrium path $1, v_{i}=v_{j}$.

Equilibrium path 2: Suppose that in equilibrium, we have $\delta_{i} v_{i}<\delta_{k} v_{k}<\delta_{j} v_{j}$. Then from Eqs.(108) and (110), we know that the expected equilibrium payoffs of players $i$ and $j$ are:

$$
v_{i}=\frac{p_{i}}{1-\delta_{i}}\left[F(x)-\omega_{k}-\delta_{k} v_{k}\right] ; \quad v_{j}=p_{j}\left[F(x)-\omega_{k}\right]
$$

Then if players $i$ and $j$ are sufficiently patient, or equivalently, $\delta_{i}=\delta_{j}$ is high enough, then for any $p_{i} \in[0,1]$ and $p_{j} \in[0,1]$, we have $v_{i}>v_{j}$, a contradiction. Hence, we have shown that $\delta_{i} v_{i}<\delta_{j} v_{j}<\delta_{k} v_{k}$ cannot be an equilibrium path.

Equilibrium path 3: Suppose that in equilibrium, we have $\delta_{k} v_{k}<\delta_{i} v_{i}<\delta_{j} v_{j}$. Then from Eq.(111), we know that the first order conditions for the dynamic problems of players $i$ and $j$ are :

$$
\frac{\partial p_{i}}{\partial y_{i}}\left[F(x)-\omega_{k}\right]-p_{i} \frac{\partial F}{\partial x_{i}}=0
$$

and

$$
\frac{\partial p_{j}}{\partial y_{j}}\left[F(x)-\omega_{k}\right]-p_{j} \frac{\partial F}{\partial x_{j}}=0
$$

respectively. Take the ratio and rearrange:

$$
\frac{\frac{\partial p_{i}}{\partial y_{i}}}{\frac{\partial p_{j}}{\partial y_{j}}}=\frac{p_{i}}{p_{j}} \frac{\frac{\partial F}{\partial x_{i}}}{\frac{\partial F}{\partial x_{j}}} .
$$

Then the proof is the same as under equilibrium path 1 . It can be shown that under equilibrium path 3 , we must have $v_{i}=v_{j}$.

Therefore, the three possible equilibrium paths imply that if $\delta_{i}=\delta_{j}$ and $\sigma_{i}=\sigma_{j}$, then $v_{i}=v_{j}$. 
Since we have shown that $v_{i}=v_{j}$, the three possible equilibrium paths reduces to two. Namely, $\delta_{i} v_{i}=\delta_{j} v_{j}<\delta_{k} s_{k}$ and $\delta_{i} v_{i}=\delta_{j} s_{j}>\delta_{k} s_{k}$. From the previous proof, we know that under these two cases, the equilibrium efforts must satisfy the equation below:

$$
\frac{\frac{\partial p_{i}}{\partial y_{i}}}{\frac{\partial p_{j}}{\partial y_{j}}}=\frac{p_{i}}{p_{j}} \frac{\frac{\partial F}{\partial x_{i}}}{\frac{\partial F}{\partial x_{j}}}
$$

and the equilibrium productive and unproductive efforts shall satisfy: $x_{i}^{*}=x_{j}^{*}$ and $y_{i}^{*}=y_{j}^{*}$. This completes the proof.

Proposition 37. Suppose that Assumptions 2, 3 and 4 hold. Then under the $k$-majority voting rule with transitory effects, in equilibrium, there always exist some players that will spend their efforts in production, i.e., $x^{*}=\left(x_{1}^{*}, x_{2}^{*}, \ldots, x_{n}^{*}\right) \neq(0,0, \ldots, 0)$.

Proof: The proof is the same as in deriving Propositions 22 and 32.

Proposition 38. Suppose that Assumptions 2, 3 and 4 hold. For any player $i, j \in N$, given that other factors are the same and their discount factors satisfy: $\delta_{i}>\delta_{j}$, then under the $k$-majority voting rule with transitory effects, if

(i) players $i$ and $j$ are in the winning coalition, i.e., $\delta_{i} v_{i}<\delta_{k} v_{k}$ and $\delta_{j} v_{j}<\delta_{k} v_{k}$, then no matter how they discount their future values, in equilibrium, their productive and unproductive efforts must satisfy: $x_{i}^{*}=x_{j}^{*}$ and $y_{i}^{*}=y_{j}^{*}$, respectively, and the discount factors and the expected equilibrium payoffs between the two players have the following relationship: $\left(1-\delta_{i}\right) v_{i}=$ $\left(1-\delta_{j}\right) v_{j}$.

(ii) players $i$ is in the winning coalition while player $j$ is excluded from the winning coalition, i.e., $\delta_{i} v_{i}<\delta_{k} v_{k}<\delta_{j} v_{j}$, in equilibrium, the productive and unproductive efforts and the expected payoffs between the two players must have the following relationships: $x_{i}^{*}>x_{j}^{*} y_{i}^{*}<y_{j}^{*}$ and $v_{i}<v_{j}$, respectively.

(iii) players $i$ is excluded from the winning coalition while player $j$ is in the winning coalition, i.e., $\delta_{i} v_{i}>\delta_{k} v_{k}>\delta_{j} v_{j}$, in equilibrium, the productive and unproductive efforts between the two players must have the following relationships: $x_{i}^{*}<x_{j}^{*}$ and $y_{i}^{*}>y_{j}^{*}$, respectively. 
(iv) players $i$ and $j$ are excluded from the winning coalition, i.e., $\delta_{i} v_{i}>\delta_{k} v_{k}$ and $\delta_{j} v_{j}>\delta_{k} v_{k}$, then no matter how they discount their future values, in equilibrium, their productive and unproductive efforts must satisfy: $x_{i}^{*}=x_{j}^{*}$ and $y_{i}^{*}=y_{j}^{*}$, respectively and the discounted factors and the expected equilibrium payoffs between the two players have the following relationship: $\left(1-\delta_{i}\right) v_{i}=\left(1-\delta_{j}\right) v_{j}$

Proof: From the proof of Proposition 36, we know that under conditions $(i)$ and $(i v)$, the optimal efforts of players $i$ and $j$ must satisfy the following equation:

$$
\frac{\frac{\partial p_{i}}{\partial y_{i}}}{\frac{\partial p_{j}}{\partial y_{j}}}=\frac{p_{i}}{p_{j}} \frac{\frac{\partial F}{\partial x_{i}}}{\frac{\partial F}{\partial x_{j}}} .
$$

Since this equation is independent of the discount factors, by going through the same steps as in deriving Proposition 36, we can show that the efforts between the two players are equal in equilibrium, i.e., $x_{i}^{*}=x_{j}^{*}$ and $y_{i}^{*}=y_{j}^{*}$.

Next, we show that under conditions $(i)$ and $(i v)$, their expected equilibrium payoffs satisfy: $(1-$ $\left.\delta_{i}\right) v_{i}=\left(1-\delta_{j}\right) v_{j}$. Under condition $(i)$, the expected payoffs of players $i$ and $j$ are:

$$
v_{i}=\frac{p_{i}}{1-\delta_{i}}\left[F(x)-\omega_{k}-\delta_{k} v_{k}\right] ; \quad v_{j}=\frac{p_{j}}{1-\delta_{j}}\left[F(x)-\omega_{k}-\delta_{k} v_{k}\right]
$$

Rearrange them:

$$
\left(1-\delta_{i}\right) v_{i}=p_{i}\left[F(x)-\omega_{k}-\delta_{k} v_{k}\right] ; \quad\left(1-\delta_{j}\right) v_{j}=p_{j}\left[F(x)-\omega_{k}-\delta_{k} v_{k}\right]
$$

Besides, $y_{i}^{*}=y_{j}^{*}$ implies that $p_{i}=p_{j}$. Hence, it can be verified that $\left(1-\delta_{i}\right) v_{i}=\left(1-\delta_{j}\right) v_{j}$. Similarly, under condition $(i v)$, the expected payoffs of players $i$ and $j$ are:

$$
v_{i}=p_{i}\left[F(x)-\omega_{k}\right] \quad v_{j}=p_{j}\left[F(x)-\omega_{k}\right]
$$

By following a similar argument as in deriving condition $(i)$, we can show that if condition (iv) is satisfied, then $\left(1-\delta_{i}\right) v_{i}=\left(1-\delta_{j}\right) v_{j}$.

Hence, we have verified the results under conditions $(i)$ and $(i v)$. 
Now we prove that under condition $(i i), x_{i}^{*}>x_{j}^{*} y_{i}^{*}<y_{j}^{*}$ and $v_{i}<v_{j}$. Since $\delta_{i}>\delta_{j}, \delta_{i} v_{i}<\delta_{k} v_{k}<$ $\delta_{j} v_{j}$ implies that $v_{i}>v_{j}$. From the proof of Proposition 35, if player $i$ is excluded from the winning coalition, then his optimal efforts must satisfy:

$$
\frac{\partial p_{i}}{\partial y_{i}}\left[F(x)-\omega_{k}-\delta_{k} v_{k}\right]=p_{i} \frac{\partial F}{\partial x_{i}}
$$

The proof of Proposition 36 shows that under condition ( $i i)$, player $j$ 's optimal efforts must satisfy:

$$
\frac{\partial p_{j}}{\partial y_{j}}\left[F(x)-\omega_{k}\right]=p_{j} \frac{\partial F}{\partial x_{j}}
$$

Take the ratio of them:

$$
\frac{\frac{\partial p_{i}}{\partial y_{i}}}{\frac{\partial p_{j}}{\partial y_{j}}} \frac{F(x)-\omega_{k}-\delta_{k} v_{k}}{F(x)-\omega_{k}}=\frac{p_{i}}{p_{j}} \frac{\frac{\partial F}{\partial x_{i}}}{\frac{\partial F}{\partial x_{j}}} .
$$

Then the proof is followed by a contradiction. Suppose not, i.e., $y_{i}^{*} \geq y_{j}^{*}$. This implies that $x_{i}^{*} \leq x_{j}^{*}$ because $x_{i}^{*}+y_{i}^{*}=\sigma_{i}, x_{j}^{*}+y_{j}^{*}=\sigma_{j}$ and $\sigma_{i}=\sigma_{j}$. By Lemma 9 , we have $p_{i}\left(y^{*}\right) \geq p_{j}\left(y^{*}\right)$ and $\frac{\partial p_{i}}{\partial y_{i}}\left(y^{*}\right) \leq \frac{\partial p_{j}}{\partial y_{j}}\left(y^{*}\right)$. Lemma 8 says that if $x_{i}^{*} \leq x_{j}^{*}$, then $\frac{\partial F}{\partial x_{i}}\left(x^{*}\right) \geq \frac{\partial F}{\partial x_{j}}\left(x^{*}\right)$. Therefore, the left hand side of Eq. $(112)<1<$ the right hand side, a contradiction. Hence, under condition $(i i)$, we must have $x_{i}^{*}>x_{j}^{*}$ and $y_{i}^{*}<y_{j}^{*}$. This completes the proof under condition $(i i)$.

Finally, we verify that under condition $(i i i), x_{i}^{*}<x_{j}^{*}$ and $y_{i}^{*}>y_{j}^{*}$. Similar to condition $(i i)$, the optimal efforts for players $i$ and $j$ shall satisfy the following relation:

$$
\frac{\frac{\partial p_{i}}{\partial y_{i}}}{\frac{\partial p_{j}}{\partial y_{j}}} \frac{F(x)-\omega_{k}}{F(x)-\omega_{k}-\delta_{k} v_{k}}=\frac{p_{i}}{p_{j}} \frac{\frac{\partial F}{\partial x_{i}}}{\frac{\partial F}{\partial x_{j}}} .
$$

Then by following similar steps as in deriving condition $(i i)$, we can prove that $x_{i}^{*} \geq x_{j}^{*}$ and $y_{i}^{*} \leq y_{j}^{*}$. Thus, we have shown that under condition $(i i i), x_{i}^{*}<x_{j}^{*}$ and $y_{i}^{*}>y_{j}^{*}$.

Proposition 39. Suppose that Assumptions 2, 3 and 4 hold. For any player $i, j \in N$, given that other factors are the same and their initial endowments satisfy: $\sigma_{i}>\sigma_{j}$, then under the $k$-majority voting rule with transitory effects, if

(i) players $i$ and $j$ are in the winning coalition, i.e., $\delta_{i} v_{i}<\delta_{k} v_{k}$ and $\delta_{j} v_{j}<\delta_{k} v_{k}$, in equilibrium, the productive and unproductive efforts and the expected payoffs between the two players must 
have the following relationships: $x_{i}^{*}>x_{j}^{*} y_{i}^{*}>y_{j}^{*}$ and $v_{i}>v_{j}$, respectively.

(ii) players $i$ is in the winning coalition while player $j$ is excluded from the winning coalition, i.e., $\delta_{i} v_{i}<\delta_{k} v_{k}<\delta_{j} v_{j}$, in equilibrium, the productive efforts and the expected payoffs between the two players must have the following relationships: $x_{i}^{*}>x_{j}^{*}$ and $v_{i}<v_{j}$, respectively.

(iii) players $i$ is excluded from the winning coalition while player $j$ is in the winning coalition, i.e., $\delta_{i} v_{i}>\delta_{k} v_{k}>\delta_{j} v_{j}$, in equilibrium, the unproductive efforts and the expected payoffs between the two players must have the following relationships: $y_{i}^{*}>y_{j}^{*}$ and $v_{i}>v_{j}$, respectively.

(iv) players $i$ and $j$ are excluded from the winning coalition, i.e., $\delta_{i} v_{i}>\delta_{k} v_{k}$ and $\delta_{j} v_{j}>\delta_{k} v_{k}$, in equilibrium, the productive and unproductive efforts and the expected payoffs between the two players must have the following relationships: $x_{i}^{*}>x_{j}^{*} y_{i}^{*}>y_{j}^{*}$ and $v_{i}>v_{j}$, respectively.

Proof: From the proof of Proposition 36, we know that under conditions $(i)$ and $(i v)$, the optimal efforts of players $i$ and $j$ must satisfy the following equation:

$$
\frac{\frac{\partial p_{i}}{\partial y_{i}}}{\frac{\partial p_{j}}{\partial y_{j}}}=\frac{p_{i}}{p_{j}} \frac{\frac{\partial F}{\partial x_{i}}}{\frac{\partial F}{\partial x_{j}}} .
$$

Similar to the proof of Proposition 36, we can show that if $y_{i}^{*}<y_{j}^{*}$ and $x_{i}^{*}>x_{j}^{*}$, the left hand side of the above equation $>1>$ the right hand side, and if $y_{i}^{*}=y_{j}^{*}$ and $x_{i}^{*}>x_{j}^{*}$, the left hand side of the above equation $=1>$ the right hand side. Therefore, if $\sigma_{i}>\sigma_{j}$, together with the resource constraints $x_{i}+y_{i}=\sigma_{i}$ and $x_{j}+y_{j}=\sigma_{j}$, in equilibrium, in order for the above equation to hold, we must have $y_{i}^{*}>y_{j}^{*}$ and $x_{i}^{*}>x_{j}^{*}$. Besides, the equilibrium expected payoffs under condition $(i)$ and (iv) satisfy Eqs.(108) and (110). Therefore, $y_{i}^{*}>y_{j}^{*}$ implies that $v_{i}>v_{j}$ under these two conditions. This completes the proof under conditions $(i)$ and $(i v)$.

To show that under condition $(i i), x_{i}^{*}>x_{j}^{*}$ and $v_{i}<v_{j}$. Since $\delta_{i}=\delta_{j}$ and $\delta_{i} v_{i}<\delta_{k} s_{k}<\delta_{j} v_{j}$, $v_{i}<v_{j}$. Then to prove that $x_{i}^{*}>x_{j}^{*}$, suppose not, i.e., $x_{i}^{*} \leq x_{j}^{*}$. Note that $x_{i}^{*} \leq x_{j}^{*}$ implies that $y_{i}^{*}>y_{j}^{*}$ because $\sigma_{i}>\sigma_{j}$ and $x_{l}+y_{l}=\sigma_{l}$, for any $l \in N$. By the proof of Proposition 36, in equilibrium, we have

$$
\frac{\frac{\partial p_{i}}{\partial y_{i}}}{\frac{\partial p_{j}}{\partial y_{j}}} \frac{F-\omega_{k}-\delta_{k} s_{k}}{F-\omega_{k}}=\frac{p_{i}}{p_{j}} \frac{\frac{\partial F}{\partial x_{i}}}{\frac{\partial F}{\partial x_{j}}}
$$


and if $x_{i}^{*} \leq x_{j}^{*}$ and $y_{i}^{*}>y_{j}^{*}$ then the above equation does not hold, a contradiction. Therefore, under condition $(i i)$, we must have $x_{i}^{*}>x_{j}^{*}$ and $v_{i}<v_{j}$.

Finally, to verify that under condition $(i i i)$, we have $y_{i}^{*}>y_{j}^{*}, v_{i}>v_{j}$. Since $\delta_{i}=\delta_{j}$ and $\delta_{i} v_{i}>$ $\delta_{k} s_{k}>\delta_{j} v_{j}$, we have $v_{i}>v_{j}$. From the proof of Proposition 26, we know that

$$
\frac{\frac{\partial p_{i}}{\partial y_{i}}}{\frac{\partial p_{j}}{\partial y_{j}}} \frac{F-\omega_{k}}{F-\omega_{k}-\delta_{k} s_{k}}=\frac{p_{i}}{p_{j}} \frac{\frac{\partial F}{\partial x_{i}}}{\frac{\partial F}{\partial x_{j}}}
$$

By following similar steps as in deriving the results under condition $(i i)$, we can show that in order for the above equation to be satisfied, in equilibrium, we must have $y_{i}^{*}>y_{j}^{*}$. This completes the proof that under condition (iii), the equilibrium unproductive efforts and expected payoff shall satisfy: $y_{i}^{*}>y_{j}^{*}, v_{i}>v_{j}$.

Lemma 4. Suppose that Assumptions 2 and 3 hold. For any player $i \in N$, given that other factors are the same, under the bargaining model with transitory effects, in comparison to the $k$ majority voting rule, player $i$ will exert more productive effort and less unproductive effort under the unanimity voting rule, i.e., $y_{i}^{* U}<y_{i}^{* k}$ and $x_{i}^{* U}>x_{i}^{* k}$.

Proof: The proof is followed by a contradiction. Suppose not. Namely, $y_{i}^{* U} \geq y_{i}^{* k}$. If $y_{i}^{* U} \geq y_{i}^{* k}$, then $x_{i}^{* U} \leq x_{i}^{* k}$, because the initial endowments for player $i$ under the two voting rules are the same and for any $\left(x_{i}, y_{i}\right)$, we have $x_{i}+y_{i}=\sigma_{i}$.

From the proof of Proposition 31, we know that the optimal effort for player $i$ under the unanimity rule satisfies the following equation:

$$
\frac{\partial p_{i}}{\partial y_{i}}\left(y^{* U}\right)\left[F\left(x^{* U}\right)-\sum_{l=1}^{n} \delta_{l} v_{l}\right]=p_{i}\left(y^{* U}\right) \frac{\partial F}{\partial x_{i}}\left(x^{* U}\right) .
$$

Under the $k$-majority rule, we need to consider two possible equilibrium path.

Equilibrium path 1: Suppose that in equilibrium $\delta_{i} v_{i}<\delta_{k} v_{k}$. Then, from the proof of Proposition 36 , the optimal effort for player $i$ under the $k$-majority rule satisfies:

$$
\frac{\partial p_{i}}{\partial y_{i}}\left(y^{* k}\right)\left[F\left(x^{* k}\right)-\omega_{k}-\delta_{k} v_{k}\right]=p_{i}\left(y^{* k}\right) \frac{\partial F}{\partial x_{i}}\left(x^{* k}\right)
$$


Take the ratio of the above two equations, we have

$$
\frac{\frac{\partial p_{i}}{\partial y_{i}}\left(y^{* U}\right)}{\frac{\partial p_{i}}{\partial y_{i}}\left(y^{* k}\right)} \frac{F\left(x^{* U}\right)-\sum_{l=1}^{n} \delta_{l} v_{l}}{F\left(x^{* k}\right)-\omega_{k}-\delta_{k} v_{k}}=\frac{p_{i}\left(y^{* U}\right)}{p_{i}\left(y^{* k}\right)} \frac{\frac{\partial F}{\partial x_{i}}\left(x^{* U}\right)}{\frac{\partial F}{\partial x_{i}}\left(x^{* k}\right)} .
$$

Assumption 3 shows that $\frac{\partial p_{i}}{\partial y_{i}}(y)>0$ and $\frac{\partial^{2} p_{i}}{\partial y_{i}^{2}}(y)<0$, for all $y \in Y$. Thus, if $y_{i}^{* K} \leq y_{i}^{* U}$, and the other players exert the same efforts under both $k$-majority and unanimity voting rules, then

$$
\frac{\partial p_{i}}{\partial y_{i}}\left(y^{* U}\right) \leq \frac{\partial p_{i}}{\partial y_{i}}\left(y^{* K}\right) ; \quad p_{i}\left(y^{* U}\right) \geq p_{i}\left(y^{* K}\right)
$$

Similarly, Assumption 2 says that $\frac{\partial F}{\partial x_{i}}(x) \geq 0$ and $\frac{\partial^{2} F}{\partial x_{i}^{2}}(x) \leq 0$, for all $x \in X$. Therefore, if $x_{i}^{* U} \leq x_{i}^{* k}$, we have

$$
F\left(x^{* U}\right) \leq F\left(x^{* k}\right) ; \quad \frac{\partial F}{\partial x_{i}}\left(x^{* U}\right) \geq \frac{\partial F}{\partial x_{i}}\left(x^{* k}\right) .
$$

Since $k \neq n$, and the other players choose the same effort under both unanimity voting rule and the $k$-majority voting rules, then by the definition of $\omega_{k}$, we have $\sum_{l \neq i} \delta_{l} v_{l}>\omega_{k}-\delta_{i} v_{i}+\delta_{k} v_{k}$, for any $k \neq n \in N$. Rearrange it, we have $\sum_{l=1}^{n} \delta_{l} v_{l}>\omega_{k}+\delta_{k} v_{k}$, for any $k \neq n \in N$.

Hence, we can show that the left hand side of Eq.(114) $<1 \leq$ the right hand side of Eq.(114), a contradiction. Thus, $y_{i}^{* k}>y_{i}^{* U}$ under equilibrium path 1 .

Equilibrium path 2: Suppose that in equilibrium $\delta_{i} v_{i}>\delta_{k} v_{k}$. Then, from the proof of Proposition 36 , the optimal effort for player $i$ under the $k$-majority rule satisfies:

$$
\frac{\partial p_{i}}{\partial y_{i}}\left(y^{* k}\right)\left[F\left(x^{* k}\right)-\omega_{k}\right]=p_{i}\left(y^{* K}\right) \frac{\partial F}{\partial x_{i}}\left(x^{* k}\right) .
$$

Take the ratio of Eqs.(113) and (115),

$$
\frac{\frac{\partial p_{i}}{\partial y_{i}}\left(y^{* U}\right)}{\frac{\partial p_{i}}{\partial y_{i}}\left(y^{* k}\right)} \frac{F\left(x^{* U}\right)-\sum_{l=1}^{n} \delta_{l} v_{l}}{F\left(x^{* k}\right)-\omega_{k}}=\frac{p_{i}\left(y^{* U}\right)}{p_{i}\left(y^{* k}\right)} \frac{\frac{\partial F}{\partial x_{i}}\left(x^{* U}\right)}{\frac{\partial F}{\partial x_{i}}\left(x^{* k}\right)} .
$$

Then the proof is followed by similar steps as under the previous case. It can be shown that if $y_{i}^{* U} \geq y_{i}^{* k}$, then the left hand side of the above equation $<1 \leq$ the right hand side. Thus, under equilibrium path 3 , we must have $y_{i}^{* k}>y_{i}^{* U}$.

Overall, the two possible equilibrium paths indicate that the equilibrium efforts under the unanimity 
and $k$-majority voting rules must satisfy: $y_{i}^{* k}>y_{i}^{* U}$ and $x_{i}^{* k}<x_{i}^{* U}$

Proposition 40. Suppose that Assumptions 2 and 3 hold. Then in comparison to the k-majority voting rule with persistent effects, the unanimity voting rule with persistent effects generates a greater social surplus and forgoes a smaller social cost.

Proof: The proof is the same as Proposition 28.

Lemma 5. Suppose that Assumptions 2 and 3 hold. For any player $i \in N$, given that other factors are the same, under the $k$-majority voting rule with transitory effects, his unproductive effort, $y_{i}^{*}$, weakly decreases in $k$ while his productive effort, $x_{i}^{*}$, weakly increases in $k$, where $k=\{1,2, \ldots, n-1\}$.

Proof: Suppose not. Namely, $y_{i}^{*}$ increases in $k$. This implies that $x_{i}^{*}$ decreases in $k$ because for any $\left(x_{i}, y_{i}\right)$, we have $x_{i}+y_{i}=\sigma_{i}$. Then, we consider two possible equilibrium paths.

Equilibrium Path 1: Suppose that in equilibrium $\delta_{i} v_{i}<\delta_{k} v_{k}$. Then, from the previous proof, we know that the first order condition of player $i$ 's dynamic problem is:

$$
\frac{\partial p_{i}}{\partial y_{i}}\left[F(x)-\omega_{k}-\delta_{k} v_{k}\right]=p_{i} \frac{\partial F}{\partial x_{i}} .
$$

Then similar to the proof of Proposition 3, it can be verified that if $y_{i}^{*}$ increases in $k$, then the above equation does not hold. Thus, under equilibrium path 1 , there is a negative relationship between $y_{i}^{*}$ and $k$.

Equilibrium Path 2: Suppose that in equilibrium $\delta_{i} v_{i}>\delta_{k} v_{k}$. Then, the first order condition of player $i$ 's dynamic problem is:

$$
\frac{\partial p_{i}}{\partial y_{i}}\left[F(x)-\omega_{k}\right]=p_{i} \frac{\partial F}{\partial x_{i}}
$$

Similar to the previous case, we can show that if $y_{i}^{*}$ increases in $k$, then the equation above does not satisfy.

Therefore, the two possible equilibrium paths reveal that in equilibrium the productive efforts increases in $k$ while the unproductive efforts decreases in $k$. 


\section{B Appendix B: I.I.D. Case}

In this section, we briefly introduce a simpler version of our model. Namely, we now assume that $\theta$ is i.i.d across every two periods and remains the same within the two periods. Note that the politically efficient tariffs are independent of how the state evolves. Therefore, they are the same as in Section 2.3.

For the i.i.d. case, under the no-delayed retaliation mechanism, the strategies of home and foreign are:

$$
\tau_{t}= \begin{cases}z^{N D I}\left(\theta_{L}\right) & \text { if } \theta_{t}=\theta_{L} \\ z^{N D I}\left(\theta_{H}\right) & \text { if } \theta_{t}=\theta_{H}\end{cases}
$$

and

$$
\tau_{t}^{*}= \begin{cases}z^{* N D I} & \text { if } \tau_{t}=z^{N D I}\left(\theta_{L}\right) \\ z^{N D I}\left(\theta_{H}\right) & \text { if } \tau_{t}=z^{N D I}\left(\theta_{H}\right)\end{cases}
$$

where $t=\{1,2\}$ and the superscript letters "ND" represent "no-delayed" and the superscript letter "I" denotes "i.i.d".

Given the above strategies, the negotiators' maximization problem becomes:

$$
\begin{aligned}
\max _{z^{N D I}\left(\theta_{L}\right), z^{N D I}\left(\theta_{H}\right), z^{* N D I}} & \left.\lambda(1+\delta)\left[\vartheta\left(z^{N D I}\left(\theta_{L}\right), z^{* N D I}, \theta_{L}\right)\right)+\vartheta^{*}\left(z^{N D I}\left(\theta_{L}\right), z^{* N D I}\right)\right] \\
& +(1-\lambda)(1+\delta)\left[\vartheta\left(z^{N D I}\left(\theta_{H}\right), z^{N D I}\left(\theta_{H}\right), \theta_{H}\right)+\vartheta^{*}\left(z^{N D I}\left(\theta_{H}\right), z^{N D I}\left(\theta_{H}\right)\right)\right]
\end{aligned}
$$

subject to

$$
(1+\delta) \vartheta\left(z^{N D I}\left(\theta_{L}\right), z^{* N D I}, \theta_{L}\right) \geq(1+\delta) \vartheta\left(z^{N D I}\left(\theta_{H}\right), z^{N D I}\left(\theta_{H}\right), \theta_{L}\right)
$$

and

$$
(1+\delta) \vartheta\left(z^{N D I}\left(\theta_{H}\right), z^{N D I}\left(\theta_{H}\right), \theta_{H}\right) \geq(1+\delta) \vartheta\left(z^{N D I}\left(\theta_{L}\right), z^{* N D I}, \theta_{H}\right)
$$

Denote the solution to problem $(117)$ as $z^{N D I S}\left(\theta_{L}\right), z^{N D I S}\left(\theta_{H}\right), z^{* N D I S}$, where the superscripts "ND", "I" and "S" denote "no-delayed", "i.i.d." and "solutions", respectively. The next proposition characterizes the unconstrained optimal tariffs under the no-delayed retaliation mechanism: 
Proposition 42. Suppose that the state remains the same under the two-period retaliation mechanism. Then the best negotiated tariffs in the low state under the no-delayed equivalent retaliation mechanism are politically efficient while the best negotiated tariff in the high state under the nodelayed equivalent retaliation mechanism is lower than the politically efficient import tariff, i.e.,

$$
z^{N D I S}\left(\theta_{L}\right)=z^{E}\left(\theta_{L}\right)=z^{* N D I S}=z^{* E}\left(\theta_{L}\right)<z^{N D I S}\left(\theta_{H}\right)<z^{E}\left(\theta_{H}\right)
$$

Proof: Write the first-order conditions that characterize $z^{N D I S}(\theta)$ and $z^{* N D I S}$ :

$$
\begin{gathered}
\vartheta_{1}\left(z^{N D S}\left(\theta_{L}\right), z^{* N D S}, \theta_{L}\right)+\vartheta_{1}^{*}\left(z^{N D S}\left(\theta_{L}\right), z^{* N D S}\right)=0 ; \\
\vartheta_{2}\left(z^{N D S}\left(\theta_{L}\right), z^{* N D S}, \theta_{L}\right)+\vartheta_{2}^{*}\left(z^{N D S}\left(\theta_{L}\right), z^{* N D S}\right)=0 ; \\
\vartheta_{1}\left(z^{N D S}\left(\theta_{H}\right), z^{N D S}\left(\theta_{H}\right), \theta_{H}\right)+\vartheta_{1}^{*}\left(z^{N D S}\left(\theta_{H}\right), z^{N D S}\left(\theta_{H}\right)\right) \\
+\vartheta_{2}\left(z^{N D S}\left(\theta_{H}\right), z^{N D S}\left(\theta_{H}\right), \theta_{H}\right)+\vartheta_{2}^{*}\left(z^{N D S}\left(\theta_{H}\right), z^{N D S}\left(\theta_{H}\right)\right)=0 .
\end{gathered}
$$

Note that they coincide with the corresponding first order condition under the markov case, i.e., Eqs.(58)-(60). Hence, the proof is the same as Proposition 2. Thus, we can derive the same result that

$$
z^{N D I S}\left(\theta_{L}\right)=z^{E}\left(\theta_{L}\right)=z^{* N D I S}=z^{* E}\left(\theta_{L}\right)<z^{N D I S}\left(\theta_{H}\right)<z^{E}\left(\theta_{H}\right)
$$

Simplifying the incentive compatibility conditions (118) and (119), we have

$$
\vartheta\left(z^{N D I}\left(\theta_{L}\right), z^{* N D I}, \theta_{L}\right) \geq \vartheta\left(z^{N D I}\left(\theta_{H}\right), z^{N D I}\left(\theta_{H}\right), \theta_{L}\right)
$$

and

$$
\vartheta\left(z^{N D I}\left(\theta_{H}\right), z^{N D I}\left(\theta_{H}\right), \theta_{H}\right) \geq \vartheta\left(z^{N D I}\left(\theta_{L}\right), z^{* N D I}, \theta_{H}\right) .
$$

Observe that they are the same as under the markov process case. Hence, we can derive the same result that:

Proposition 43. Suppose that the state remains the same under the two-period retaliation mech- 
anism. Then under the no-delayed equivalent retaliation mechanism, the incentive compatibility conditions (118) and (119) are slack.

Under the delayed retaliation mechanism, the strategies of home $\left(\right.$ no $\left.^{*}\right)$ and foreign $\left({ }^{*}\right)$ are:

$$
\begin{gathered}
\tau_{t}= \begin{cases}z^{D I}\left(\theta_{L}\right) & \text { if } \theta_{t}=\theta_{L} \\
z^{D I}\left(\theta_{H}\right) & \text { if } \theta_{t}=\theta_{H} ;\end{cases} \\
\tau_{1}^{*}=z^{* E}\left(\theta_{L}\right), \quad \tau_{2}^{*}= \begin{cases}z^{* E}\left(\theta_{L}\right) & \text { if } \tau_{t}=z^{D I}\left(\theta_{L}\right) \\
z^{D I}\left(\theta_{H}\right) & \text { if } \tau_{t}=z^{D I}\left(\theta_{H}\right),\end{cases}
\end{gathered}
$$

where $t=\{1,2\}$ and the superscript letters "D" and "I" denote "delayed" and "i.i.d.", respectively. According to the strategies above, the negotiators' maximization problem under the delayed retaliation mechanism is:

$$
\begin{aligned}
\max _{z^{D I}\left(\theta_{L}\right), z^{D I}\left(\theta_{H}\right)} & \lambda(1+\delta)\left[\vartheta\left(z^{D I}\left(\theta_{L}\right), z^{* E}\left(\theta_{L}\right), \theta_{L}\right)+\vartheta^{*}\left(z^{D I}\left(\theta_{L}\right), z^{* E}\left(\theta_{L}\right)\right)\right] \\
& +(1-\lambda)\left[\vartheta\left(z^{D I}\left(\theta_{H}\right), z^{* E}\left(\theta_{L}\right), \theta_{H}\right)+\vartheta^{*}\left(z^{D I}\left(\theta_{H}\right), z^{* E}\left(\theta_{L}\right)\right)\right. \\
& \left.+\delta \vartheta\left(z^{D I}\left(\theta_{H}\right), z^{D I}\left(\theta_{H}\right), \theta_{H}\right)+\delta \vartheta^{*}\left(z^{D I}\left(\theta_{H}\right), z^{D I}\left(\theta_{H}\right)\right)\right]
\end{aligned}
$$

subject to

$$
(1+\delta) \vartheta\left(z^{D I}\left(\theta_{L}\right), z^{* E}\left(\theta_{L}\right), \theta_{L}\right) \geq \vartheta\left(z^{D I}\left(\theta_{H}\right), z^{* E}\left(\theta_{L}\right), \theta_{L}\right)+\delta \vartheta\left(z^{D I}\left(\theta_{H}\right), z^{D I}\left(\theta_{H}\right), \theta_{L}\right)
$$

and

$$
\vartheta\left(z^{D I}\left(\theta_{H}\right), z^{* E}\left(\theta_{L}\right), \theta_{H}\right)+\delta \vartheta\left(z^{D I}\left(\theta_{H}\right), z^{D I}\left(\theta_{H}\right), \theta_{H}\right) \geq(1+\delta) \vartheta\left(z^{D I}\left(\theta_{L}\right), z^{* E}\left(\theta_{L}\right), \theta_{H}\right) .
$$

Denote the solution to problem (120) as follows,

$$
z^{D I S}\left(\theta_{L}\right)=\underset{z^{D I}\left(\theta_{L}\right)}{\operatorname{argmax}} \vartheta\left(z^{D I}\left(\theta_{L}\right), z^{* E}\left(\theta_{L}\right), \theta_{L}\right)+\vartheta^{*}\left(z^{D I}\left(\theta_{L}\right), z^{* E}\left(\theta_{L}\right)\right)
$$




$$
\begin{aligned}
z^{D I S}\left(\theta_{H}\right)=\underset{z^{D I}\left(\theta_{H}\right)}{\operatorname{argmax}} & \vartheta\left(z^{D I}\left(\theta_{H}\right), z^{* E}\left(\theta_{L}\right), \theta_{H}\right)+\vartheta^{*}\left(z^{D I}\left(\theta_{H}\right), z^{* E}\left(\theta_{L}\right)\right) \\
& +\delta \vartheta\left(z^{D I}\left(\theta_{H}\right), z^{D I}\left(\theta_{H}\right), \theta_{H}\right)+\delta \vartheta^{*}\left(z^{D I}\left(\theta_{H}\right), z^{D I}\left(\theta_{H}\right)\right)
\end{aligned}
$$

To analyze the properties of the best tariff schedule, $\left(z^{D I S}\left(\theta_{L}\right), z^{D I S}\left(\theta_{H}\right)\right)$, write the first-order condition that characterizes $z^{D I S}\left(\theta_{H}\right)$ as follows,

$$
\begin{aligned}
& \vartheta_{1}\left(z^{D I S}\left(\theta_{H}\right), z^{* E}\left(\theta_{L}\right), \theta_{H}\right)+\vartheta_{1}^{*}\left(z^{D I S}\left(\theta_{H}\right), z^{* E}\left(\theta_{L}\right)\right) \\
& +\delta\left[\vartheta_{1}\left(z^{D I S}\left(\theta_{H}\right), z^{D I S}\left(\theta_{H}\right), \theta_{H}\right)+\vartheta_{1}^{*}\left(z^{D I S}\left(\theta_{H}\right), z^{D I S}\left(\theta_{H}\right)\right)\right. \\
& \left.+\vartheta_{2}\left(z^{D I S}\left(\theta_{H}\right), z^{D I S}\left(\theta_{H}\right), \theta_{H}\right)+\vartheta_{2}^{*}\left(z^{D I S}\left(\theta_{H}\right), z^{D I S}\left(\theta_{H}\right)\right)\right]=0
\end{aligned}
$$

Different from the retaliation without delay mechanism, the best tariff scheme under the delayed case depends on the discount factor, $\delta$. In particular, we can rewrite the solution to Eq.(123) as a function of $\delta$, denoted as $z^{D I S}\left(\theta_{H}, \delta\right)$. Define

$$
g\left(z^{D I S}\left(\theta_{H}\right)\right)=\vartheta_{1}\left(z^{D I S}\left(\theta_{H}\right), z^{* E}\left(\theta_{L}\right), \theta_{H}\right)+\vartheta_{1}^{*}\left(z^{D I S}\left(\theta_{H}\right), z^{* E}\left(\theta_{L}\right)\right)
$$

and

$$
\begin{aligned}
f\left(z^{D I S}\left(\theta_{H}\right)\right) & =\vartheta_{1}\left(z^{D I S}\left(\theta_{H}\right), z^{D I S}\left(\theta_{H}\right), \theta_{H}\right)+\vartheta_{1}^{*}\left(z^{D I S}\left(\theta_{H}\right), z^{D I S}\left(\theta_{H}\right)\right) \\
& +\vartheta_{2}\left(z^{D I S}\left(\theta_{H}\right), z^{D I S}\left(\theta_{H}\right), \theta_{H}\right)+\vartheta_{2}^{*}\left(z^{D I S}\left(\theta_{H}\right), z^{D I S}\left(\theta_{H}\right)\right) .
\end{aligned}
$$

Now we're ready to provide some useful propositions regarding the import tariffs under the delayed retaliation mechanism and the politically efficient tariffs.

Proposition 44. Suppose that the state remains the same under the two-period retaliation mechanism. Then under the delayed equivalent retaliation mechanism, the best negotiated import tariff in the low state is politically efficient, i.e., $z^{D I S}\left(\theta_{L}\right)=z^{E}\left(\theta_{L}\right)$ and the best negotiated import tariff in the high state is monotonic decreasing in the discount factor, $\delta$, i.e., $\frac{\partial z^{D I S}\left(\theta_{H}, \delta\right)}{\partial \delta}<0$. Furthermore, there exists a $\delta^{E I} \in(0,1)$ such that when $\delta=\delta^{E I}$, the best negotiated tariff in the high state under the delayed equivalent retaliation mechanism is politically efficient, i.e., $z^{D I S}\left(\theta_{H}, \delta^{E I}\right)=z^{E}\left(\theta_{H}\right)$.

Proof: First, it is obvious that $z^{D I S}\left(\theta_{L}\right)=z^{E}\left(\theta_{L}\right)$. 
To show that an increase in $\delta$ results in a decrease in $z^{D I S}\left(\theta_{H}\right)$, on the contrary, suppose that $\frac{\partial z^{D I S}\left(\theta_{H}, \delta\right)}{\partial \delta}>0$, or $\frac{\partial z^{D I S}\left(\theta_{H}, \delta\right)}{\partial \delta}=0$. If $\frac{\partial z^{D I S}\left(\theta_{H}, \delta\right)}{\partial \delta}>0$, then by Assumption 1 , we have $g$ and $f$ decrease in $z^{D I S}\left(\theta_{H}\right)$. Thus an increase in $\delta$ leads to a decrease in $g$ and $f$. Together with the fact that $\left|\frac{\partial g}{\partial z^{D I S}\left(\theta_{H}\right)}\right|<\left|\frac{\partial f}{\partial z^{D I S}\left(\theta_{H}\right)}\right|$, there does not exist any $z^{D I S}\left(\theta_{H}\right)$ that satisfies Eq.(62). If $\frac{\partial z^{D I S}\left(\theta_{H}, \delta\right)}{\partial \delta}=0$, it is obvious that Eq.(62) does not hold. Hence, when $\delta$ increases, in order for Eq.(62) to hold, $z^{D I S}\left(\theta_{H}\right)$ shall decrease. That is, $\frac{\partial z^{D I S}\left(\theta_{H}, \delta\right)}{\partial \delta}<0$.

To verify the existence of $\delta^{E I}$, note that since $z^{* E}\left(\theta_{L}\right)>z^{* E}\left(\theta_{H}\right)$, together with Eqs.(61) and (62), we have $z^{D I S}\left(\theta_{H}, 0\right)>z^{E}\left(\theta_{H}\right)$. Also, from the previous proof, we have $\frac{\partial z^{D I S}\left(\theta_{H}, \delta\right)}{\partial \delta}<0$. Then as long as we can show that $z^{D I S}\left(\theta_{H}, 1\right)<z^{E}\left(\theta_{H}\right)$, the existence of $\delta^{E I}$ can be verified. To prove that $z^{D I S}\left(\theta_{H}, 1\right)<z^{E}\left(\theta_{H}\right)$, on the contrary, suppose that $z^{D I S}\left(\theta_{H}, 1\right)>z^{E}\left(\theta_{H}\right)$, or $z^{D I S}\left(\theta_{H}, 1\right)=z^{E}\left(\theta_{H}\right)$. It is obvious that if $z^{D I S}\left(\theta_{H}, 1\right)=z^{E}\left(\theta_{H}\right)$, together with Eq.(61), Eq.(62) cannot be satisfied. If $z^{D I S}\left(\theta_{H}, 1\right)>z^{E}\left(\theta_{H}\right)$, then we have $g\left(z^{D I S}\left(\theta_{H}\right)\right)>0$ and $f\left(z^{D I S}\left(\theta_{H}\right)\right)>0$. It implies that Eq.(62) does not hold, either. Hence, $z^{D I S}\left(\theta_{H}, 1\right)<z^{E}\left(\theta_{H}\right)$. Therefore, there exists a $\delta^{E I} \in(0,1)$ such that $z^{D I S}\left(\theta_{H}, \delta^{E I}\right)=z^{E}\left(\theta_{H}\right)$.

Note that under the delayed retaliation mechanism, the discount factor plays a role in the truthtelling constraints (121) and (122). In particular, when the second period has no values for both home and foreign, i.e., $\delta=0$, then condition (122) will bind. On the other hand, when home highly values the payoffs of the second period, then both conditions are slack. Thus, it can be inferred that there may exist a cutoff point of $\delta^{\prime}$ such that the conditions hold with equality.

Proposition 45. Suppose that the state remains the same under the two-period retaliation mechanism. Then under the delayed equivalent retaliation mechanism, there exists a $\delta^{\prime} \in(0,1)$ such that if $\delta \in\left[\delta^{\prime}, 1\right]$, the incentive compatibility conditions (121) and (122) are slack.

\section{Proof: Let}

$$
G(\delta)=(1+\delta) \vartheta\left(z^{D I S}\left(\theta_{L}\right), z^{* E}\left(\theta_{L}\right), \theta_{L}\right)-\vartheta\left(z^{D I S}\left(\theta_{H}\right), z^{* E}\left(\theta_{L}\right), \theta_{L}\right)-\delta \vartheta\left(z^{D I S}\left(\theta_{H}\right), z^{D I S}\left(\theta_{H}\right), \theta_{L}\right)
$$


From Proposition 44, we have $z^{D I S}\left(\theta_{L}\right)=z^{E}\left(\theta_{L}\right)$ and $\frac{\partial z^{D I S}\left(\theta_{H}, \delta\right)}{\partial \delta}<0$. Assumption 1 implies that

$$
\begin{aligned}
& \left|\frac{d\left[\vartheta\left(z^{D I S}\left(\theta_{L}\right), z^{* E}\left(\theta_{L}\right), \theta_{L}\right)-\vartheta\left(z^{D I S}\left(\theta_{H}\right), z^{* E}\left(\theta_{L}\right), \theta_{L}\right)\right]}{d z^{D I S}\left(\theta_{H}\right)}\right| \\
& >\delta\left|\frac{d\left[\vartheta\left(z^{D I S}\left(\theta_{L}\right), z^{* E}\left(\theta_{L}\right), \theta_{L}\right)-\vartheta\left(z^{D I S}\left(\theta_{H}\right), z^{D I S}\left(\theta_{H}\right), \theta_{L}\right)\right]}{d z^{D I S}\left(\theta_{H}\right)}\right| .
\end{aligned}
$$

Hence, $\frac{d G}{d \delta}>0$. Therefore, $G(0)<0$ and $G(1)>0$ indicate that there exists a $\delta^{\prime}$ such that $G\left(\delta^{\prime}\right)=0$. Moreover, when $\delta \in\left[\delta^{\prime}, 1\right]$, condition (121) is not binding, i.e., $G(\delta) \geq 0, \forall \delta \in\left[\delta^{\prime}, 1\right]$.

To show that condition (122) is slack, let

$H(\delta)=\vartheta\left(z^{D I S}\left(\theta_{H}\right), z^{* E}\left(\theta_{L}\right), \theta_{H}\right)+\delta \vartheta\left(z^{D I S}\left(\theta_{H}\right), z^{D I S}\left(\theta_{H}\right), \theta_{H}\right)-(1+\delta) \vartheta\left(z^{D I S}\left(\theta_{L}\right), z^{* E}\left(\theta_{L}\right), \theta_{H}\right)$.

Since $z^{D I S}\left(\theta_{L}\right)=z^{E}\left(\theta_{L}\right), \frac{\partial z^{D I S}\left(\theta_{H}, \delta\right)}{\partial \delta}>0$, and

$$
\begin{aligned}
& \left|\frac{d\left[\vartheta\left(z^{D I S}\left(\theta_{H}\right), z^{* E}\left(\theta_{L}\right), \theta_{H}\right)-\vartheta\left(z^{D I S}\left(\theta_{L}\right), z^{* E}\left(\theta_{L}\right), \theta_{H}\right)\right]}{d z^{D I S}\left(\theta_{H}\right)}\right| \\
& >\delta\left|\frac{d\left[\vartheta\left(z^{D I S}\left(\theta_{H}\right), z^{D I S}\left(\theta_{H}\right), \theta_{H}\right)-\vartheta\left(z^{D I S}\left(\theta_{L}\right), z^{* E}\left(\theta_{L}\right), \theta_{H}\right)\right]}{d z^{D I S}\left(\theta_{H}\right)}\right|,
\end{aligned}
$$

we have $\frac{d H}{d \delta}<0$. Then $z^{D I S}\left(\theta_{H}\right)>z^{* E}\left(\theta_{L}\right)=z^{E}\left(\theta_{L}\right)$ implies that $H(1)>0$. Therefore, condition (122) is not binding, i.e., $H(\delta)>0, \forall \delta \in[0,1]$.

By following similar arguments as in deriving Proposition 5, we can show that

Proposition 46. Suppose that the state remains the same under the two-period retaliation mechanism. Then the best negotiated import tariff in the low state under the no-delayed and delayed equivalent retaliation mechanisms are equal, i.e., $z^{N D I S}\left(\theta_{L}\right)=z^{D I S}\left(\theta_{L}\right)$ while the best negotiated import tariff in the high state under the no-delayed equivalent retaliation mechanism is lower than under the delayed equivalent retaliation mechanism, i.e., $z^{N D I S}\left(\theta_{H}\right)<z^{D I S}\left(\theta_{H}\right)$.

Propositions 42 and 46 indicate that:

Proposition 47. Suppose that the state remains the same under the two-period retaliation mechanism and the incentive compatibility conditions under the delayed equivalent retaliation mechanisms 
are slack, i.e., $\delta \in\left[\delta^{\prime}, 1\right]$. Then if $\delta \in\left[\delta^{E I}, 1\right)$, the delayed equivalent retaliation mechanism generates higher joint political payoff than does the no-delayed equivalent retaliation mechanism.

Proof: The proof is the same as in deriving Proposition 7.

Now we consider the "off-schedule violation" under a repeated game setup. As mentioned in the introduction, we assume that the two-period game described previously is repeated infinitely many times and the state variables are not correlated between each two-period. We still use the infinite Nash reversion as a threat to this violation.

The voluntary participation conditions under the no-delayed retaliation mechanism are

$$
\begin{aligned}
& (1+\delta) \vartheta\left(z^{N D I S}\left(\theta_{H}\right), z^{N D I S}\left(\theta_{H}\right), \theta_{H}\right) \\
& +\frac{\delta^{2}}{1-\delta}\left[\lambda \vartheta\left(z^{N D I S}\left(\theta_{L}\right), z^{* E}\left(\theta_{L}\right), \theta_{L}\right)+(1-\lambda) \vartheta\left(z^{N D I S}\left(\theta_{H}\right), z^{N D I S}\left(\theta_{H}\right), \theta_{H}\right)\right] \geq \\
& \vartheta\left(z^{N D I S d}\left(\theta_{H}\right), z^{* N D I S}, \theta_{H}\right)+\delta \vartheta\left(z^{N}\left(\theta_{H}\right), z^{* N}, \theta_{H}\right) \\
& +\frac{\delta^{2}}{1-\delta}\left[\lambda \vartheta\left(z^{N}\left(\theta_{L}\right), z^{* N}, \theta_{L}\right)+(1-\lambda) \vartheta\left(z^{N}\left(\theta_{H}\right), z^{* N}, \theta_{H}\right)\right]
\end{aligned}
$$

and

$$
\begin{aligned}
& (1+\delta) \vartheta\left(z^{N D I S}\left(\theta_{L}\right), z^{* E}\left(\theta_{L}\right), \theta_{H}\right) \\
& +\frac{\delta^{2}}{1-\delta}\left[\lambda \vartheta\left(z^{N D I S}\left(\theta_{L}\right), z^{* E}\left(\theta_{L}\right), \theta_{L}\right)+(1-\lambda) \vartheta\left(z^{N D I S}\left(\theta_{H}\right), z^{N D I S}\left(\theta_{H}\right), \theta_{H}\right)\right] \geq \\
& \vartheta\left(z^{N D I S d}\left(\theta_{L}\right), z^{* N D I S}, \theta_{L}\right)+\delta \vartheta\left(z^{N}\left(\theta_{L}\right), z^{* N}, \theta_{L}\right) \\
& +\frac{\delta^{2}}{1-\delta}\left[\lambda \vartheta\left(z^{N}\left(\theta_{L}\right), z^{* N}, \theta_{L}\right)+(1-\lambda) \vartheta\left(z^{N}\left(\theta_{H}\right), z^{* N}, \theta_{H}\right)\right],
\end{aligned}
$$

where $z^{N D I S d}(\theta)=\underset{\tau}{\operatorname{argmax}} \quad \vartheta\left(z^{N D I S d}(\theta), z^{* N D I S}, \theta\right)$. 
Similarly, the voluntary participation conditions under the delayed retaliation mechanism are

$$
\begin{aligned}
& \vartheta\left(z^{D I S}\left(\theta_{H}\right), z^{* E}\left(\theta_{L}\right), \theta_{H}\right)+\delta \vartheta\left(z^{D I S}\left(\theta_{H}\right), z^{N D I S}\left(\theta_{H}\right), \theta_{H}\right) \\
& +\frac{\delta^{2}}{1-\delta^{2}}\left\{\lambda(1+\delta) \vartheta\left(z^{D I S}\left(\theta_{L}\right), z^{* E}\left(\theta_{L}\right), \theta_{L}\right)\right. \\
& \left.+(1-\lambda)\left[\vartheta\left(z^{D I S}\left(\theta_{H}\right), z^{* E}\left(\theta_{L}\right), \theta_{H}\right)+\delta \vartheta\left(z^{D I S}\left(\theta_{H}\right), z^{D I S}\left(\theta_{H}\right), \theta_{H}\right)\right]\right\} \geq \\
& \vartheta\left(z^{D I S d}\left(\theta_{H}\right), z^{* E}\left(\theta_{L}\right), \theta_{L}\right)+\delta \vartheta\left(z^{N}\left(\theta_{H}\right), z^{* N}, \theta_{H}\right) \\
& +\frac{\delta^{2}}{1-\delta}\left[\lambda \vartheta\left(z^{N}\left(\theta_{L}\right), z^{* N}, \theta_{L}\right)+(1-\lambda) \vartheta\left(z^{N}\left(\theta_{H}\right), z^{* N}, \theta_{H}\right)\right]
\end{aligned}
$$

and

$$
\begin{aligned}
& (1+\delta) \vartheta\left(z^{D I S}\left(\theta_{L}\right), z^{* E}\left(\theta_{L}\right), \theta_{H}\right)+\frac{\delta^{2}}{1-\delta^{2}}\left\{\lambda(1+\delta) \vartheta\left(z^{D I S}\left(\theta_{L}\right), z^{* E}\left(\theta_{L}\right), \theta_{L}\right)\right. \\
& \left.+(1-\lambda)\left[\vartheta\left(z^{D I S}\left(\theta_{H}\right), z^{* E}\left(\theta_{L}\right), \theta_{H}\right)+\delta \vartheta\left(z^{D I S}\left(\theta_{H}\right), z^{D I S}\left(\theta_{H}\right), \theta_{H}\right)\right]\right\} \geq \\
& \vartheta\left(z^{D I S d}\left(\theta_{L}\right), z^{* E}\left(\theta_{L}\right), \theta_{L}\right)+\delta \vartheta_{a}\left(z^{N}\left(\theta_{L}\right), z^{* N}, \theta_{L}\right) \\
& +\frac{\delta^{2}}{1-\delta}\left[\lambda \vartheta\left(z^{N}\left(\theta_{L}\right), z^{* N}, \theta_{L}\right)+(1-\lambda) \vartheta\left(z^{N}\left(\theta_{H}\right), z^{* N}, \theta_{H}\right)\right],
\end{aligned}
$$

where $z^{D I S d}(\theta)=\operatorname{argmax} \quad \vartheta\left(z^{D I S d}(\theta), z^{* E}\left(\theta_{L}\right), \theta\right)$.

Based on the voluntary participation conditions defined above, we can verify that:

Proposition 48. Suppose that the state is i.i.d. across every two periods while remains the same within the two periods and the incentive compatibility conditions under the delayed equivalent retaliation mechanism are slack, i.e., $\delta \in\left[\delta^{\prime}, 1\right]$. Then if $\delta \in\left[\delta^{E I}, 1\right)$, the delayed equivalent retaliation mechanism supports a higher self-enforcing level of cooperation than does the no-delayed equivalent retaliation mechanism.

Proof: When $\delta \in\left[\delta^{\prime}, 1\right]$, by Proposition 46, we have $z^{D I S}\left(\theta_{H}\right) \geq z^{N D I S}\left(\theta_{H}\right)$ and $z^{N D I S}\left(\theta_{L}\right)=$ $z^{D I S}\left(\theta_{L}\right)=z^{E}\left(\theta_{L}\right)$, indicating that the discounted future value of cooperation under the delayed 
retaliation mechanism is higher than under the no-delayed one, i.e.,

$$
\begin{aligned}
& \frac{\delta^{2}}{1-\delta^{2}}\left\{\lambda(1+\delta) \vartheta\left(z^{D I S}\left(\theta_{L}\right), z^{* E}\left(\theta_{L}\right), \theta_{L}\right)\right. \\
& \left.+(1-\lambda)\left[\vartheta\left(z^{D I S}\left(\theta_{H}\right), z^{* E}\left(\theta_{L}\right), \theta_{H}\right)+\delta \vartheta\left(z^{D I S}\left(\theta_{H}\right), z^{D I S}\left(\theta_{H}\right), \theta_{H}\right)\right]\right\} \\
& >\frac{\delta^{2}}{1-\delta}\left[\lambda \vartheta\left(z^{N D I S}\left(\theta_{L}\right), z^{* E}\left(\theta_{L}\right), \theta_{L}\right)+(1-\lambda) \vartheta\left(z^{N D I S}\left(\theta_{H}\right), z^{N D I S}\left(\theta_{H}\right), \theta_{H}\right)\right]
\end{aligned}
$$

and

$$
\begin{aligned}
& \frac{\delta^{2}}{1-\delta^{2}}\left\{\lambda(1+\delta) \vartheta\left(z^{D I S}\left(\theta_{L}\right), z^{* E}\left(\theta_{L}\right), \theta_{L}\right)\right. \\
& \left.+(1-\lambda)\left[\vartheta\left(z^{D I S}\left(\theta_{H}\right), z^{* E}\left(\theta_{L}\right), \theta_{H}\right)+\delta \vartheta\left(z^{D I S}\left(\theta_{H}\right), z^{D I S}\left(\theta_{H}\right), \theta_{H}\right)\right]\right\} \\
& >\frac{\delta^{2}}{1-\delta}\left[\lambda \vartheta\left(z^{N D I S}\left(\theta_{L}\right), z^{* E}\left(\theta_{L}\right), \theta_{L}\right)+(1-\lambda) \vartheta\left(z^{N D I S}\left(\theta_{H}\right), z^{N D I S}\left(\theta_{H}\right), \theta_{H}\right)\right]
\end{aligned}
$$

Thus, the retaliation with delay mechanism has a higher future deviation cost.

On the other hand, $z^{D I S}\left(\theta_{H}\right) \geq z^{N D I S}\left(\theta_{H}\right)$ and $z^{D I S}\left(\theta_{L}\right)=z^{N D I S}\left(\theta_{L}\right)=z^{E}\left(\theta_{L}\right)$ also imply that the retaliation without delay mechanism has a higher benefit of deviation, i.e.,

$$
\begin{aligned}
& \vartheta\left(z^{N D I S d}\left(\theta_{H}\right), z^{* N D I S}, \theta_{H}\right)+\delta \vartheta\left(z^{N}\left(\theta_{H}\right), z^{* N}, \theta_{H}\right) \\
& -(1+\delta) \vartheta\left(z^{N D I S}\left(\theta_{H}\right), z^{N D I S}\left(\theta_{H}\right), \theta_{H}\right) \\
& >\vartheta\left(z^{D I S d}\left(\theta_{H}\right), z^{* E}\left(\theta_{L}\right), \theta_{H}\right)+\delta \vartheta\left(z^{N}\left(\theta_{H}\right), z^{* N}, \theta_{H}\right) \\
& -\vartheta\left(z^{D I S}\left(\theta_{H}\right), z^{* E}\left(\theta_{L}\right), \theta_{H}\right)-\delta \vartheta\left(z^{D I S}\left(\theta_{H}\right), z^{D I S}\left(\theta_{H}\right), \theta_{H}\right)
\end{aligned}
$$

and

$$
\begin{aligned}
& \vartheta\left(z^{N D I S d}\left(\theta_{L}\right), z^{* N D I S}, \theta_{L}\right)+\delta \vartheta\left(z^{N}\left(\theta_{L}\right), z^{* N}, \theta_{L}\right) \\
& -(1+\delta) \vartheta\left(z^{N D I S}\left(\theta_{L}\right), z^{N D I S}\left(\theta_{L}\right), \theta_{L}\right) \\
& >\vartheta\left(z^{D I S d}\left(\theta_{L}\right), z^{* E}\left(\theta_{L}\right), \theta_{L}\right)+\delta \vartheta\left(z^{N}\left(\theta_{L}\right), z^{* N}, \theta_{L}\right) \\
& -\vartheta\left(z^{D I S}\left(\theta_{L}\right), z^{* E}\left(\theta_{L}\right), \theta_{L}\right)-\delta \vartheta\left(z^{D I S}\left(\theta_{L}\right), z^{*} E\left(\theta_{L}\right), \theta_{L}\right) .
\end{aligned}
$$

Therefore, in comparison to the negotiated agreement under retaliation with delay mechanism, deviating from the negotiated agreement under retaliation without delay mechanism has a higher 
benefit and a lower cost. This indicates that the voluntary participation constraints under the delayed retaliation mechanism are looser than under the no-delayed retaliation mechanism. Or, the delayed retaliation mechanism enhances more cooperation between the governments. 


\section{Appendix C: Delayed Retaliation}

Now we consider the case where the retaliation is delayed for one-period. We show that although there is a time lag between the initial violation and the corresponding retaliation, under certain conditions, the same-sector retaliation mechanism can still generate higher joint political welfare and supports a higher self-enforcing level of cooperation than the cross-sector retaliation mechanism. The timing of the game in each period is the same as the no-delayed case. We still consider two types of violation, the "on-schedule" and the "off-schedule" violations. However, since now we need to analyze the delayed retaliation, even if we confine our analysis to the "on-schedule" violation, the mechanism has to be a two-period one. We assume that under a two-period game, the process in period 1 repeats once. As before, if we add "off-schedule" violation into the model, then we will use the Nash reversion strategies as a threat to this violation in a dynamic game setup. Under this dynamic game, the game in the first period repeats infinitely many times with the state evolves according to a markov process.

The strategies of the home $\left(\right.$ no ${ }^{*}$ ) and foreign $\left(^{*}\right)$ countries under the delayed same-sector retaliation mechanism are as follows:

$$
\tau_{t a}=\left\{\begin{array}{ll}
z_{a}^{D S}\left(\theta_{L}\right) & \text { if } \theta_{t}=\theta_{L} \\
z_{a}^{D S}\left(\theta_{H}\right) & \text { if } \theta_{t}=\theta_{H}
\end{array} \quad \tau_{t b}=0\right.
$$

and

$$
\tau_{1 a}^{*}=0 \quad \tau_{2 a}^{*}=\left\{\begin{array}{ll}
z_{a}^{D S}\left(\theta_{H}\right) & \text { if } \tau_{1 a}=\tau_{2 a}=z_{a}^{D S}\left(\theta_{H}\right) \\
0 & \text { otherwise }
\end{array} \quad \tau_{t b}^{*}=0\right.
$$

where $t=\{1,2\}$ and the superscript "D" and "S" represent "delayed" and "same-sector", respectively.

The strategies of the home $\left(\right.$ no $\left.{ }^{*}\right)$ and foreign $\left(^{*}\right)$ countries under the delayed cross-sector retaliation mechanism are:

$$
\tau_{t a}=\left\{\begin{array}{ll}
0 & \text { if } \theta_{t}=\theta_{L} \\
z_{a}^{D C}\left(\theta_{H}\right) & \text { if } \theta_{t}=\theta_{H}
\end{array} \quad \tau_{t b}=0\right.
$$




$$
\tau_{t a}^{*}=0 ; \quad \tau_{1 b}^{*}=0 ; \quad \tau_{2 b}^{*}= \begin{cases}z_{a}^{D C}\left(\theta_{H}\right) & \text { if } \tau_{1 a}=\tau_{2 a}=z_{a}^{D C}\left(\theta_{H}\right) \\ 0 & \text { otherwise }\end{cases}
$$

where $t=\{1,2\}$ and the superscript "D" and "C" denote "delayed" and "cross-sector", respectively. For the same reason as alluded to under the same-sector retaliation without delay, under the samesector retaliation with delay, we only need to focus on the negotiators' maximization problem in sector $a$. Namely,

$$
\begin{aligned}
\max _{z_{a}^{D S}\left(\theta_{L}\right), z_{a}^{D S}\left(\theta_{H}\right)} & \lambda\left\{\vartheta_{a}\left(z_{a}^{D S}\left(\theta_{L}\right), 0\right), \theta_{L}\right)+\vartheta_{a}^{*}\left(z_{a}^{D S}\left(\theta_{L}\right), 0, \theta_{L}\right) \\
& +\delta \beta\left[\vartheta_{a}\left(z_{a}^{D S}\left(\theta_{L}\right), 0, \theta_{L}\right)+\vartheta_{a}^{*}\left(z_{a}^{D S}\left(\theta_{L}\right), 0, \theta_{L}\right)\right] \\
& \left.+\delta(1-\beta)\left[\vartheta_{a}\left(z_{a}^{D S}\left(\theta_{H}\right), 0, \theta_{H}\right)+\vartheta_{a}^{*}\left(z_{a}^{D S}\left(\theta_{H}\right), 0, \theta_{L}\right)\right]\right\} \\
& +(1-\lambda)\left\{\vartheta_{a}\left(z_{a}^{D S}\left(\theta_{H}\right), 0, \theta_{H}\right)+\vartheta_{a}^{*}\left(z_{a}^{D S}\left(\theta_{H}\right), 0, \theta_{L}\right)\right. \\
& +\delta \beta\left[\vartheta_{a}\left(z_{a}^{D S}\left(\theta_{H}\right), z_{a}^{D S}\left(\theta_{H}\right), \theta_{H}\right)+\vartheta_{a}^{*}\left(z^{D S}\left(\theta_{H}\right), z_{a}^{D S}\left(\theta_{H}\right), \theta_{L}\right)\right] \\
& \left.+\delta(1-\beta)\left[\vartheta_{a}\left(z_{a}^{D S}\left(\theta_{L}\right), 0, \theta_{L}\right)+\vartheta_{a}^{*}\left(z_{a}\left(\theta_{L}\right), 0, \theta_{L}\right)\right]\right\}
\end{aligned}
$$

subject to

$$
\begin{aligned}
& \vartheta_{a}\left(z_{a}^{D S}\left(\theta_{L}\right), 0, \theta_{L}\right)+\delta \beta \vartheta_{a}\left(z_{a}^{D S}\left(\theta_{L}\right), 0, \theta_{L}\right)+\delta(1-\beta) \vartheta_{a}\left(z_{a}^{D S}\left(\theta_{H}\right), 0, \theta_{H}\right) \geq \\
& \vartheta_{a}\left(z_{a}^{D S}\left(\theta_{H}\right), 0, \theta_{L}\right)+\delta \beta \vartheta_{a}\left(z_{a}^{D S}\left(\theta_{H}\right), z_{a}^{D S}\left(\theta_{H}\right), \theta_{L}\right)+\delta(1-\beta) \vartheta_{a}\left(z_{a}^{D S}\left(\theta_{H}\right), 0, \theta_{H}\right)
\end{aligned}
$$

and

$$
\begin{aligned}
& \vartheta_{a}\left(z_{a}^{D S}\left(\theta_{H}\right), 0, \theta_{H}\right)+\delta \beta \vartheta_{a}\left(z_{a}^{D S}\left(\theta_{H}\right), z_{a}^{D S}\left(\theta_{H}\right), \theta_{H}\right)+\delta(1-\beta) \vartheta_{a}\left(z_{a}^{D S}\left(\theta_{L}\right), 0, \theta_{L}\right) \geq \\
& (1+\delta \beta) \vartheta_{a}\left(z_{a}^{D S}\left(\theta_{L}\right), 0, \theta_{H}\right)+\delta(1-\beta) \vartheta_{a}\left(z_{a}^{D S}\left(\theta_{L}\right), 0, \theta_{L}\right) .
\end{aligned}
$$

Denote the solution to problem (124) as $\left(z_{a}^{D S M}\left(\theta_{L}\right), z_{a}^{D S M}\left(\theta_{H}\right), z_{a}^{* D S M}\right)$, where the superscript "D" represents "delayed", the first superscript "S" represents "same-sector" and the second superscript "S" represents "solutions." Then we can derive the following proposition under the delayed samesector retaliation mechanism with markov process: 
Proposition 49. $z_{a}^{D S S}\left(\theta_{L}\right)=0$;

$$
\begin{aligned}
z_{a}^{D S S}\left(\theta_{H}\right)= & \left(\theta_{H}-1\right)\left(4 b_{1} c f+4 A c-4 c f-f\right)(1-2 \beta \delta \lambda+\beta \delta+\delta \lambda-\lambda)\left(2 b_{1} c-2 c-1\right)^{-1} \\
& \left(4 b \beta c \delta \lambda-4 b \beta c \delta+12 \beta c \delta \lambda-2 \beta \delta \lambda \theta_{H}-8 \beta c \delta+2 \beta \delta \lambda+\beta \delta \theta_{H}-4 c \delta \lambda+\delta \lambda \theta_{H}\right. \\
& \left.-\beta \delta+4 c \lambda-\delta \lambda-\lambda \theta_{H}-4 c+\lambda+\theta_{H}-1\right)^{-1}
\end{aligned}
$$

Proof: Rearrange problem (124):

$$
\begin{aligned}
\max _{z_{a}^{D S}\left(\theta_{L}\right), z_{a}^{D S}\left(\theta_{H}\right)} & (\lambda+2 \delta \lambda \beta+\delta-\delta \beta-\delta \lambda)\left[\vartheta_{a}\left(z_{a}^{D S}\left(\theta_{L}\right), 0, \theta_{L}\right)+\vartheta_{a}^{*}\left(z_{a}^{D S}\left(\theta_{L}\right), 0, \theta_{L}\right)\right] \\
& +(1-\lambda+\lambda \delta-\lambda \delta \beta)\left[\vartheta_{a}\left(z_{a}^{D S}\left(\theta_{H}\right), 0, \theta_{H}\right)+\vartheta_{a}^{*}\left(z_{a}^{D S}\left(\theta_{H}\right), 0, \theta_{H}\right)\right] \\
& +(\delta \beta-\delta \lambda \beta)\left[\vartheta_{a}\left(z_{a}^{D S}\left(\theta_{H}\right), z_{a}^{D S}\left(\theta_{H}\right), \theta_{H}\right)+\vartheta_{a}^{*}\left(z_{a}^{D S}\left(\theta_{H}\right), z_{a}^{D S}\left(\theta_{H}\right), \theta_{H}\right)\right] .
\end{aligned}
$$

Then the solutions to the above problem are as follows:

$$
\begin{gathered}
z_{a}^{D S S}\left(\theta_{L}\right)=\underset{z_{a}^{D S}\left(\theta_{L}\right)}{\operatorname{argmax}}(\lambda+2 \delta \lambda \beta+\delta-\delta \beta-\delta \lambda) \vartheta_{a}\left(z_{a}^{D S}\left(\theta_{L}\right), 0, \theta_{L}\right)+\vartheta_{a}^{*}\left(z_{a}^{D S}\left(\theta_{L}\right), 0, \theta_{L}\right) ; \\
z_{a}^{D S S}\left(\theta_{H}\right)=\underset{z_{a}^{D S}\left(\theta_{H}\right)}{\operatorname{argmax}} \\
\quad(1-\lambda+\lambda \delta-\lambda \delta \beta)\left[\vartheta_{a}\left(z_{a}^{D S}\left(\theta_{H}\right), 0, \theta_{H}\right)+\vartheta_{a}^{*}\left(z_{a}^{D S}\left(\theta_{H}\right), 0, \theta_{H}\right)\right] \\
+(\delta \beta-\delta \lambda \beta)\left[\vartheta_{a}\left(z_{a}^{D S}\left(\theta_{H}\right), z_{a}^{D S}\left(\theta_{H}\right), \theta_{H}\right)+\vartheta_{a}^{*}\left(z_{a}^{D S}\left(\theta_{H}\right), z_{a}^{D S}\left(\theta_{H}\right), \theta_{H}\right)\right] .
\end{gathered}
$$

Since $\lambda+2 \delta \lambda \beta+\delta-\delta \beta-\delta \lambda>0$ is constant, we have

$$
z_{a}^{D S S}\left(\theta_{L}\right)=\underset{z_{a}^{D S}\left(\theta_{L}\right)}{\operatorname{argmax}} \quad \vartheta_{a}\left(z_{a}^{D S}\left(\theta_{L}\right), 0, \theta_{L}\right)+\vartheta_{a}^{*}\left(z_{a}^{D S}\left(\theta_{L}\right), 0, \theta_{L}\right)
$$

Together with Eq.(64), it is obvious that $z_{a}^{D S S}\left(\theta_{L}\right)=0$.

Next we show that

$$
\begin{aligned}
z_{a}^{D S S}\left(\theta_{H}\right)= & \left(\theta_{H}-1\right)\left(4 b_{1} c f+4 A c-4 c f-f\right)(1-2 \beta \delta \lambda+\beta \delta+\delta \lambda-\lambda)\left(2 b_{1} c-2 c-1\right)^{-1} \\
& \left(4 b \beta c \delta \lambda-4 b \beta c \delta+12 \beta c \delta \lambda-2 \beta \delta \lambda \theta_{H}-8 \beta c \delta+2 \beta \delta \lambda+\beta \delta \theta_{H}-4 c \delta \lambda+\delta \lambda \theta_{H}\right. \\
& \left.-\beta \delta+4 c \lambda-\delta \lambda-\lambda \theta_{H}-4 c+\lambda+\theta_{H}-1\right)^{-1}
\end{aligned}
$$


Note that Eq.(127) is equivalent to:

$$
\begin{aligned}
& (1-\lambda+\lambda \delta-\lambda \delta \beta)\left[\vartheta_{a 1}\left(z_{a}\left(\theta_{H}\right), z_{a}^{*}, \theta_{H}\right)+\vartheta_{a 1}^{*}\left(z_{a}\left(\theta_{H}\right), z_{a}^{*}, \theta_{H}\right)\right] \\
& +(\delta \beta-\delta \lambda \beta)\left[\vartheta_{a 1}\left(z_{a}\left(\theta_{H}\right), z_{a}\left(\theta_{H}\right), \theta_{H}\right)+\vartheta_{a 1}^{*}\left(z_{a}\left(\theta_{H}\right), z_{a}\left(\theta_{H}\right), \theta_{H}\right)\right] \\
& +(\delta \beta-\delta \lambda \beta)\left[\vartheta_{a 2}\left(z_{a}\left(\theta_{H}\right), z_{a}\left(\theta_{H}\right), \theta_{H}\right)+\vartheta_{a 2}^{*}\left(z_{a}\left(\theta_{H}\right), z_{a}\left(\theta_{H}\right), \theta_{H}\right)\right]=0 .
\end{aligned}
$$

Substitute Eq.(64) into it and then simplify it:

$$
z_{a}^{D S S}\left(\theta_{H}\right)=\frac{1}{2}\left(\theta_{H}-1\right) \frac{1-\lambda+\delta \lambda-\delta \beta-2 \delta \lambda \beta}{1-\lambda+\delta \lambda+2 \delta \beta-3 \delta \lambda \beta+b_{1} \delta \beta-b_{1} \delta \lambda \beta} \frac{p_{y_{a}}-F}{2 c} .
$$

Besides, from Lemma 6, we know that

$$
\begin{aligned}
p_{y_{a}} & =\frac{1}{2} \frac{-2 b c \tau+4 A c+2 c \tau+f+\tau}{1-2 b c+2 c} \\
& =\frac{1}{2} \frac{-2 b c z_{a}^{D S S}\left(\theta_{H}\right)+4 A c+2 c z_{a}^{D S S}\left(\theta_{H}\right)+f+z_{a}^{D S S}\left(\theta_{H}\right)}{1-2 b c+2 c} .
\end{aligned}
$$

Hence, it verifies that

$$
\begin{aligned}
z_{a}^{D S S}\left(\theta_{H}\right)= & \left(\theta_{H}-1\right)\left(4 b_{1} c f+4 A c-4 c f-f\right)(1-2 \beta \delta \lambda+\beta \delta+\delta \lambda-\lambda)\left(2 b_{1} c-2 c-1\right)^{-1} \\
& \left(4 b \beta c \delta \lambda-4 b \beta c \delta+12 \beta c \delta \lambda-2 \beta \delta \lambda \theta_{H}-8 \beta c \delta+2 \beta \delta \lambda+\beta \delta \theta_{H}-4 c \delta \lambda+\delta \lambda \theta_{H}\right. \\
& \left.-\beta \delta+4 c \lambda-\delta \lambda-\lambda \theta_{H}-4 c+\lambda+\theta_{H}-1\right)^{-1} .
\end{aligned}
$$

Under the delayed cross-sector retaliation mechanism, based on the strategies, the negotiators choose the tariff scheme, $\left(z_{a}^{D C}\left(\theta_{L}\right), z_{a}^{D C}\left(\theta_{H}\right)\right)$, to maximize the two period discounted joint political 
payoff, or,

$$
\begin{aligned}
\max _{z_{a}^{D C}\left(\theta_{L}\right), z_{a}^{D C}\left(\theta_{H}\right)} & \lambda\left\{\left[\vartheta_{a}\left(z_{a}^{D C}\left(\theta_{L}\right), 0, \theta_{L}\right)+\vartheta_{a}^{*}\left(z_{a}^{D C}\left(\theta_{L}\right), 0\right)+\vartheta_{b}(0,0)+\vartheta_{b}^{*}(0,0)\right]\right. \\
+ & \delta \beta\left[\vartheta_{a}\left(z_{a}^{D C}\left(\theta_{L}\right), 0, \theta_{L}\right)+\vartheta_{a}^{*}\left(z_{a}^{D C}\left(\theta_{L}\right), 0\right)+\vartheta_{b}(0,0)+\vartheta_{b}^{*}(0,0)\right] \\
+ & \left.\delta(1-\beta)\left[\vartheta_{a}\left(z_{a}^{D C}\left(\theta_{H}\right), 0, \theta_{H}\right)+\vartheta_{a}^{*}\left(z_{a}^{D C}\left(\theta_{H}\right), 0\right)+\vartheta_{b}(0,0)+\vartheta_{b}^{*}(0,0)\right]\right\} \\
+ & (1-\lambda)\left\{\left[\vartheta_{a}\left(z_{a}^{D C}\left(\theta_{H}\right), 0, \theta_{H}\right)+\vartheta_{a}^{*}\left(z_{a}^{D C}\left(\theta_{H}\right), 0\right)+\vartheta_{b}(0,0)+\vartheta_{b}^{*}(0,0)\right]\right. \\
+ & \delta \beta\left[\vartheta_{a}\left(z_{a}^{D C}\left(\theta_{H}\right), 0, \theta_{H}\right)+\vartheta_{a}^{*}\left(z_{a}^{D C}\left(\theta_{H}\right), 0\right)+\vartheta_{b}\left(0, z_{a}^{D C}\left(\theta_{H}\right)\right)+\vartheta_{b}^{*}\left(0, z_{a}^{D C}\left(\theta_{H}\right)\right)\right] \\
+ & \left.\delta(1-\beta)\left[\vartheta_{a}\left(z_{a}^{D C}\left(\theta_{L}\right), 0, \theta_{L}\right)+\vartheta_{a}^{*}\left(z_{a}^{D C}\left(\theta_{L}\right), 0\right)+\vartheta_{b}(0,0)+\vartheta_{b}^{*}(0,0)\right]\right\}
\end{aligned}
$$

subject to

$$
\begin{aligned}
& (1+\delta \beta)\left[\vartheta_{a}\left(z_{a}^{D C}\left(\theta_{L}\right), 0, \theta_{L}\right)+\vartheta_{b}(0,0)\right]+\delta(1-\beta)\left[\vartheta_{a}\left(z_{a}^{D C}\left(\theta_{H}\right), 0, \theta_{H}\right)+\vartheta_{b}(0,0)\right] \\
& \geq(1+\delta \beta)\left[\vartheta_{a}\left(z_{a}^{D C}\left(\theta_{H}\right), 0, \theta_{L}\right)+\vartheta_{b}(0,0)\right]+\delta(1-\beta)\left[\vartheta_{a}\left(z_{a}^{D C}\left(\theta_{H}\right), 0, \theta_{H}\right)+\vartheta_{b}\left(0, z_{a}^{D C}\left(\theta_{H}\right)\right)\right]
\end{aligned}
$$

and

$$
\begin{aligned}
& \vartheta_{a}\left(z_{a}^{D C}\left(\theta_{H}\right), 0, \theta_{H}\right)+\vartheta_{b}(0,0)+\delta \beta\left[\vartheta_{a}\left(z_{a}^{D C}\left(\theta_{H}\right), 0, \theta_{H}\right)+\vartheta_{b}\left(0, z_{a}^{D C}\left(\theta_{H}\right)\right)\right] \\
& +\delta(1-\beta)\left[\vartheta_{a}^{D C}\left(z_{a}\left(\theta_{L}\right), 0, \theta_{L}\right)+\vartheta_{b}(0,0)\right] \geq(1+\delta \beta)\left[\vartheta_{a}\left(z_{a}^{D C}\left(\theta_{L}\right), 0, \theta_{H}\right)+\vartheta_{b}(0,0)\right] \\
& +\delta(1-\beta)\left[\vartheta_{a}\left(z_{a}^{D C}\left(\theta_{L}\right), 0, \theta_{L}\right)+\vartheta_{b}(0,0)\right] .
\end{aligned}
$$

Denote the solution to problem $(128)$ as $\left(z_{a}^{D C S}\left(\theta_{L}\right), z_{a}^{D C S}\left(\theta_{H}\right)\right)$, where the superscripts "D", "C" and "S" denote "delayed", "cross-sector" and "solution", respectively. Then, by following similar steps as in deriving Proposition 49, it can be verified that the best tariffs under the delayed and cross-sector retaliation mechanism have the following properties:

Proposition 50. $z_{a}^{D C S}\left(\theta_{L}\right)=0$;

$$
\begin{aligned}
z_{a}^{D C S}\left(\theta_{H}\right)= & \left(\theta_{H}-1\right)(1-2 \beta \delta \lambda+\beta \delta+\delta \lambda-\lambda)\left(4 b_{1} c f+4 A c-4 c f-f\right)\left(2 b_{1} c-2 c-1\right)^{-1} \\
& \left(12 \beta c \delta \lambda-2 \beta \delta \lambda \theta_{H}-8 \beta c \delta+2 \beta \delta \lambda+\beta \delta \theta_{H}-4 c \delta \lambda+\delta \lambda \theta_{H}-\beta \delta+4 c \lambda-\delta \lambda\right. \\
& \left.-\lambda \theta_{H}-4 c+\lambda+\theta_{H}-1\right)^{-1} .
\end{aligned}
$$


Propositions 49 and 50 indicate that

Proposition 51. Suppose that the goods in sector a are strategic substitutes, i.e., $b_{1} \in(0,1)$, then the best negotiated import tariffs in the low state under the delayed same-sector and cross-sector retaliation mechanisms are politically efficient and the best negotiated import tariffs in the high state under the cross-sector retaliation is higher than under the same-sector retaliation mechanism, i.e., $z_{a}^{D S S}\left(\theta_{L}\right)=z_{a}^{D C S}\left(\theta_{L}\right)=z_{a}^{E}\left(\theta_{L}\right)$ and $z_{a}^{D S S}\left(\theta_{H}\right)<z_{a}^{D C S}\left(\theta_{H}\right)$.

The next two propositions demonstrate that on contrary to the no-delayed retaliation mechanisms, the incentive compatibility constraints will bind in both delayed same-sector and cross-sector retaliation mechanisms under certain conditions.

Proposition 52. Suppose that the goods in sector a is strategic substitutes, i.e., $b_{1} \in(0,1)$. Then for any given $\lambda \in(0,1)$, there exist some parameters $\delta^{\prime} \in[0,1]$ and $\beta^{\prime} \in[0,1]$ such that if $\delta \beta \in$ $\left[\delta^{\prime} \beta^{\prime}, 1\right]$, the incentive compatibility conditions (125) and (126) are slack.

Proof: Simplify the incentive compatibility constraints (125) and (126),

$$
\vartheta_{a}\left(z_{a}^{D S}\left(\theta_{L}\right), 0, \theta_{L}\right)+\delta \beta \vartheta_{a}\left(z_{a}^{D S}\left(\theta_{L}\right), 0, \theta_{L}\right) \geq \vartheta_{a}\left(z_{a}^{D S}\left(\theta_{H}\right), 0, \theta_{L}\right)+\delta \beta \vartheta_{a}\left(z_{a}^{D S}\left(\theta_{H}\right), z_{a}^{D S}\left(\theta_{H}\right), \theta_{L}\right)
$$

and

$$
\vartheta_{a}\left(z_{a}^{D S}\left(\theta_{H}\right), 0, \theta_{H}\right)+\delta \beta \vartheta_{a}\left(z_{a}^{D S}\left(\theta_{H}\right), z_{a}^{D S}\left(\theta_{H}\right), \theta_{H}\right) \geq(1+\delta \beta) \vartheta_{a}\left(z_{a}^{D S}\left(\theta_{L}\right), 0, \theta_{H}\right) .
$$

Let $\delta \beta=B \in[0,1]$. Then, we have

$$
\vartheta_{a}\left(z_{a}^{D S}\left(\theta_{L}\right), 0, \theta_{L}\right)+B \vartheta_{a}\left(z_{a}^{D S}\left(\theta_{L}\right), 0, \theta_{L}\right) \geq \vartheta_{a}\left(z_{a}^{D S}\left(\theta_{H}\right), 0, \theta_{L}\right)+B \vartheta_{a}\left(z_{a}^{D S}\left(\theta_{H}\right), z_{a}^{D S}\left(\theta_{H}\right), \theta_{L}\right)
$$

and

$$
\vartheta_{a}\left(z_{a}^{D S}\left(\theta_{H}\right), 0, \theta_{H}\right)+B \vartheta_{a}\left(z_{a}^{D S}\left(\theta_{H}\right), z_{a}^{D S}\left(\theta_{H}\right), \theta_{H}\right) \geq(1+A) \vartheta_{a}\left(z_{a}^{D S}\left(\theta_{L}\right), 0, \theta_{H}\right) .
$$


Let

$$
\begin{aligned}
& G(B)=(1+B) \vartheta_{a}\left(z_{a}^{D S S}\left(\theta_{L}\right), 0, \theta_{L}\right) \\
& -\vartheta_{a}\left(z_{a}^{D S S}\left(\theta_{H}\right), 0, \theta_{L}\right)-B \vartheta_{a}\left(z_{a}^{D S S}\left(\theta_{H}\right), z_{a}^{D S S}\left(\theta_{H}\right), \theta_{L}\right) .
\end{aligned}
$$

Proposition 49 implies that $\frac{\partial z_{a}^{D S S}\left(\theta_{H}, \delta\right)}{\partial \delta}<0$ and $\frac{\partial z_{a}^{D S S}\left(\theta_{H}, \delta\right)}{\partial \beta}<0$. Hence,

$$
\frac{\partial z_{a}^{D S S}\left(\theta_{H}\right)}{\partial B}<0
$$

By the welfare function defined in Eq.(20), we have

$$
\begin{aligned}
& \left|\frac{d\left[\vartheta_{a}\left(z_{a}^{D S S}\left(\theta_{L}\right), 0, \theta_{L}\right)-\vartheta_{a}\left(z_{a}^{D S S}\left(\theta_{H}\right), 0, \theta_{L}\right)\right]}{d z_{a}^{D S S}\left(\theta_{H}\right)}\right| \\
& >\delta\left|\frac{d\left[\vartheta\left(z_{a}^{D S S}\left(\theta_{L}\right), 0, \theta_{L}\right)-\vartheta\left(z_{a}^{D S S}\left(\theta_{H}\right), z_{a}^{D S S}\left(\theta_{H}\right), \theta_{L}\right)\right]}{d z_{a}^{D S S}\left(\theta_{H}\right)}\right| .
\end{aligned}
$$

Therefore, $\frac{d G}{d B}>0$. Then $G(0)<0$ and $G(1)>0$ indicate that there exists a $\hat{B}$ such that $G(\hat{B})=0$. Or, for any given $b_{1} \in(0,1)$ and $\lambda \in(0,1)$, there exist some parameters $\delta^{\prime} \in[0,1]$ and $\beta^{\prime} \in[0,1]$ such that if $\delta \beta \in\left[\delta^{\prime} \beta^{\prime}, 1\right]$, conditions (125) is slack.

To show that condition (126) is slack, let

$$
H(B)=\vartheta_{a}\left(z_{a}^{D S S}\left(\theta_{H}\right), 0, \theta_{H}\right)+B \vartheta_{a}\left(z_{a}^{D S S}\left(\theta_{H}\right), z_{a}^{D S S}\left(\theta_{H}\right), \theta_{H}\right)-(1+B) \vartheta_{a}\left(z_{a}^{D S S}\left(\theta_{L}\right), 0, \theta_{H}\right) .
$$

From Proposition 49, we have $z_{a}^{D S S}\left(\theta_{L}\right)=z_{a}^{E}\left(\theta_{L}\right)=0, \frac{\partial z_{a}^{D S S}\left(\theta_{H}, \delta\right)}{\partial \delta}<0$ and $\frac{\partial z_{a}^{D S S}\left(\theta_{H}, \delta\right)}{\partial \beta}<0$ and from the assumption of the welfare function, we have

$$
\begin{aligned}
& \left|\frac{d\left[\vartheta_{a}\left(z_{a}^{D S S}\left(\theta_{H}\right), 0, \theta_{H}\right)-\vartheta_{a}\left(z_{a}^{D S S}\left(\theta_{L}\right), 0, \theta_{H}\right)\right]}{d z_{a}^{D S S}\left(\theta_{H}\right)}\right| \\
& >\delta\left|\frac{d\left[\vartheta_{a}\left(z_{a}^{D S S}\left(\theta_{H}\right), z_{a}^{D S S}\left(\theta_{H}\right), \theta_{H}\right)-\vartheta_{a}\left(z_{a}^{D S S}\left(\theta_{L}\right), 0, \theta_{H}\right)\right]}{d z_{a}^{D S S}\left(\theta_{H}\right)}\right| .
\end{aligned}
$$

Thus, $\frac{d H}{d B}>0$. Then, $z_{a}^{D S S}\left(\theta_{H}\right)>0=z_{a}^{D S S}\left(\theta_{L}\right)$ (from Proposition 49) implies that $H(0)>0$. Therefore, condition (125) is slack, i.e., $H(B)>0$, for any $B \in[0,1]$. We have shown that if $\delta \beta \in\left[\delta^{\prime} \beta^{\prime}, 1\right]$, the two incentive compatibility conditions are slack. This completes the proof. 
Proposition 53. For any given $b_{1} \in(0,1), \delta \in(0,1)$ and $\beta \in(0,1)$ there exists a $b_{2}^{\prime \prime} \in(0,1)$ such that if $b_{2} \in\left[b_{2}^{\prime \prime}, 1\right)$, the incentive compatibility conditions (129) and (130) are slack.

Proof: Rearranging and simplifying the two incentive-compatibility conditions derive:

$$
\begin{aligned}
& (1+\delta \beta) \vartheta_{a}\left(z_{a}^{D C}\left(\theta_{L}\right), 0, \theta_{L}\right)+\delta(1-\beta) \vartheta_{b}(0,0) \\
& \left.\geq(1+\delta \beta) \vartheta_{a}\left(z_{a}^{D C}\left(\theta_{H}\right), 0, \theta_{L}\right)\right)+\delta(1-\beta) \vartheta_{b}\left(0, z_{a}^{D C}\left(\theta_{H}\right)\right)
\end{aligned}
$$

and

$$
\begin{aligned}
& (1+\delta \beta) \vartheta_{a}\left(z_{a}^{D C}\left(\theta_{H}\right), 0, \theta_{H}\right)+\vartheta_{b}(0,0)+\delta \beta \vartheta_{b}\left(0, z_{a}^{D C}\left(\theta_{H}\right)\right) \\
& \geq(1+\delta \beta)\left[\vartheta_{a}\left(z_{a}^{D C}\left(\theta_{L}\right), 0, \theta_{H}\right)+\vartheta_{b}(0,0)\right]
\end{aligned}
$$

Then $z_{a}^{D C S}\left(\theta_{L}\right)<z_{a}^{D C S}\left(\theta_{H}\right)$ (Proposition 50), together with the welfare function defined in Eq.(20), implies that

$$
\left.\vartheta_{a}\left(z_{a}^{D C S}\left(\theta_{L}\right), 0, \theta_{L}\right)>\vartheta_{a}\left(z_{a}^{D C S}\left(\theta_{H}\right), 0, \theta_{L}\right)\right)
$$

and

$$
\vartheta_{b}(0,0)>\vartheta_{b}\left(0, z_{a}^{D S C}\left(\theta_{H}\right)\right)
$$

Thus, Eq.(129) is slack.

Let $\delta \beta=B \in(0,1)$ and rewrite Eq.(132):

$$
\begin{aligned}
& (1+B) \vartheta_{a}\left(z_{a}^{D C}\left(\theta_{H}\right), 0, \theta_{H}\right)+\vartheta_{b}(0,0)+B \vartheta_{b}\left(0, z_{a}^{D C}\left(\theta_{H}\right)\right) \\
& -(1+B)\left[\vartheta_{a}\left(z_{a}^{D C}\left(\theta_{L}\right), 0, \theta_{H}\right)+\vartheta_{b}(0,0)\right] \geq 0 .
\end{aligned}
$$

Let $G$ denote the left hand side of Eq.(133). Since all other parameters are fixed, then $G$ only depends on $b_{2}$. Furthermore, given that $z_{a}^{D C S}\left(\theta_{L}\right)$ and $z_{a}^{D C S}\left(\theta_{H}\right)$ are independent of $b_{2}$, together with the utility function defined in Eq.(20), it is easy to verify that $G$ is strictly increasing in $b_{2}$. When $b_{2}$ is close to 1 , we have $G\left(b_{2}\right)>0$ and when $b_{2}=0$, we have $G\left(b_{2}\right)<0$. Therefore, there exists a cutoff point such that when $b_{2} \in\left[b_{2}^{\prime \prime}, 1\right)$, condition (130) is slack.

Proposition 54. Suppose that the goods in both sectors are strategic substitutes, i.e., $b_{1} \in(0,1)$ and $b_{2} \in(0,1)$ and the incentive compatibility conditions are slack, i.e., $\delta \beta \in\left[\delta^{\prime} \beta^{\prime}, 1\right]$ and $b_{2} \in$ 
$\left[b_{2}^{\prime \prime}, 1\right)$. Then for any given $b_{1} \in(0,1)$, there exists a $\hat{b_{2}} \in(0,1)$ such that for any $b_{2} \in\left(0, \hat{b_{2}}\right)$, the best incentive-compatible negotiated tariffs under the same-sector retaliation mechanism generate a higher expected joint political payoff than do the best incentive-compatible negotiated tariffs under the cross-sector retaliation mechanism.

Proof: The proof follows by similar steps as in the proof of Proposition 17.

Now we extend the two-period model to a dynamic setup and consider the "off-schedule" violation. Observe that under the delayed same-sector retaliation mechanisms, the future values can be represented by the following two bellman equations:

$$
\begin{aligned}
X^{D S}\left(z_{a}^{D S S}\left(\theta_{H}\right), z_{a}^{D S S}\left(\theta_{L}\right), \theta_{L}\right) & =\vartheta_{a}\left(z_{a}^{D S S}\left(\theta_{L}\right), 0, \theta_{L}\right)+\vartheta_{b}(0,0) \\
& +\delta\left[\beta \vartheta_{a}\left(z_{a}^{D S S}\left(\theta_{L}\right), 0, \theta_{L}\right)\right. \\
& \left.+(1-\beta) \vartheta_{a}\left(z_{a}^{D S S}\left(\theta_{H}\right), 0, \theta_{H}\right)\right] \\
& +\delta \vartheta_{b}(0,0) \\
& +\delta^{2}\left\{\left[\beta^{2}+(1-\beta) \beta\right] X^{D S}\left(z_{a}^{D S S}\left(\theta_{H}\right), z_{a}^{D S S}\left(\theta_{L}\right), \theta_{L}\right)\right. \\
& \left.+[(1-\beta) \beta+\beta(1-\beta)] X^{D S}\left(z_{a}^{D S S}\left(\theta_{H}\right), z_{a}^{D S S}\left(\theta_{L}\right), \theta_{H}\right)\right\}
\end{aligned}
$$

and

$$
\begin{aligned}
X^{D S}\left(z_{a}^{D S S}\left(\theta_{H}\right), z_{a}^{D S S}\left(\theta_{L}\right), \theta_{H}\right) & =\vartheta_{a}\left(z_{a}^{D S S}\left(\theta_{H}\right), 0, \theta_{H}\right)+\vartheta_{b}(0,0) \\
& +\delta\left[\beta \vartheta_{a}\left(z_{a}^{D S S}\left(\theta_{H}\right), z_{a}^{D S S}\left(\theta_{H}\right), \theta_{H}\right)\right. \\
& \left.+(1-\beta) \vartheta_{a}\left(z_{a}^{D S S}\left(\theta_{L}\right), 0, \theta_{L}\right)\right] \\
& +\delta \vartheta_{b}(0,0) \\
& +\delta^{2}\left\{\left[\beta^{2}+(1-\beta) \beta\right]\right] X^{D S}\left(z_{a}^{D S S}\left(\theta_{H}\right), z_{a}^{D S S}\left(\theta_{L}\right), \theta_{H}\right) \\
& \left.+[(1-\beta) \beta+\beta(1-\beta)] X^{D S}\left(z_{a}^{D S S}\left(\theta_{H}\right), z_{a}^{D S S}\left(\theta_{L}\right), \theta_{L}\right)\right\} .
\end{aligned}
$$


Similarly, under the delayed cross-sector retaliation mechanism, the bellman equations are:

$$
\begin{aligned}
X^{D C}\left(z_{a}^{D C S}\left(\theta_{H}\right), z_{a}^{D C S}\left(\theta_{L}\right), \theta_{L}\right) & =\vartheta_{a}\left(z_{a}^{D C S}\left(\theta_{L}\right), 0, \theta_{L}\right)+\vartheta_{b}(0,0) \\
& +\delta\left\{\beta\left[\vartheta_{a}\left(z_{a}^{D C S}\left(\theta_{L}\right), 0, \theta_{L}\right)+\vartheta_{b}(0,0)\right]\right. \\
& \left.+(1-\beta)\left[\vartheta_{a}\left(z_{a}^{D C S}\left(\theta_{H}\right), 0, \theta_{H}\right)+\vartheta_{b}(0,0)\right]\right\} \\
& +\delta^{2}\left\{\left[\beta^{2}+(1-\beta) \beta\right] X^{D C}\left(z_{a}^{D C S}\left(\theta_{H}\right), z_{a}^{D C S}\left(\theta_{L}\right), \theta_{L}\right)\right. \\
& \left.+[(1-\beta) \beta+\beta(1-\beta)] X^{D C}\left(z_{a}^{D C S}\left(\theta_{H}\right), z_{a}^{D C S}\left(\theta_{L}\right), \theta_{H}\right)\right\}
\end{aligned}
$$

and

$$
\begin{aligned}
X^{D C}\left(z_{a}^{D C S}\left(\theta_{H}\right), z_{a}^{D C S}\left(\theta_{L}\right), \theta_{H}\right) & =\vartheta_{a}\left(z_{a}^{D C S}\left(\theta_{H}\right), 0, \theta_{H}\right)+\vartheta_{b}(0,0) \\
& +\delta\left\{\beta\left[\vartheta_{a}\left(z_{a}^{D C S}\left(\theta_{H}\right), 0, \theta_{H}\right)+\vartheta_{b}\left(0, z_{a}^{D C S}\left(\theta_{H}\right)\right)\right]\right. \\
& \left.+(1-\beta)\left[\vartheta_{a}\left(z_{a}^{D C S}\left(\theta_{L}\right), 0, \theta_{L}\right)+\vartheta_{b}(0,0)\right]\right\} \\
& +\delta^{2}\left\{\left[\beta^{2}+(1-\beta) \beta\right]\right] X^{D C}\left(z_{a}^{D C S}\left(\theta_{H}\right), z_{a}^{D C S}\left(\theta_{L}\right), \theta_{H}\right) \\
& \left.+[(1-\beta) \beta+\beta(1-\beta)] X^{D C}\left(z_{a}^{D C S}\left(\theta_{H}\right), z_{a}^{D C S}\left(\theta_{L}\right), \theta_{L}\right)\right\} .
\end{aligned}
$$

The future values of the "off-schedule" violation under the delayed same-sector retaliation mechanisms can be represented by Eqs.(39) and (40). The future values of home's "off-schedule" violation under the delayed and cross-sector retaliation mechanisms can be captured by the following two bellman equations:

$$
\begin{aligned}
X^{D C d}\left(z_{a}^{D C S d}\left(\theta_{H}\right), z_{a}^{D C S d}\left(\theta_{L}\right), z_{b}^{N}, z_{b}^{* N}, \theta_{L}\right) & =\vartheta_{a}\left(z_{a}^{D C S d}\left(\theta_{L}\right), 0, \theta_{L}\right)+(1+\delta) \vartheta_{b}\left(z_{b}^{N}, z_{b}^{* N}\right) \\
& +\delta\left[\beta \vartheta_{a}\left(z_{a}^{D C S d}\left(\theta_{L}\right), 0, \theta_{L}\right)\right. \\
& \left.+(1-\beta) \vartheta_{a}\left(z_{a}^{D C S d}\left(\theta_{H}\right), 0, \theta_{H}\right)\right] \\
& +\delta^{2}\left\{\left[\beta^{2}+(1-\beta) \beta\right]\right. \\
& X^{D C d}\left(z_{a}^{D C S d}\left(\theta_{H}\right), z_{a}^{D C S d}\left(\theta_{L}\right), z_{b}^{N}, z_{b}^{* N}, \theta_{L}\right) \\
& +[(1-\beta) \beta+\beta(1-\beta)] \\
& \left.X^{D C d}\left(z_{a}^{D C S d}\left(\theta_{H}\right), z_{a}^{D C S d}\left(\theta_{L}\right), z_{b}^{N}, z_{b}^{* N}, \theta_{H}\right)\right\}
\end{aligned}
$$


and

$$
\begin{aligned}
X^{D C d}\left(z_{a}^{D C S d}\left(\theta_{H}\right), z_{a}^{D C S d}\left(\theta_{L}\right), z_{b}^{N}, z_{b}^{* N}, \theta_{H}\right) & =\vartheta_{a}\left(z_{a}^{D C S d}\left(\theta_{H}\right), 0, \theta_{H}\right)+(1+\delta) \vartheta_{b}\left(z_{b}^{N}, z_{b}^{* N}\right) \\
& +\delta\left[\beta \vartheta_{a}\left(z_{a}^{D C S d}\left(\theta_{H}\right), 0, \theta_{H}\right)\right. \\
& \left.+(1-\beta) \vartheta_{a}\left(z_{a}^{D C S d}\left(\theta_{H}\right), 0, \theta_{H}\right)\right] \\
& +\delta^{2}\left\{\left[\beta^{2}+(1-\beta) \beta\right]\right. \\
& X^{D C d}\left(z_{a}^{D C S d}\left(\theta_{H}\right), z_{a}^{D C S d}\left(\theta_{L}\right), z_{b}^{N}, z_{b}^{* N}, \theta_{H}\right) \\
& +[(1-\beta) \beta+\beta(1-\beta)] \\
& \left.X^{D C d}\left(z_{a}^{D C S d}\left(\theta_{H}\right), z_{a}^{D C S d}\left(\theta_{L}\right), z_{b}^{N}, z_{b}^{* N}, \theta_{L}\right)\right\}
\end{aligned}
$$

where $z_{a}^{D C S d}(\theta)=\underset{\tau_{a}}{\operatorname{argmax}} \vartheta_{a}\left(\tau_{a}, 0, \theta\right)$.

Now we are ready to show the voluntary participation constraints and compare the self-enforcing levels of cooperation between the governments under the two mechanisms.

The voluntary participation constraints under the delayed and same sector retaliation mechanism are:

$$
\begin{aligned}
& \vartheta_{a}\left(z_{a}^{D S S}\left(\theta_{L}\right), 0, \theta_{L}\right)+\vartheta_{b}(0,0) \\
& +\delta\left[\beta \vartheta_{a}\left(z_{a}^{D S S}\left(\theta_{L}\right), 0, \theta_{L}\right)+(1-\beta) \vartheta_{a}\left(z_{a}^{D S S}\left(\theta_{H}\right), 0, \theta_{H}\right)\right]+\delta \vartheta_{b}(0,0) \\
& +\delta^{2}\left\{\left[\beta^{2}+(1-\beta) \beta\right] X^{D S}\left(z_{a}^{D S S}\left(\theta_{H}\right), z_{a}^{D S S}\left(\theta_{L}\right), \theta_{L}\right)\right. \\
& \left.+[(1-\beta) \beta+\beta(1-\beta)] X^{D S}\left(z_{a}^{D S S}\left(\theta_{H}\right), z_{a}^{D S S}\left(\theta_{L}\right), \theta_{H}\right)\right\} \geq \\
& \vartheta_{a}\left(z_{a}^{D S S d}\left(\theta_{L}\right), 0, \theta_{L}\right)+\delta\left[\beta \vartheta_{a}\left(z_{a}^{N}\left(\theta_{L}\right), z_{a}^{* N}, \theta_{L}\right)+(1-\beta) \vartheta_{a}\left(z_{a}^{N}\left(\theta_{H}\right), z_{a}^{* N}, \theta_{H}\right)\right] \\
& +(1+\delta) \vartheta_{b}(0,0) \\
& +\delta^{2}\left\{\left[\beta^{2}+(1-\beta) \beta\right] X^{S d}\left(z_{a}^{N}\left(\theta_{H}\right), z_{a}^{N}\left(\theta_{L}\right), z_{a}^{* N}, \theta_{L}\right)\right. \\
& \left.+[(1-\beta) \beta+\beta(1-\beta)] X^{S d}\left(z_{a}^{N}\left(\theta_{H}\right), z_{a}^{N}\left(\theta_{L}\right), z_{a}^{* N}, \theta_{H}\right)\right\}
\end{aligned}
$$


and

$$
\begin{aligned}
& \vartheta_{a}\left(z_{a}^{D S S}\left(\theta_{H}\right), 0, \theta_{H}\right)+\vartheta_{b}(0,0) \\
& +\delta\left[\beta \vartheta_{a}\left(z_{a}^{D S S}\left(\theta_{H}\right), z_{a}^{D S S}\left(\theta_{H}\right), \theta_{H}\right)+(1-\beta) \vartheta_{a}\left(z_{a}^{D S S}\left(\theta_{L}\right), 0, \theta_{L}\right)\right] \\
& +\delta \vartheta_{b}(0,0) \\
& +\delta^{2}\left\{\left[\beta^{2}+(1-\beta) \beta\right]\right] X^{D S}\left(z_{a}^{D S S}\left(\theta_{H}\right), z_{a}^{D S S}\left(\theta_{L}\right), \theta_{H}\right) \\
& \left.+[(1-\beta) \beta+\beta(1-\beta)] X^{D S}\left(z_{a}^{D S S}\left(\theta_{H}\right), z_{a}^{D S S}\left(\theta_{L}\right), \theta_{L}\right)\right\} \geq \\
& \vartheta_{a}\left(z_{a}^{D S S d}\left(\theta_{H}\right), 0, \theta_{H}\right)+\delta\left[\beta \vartheta_{a}\left(z_{a}^{N}\left(\theta_{L}\right), z_{a}^{* N}, \theta_{L}\right)+(1-\beta) \vartheta_{a}\left(z_{a}^{N}\left(\theta_{H}\right), z_{a}^{* N}, \theta_{H}\right)\right] \\
& +(1+\delta) \vartheta_{b}(0,0) \\
& +\delta^{2}\left\{\left[\beta^{2}+(1-\beta) \beta\right] X^{S d}\left(z_{a}^{N}\left(\theta_{H}\right), z_{a}^{N}\left(\theta_{L}\right), z_{a}^{* N}, \theta_{L}\right)\right. \\
& \left.+[(1-\beta) \beta+\beta(1-\beta)] X^{S d}\left(z_{a}^{N}\left(\theta_{H}\right), z_{a}^{N}\left(\theta_{L}\right), z_{a}^{* N}, \theta_{H}\right)\right\}
\end{aligned}
$$

where $z_{a}^{D S S d}(\theta)=\underset{\tau_{a}}{\operatorname{argmax}} \quad \vartheta_{a}\left(\tau_{a}, 0, \theta\right)$.

The voluntary participation constraints under the delayed and cross-sector retaliation mechanism are:

$$
\begin{aligned}
& \vartheta_{a}\left(z_{a}^{D C S}\left(\theta_{L}\right), 0, \theta_{L}\right)+\vartheta_{b}(0,0) \\
& +\delta\left\{\beta\left[\vartheta_{a}\left(z_{a}^{D C S}\left(\theta_{L}\right), 0, \theta_{L}\right)+\vartheta_{b}(0,0)\right]+(1-\beta)\left[\vartheta_{a}\left(z_{a}^{D C S}\left(\theta_{H}\right), 0, \theta_{H}\right)+\vartheta_{b}(0,0)\right]\right\} \\
& +\delta^{2}\left\{\left[\beta^{2}+(1-\beta) \beta\right] X^{D C}\left(z_{a}^{D C S}\left(\theta_{H}\right), z_{a}^{D C S}\left(\theta_{L}\right), \theta_{L}\right)\right. \\
& \left.+[(1-\beta) \beta+\beta(1-\beta)] X^{D C}\left(z_{a}^{D C S}\left(\theta_{H}\right), z_{a}^{D C S}\left(\theta_{L}\right), \theta_{H}\right)\right\} \geq \\
& \vartheta_{a}\left(z_{a}^{D C S d}\left(\theta_{L}\right), 0, \theta_{L}\right)+\vartheta_{b}(0,0) \\
& +\delta\left\{\beta\left[\vartheta_{a}\left(z_{a}^{D C S d}\left(\theta_{L}\right), 0, \theta_{L}\right)+\vartheta_{b}\left(z_{b}^{N}, z_{b}^{* N}\right)\right]+(1-\beta)\left[\vartheta_{a}\left(z_{a}^{D C S d}\left(\theta_{H}\right), 0, \theta_{H}\right)+\vartheta_{b}\left(z_{b}^{N}, z_{b}^{* N}\right)\right]\right\} \\
& +\delta^{2}\left\{\left[\beta^{2}+(1-\beta) \beta\right] X^{D C d}\left(z_{a}^{D C S d}\left(\theta_{H}\right), z_{a}^{D C S d}\left(\theta_{L}\right), z_{b}^{N}, z_{b}^{* N}, \theta_{L}\right)\right. \\
& \left.+[(1-\beta) \beta+\beta(1-\beta)] X^{D C d}\left(z_{a}^{D C S d}\left(\theta_{H}\right), z_{a}^{D C S d}\left(\theta_{L}\right), z_{b}^{N}, z_{b}^{* N}, \theta_{H}\right)\right\}
\end{aligned}
$$


and

$$
\begin{aligned}
& \vartheta_{a}\left(z_{a}^{D C S}\left(\theta_{H}\right), 0, \theta_{H}\right)+\vartheta_{b}(0,0) \\
& +\delta\left\{\beta\left[\vartheta_{a}\left(z_{a}^{D C S}\left(\theta_{H}\right), 0, \theta_{H}\right)+\vartheta_{b}\left(0, z_{a}^{D C S}\left(\theta_{H}\right)\right)\right]+(1-\beta)\left[\vartheta_{a}\left(z_{a}^{D C S}\left(\theta_{L}\right), 0, \theta_{L}\right)+\vartheta_{b}(0,0)\right]\right\} \\
& +\delta^{2}\left\{\left[\beta^{2}+(1-\beta) \beta\right]\right] X^{D C}\left(z_{a}^{D C S}\left(\theta_{H}\right), z_{a}^{D C S}\left(\theta_{L}\right), \theta_{H}\right) \\
& \left.+[(1-\beta) \beta+\beta(1-\beta)] X^{D C}\left(z_{a}^{D C S}\left(\theta_{H}\right), z_{a}^{D C S}\left(\theta_{L}\right), \theta_{L}\right)\right\} \geq \\
& \vartheta_{a}\left(z_{a}^{D C S d}\left(\theta_{H}\right), 0, \theta_{H}\right)+\vartheta_{b}(0,0) \\
& +\delta\left\{\beta\left[\vartheta_{a}\left(z_{a}^{D C S d}\left(\theta_{H}\right), 0, \theta_{H}\right)+\vartheta_{b}\left(z_{b}^{N}, z_{b}^{* N}\right)\right]+(1-\beta)\left[\vartheta_{a}\left(z_{a}^{D C S d}\left(\theta_{L}\right), 0, \theta_{L}\right)+\vartheta_{b}\left(z_{b}^{N}, z_{b}^{* N}\right)\right]\right\} \\
& +\delta^{2}\left\{\left[\beta^{2}+(1-\beta) \beta\right] X^{D C d}\left(z_{a}^{D C S d}\left(\theta_{H}\right), z_{a}^{D C S d}\left(\theta_{L}\right), z_{b}^{N}, z_{b}^{* N}, \theta_{H}\right)\right. \\
& \left.+[(1-\beta) \beta+\beta(1-\beta)] X^{D C d}\left(z_{a}^{D C S d}\left(\theta_{H}\right), z_{a}^{D C S d}\left(\theta_{L}\right), z_{b}^{N}, z_{b}^{* N}, \theta_{L}\right)\right\} .
\end{aligned}
$$

Then we can obtain the following result with a similar proof as of Proposition 18.

Proposition 55. For any given $b_{1} \in(0,1)$, there exists a $b_{2}^{* *} \in(0,1)$ such that for any $b_{2} \in\left(0, b_{2}^{* *}\right)$, the delayed same-sector retaliation mechanism supports a higher self-enforcing level of cooperation than the delayed cross-sector retaliation mechanism. 


\section{Bibliography}

[1] S. N. Ali., 2015. Recognition for Sale, Journal of Economics Theory 155, 16-29. 58, 59

[2] R. E. Baldwin, 1987. Politically Realitic Objective Functions and Trade Policy: PROFs and Tariffs. Economic Letters 24, 287-290. 9, 35

[3] K. Bagwell and R. Staiger, 1990. A Theory of Managed Trade. American Ecnomic Review 80, 779-795. 22,49

[4] K. Bagwell and R. Staiger, 2005. Enforcement, Private Political Pressure and the GATT/WTO Escape Clause. Journal of Legal Studies 34, 471-513. 7, 33

[5] K. Bagwell, 2009. Self-enforcing Trade Agreements and Private Information. National Bureau of Economic Research Working Paper 14812. 4, 7, 33

[6] D. Baron and J. Ferejohn, 1989. Bargaining in Legislatures, American Political Science Review 83, 1181-1206. 57, 128

[7] M. Beshkar, 2009. Optimal Remedies in International Trade Agreements. European Economic Review 54, 455-466. 6,31

[8] M. Beshkar, 2010. Trade Skirmishes Safeguards: A theory of the WTO Dispute Settlement Process. Jounal of International Economics 82, 35-48. 7, 33

[9] K. Binmore, 1987. Perfect Equilibria in Bargaining Models, Economics of Bargaining, Basil Blackwell, Oxford, 77-105. 57

[10] R. Chisik and H. Onder, 2017. Does Limited Punishment Limit the Scope for Cross-retalition? Economic Inquiry, forthcoming. 33

[11] H. Eraslan, 2002. Uniqueness of Stationary Equilibrium Payoffs in the Baron-Ferejohn Model, Journal of Economic Theory 103, 11-30. 57

[12] H. Eraslan and A. Merlo, 2002. Majority Rule in a Stochastic Model of Bargaining, Journal of Economic Theory 103, 31-48. 57, 58

[13] M. R. Garfinkel and S. Skaperdas, 2007. Economics of Conflict: An Overview. Handbook of Defense Economics 2, 649-709. 58

[14] G. M. Grossmand and E. Helpman, 1995. Trade Wars and Trade Talks. Journal of Political Economy, 103, $675-708.9$

[15] A. L. Hillman, 1982. Decling Industries and Political-Suppport Protectionist Motives. American Economic Review, 72, 1180-1187. 9

[16] R. E. Lucas, 1978. Asset Prices in an Exchange Economy. Econometrica, 46, 1429-1445. 5

[17] S. P. Magee, W. A. Brock and L. Young, 1989. Black Hole Tariffs and Endogenous Policy Theory: Political Economy in General Equilibrium. Cambridge, Mass: MIT Press. 9

[18] A. Merlo and C. Wilson, 1995. A Stochastic Model of Sequential Bargaining with Complete Information, Econometrica 63, 371-399. 57

[19] A. Merlo and C. Wilson, 1998. Efficient Delays in a Stochastic Model of Bargaining, Economic Theory 11, 39-55. 57 
[20] S. Skaperdas, 1992. Cooperation, Conflict and Power in the Absence of Property Rights American Economic Review 82, 720-739. 58, 59, 74

[21] A. Rubinstein, 1982. Perfect Equilibrium in a Bargaining Model, Econometrica 50, 97-109. 57

[22] H. Yildirim, Proposal Power and Majority Rule in Multilateral Bargaining with Costly Recognition, Journal of Economic Theory 136 (2007), 167-196. 58

[23] H. Yildirim, Distribution of Surplus in Sequential Bargaining with Endogenous Recognition, Public Choice 142 (2010), 41-57. 58 